INSTITUTO DE ENERGIA E AMBIENTE PROGRAMA DE PÓS-GRADUAÇÃ̃O EM ENERGIA

JULIANA FERRARI CHADE MUMMEY

UMA CONTRIBUIÇÃO METODOLÓGICA PARA A OTIMIZAÇÃO DA OPERAÇÃO E EXPANSÃO DO SISTEMA HIDROTÉRMICO BRASILEIRO MEDIANTE A REPRESENTAÇÃO ESTOCÁSTICA DA GERAÇÃO EÓLICA 


\title{
UMA CONTRIBUIÇÃO METODOLÓGICA PARA A OTIMIZAÇÃO DA OPERAÇÃO E EXPANSÃO DO SISTEMA HIDROTÉRMICO BRASILEIRO MEDIANTE A REPRESENTAÇÃO ESTOCÁSTICA DA GERAÇÃO EÓLICA
}

\author{
Tese apresentada ao Programa de Pós-Graduação \\ em Energia do Instituto de Energia e Ambiente da \\ Universidade de São Paulo para a obtenção do \\ Título de Doutor em Ciências. \\ Orientador: Prof. Dr. Ildo Luís Sauer \\ Coorientador: Prof. Dr. Dorel Soares Ramos
}

Versão Corrigida

(Versão original disponível na Biblioteca do Instituto de Energia e Ambiente e na Biblioteca Digital de Teses e Dissertações da USP)

\author{
SÃO PAULO
}

2017 


\section{AUTORIZO A REPRODUÇÃO E DIVULGAÇÃO TOTAL OU PARCIAL DESTE TRABALHO, POR QUALQUER MEIO CONVENCIONAL OU ELETRÔNICO, PARA FINS DE ESTUDO E PESQUISA, DESDE QUE CITADA A FONTE.}

\section{FICHA CATALOGRÁFICA}

\section{Mummey, Juliana Ferrari Chade.}

Uma contribuição metodológica para a otimização da operação e expansão do sistema hidrotérmico brasileiro mediante a representação estocástica da geração eólica. / Juliana Ferrari Chade Mummey; Orientador: Ildo Luís Sauer; Coorientador: Dorel Soares Ramos. - São Paulo, 2017.

184 f.: il.; $30 \mathrm{~cm}$

Tese (Doutorado em Ciência) - Programa de Pós-Graduação em Energia Instituto de Energia e Ambiente da Universidade de São Paulo

1. Otimização estocástica. 2. Energia eólica. 3. Sistemas hidrotérmicos - planejamento. 4. Complementariedade. 5. Geração de séries sintéticas. I. Título. 
Nome: MUMMEY, Juliana Ferrari Chade

Título: Uma contribuição metodológica para a otimização da operação e expansão do sistema hidrotérmico brasileiro mediante a representação estocástica da geração eólica

Tese de doutorado apresentada ao Programa de Pós-Graduação em Energia do Instituto de Energia e Ambiente da Universidade de São Paulo para obtenção do Título de Doutor em Ciências.

Tese defendida e aprovada em 12 de maio de 2017 pela comissão julgadora:

Prof. Dr. Ildo Luís Sauer - PPGE-IEE/USP

Orientador e Presidente da Comissão Julgadora

Prof. Dr. Dorel Soares Ramos - EP/USP

Coorientador

Dr. Luiz Augusto Nóbrega Barroso - EPE

Dr ${ }^{\mathrm{a}}$ Elbia Aparecida Silva Gannoum - ABEEólica

Dr ${ }^{\mathrm{a}}$ Leontina Maria Viana Graziadio Pinto - EPDC LTDA 


\section{DEDICATÓRIA}

À minha avó Leda (in memoriam)

Ao meu pai, Douglas Chade (in memoriam)

Ao Vicente Leão (in memoriam)

À minha mãe, Sandra Chade

Aos meus irmãos Ricardo e Fabiana

Aos meus sobrinhos: Duda, Juju e Jorginho

Ao meu marido Adrian 


\section{AGRADECIMENTOS}

Ao Professor e orientador Ildo Luís Sauer pelas oportunidades de realizar o mestrado e o doutorado, confiança depositada e desafios concedidos a minha vida acadêmica, sobretudo pelas significativas contribuições para a realização deste trabalho.

Ao Professor e coorientador Dorel Soares Ramos por todos os incentivos e conversas esclarecedoras, capaz de me nortear e tranquilizar em momentos difíceis.

Ao Professor William Yeh pelas contribuições, ensinamentos e auxílio em todos os momentos que estive na UCLA.

A minha ilustre banca examinadora: Leontina Pinto, Elbia Silva Gannoum, Luiz Augusto Barroso, Dorel Soares Ramos e Ildo Luís Sauer pelas valiosas contribuições, colaborando para o enriquecimento acadêmico deste trabalho, além das críticas que me ajudaram a fazer uma avaliação mais precisa das modificações necessárias.

À minha família: Sandra Chade, Guaracy Pereira, Ricardo Chade, Vidar Persson, Fabiana Yammine, Jorge Yammine, Maria Eduarda Yammine, Maria Julia Yammine, Jorginho Yammine, Patrícia Leão e todos de Pirajuí pelo amor, incentivo e apoio para a realização deste trabalho.

Aos meus grandes amigos: Camila Giglio, Sabrina Kato, Cássia Shira, Carolina Nunes, Marjory Abussamra, Natalia Bertinat, Tais Castro, Leandro Issao, Larissa Araium, Josiane Palomino, Tatiana Tomazini, Carla Dias, Ana Carla Petti, Michelle Pizza, Maurício Malachias, Yanni Sellito, Gustavo Arfux, Marcelo Luna e Sandra Kise pelos incentivos e maravilhosos momentos de alegria que passamos juntos.

Ao grande amigo do ONS, em memória, Sérgio Menezes Medeiros, que me deu diversas dicas de como representar os reservatórios equivalentes de energia, características do Newave, sempre disposto a ajudar e sempre ficava feliz com os aprimoramentos do trabalho.

Ao Sandro Yamamoto da ABEEólica pelos dados fornecidos.

A todos os amigos do IEE, em especial: Lilian Silva, Alcântaro Rodrigues, Adriana Pelege, Juliana Oliveira e Renata Boaventura pelo apoio e ajuda. 
Aos amigos da Comerc: Amanda Holanda, Anderlan Siqueira, Paulo Bedaque, Pedro Franklin, Antônio Carlos Querido Messora que me ouviram antes da minha defesa e fizeram valiosos comentários. Aos demais amigos da Comerc que me ajudaram para a conclusão deste trabalho, em especial: Marcelo Ávila, Cristopher Vlavianos, Enrico Begliomini e Fabio Augusto.

Aos amigos da UCLA, em especial: Renato Zambon, Bin, Tim, Jacky e Scott que sempre me ajudaram com bibliografia, dividiram experiências e me ajudaram neste trabalho.

A todos os amigos do setor elétrico pelo apoio demonstrado e a todos que direta ou indiretamente contribuíram para a conclusão deste trabalho.

À família do Adrian que sempre me incentivou e motivou.

Ao meu amado marido Adrian Mummey por todo o suporte, motivação, paciência, ajuda em questões de automatização, por me ouvir inúmeras vezes explicando o meu trabalho, dando ideias e estando ao meu lado, com amor e carinho, em todos os momentos.

A Deus por tudo. 
"What counts in life is not the mere fact that we have lived. It is what difference we have made to the lives of others that will determine the significance of the life we lead." 


\section{RESUMO}

MUMMEY, Juliana Ferrari Chade. Uma contribuição metodológica para a otimização da operação e expansão do sistema hidrotérmico brasileiro mediante a representação estocástica da geração eólica. 2017. 184 f. Tese (Doutorado em Ciências) - Programa de Pósgraduação em Energia da Universidade de São Paulo, 2017.

A participação da energia eólica na geração de energia elétrica tem apresentado incremento importante nos últimos anos e a tendência é de representar $11,6 \%$ da capacidade instalada brasileira em 2024, segundo a Empresa de Pesquisa Energética (EPE). Hoje, nos modelos de otimização para o despacho das usinas no atendimento da carga de energia do sistema, a energia eólica, assim como as pequenas centrais hidrelétricas e a energia a biomassa, são abatidas da carga de forma determinística, não representando a incerteza na produção dessas usinas. Dada a variabilidade na geração de energia eólica, devido às variações nas velocidades dos ventos e considerando o aumento da participação eólica na matriz de eletricidade brasileira, fato que realça a relevância da fonte, este trabalho desenvolve uma representação estocástica da geração eólica a partir de dados históricos reconstruídos de velocidades de vento de 16 coordenadas do Brasil, em especial das regiões Nordeste e Sul. Os valores de velocidade de vento são transformados em energia eólica através de curvas de potência de turbinas e as usinas eólicas são representadas como se fossem usinas hidráulicas a fio d' água no modelo de otimização Newave. A representação do histórico de geração eólica é feita através de vazões nos rios, considerando-se também a expansão no horizonte até 2020. O trabalho tem como base os dados do Newave oficial de agosto de 2016. Com a simulação do modelo considerando-se as séries históricas e sintéticas, o trabalho simula o despacho das usinas, o comportamento dos custos marginais, verificando-se as diferenças no comportamento dessas variáveis quando se utiliza uma representação estocástica para a energia eólica, em comparação com a modelagem determinística utilizada hoje.

Palavras-chave: Otimização estocástica. Planejamento de sistemas hidrotérmicos. Energia eólica. Complementaridade. Geração de séries sintéticas. 


\begin{abstract}
MUMMEY, Juliana Ferrari Chade. A proposal of methodology to optimize the operation and expansion of the Brazilian hydrotermal system by representing the wind power generation stochastically. 2017. 184 p. Thesis (Doctor of Sciences) - Graduate Program in Energy, University of São Paulo, 2017.
\end{abstract}

Wind power has an increasing share of the Brazilian energy market and has the potential to represent $11.6 \%$ of the total capacity by 2024, according to Energy Research Company (EPE). The current optimization models, that dispatch power plants to meet demand, only optimize the demand using hydroelectric and thermal power plants. The remaining sources of generation including wind power, small hydroelectric plants and biomass plants, are not part of the optimization model and are included deterministically. There is variability in wind power generation because of wind speeds variations and considering the increase of the wind power share in the Brazilian electricity matrix, which stresses its importance, this work evaluates a stochastic representation for wind power generation through historical wind speed data of 16 coordinates from the Northeast and South of Brazil. It proposes to introduce wind power plants into the optimization model called "Newave" by proxy of run-of-river hydropower plants and their "inflow". This study also considers wind power expansion in Brazil up to 2020 and the database is the official Newave as of August 2016. This work aims to verify the dispatches of the power plants and the marginal costs, considering the differences between the model used today and the stochastic model presented in the study.

Keywords: Stochastic optimization. Hydrothermic systems planning. Wind power. Complementarity. Synthetic series generation. 


\section{LISTA DE FIGURAS}

Figura 1: Operação e preço da energia no Brasil........................................................................... 2

Figura 2: Capacidade instalada acumulada de eólicas 2000-2016 ............................................ 18

Figura 3: 10 maiores países em capacidade eólica instalada e acumulada................................... 19

Figura 4: Participação da eólica na capacidade instalada em 2016 e projeção para 2024 ............ 20

Figura 5: Evolução do preço médio de leilão de energia eólica em US\$/MWh ........................... 21

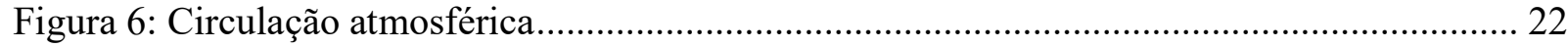

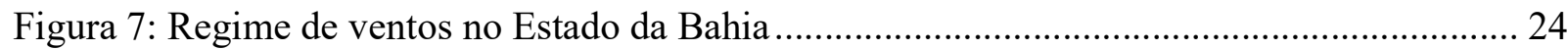

Figura 8: Curvas de Potências consideradas no cálculo do potencial eólico da Bahia ................. 25

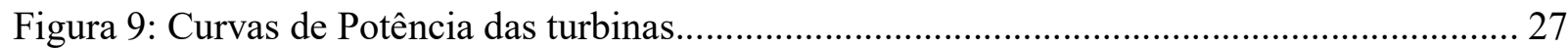

Figura 10: Participação da geração eólica na geração de energia do Nordeste ............................. 32

Figura 11: Evolução da capacidade instalada e geração eólica no Nordeste................................ 32

Figura 12: Evolução da capacidade instalada e geração eólica no Sul.......................................... 33

Figura 13: Capacidade instalada e geração eólica por Estado Brasileiro ...................................... 34

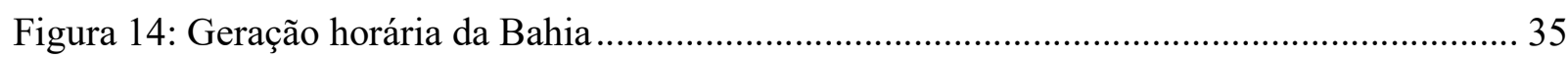

Figura 15: Geração horária do Ceará....................................................................................... 35

Figura 16: Geração horária do Rio Grande do Norte ................................................................. 36

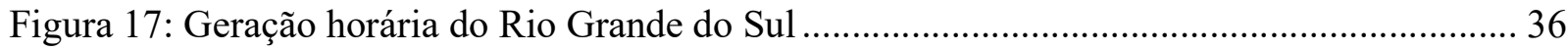

Figura 18: Redução dos níveis dos reservatórios do Nordeste e aumento da geração eólica........ 37

Figura 19: Geração eólica prevista e verificada no Nordeste....................................................... 38

Figura 20: Geração eólica prevista e verificada no Sul ................................................................. 39

Figura 21: Representação gráfica do custo total da operação ....................................................... 42

Figura 22: Sequências de afluências da árvore incompleta ............................................................. 44

Figura 23: Geração de séries com base em dados históricos........................................................ 48

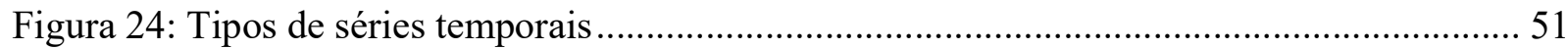

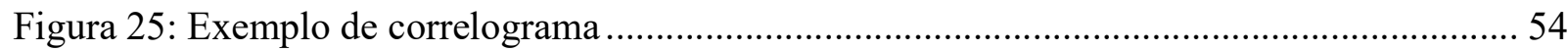

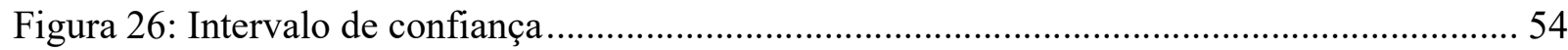

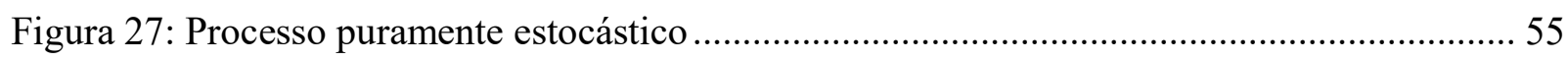

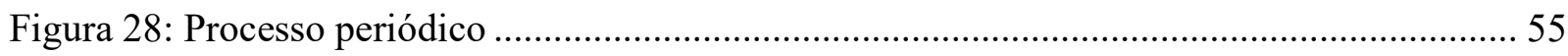

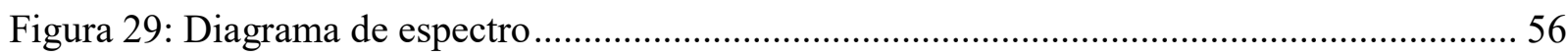

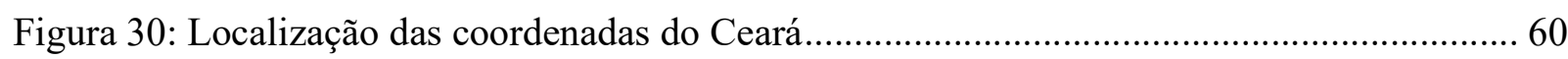


Figura 31: Localização das coordenadas do Rio Grande do Norte 60

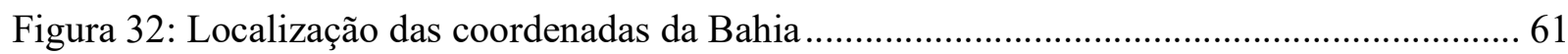

Figura 33: Localização das coordenadas de Pernambuco ........................................................... 61

Figura 34: Localização das coordenadas do Rio Grande do Sul ................................................... 62

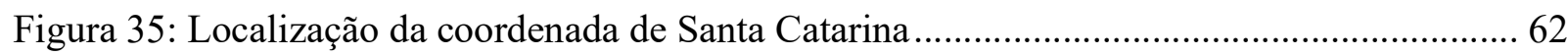

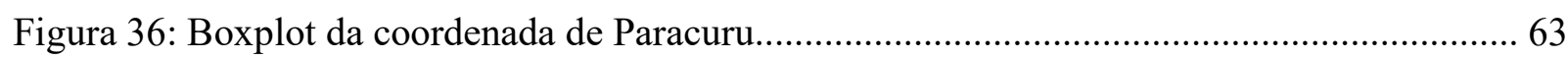

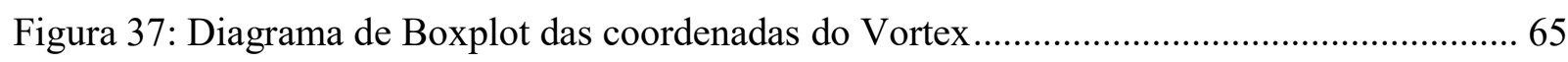

Figura 38: Correlação entre as coordenadas do Ceará com base MERRA e Vortex .................... 65

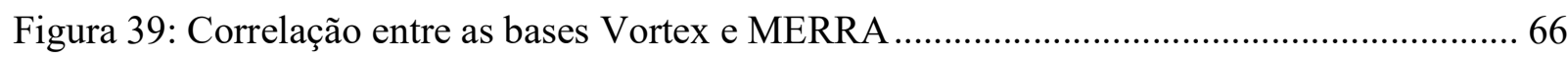

Figura 40: Histograma de Paracuru e ajuste da distribuição de Weibull...................................... 67

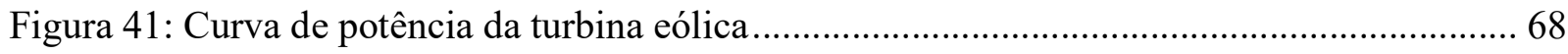

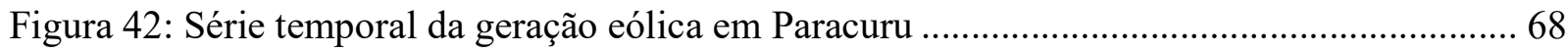

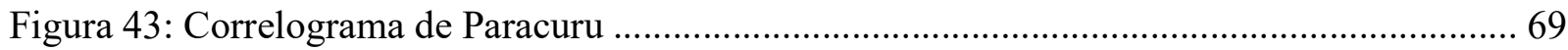

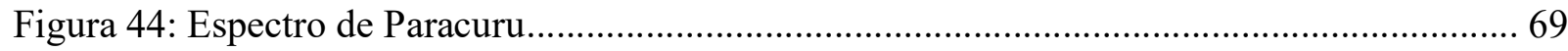

Figura 45: Curva logaritimica da velocidade horária do Vortex e a altura ................................. 71

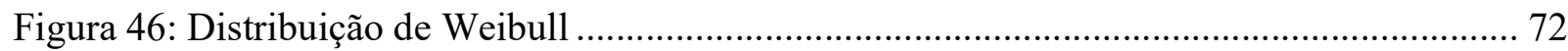

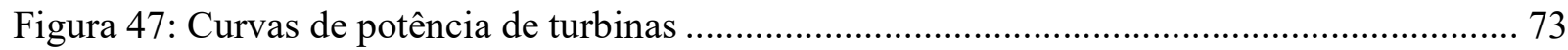

Figura 48: Geração eólica e total das usinas não simuladas no Nordeste ..................................... 74

Figura 49: Geração eólica e total das usinas não simuladas no Sul ............................................ 75

Figura 50: Geração anual eólica e total das usinas não simuladas no Nordeste............................. 76

Figura 51: Geração anual eólica e total das usinas não simuladas no Sul.................................... 76

Figura 52: Capacidade eólica instalada por Estado e a respectiva expansão ............................... 77

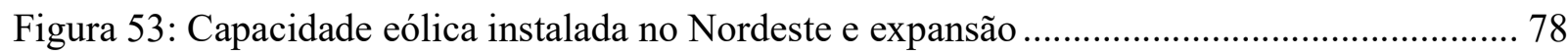

Figura 54: Capacidade eólica instalada no Sul e expansão ......................................................... 78

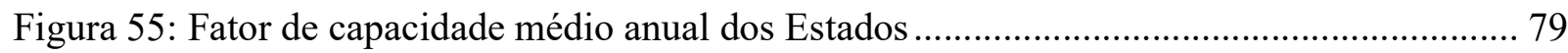

Figura 56: Fator de capacidade mensal do Nordeste ............................................................... 80

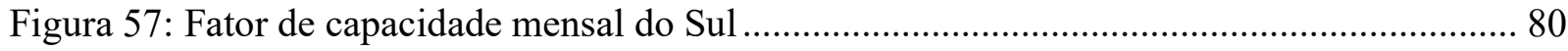

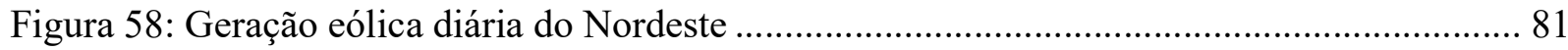

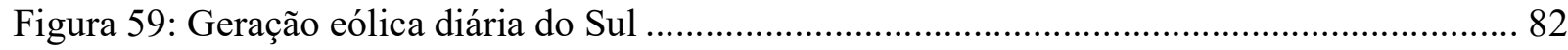

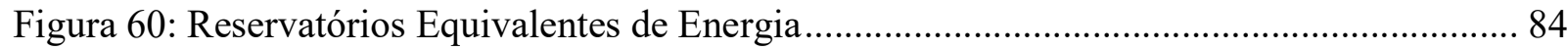

Figura 61: Nova representação dos Reservatórios Equivalentes de Energia................................. 85 
Figura 62: Representação dos Reservatórios Equivalentes no modelo Newave 88

Figura 63: Representação dos Reservatórios Equivalentes com sites eólicos e expansão ..... 89

Figura 64: Representação das vazões mínimas das usinas com sites eólicos. 90

Figura 65: Gerador de arquivos binário e texto para alteração das informações no deck 91

Figura 66: Tela do arquivo POSTOS.DAT considerando a inserção das eólicas 92

Figura 67: Tela do arquivo VAZPAST.DAT considerando a inserção das eólicas 93

Figura 68: Tela do arquivo VAZOES.DAT considerando a inserção das eólicas 94

Figura 69: Histórico reconstruída de geração eólica 95

Figura 70: Tela do hydroedit para leitura e inserção de novas usinas ......................................... 96

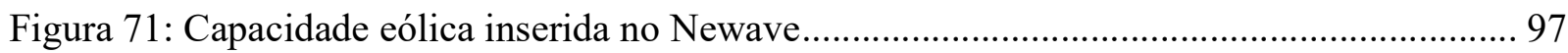

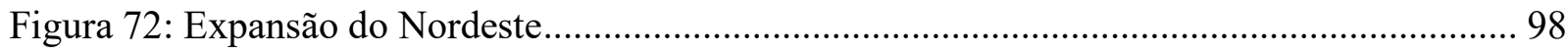

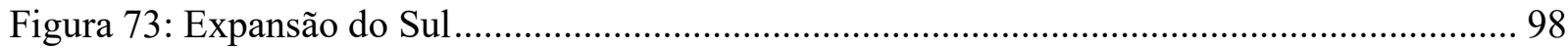

Figura 74: ENA hidráulica e ENA eólica do Nordeste de 1951 a 1955 ..................................... 100

Figura 75: ENA hidráulica e ENA eólica do Nordeste de 2010 a 2014 ..................................... 101

Figura 76: Nível dos reservatórios dos submercados caso oficial vs. Simulação Caso 1 ........... 104

Figura 77: CMO médio anual dos submercados com séries oficiais vs. Simulação caso 1 ........ 105

Figura 78: CMO médio mensal dos submercados com séries oficiais vs. Simulação caso 1 ..... 106

Figura 79: CMO médio mensal dos submercados com séries oficiais vs. Simulação caso 1 (1951$1955)$

Figura 80: CMO médio mensal dos submercados com séries oficiais vs. Simulação caso 1 (20102014) 108

Figura 81: Geração hidráulica anos médios oficial vs. Simulação caso 1.................................. 109

Figura 82: Geração hidráulica do SIN anos médios oficial vs. Simulação caso 1 ...................... 109

Figura 83: Geração hidráulica oficial vs. Simulação caso 1 (1951-1955)................................... 110

Figura 84: Geração hidráulica no SIN oficial vs. Simulação caso 1 (1951 a 1955).................... 111

Figura 85: Geração hidráulica oficial vs. Simulação caso 1 (2010-2014).................................. 111

Figura 86: Geração hidráulica no SIN oficial vs. Simulação caso 1 (2010 a 2014).................... 112

Figura 87: Geração térmica anos médios oficial vs. Simulação caso 1 ....................................... 113

Figura 88: Geração térmica oficial no SIN vs. Simulação caso 1 (média) ................................... 113

Figura 89: Geração térmica oficial vs. Simulação caso 1 .......................................................... 114

Figura 90: Geração térmica oficial no SIN vs. Simulação caso 1 (1951 a 1955)......................... 115 
Figura 91: Geração térmica oficial vs. Simulação caso 1 116

Figura 92: Geração térmica oficial no SIN vs. Simulação caso 1 (2010 a 2014). 117

Figura 93: Geração Eólica séries históricas vs. Simulação caso 1 (média) 118

Figura 94: Geração Eólica séries históricas vs. Simulação caso 1 (1951 a 1955). 118

Figura 95: Geração Eólica no Nordeste e no Sul (média) caso 1 119

Figura 96: Geração Eólica no Nordeste e no Sul oficial caso 1 119

Figura 97: Geração eólica do Nordeste e do Sul caso 1 vs. Caso 2 122

Figura 98: CMO médio anual dos submercados com séries oficiais vs. Simulação caso 2 123

Figura 99: CMO médio mensal dos submercados com séries oficiais vs. Simulação caso 2 ..... 124 Figura 100: CMO médio mensal dos submercados com séries oficiais vs. Simulação caso 2 (1951$1955)$ 125

Figura 101: Geração hidráulica anos médios oficial vs. Simulação caso 2. 126

Figura 102: Geração hidráulica oficial vs. Simulação caso 2 (1951 a 1955) 127

Figura 103: Geração térmica anos médios oficial vs. Simulação caso 2 .. 128

Figura 104: Geração térmica crítico oficial vs. Simulação caso 2 (1951 a 1955). 129

Figura 105: Geração Eólica séries históricas vs. Simulação caso 2 . 129

Figura 106: Geração Eólica séries históricas vs. Simulação caso 2 (1951 a 55). 130

Figura 107: Geração Eólica no Nordeste e no Sul (média) caso 2 . 130

Figura 108: Geração Eólica no Nordeste e no Sul (1951-55) caso 2 131

Figura 109: Aumento da carga do Sul e Nordeste para simulação de aumento de eólicas 132

Figura 110: CMO mensal na média e anos secos caso 3 135

Figura 111: Geração Hidráulica vs. Eólica (média e anos secos) caso 4 135

Figura 112: CMO médio anual dos submercados com séries oficiais vs. Simulação caso 4 139

Figura 113: CMO médio mensal dos submercados com séries oficiais vs. Simulação caso 4 ... 140

Figura 114: Geração hidráulica anos médios oficial vs. Simulação caso 4. 141

Figura 115: Geração térmica anos médios oficial vs. Simulação caso 4 142

Figura 116: Geração Eólica séries históricas vs. Simulação caso 4 143

Figura 117: Geração Eólica no Nordeste e no Sul (média) caso 4 143 


\section{LISTA DE TABELAS}

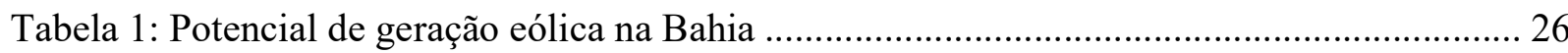

Tabela 2: Potencial de geração eólica no Rio Grande do Norte ................................................... 28

Tabela 3: Potencial de geração eólica no Rio Grande do Norte com diferente taxa de ocupação 28

Tabela 4: Potencial de geração eólica no Ceará …........................................................................... 29

Tabela 5: Potencial de geração eólica no Ceará com diferente taxa de ocupação......................... 29

Tabela 6: Potencial de geração eólica no Rio Grande do Sul........................................................ 31

Tabela 7: Potência instalada, geração eólica e fator de capacidade em ago/16............................ 34

Tabela 8: Variação do previsto vs. verificado de geração eólica no Sul e no Nordeste................ 39

Tabela 9: Coeficiente de rugosidade para diversos tipos de terreno ........................................... 57

Tabela 10: Latitudes e Longitudes das coordenadas do MERRA ................................................. 58

Tabela 11: Latitude e Longitude das coordenadas do Vortex ....................................................... 59

Tabela 12: Localizações próximas das usinas em operação e em construção consideradas na

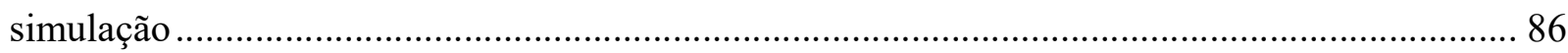

Tabela 13: Níveis dos reservatórios iniciais em agosto de 2014, 2015 e 2016 ............................ 99

Tabela 14: Análise de CMO e geração em agosto do quarto ano................................................ 102

Tabela 15: Análise de CMO e geração em fevereiro do quinto ano............................................ 103

Tabela 16: Análise de CMO e geração em agosto do quarto ano................................................ 120

Tabela 17: Análise de CMO e geração em fevereiro do quinto ano........................................... 121

Tabela 18: Análise de CMO e geração em agosto do quarto ano................................................. 133

Tabela 19: Análise de CMO e geração em fevereiro do quinto ano............................................ 134

Tabela 20: Análise de CMO e geração em agosto do quarto ano................................................ 137

Tabela 21: Análise de CMO e geração em fevereiro do quinto ano........................................... 138

Tabela 22: Custo da geração térmica e custo total de operação dos casos................................... 144

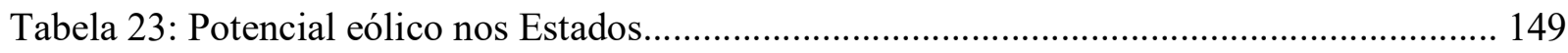




\section{LISTA DE ABREVIATURAS E SIGLAS}

ANEEL Agência Nacional de Energia Elétrica

ARIMA Modelo Autoregressivo Integrado de Média Móvel

BIG Banco de Informações da Geração

CCEE Câmera de Comercialização de Energia Elétrica

CEPEL Centro de Pesquisa de Energia Elétrica

CMO Custo Marginal de Operação

EAR Energia Armazenada

ENA Energia Natural Afluente

EOL Usina eólica

EPE Empresa de Pesquisa Energética

FCF Função de Custo Futuro

FCI Função de Custo Imediato

GWEC Global Wind Energy Council

MLT Média de Longo Termo

MME Ministério de Minas e Energia

ONS Operador Nacional do Sistema Elétrico

PCH Pequena Central Hidrelétrica

PDE Plano Decenal de Energia

PDDE Programação Dinâmica Dual Estocástica

PLD Preço de Liquidação das Diferenças

PMO Programa Mensal da Operação

PROINFA Programa de Incentivo às Fontes Alternativas de Energia Elétrica

REE Reservatório Equivalente de Energia

SIN Sistema Interligado Nacional

UHE Usina Hidrelétrica

UTE Usina Termelétrica 


\section{SUMÁRIO}

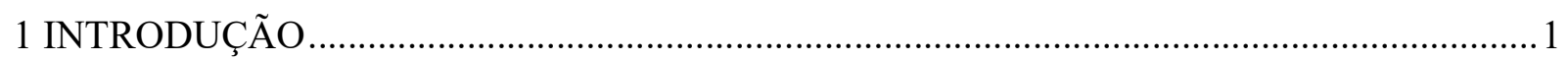

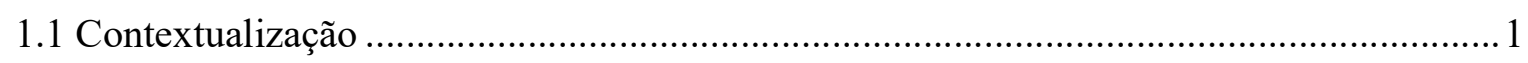

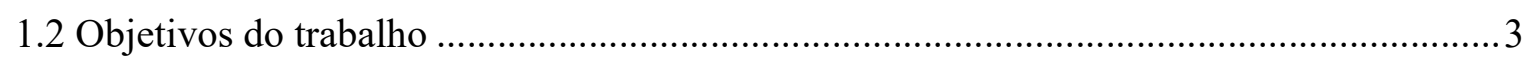

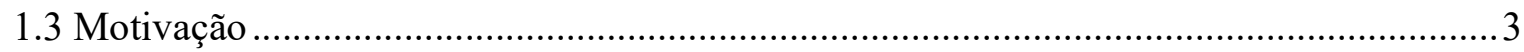

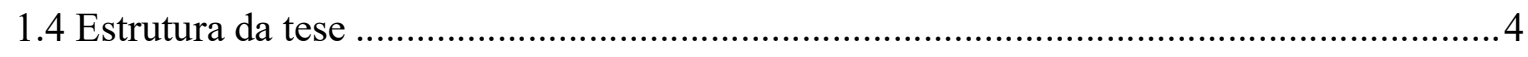

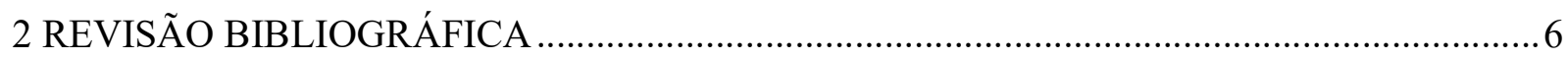

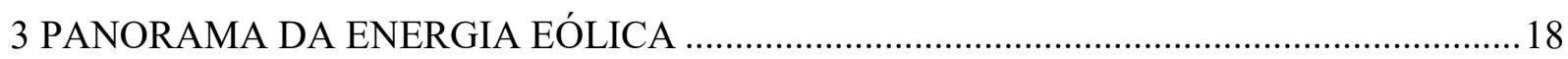

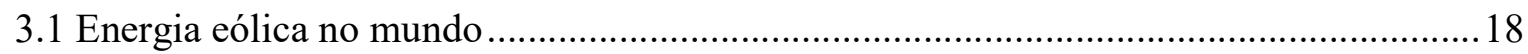

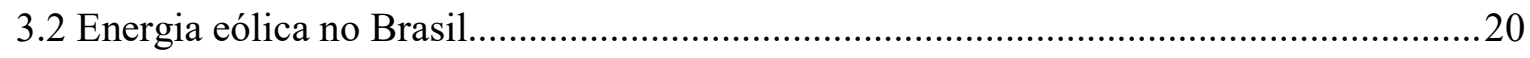

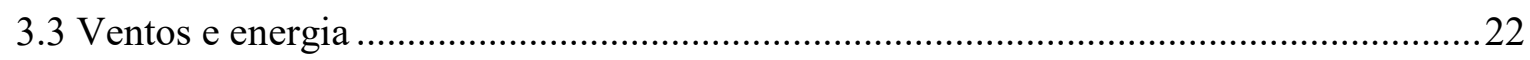

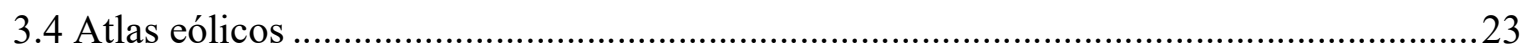

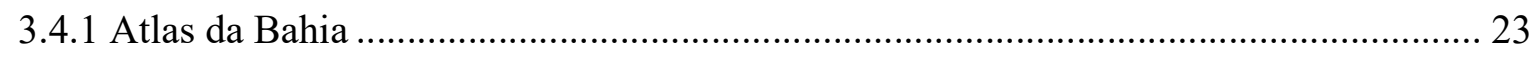

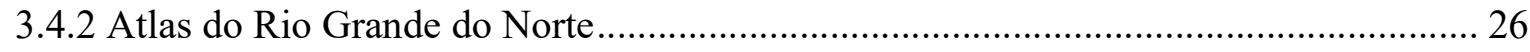

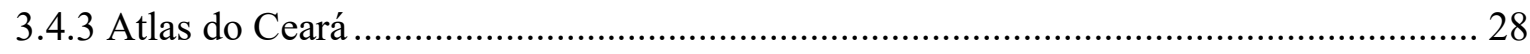

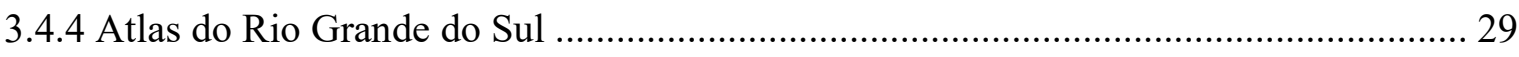

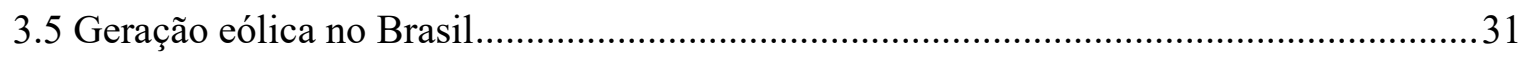

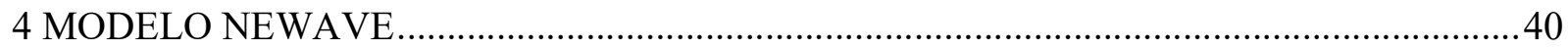

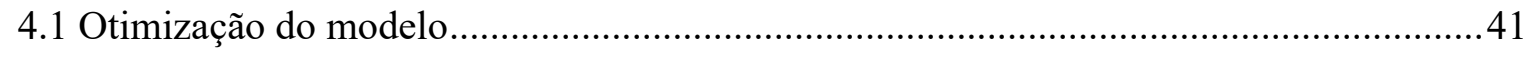

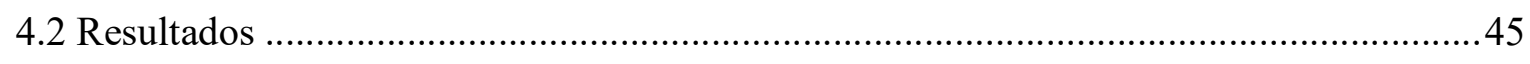

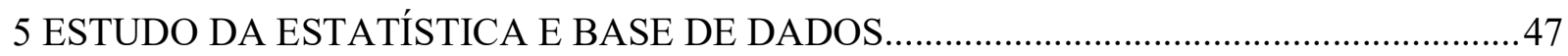

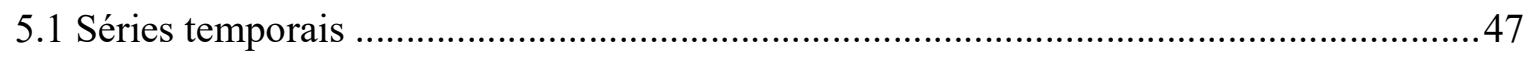

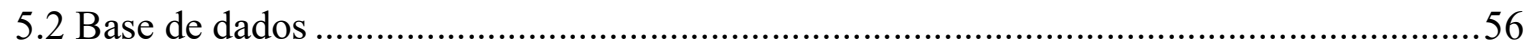

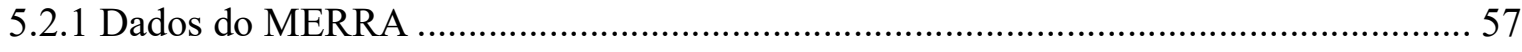

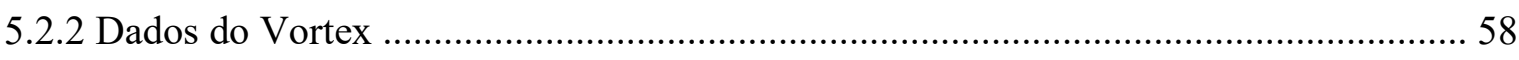

5.2.3 Localização geográfica dos dados do MERRA e Vortex............................................. 59

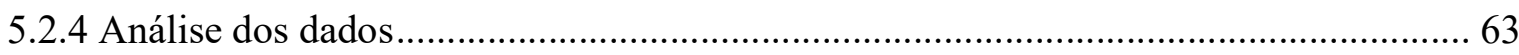

5.3 Metodologia de reconstrução da base de velocidade de vento ..........................................70

6 INSERÇÃO DA GERAÇÃO EÓLICA ESTOCÁSTICA ….....................................................74

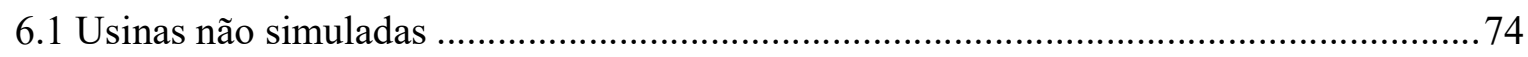

6.2 Capacidade instalada dos Estados e expansão .............................................................. 77

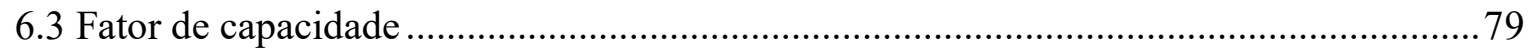

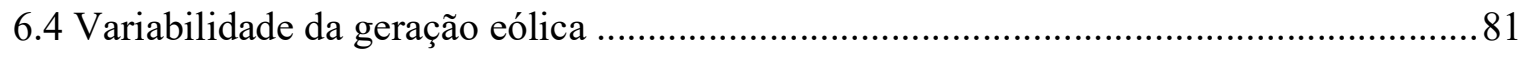

7 INSERÇÃO DOS DADOS DE ENERGIA EÓLICA NO MODELO NEWAVE......................83 


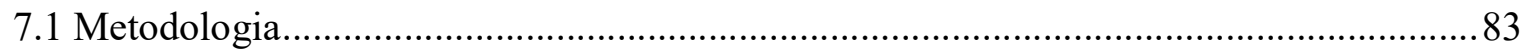

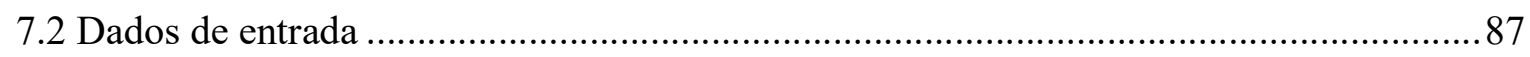

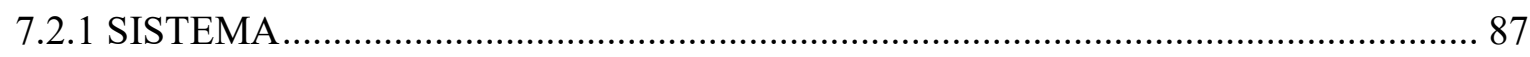

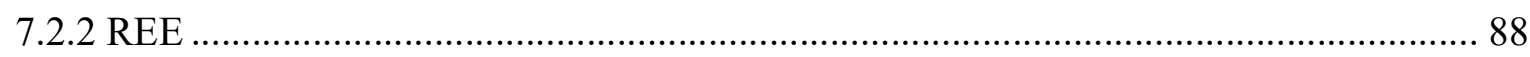

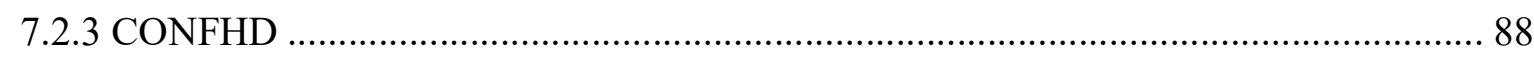

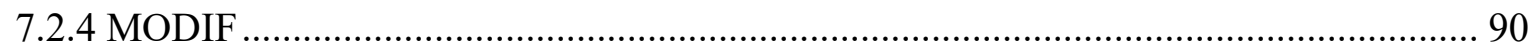

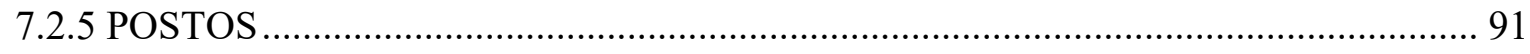

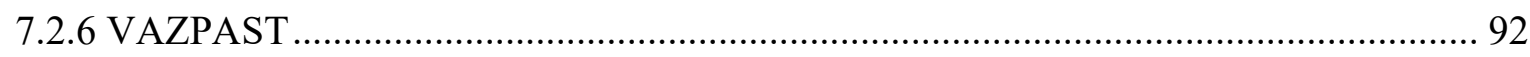

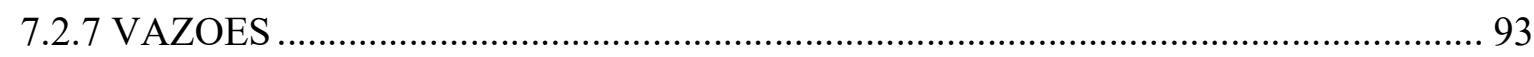

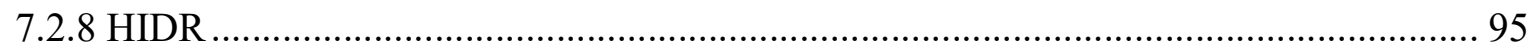

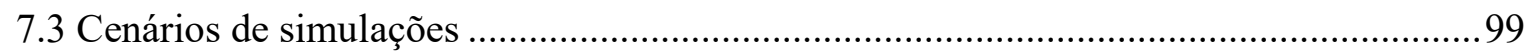

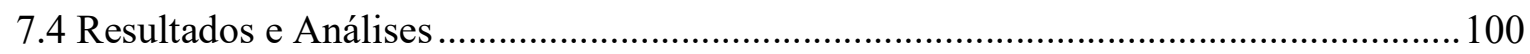

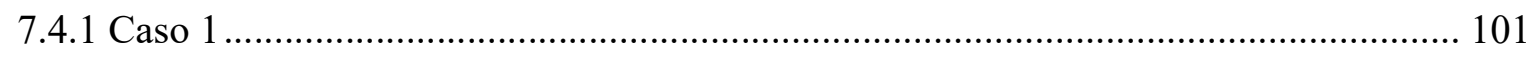

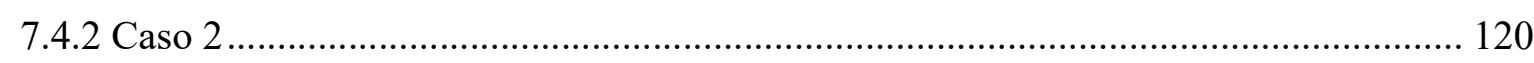

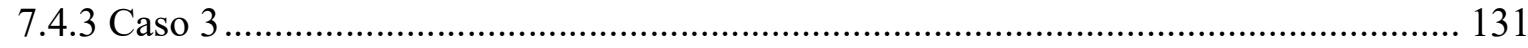

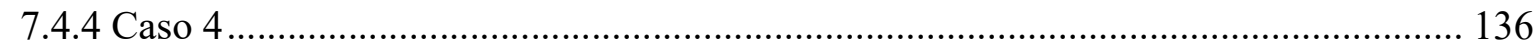

8 SÍNTESE, CONCLUSÕES E RECOMENDAÇÕES ......................................................... 145

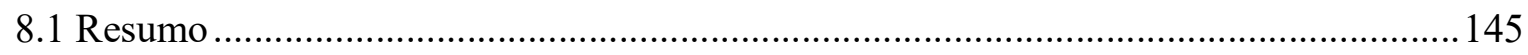

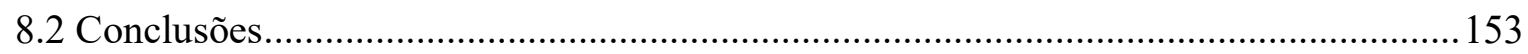

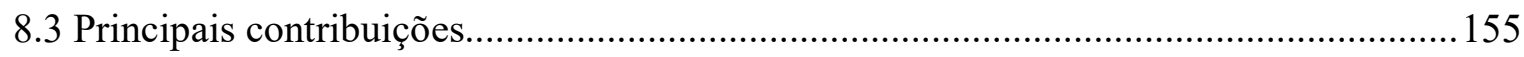

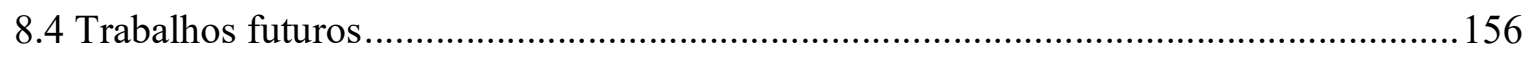

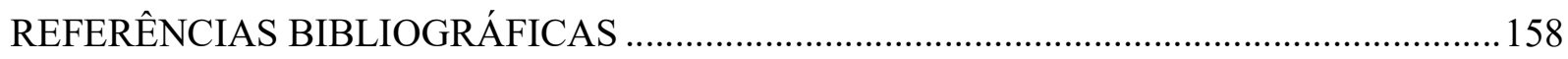

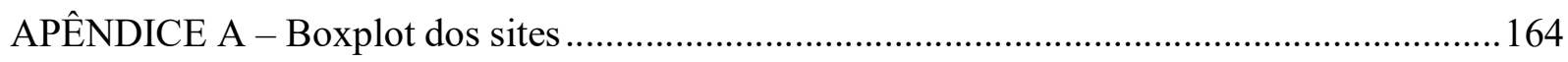

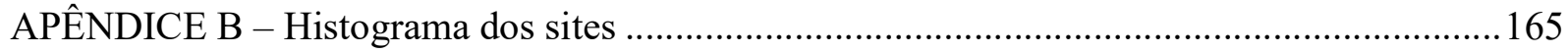

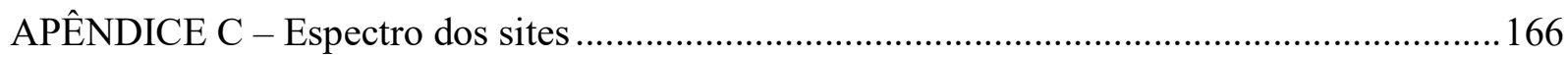




\section{INTRODUÇÃO}

\subsection{Contextualização}

A principal fonte para geração de energia no Brasil é a hidrelétrica que em 2016 representou em média $76 \%$ da geração do país. A geração térmica representou $19 \%$ em média para o mesmo período (considerando térmicas com combustível fóssil e nucleares), sendo que a geração eólica representou em média 6\%, com maior participação em setembro de 2016 com 8\% da participação da geração de energia (ONS, 2016).

Estes mesmos números para 2011, quando o preço da energia elétrica era considerado baixo (preço médio anual do Sudeste de $30 \mathrm{R} \$ / \mathrm{MWh}$ ), a geração hidrelétrica representou $91 \%$ da geração média anual, a geração térmica representou $8 \%$ e a geração eólica, que estava iniciando, representou $0,4 \%$.

Embora a geração da energia eólica tenha a menor participação na geração de energia elétrica, espera-se que a participação da fonte aumente significativamente no futuro, representando 11,6\% da capacidade instalada em 2024, de acordo com o Plano Decenal da Empresa de Pesquisa Energética (EPE) 2024.

Com a redução dos níveis dos reservatórios das usinas hidráulicas brasileiras, são despachadas fontes termelétricas para complementar o atendimento da carga. Esta geração térmica aumenta o custo de operação do sistema, em função dos altos custos dos combustíveis fósseis.

A Figura 1 mostra a redução dos níveis dos reservatórios desde 2012 para a região Sudeste, permitindo observar também as afluências em grande parte do tempo abaixo da média histórica (\% da $\mathrm{MLT}^{1}$ ) e o impacto no preço da energia da região. As linhas tracejadas representam o máximo de Energia Armazenada² (EAR) e Energia Natural Afluente ${ }^{3}$ (ENA).

\footnotetext{
${ }^{1}$ Média de Longo Termo mensal do histórico de afluências desde 1931 a 2015, considerando o ano atual de 2017.

2 Energia armazenada em um sistema de reservatórios representado em energia ou em percentual da capacidade máxima de armazenamento.

${ }^{3}$ Energia que pode ser produzida a partir das vazões afluentes aos reservatórios e a produtibilidade das usinas representada em energia ou em percentual da MLT.
} 
Figura 1: Operação e preço da energia no Brasil

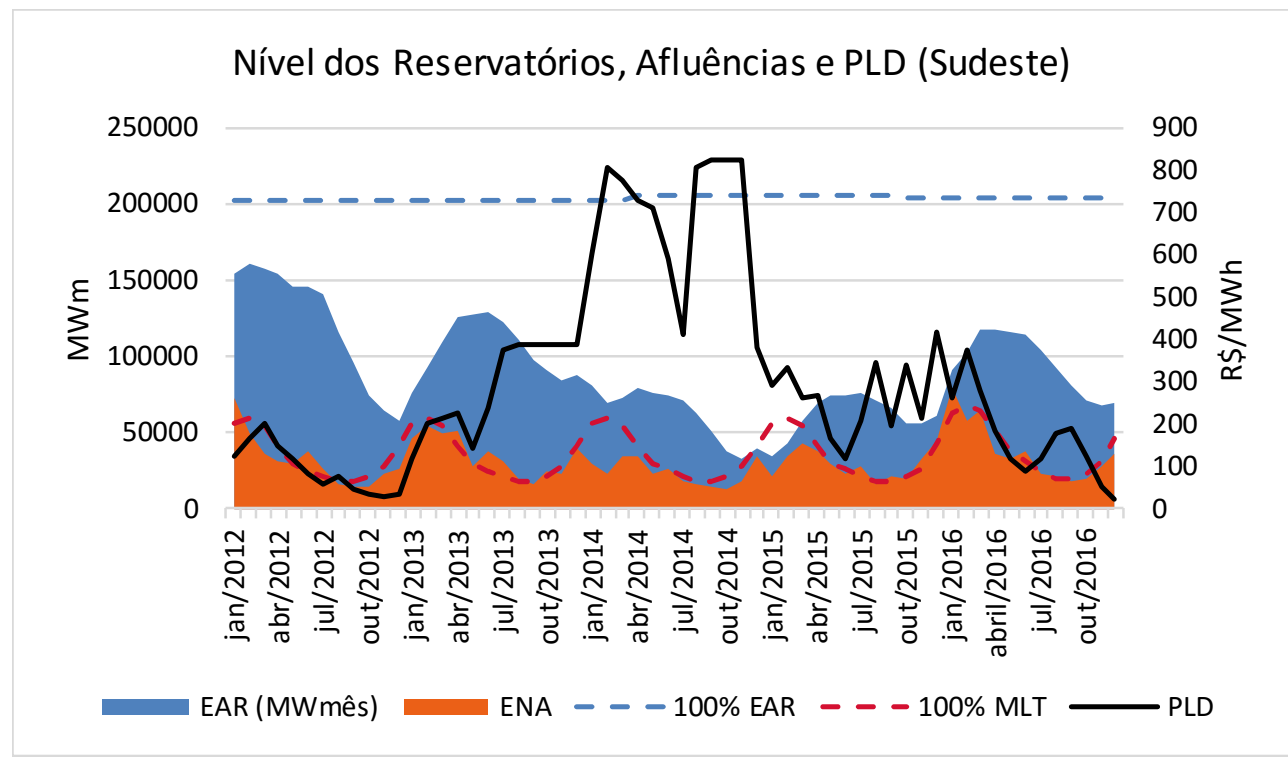

Fonte: Elaboração própria com base em ONS e CCEE (2016).

O ONS (Operador Nacional do Sistema) determina a geração de energia elétrica no sistema brasileiro, seguindo o despacho dos modelos Newave e Decomp (CCEE, 2015). O objetivo do modelo Newave é minimizar a expectativa do custo total de operação para um horizonte de até 5 anos. O modelo otimiza e determina o montante de geração hidráulica e térmica em cada período de tempo (mês) para o atendimento da carga.

A geração das pequenas usinas ou usinas não simuladas (usinas não despachadas centralizadamente) é abatida da carga do respectivo subsistema de forma determinística (CEPEL, 2013). Essa geração contempla as fontes eólicas, Pequenas Centrais Hidrelétricas (PCHs) e Biomassa. Devido à representação com perfil determinístico, sendo um montante médio de geração anual com sazonalidade mensal e expectativa de aumento dada a expansão da fonte, não há representação da incerteza nos modelos para essas usinas. De fato, a metodologia empregada atualmente, não representa a variabilidade da geração de energia eólica, devido às variações nas velocidades dos ventos e também não caracteriza a complementaridade com a fonte hidráulica no Nordeste. Considerando o aumento da participação eólica na matriz de eletricidade brasileira, a representação estocástica da geração eólica torna-se importante e urgente de ser analisada e considerada no planejamento do setor elétrico brasileiro. 


\subsection{Objetivos do trabalho}

Este trabalho propõe como objetivo geral a análise e proposta metodológica que permita incluir a variabilidade da geração eólica nos modelos de otimização oficiais do setor elétrico brasileiro.

Os objetivos específicos são:

Apresentar um panorama geral da fonte eólica no mundo e apresentar análises sobre as velocidades de vento e geração eólica em diversas regiões do Brasil;

Detalhar o modelo de otimização Newave e como seriam realizadas as modificações para a inserção da eólica com geração de séries históricas e sintéticas;

Mensurar o impacto da mudança no modelo, comparando-se com o modelo utilizado atualmente de forma determinística e avaliar os índices: despacho das usinas térmicas, hidráulicas e custos marginais de operação;

Avaliar a complementaridade das hidráulicas com eólicas.

\subsection{Motivação}

A decisão de escolher este estudo de geração de séries sintéticas de geração eólica para a otimização dos modelos de preços e despacho das usinas, teve como motivador o fato da geração das pequenas usinas serem abatidas da carga, sem considerar incertezas dessa geração no SIN. A princípio, não se afigura correto determinar o montante de geração eólica futura com base no histórico de geração e expectativa de expansão. A razão é que, esta metodologia de abatimento da carga para as eólicas não considera a variabilidade da fonte e a consequente complementaridade com a hidráulica. Como consequência desta metodologia, o requisito de carga é simplesmente reduzido, considerando-se deterministicamente a geração média como o montante fosse realmente ser gerado, o que na prática pode não ocorrer. Desta forma, a motivação principal do trabalho é identificar o impacto de se incorporar a variabilidade da geração eólica nos modelos de otimização 
do Sistema Elétrico Brasileiro, verificando-se os rebatimentos da mudança metodológica em termos de despachos hidráulicos, térmicos, custos marginais e as contribuições para o planejamento da operação do sistema.

As demais motivações para este estudo contemplam: incremento da geração eólica na matriz de eletricidade brasileira; redução dos custos da fonte nos leilões; complementariedade com a geração hidráulica; potencial eólico brasileiro; estudo de metodologia que possibilite uma análise mais precisa da geração eólica.

\subsection{Estrutura da tese}

O primeiro capítulo desta tese retratou a contextualização do problema da geração de energia eólica nos modelos de otimização do setor elétrico brasileiro. Identificou-se os objetivos a serem desenvolvidos no decorrer do texto e a motivação do trabalho.

O segundo capítulo exibe a revisão de literatura relacionada à geração de séries de vento e de afluências e modelos de otimização.

O terceiro capítulo apresenta um panorama da energia eólica no mundo e no Brasil, mostrando a potência instalada hoje e projeção de crescimento para 2024. Os preços dos leilões de eólicas praticados no Brasil, evidenciando os motivos da redução até 2013 e elevação posterior. Aborda a formação dos ventos e a transformação da energia cinética em elétrica. O capítulo mostra os atlas da Bahia, Rio Grande do Norte, Ceará e Rio Grande do Sul, além dos regimes de ventos das regiões, a geração eólica nos estados e variações diárias na geração de energia.

Apesar do segundo capítulo já explanar sobre a metodologia do Newave na revisão de literatura, o quarto capítulo aprofunda o detalhamento do modelo de otimização, mostrando o cálculo do custo total da operação e a geração de séries de afluências. Este capítulo é importante para o entendimento do modelo, uma vez que as simulações realizadas no trabalho utilizam o Newave.

O quinto capítulo analisa as bases de dados de velocidade de vento tanto cedidos pela Vortex quanto considerado da base Grads, do MERRA (Modern-Era Retrospective Analysis for Research and Applications). Através de curva de potência de turbina eólica, é calculada a energia 
que poderia ser gerada nestas condições de velocidades de vento, identificando-se as regiões com maior potencial e a uniformidade entre as coordenadas. A metodologia de reconstrução de dados eólicos para a geração de energia é detalhada no capítulo.

O sexto capítulo apresenta as usinas não simuladas consideradas no Newave e o montante representado por eólica no Nordeste e Sul do Brasil, além da capacidade eólica instalada em oito estados brasileiros e a expectativa de expansão consideradas nos modelos de otimização. $\mathrm{O}$ fator de capacidade e a variabilidade diária da eólica também são abordadas no capítulo.

O sétimo capítulo visa mostrar as alterações necessárias no modelo de otimização Newave para separação dos arquivos de geração eólica em reservatórios equivalentes de energia e a consideração das séries sintéticas de geração eólica. Além disso, são simulados cenários considerando as eólicas em reservatórios equivalentes de energia e sua respectiva expansão, sendo estes: (i) considerando o histórico reconstruído de geração eólica e comparando com a simulação oficial histórica de agosto de 2016; (ii) idem ao item anterior, considerando um cenário crítico de níveis de reservatório e aumento de carga; (iii) simulação considerando aumento de capacidade eólica em "dez" vezes; e (iv), idem ao primeiro item, porém considerando-se as séries sintéticas. A partir dos cenários, verificam-se as diferenças com a metodologia determinística, analisando-se os custos marginais de operação, geração térmica, geração hidráulica e geração eólica.

As considerações finais do estudo bem como as contribuições e recomendações para trabalhos futuros são apresentados no oitavo capítulo desta tese.

As referências utilizadas no trabalho seguem no capítulo seguinte.

Os apêndices A, B e C mostram gráficos de boxplot, histograma e espectro de todas as coordenadas da base de dados Vortex utilizada no trabalho. 


\section{REVISÃO BIBLIOGRÁFICA}

Com o aumento da inserção da fonte eólica na matriz energética de importante número de países e, ao mesmo tempo, considerando a incerteza intrínseca de produção, surgiram diversos trabalhos descrevendo metodologias para a modelagem das séries temporais das velocidades dos ventos e previsão de geração de energia eólica. Muitos tomam como base a geração de séries sintéticas de afluências, dado o conhecimento da incerteza das vazões em modelos hidráulicos ou hidrotérmicos. Estes trabalhos visam, sobretudo, a modelagem da inserção eólica para subsidiar o planejamento da operação dos sistemas elétricos dos respectivos países, prevendo a geração eólica e modelos para identificar o comportamento estratégico dos despachos das outras fontes de energia. Para os objetivos deste trabalho, por outro lado, ao invés de prever a operação eólica em horizonte de curto prazo (dia seguinte ou, no máximo, uma semana à frente, como se faz em outros países), o que importa é gerar cenários plausíveis de geração eólica, compatíveis com os cenários hidrológicos, dada a sua complementaridade, em horizonte de até 5 anos à frente, que no caso brasileiro é o horizonte do planejamento energético da operação.

Em relação aos processos hidrológicos, a maioria deles são considerados estocásticos pois são governados por leis probabilísticas, uma vez que contém componentes aleatórias que se superpõem a eventuais regularidades, como estações do ano ou variações de radiação solar. (NAGHETTINI \& PINTO, 2007) exemplificam a precipitação, as capacidades de infiltração, os escoamentos superficiais, como processos hidrológicos estocásticos. O estudo do processo estocástico refere-se à interpretação da aleatoriedade presente através de modelos matemáticos, buscando estabelecer conexões em sequência, no tempo ou no espaço. O acoplamento espacial decorre do fato do despacho de uma usina hidrelétrica afetar o despacho de outra na cascata.

Devido às incertezas das vazões e a necessidade de despacho antecipado das fontes hidráulicas e térmica para o planejamento da operação, alguns estudos mostram modelos de otimização para o mínimo custo total da operação. (PEREIRA et al., 1984) descrevem o desenvolvimento de um modelo mensal de afluências para o sistema hidrotérmico brasileiro. $\mathrm{O}$ modelo leva em consideração a desagregação de afluências autoregressivas anuais em mensais. Primeiramente uma distribuição log-normal de três parâmetros é ajustada às afluências incrementais anuais, em seguida geram-se valores anuais que são desagregados em valores mensais 
e por fim realiza-se a soma das afluências incrementais mensais das cascatas dos rios para obtenção do valor total. (PEREIRA \& PINTO, 1985) apresentam um modelo que determina para cada estágio a estratégia de geração mais econômica para cada usina do sistema hidrotérmico. O algoritmo é baseado em um processo estocástico de decomposição de Benders e podem ser utilizados semanalmente ou mensalmente para a operação do sistema.

O modelo de otimização utilizado oficialmente no Brasil é o Newave. O programa resolve os problemas de planejamento da operação interligada de sistemas hidrotérmicos empregando a técnica da Programação Dinâmica Dual Estocástica (PDDE), aplicada a um problema com múltiplos estágios (PEREIRA \& PINTO, 1991). (SIQUEIRA et al., 2003) mostra que a PDDE é uma técnica alternativa à Programação Dinâmica Estocástica (PDE) que propõe solucionar o problema da dimensionalidade não apresentando a necessidade de discretização do espaço de estados. A vazão afluente no início do estágio é assumida conhecida. A partir da distribuição das afluências, é obtido um conjunto de afluências equiprováveis. O problema é resolvido para cada afluência separadamente, resultando em diferentes soluções ótimas individuais. Para o mesmo estado existem diferentes custos de operação. O custo total atribuído ao estado é obtido através do valor esperado ou esperança matemática dos custos relacionados a cada uma das afluências equiprováveis.

No Newave, a incerteza hidrológica é considerada através de cenários sintéticos de sequência de Energias Naturais Afluentes às sub-regiões, para os próximos 5 anos, geradas pelo modelo Gevazp (modelagem autoregressiva linear) com base nos últimos 11 meses, (MACEIRA; MERCIO, 1997). O modelo estocástico utilizado no Gevazp, capaz de se ajustar a modelagem das afluências, é o PAR (p), modelo autoregressivo periódico de ordem p. As afluências neste modelo dependem das afluências que ocorreram nos mesmos locais em até p meses anteriores. Para cada mês pode haver um valor diferente para o parâmetro "p". Normalmente, afluências em meses iniciais do período chuvoso dependem de 1 ou 2 meses anteriores. Já em meses do período seco, dependem do que ocorreu em vários meses do período úmido anterior.

Apesar do Newave ser o modelo oficial, outros estudos mostram modelos que apresentam também o objetivo de determinar a estratégia de operação ou cenarizar as vazões, mas com características distintas. Um exemplo é o Hidroterm, mostrado por (ZAMBON et al., 2012), sendo um modelo matemático de otimização e gerenciamento da operação do sistema hidrotérmico 
brasileiro. O sistema consiste em um grande número de usinas hidrelétricas individualizadas e termelétricas. A energia gerada no sistema é interconectada por uma rede de transmissão que pode ser transmitida para os centros de consumo do país. O modelo considera diferentes tipos de restrições de transferência de água entre bacias, usos múltiplos da água e restrições ambientais. O objetivo do programa é produzir energia para o atendimento da demanda a um custo mínimo. O modelo utiliza a linguagem General Algebric Modeling System (GAMS) com programação linear e não linear, além disso, permite modificar a simulação do modelo de base mensal para semanal.

(PALFI; ZAMBON, 2013) afirmam que o planejamento da operação do sistema utiliza uma previsão determinística da produção de energia eólica com base na média dos valores esperados e apenas as afluências são consideradas de forma sintética com modelo estocástico. Com a tendência de aumento da geração eólica, o impacto da sazonalidade dos ventos pode ser observado considerando a geração de cenários que preservam a correlação temporal e espacial entre as fontes que podem ser incluídos em modelos de planejamento da operação como o Hidroterm, SolverSIN e o Newave. O estudo apresenta a correlação temporal entre o regime hidrológico e o comportamento dos ventos no Nordeste, Sudeste e Sul do Brasil, mostrando que o Nordeste e o Sudeste apresentam complementaridade com as séries de afluências, além disso, o estudo aponta que os meses de agosto a outubro são os mais favoráveis para a geração eólica principalmente no Nordeste, e os meses de janeiro a abril são os menos favoráveis.

(LUCAS et al., 2009) aplicam um modelo hidrológico determinístico mensal de dois parâmetros e o modelo estocástico ARIMA (Autoregressivo Integrado de Média Móvel) para simular a vazão mensal nas sub-bacias do rio Xingú, no Pará, para a modelagem hidrológica determinística e estocástica na bacia do rio. O modelo determinístico apresenta valores sensíveis a eventos extremos. O modelo ARIMA captura a dinâmica das séries temporais, apresentando resultados satisfatórios nas simulações de vazões. De forma geral, os autores mostram que as duas metodologias são satisfatórias, mas sugerem cautela no período chuvoso, uma vez que a maior parte dos eventos extremos de precipitação e vazões de pico ocorrem neste período.

A seguir são apresentados resumidamente alguns trabalhos internacionais e nacionais que são muito importantes e, mesmo que não sejam aplicados diretamente ao problema de otimização brasileiro, os artigos discutem aspectos relevantes de modelagem de séries sintéticas de geração eólica e estratégia de solução. 
(CASTINO et al., 1998) descreve metodologia estocástica para geração de séries temporais de velocidades de vento e direção do vento. Estes modelos utilizam a cadeia de Markov (caracterizado por uma matriz de transição entre estados) e Modelo Auto Regressivo Discreto de ordem 2 (DAR (2)), considerando a dinâmica da direção do vento em cada estado e a velocidade do vento, simulam-se séries de vento a cada três horas. No trabalho, os 42 anos de dados são utilizados próximo ao aeroporto de Brindisi na Itália, do centro regional meteorológico da força aérea Italiana. Os resultados mostram que o modelo é capaz de gerar sequências de velocidade de vento estatisticamente próximas dos valores observados, mas apresenta como melhoria uma metodologia que apresente uma dependência da velocidade com a direção do vento.

(ALEXIADIS et al., 1998) preveem a velocidade de vento e a potência elétrica relacionada para turbinas eólicas com modelos de inteligência artificial. Variações da geração eólica podem causar flutuações de tensão e frequência. Além disso, cut-offs ${ }^{4}$ repentinos podem causar choques inaceitáveis nas unidades de potência. A previsão da geração eólica se torna importante para eficiência do gerenciamento da carga e operação do sistema. A curva de velocidade de vento é transformada em potência eólica utilizando curvas de fabricantes. Neste caso, os dados foram de 7 anos, em 6 diferentes sites, na Grécia. Dados vizinhos aos sites foram observados para se verificar correlação espacial. Os dados mostraram-se não estacionários e uma periodicidade principalmente no verão. Modelos autoregressivos e redes artificiais neurais foram testadas, sendo que as redes neurais apresentaram resultados mais próximos dos valores observados.

(RODRIGUES, 2007) estuda redes neurais para previsão de vento no horizonte de 24 horas. Para o estudo foram realizadas simulações com série de velocidade de vento do Sul do Brasil e os resultados se mostraram 18,8\% mais eficazes do que o método de persistência (previsão simples em que o valor previsto é calculado a partir do último valor da série). Rodrigues (2007, p.14) ainda afirma que "a principal característica da série temporal das medições de vento (velocidade e direção) é sua grande variabilidade, e é exatamente essa característica que pode dificultar o planejamento, a operação e a estabilidade do Sistema Interligado Nacional”. Com o intuito de eliminar essas dificuldades, o autor propôs modelo de previsão de vento com redes neurais, mas

\footnotetext{
${ }^{4}$ Velocidade de corte do vento
} 
sugere como trabalhos futuros a utilização da combinação de redes neurais com outras técnicas inteligentes como lógica fuzzy e algoritmos genéticos.

(ZANG et al., 2014) mostram que a geração eólica é um processo não linear e não estável, podendo ser modelado como um processo estocástico. A velocidade do vento e a sua curva de potência apresentam alta variabilidade o que traz incerteza na previsão. Ao contrário da previsão pontual que produz apenas um único valor de saída de geração eólica, previsões de incertezas podem trazer informação quantitativa adicional sobre a própria incerteza. As técnicas são classificadas em três categorias: previsão probabilística (geração eólica vista como variável aleatória), índice de risco (nível esperado de previsão do erro) e previsão de cenários (contém séries de previsões pontuais para um período de tempo). Com cada vez mais sistemas estocásticos integrados, as incertezas nas previsões apresentam escolhas para tomadores de decisão e as previsões tradicionais não mais resolverão os requerimentos das previsões de incertezas em problemas de tomada de decisão.

(JUNG; BROADWATER, 2014) apresentam um resumo das pesquisas sobre previsão de velocidade do vento e geração de energia eólica, previsão de correlação espacial, regional, probabilística e off-shore. $\mathrm{O}$ artigo mostra que vários autores apresentam modelos de previsão de velocidade de vento e geração de energia, mas é difícil dizer qual é o melhor porque cada modelo é dependente dos sites observados. As previsões podem ser divididas em quatro períodos distintos: curtíssimo prazo (segundos até 30 minutos que servem para o controle da turbina ou rastreamento da carga), curto prazo (30 minutos até 6 horas que servem para carregamento compartilhado), médio prazo (6 a 24 horas que servem para o gerenciamento do sistema e comercialização de energia) e longo prazo (1 a 7 dias que servem para planejamento de manutenção das turbinas). Duas abordagens principais de previsão são denominadas de físicas e estatísticas. A primeira utiliza a descrição física detalhada do local para modelar as condições do site eólico, realizando o aperfeiçoamento dos dados numéricos climáticos, levando-se em consideração as condições do site como terreno, layout das torres e curva de potência da turbina. A segunda, com base em estatística, apresenta necessidade de histórico de dados para treinamento e construção do modelo. Para a estatística convencional, de acordo com Box-Jenkins, os modelos são divididos em quatro partes: identificação do modelo, estimativas, checagem e previsão. Exemplos são os modelos 
autoregressivos (AR), médias móveis (MA), autoregressivos de médias móveis (ARMA) e autoregressivos integrados de médias móveis (ARIMA).

Dado que esta tese implicitamente considera a geração de séries sintéticas para a geração de energia eólica, com base na metodologia existente de geração de séries de afluências do PAR (p) dentro do Newave, a análise do trabalho de (MACHADO, 2016) é muito importante. Nessa Referência o Autor estuda a geração de cenários hidroeólicos utilizando o modelo autoregressivo periódico (PAR) para o planejamento da operação de médio prazo. O trabalho aborda uma modelagem multivariada, dado que o SIN possui mais de uma centena de usinas hidrelétricas e eólicas. Para isso, desenvolve metodologia de cálculo de correlação espacial entre as séries de diferentes localidades. Assim, o estudo mostra a alteração do cálculo do ruído do modelo PAR, transformando-o em um ruído espacialmente correlacionado. O estudo mostra que este modelo gera séries sintéticas hidroeólicas satisfatórias, sendo melhor para a geração de séries sintéticas de energia eólica do que para a própria geração de séries de afluências incrementais. Além disso, mostra-se a geração de séries eólicas específicas para o caso brasileiro, fruto de uma parceria entre UFSC e USP. Uma das recomendações de trabalho futuro de Machado (2016, p.137) é "estudar o impacto da geração eólica, de forma estocástica via modelo PAR, no Planejamento de Médio Prazo da Operação Hidrotérmica”. Assim, esta tese parte do pressuposto que a metodologia do PAR (p) é aceitável para fins das simulações que se pretende realizar na sequência.

Conforme HAMILTON (1994), a metodologia Box \& Jenkis se baseia em ajustes de modelos sequenciais conhecidos como ARIMA a séries temporais com valores observados, sendo que a diferença entre os valores observados e gerados representam uma sequência de ruídos brancos. THOMAS \& FIERING (1962, de acordo com OLIVEIRA \& SOUZA, 2011) pesquisaram o modelo PAR (p), que é um modelo autoregressivo para cada estação de estudo, sendo que no modelo Newave, cada mês representa uma estação e os modelos são ajustados às séries de vazões ou ENA (Energia Natural Afluente). A identificação do modelo representa na escolha de número de termos autoregressivos. Métodos para identificação do modelo são representados por funções de autocorrelação e autocorrelação parcial. Segundo MARCATO (2002, de acordo com OLIVEIRA \& SOUZA, 2011), na otimização do Newave, o modelo estocástico linear PAR (p) é utilizado na estrutura de derivadas durante as recursões do algoritmo da PDDE, para a construção iterativa da função de custo futuro. No entanto, para se ter vazões ou ENAs não negativas, observa- 
se uma alteração na equação linear autoregressiva do modelo, tornando-se um agravante para a PDDE.

(OLIVEIRA, 2013), defende em sua tese uma nova metodologia alternativa para construção de árvores de cenários, alegando que a estrutura utilizada para simulação de séries sintéticas no modelo vigente gera uma não linearidade nas equações do sistema, o que pode gerar não convexidade que inviabiliza o cálculo correto da função de custo futuro. A metodologia utilizou a técnica de Bootstrap e simulação de Monte Carlo e mostrou que reproduz estruturas compatíveis com o modelo vigente, não causando não linearidade na equação do PAR (p) e a possível não convexidade.

Assim, apesar de alguns estudos recomendarem a modelagem do PAR (p), existe limitação em relação a correlação espacial na geração dos ruídos, questões de linearidade, convexidade e se a metodologia é ideal para a geração de séries eólicas.

A complementaridade da fonte hidráulica com a eólica é abordada por alguns autores: $\mathrm{O}$ artigo de (DENAULT et al., 2009) apresenta a complementaridade da fonte hidráulica e eólica, considerando o efeito da fonte eólica reduzir o risco de afluências escassas, em Quebec no Canadá. Os resultados indicam que para os cenários considerados, qualquer proporção até 30\% de eólicas diminui o risco de déficit do que um sistema com apenas hidráulicas. (RICOSTI; SAUER, 2013) mostram uma tendência de complementaridade sazonal intra e plurianual considerando-se 10 coordenadas de dados eólicos e afluências hidráulicas da região Nordeste do Brasil. O estudo mostrou também que apesar da grande capacidade de geração eólica no Sul, não há complementaridade com o regime de afluências da região.

(KAWANA, 2014) apresenta simulações utilizando o modelo Newave e conclui que a inserção da fonte eólica traz como benefício a redução no CMO e no risco de déficit para o Sistema. No Sudeste, com a importação de energia excedente do Nordeste, o risco diminui significativamente no período seco, confirmando a complementaridade com a fonte hidráulica. $\mathrm{O}$ estudo aborda o benefício que o Sistema teria se a expansão eólica se desse no Sudeste ao invés do Nordeste, os resultados mostram redução no custo de operação de 6,5\% em valor presente. Kawana afirma que os regimes hidrológicos e de vento possuem correlação negativa, sendo que o aumento 
da capacidade eólica considerando ventos intensos reduz o despacho hídrico, dada a preservação da água nos reservatórios.

(JONG et al., 2013) analisam a efetividade da geração eólica e solar para atender a demanda de pico no Nordeste do Brasil. Uma análise comparativa é feita entre a curva de eletricidade para um ano típico e para um dia típico, considerando-se dados estatísticos de velocidade de vento (a 10 metros de altura) e radiação solar (em uma superfície horizontal em MJ/m2). O estudo mostra que há correlação e a energia renovável pode ajudar no atendimento da demanda temporal da rede de eletricidade de forma eficiente e amigável ao ambiente do que fontes fósseis. Os autores do artigo mostram complementaridade entre as fontes hidráulicas com eólicas e solar no Nordeste, ou seja, no período seco, quando o preço de energia tende a ser mais caro, há maior disponibilidade de geração eólica e solar. A radiação solar tem uma variação de $40 \%$ entre o seu mínimo e máximo, durante o ano. Enquanto a variação eólica é de $27 \%$ no estudo. As fontes também se complementam, sendo que velocidades de vento mais baixas tendem a ocorrer no verão (novembro a março), enquanto a radiação solar é máxima, e vice-versa. Entre outubro e dezembro, quando o consumo tende ao máximo, os reservatórios das hidrelétricas estão nos seus níveis mínimos. Neste período mais crítico, as fontes eólicas e solares apresentam alta geração, velocidades de vento a $85 \%$ do máximo e radiação solar com $95 \%$ do máximo. Além disso, a fonte eólica e solar tem o potencial de ajudar com energia durante a manhã e tarde no atendimento da carga diária, enquanto a eólica pode também suprir a demanda noturna.

(CAVADOS, 2015) fez estudo sobre o impacto da expansão da energia eólica para o sistema elétrico brasileiro no futuro (2022) sob ótica energética e econômica e a redução dos impactos com a instalação de usinas flexíveis a gás natural. Os maiores impactos estão relacionados com a variabilidade da geração eólica ou intermitência horária na capacidade de produção. Como não é possível estudar os impactos da intermitência horária da geração eólica nos modelos oficiais do setor elétrico pois não estão preparados para a estocasticidade e variabilidade horária da geração eólica, o estudo utilizou o modelo Plexos que utiliza programação linear para otimização e minimização da função objetivo do custo de eletricidade. Através do risco de déficit de suprimento calcula-se o risco sob a ótica energética e através dos preços de eletricidade a cada hora para obtenção do risco sob a ótica econômica. $\mathrm{O}$ resultado das simulações dos cenários mostrou um sistema muito vulnerável a grandes variações horárias de geração, principalmente nos períodos de 
reservatórios em baixa e geração eólica em alta. Percebeu-se através do estudo que para haver maior expansão de fontes que apresentam intermitência horária ou imprevisibilidade na geração sem que haja risco de déficit, deve haver flexibilidade suficiente no sistema elétrico com inserção de fontes térmicas flexíveis a gás natural.

(MIGUEL, J. 2016) apresenta estudo sobre a influência da duração da medição anemométrica na avaliação dos recursos eólicos com metodologia MCP (Medir-CorrelacionarPredizer) a fim de melhorar as previsões de geração eólica. $O$ trabalho identifica que na medida que se aumenta a duração da medição anemométrica a incerteza dos recursos sofre queda significativa. Os fatores de capacidade verificados com informações do ONS ficam aquém dos previstos em todos os anos de 2009 a 2015, exceto 2014, mostrando a importância do aprimoramento do estudo dos recursos, uma vez que a supervalorização das expectativas traz preocupação em relação à segurança energética nacional.

O artigo de (SUOMALAINEN et al., 2015) estuda a distribuição espacial e temporal das fontes eólicas e hídricas, junto com análise de demanda e preço, com o objetivo de analisar o desenvolvimento da energia eólica em diferentes partes da Nova Zelândia. O estudo mostra a importância de entender os impactos da alta penetração da fonte eólica em um mercado altamente influenciado pela geração sazonal hidráulica. Os reservatórios das hidrelétricas são limitados na Nova Zelândia e é muito pouco provável que sejam construídas hidrelétricas de grande reservatório no futuro. Assim, o sistema é vulnerável a eventos climáticos, como as secas. Os desvios diários em relação aos valores sazonais esperados mostram que em algumas localidades, as anomalias apresentam correlação mais significativa com os preços do que os padrões sazonais. Isso mostra que a correlação resultante de anomalias de diferentes sites pode fornecer informação relevante em períodos críticos do ano, como nas estações secas. A metodologia ajuda a entender eventos extremos e pode ser aplicada em qualquer sistema hidroeólico, não apenas no país em questão.

(WOO et al., 2014) mostram que a fonte eólica combinada com fonte solar e gerenciamento da demanda poderiam evitar o aumento em 6 a 9 US\$/MWh dos preços horários em tempo real da Califórnia com o desligamento da usina térmica nuclear San Onofre. O desligamento foi decretado após o acidente nuclear de Fukushima no Japão em 2011. 
Para a consideração das séries de geração eólica, esta tese refere ao estudo de (WITZLER, 2014 \& WITZLER et al., 2015). O estudo mostra a metodologia para reconstrução de séries históricas de vento e geração eólica e análise de complementariedade entre fontes eólicas e hidráulicas no SIN. A base de dados de vento é proveniente de dados de 1948 a 2010 do modelo numérico do National Oceanic and Atmospheric Administration (NOAA) e National Center for Environmental Prediction (NCEP), dados de 2000 a 2010 do modelo de mesoescala ${ }^{5}$ da Vestas do Brasil e dados de 1982 a 2014 do modelo de mesoescala do Vortex. Os dados do NOAA são representados por quadrículas de 2,5 por 2,5 graus com velocidades de vento das regiões Nordeste e Sul. O modelo da Vestas calcula séries de velocidade de vento horárias e são utilizadas em combinação com séries observadas no local. Este modelo é baseado no Weather Research and Forecasting model (WRF). O Vortex é um modelo de mesoescala online que fornece velocidades de vento estimadas em locais onde não existem medições de longo prazo. Com base nos dados das diferentes fontes, analisou-se a correlação dos mesmos períodos e verificou-se a complementaridade entre vento e afluência. Além disso, foi observado que os fenômenos de El Niño e La Niña afetam a geração eólica significativamente. O capítulo cinco detalha como foram consideradas as séries de velocidade de vento reconstruídas para este trabalho.

“A geração hidrelétrica é dependente da afluência, no entanto, é possível minimizar a variação da energia natural afluente por meio dos reservatórios. Por sua vez, a geração eólica tem como desvantagem a volatilidade devido a sua dependência em relação ao vento". (MIGUEL, F. 2016). No entanto, com a expansão das fontes hidráulicas apenas a fio d'água por questões ambientais, há um aumento da variabilidade para esta fonte também, que pode ser reduzida com a complementaridade com a eólica.

(BEZERRA et al., 2013 e CÉSAR et al., 2011) apresentam o impacto da redução da capacidade de regularização com a introdução de usinas hidrelétricas a fio d'água, mostrando o aumento da produção térmica, com consequentes aumentos dos custos marginais de operação e ampliação da variabilidade (incerteza) do preço de energia elétrica no mercado à vista e dos preços dos contratos de curto prazo. A cenarização com geração eólica, dada a complementaridade com a fonte hidráulica, ajuda a diminuir a incerteza e a variabilidade. O estudo de (CÉSAR et al., 2011)

\footnotetext{
${ }^{5}$ Mesoescala: escala intermediária entre a sinótica (global) e a microescala, ou seja, variando de um a centenas de quilômetros espacialmente, e de algumas a várias unidades de horas, temporalmente.
} 
mostra que a complementaridade da geração eólica com a hidráulica proporciona um ganho na capacidade de suprimento e representa a eólica estocasticamente como se fosse uma geração hidroelétrica a fio d' água. Apesar de apresentar o mesmo enfoque desta tese, o trabalho não detalha a metodologia de representação estocástica, não oferecendo nenhum detalhamento de como são feitas as alterações de usinas hidrelétricas para usinas eólicas, frisando-se também que não foi utilizado o modelo oficial do setor elétrico. Já o estudo de (BEZERRA et al., 2013) mostra a inserção da energia eólica no SIN sob a ótica energética, avaliando como a redução na capacidade de regularização do sistema com a expansão das hidrelétricas baseadas em usinas a fio d' água, impactam a inserção da eólica. Uma inserção de até $40 \mathrm{GW}$ de capacidade eólica no SIN, não aumentaria o risco de déficit e uma probabilidade de despacho térmico de $30 \%$ para atendimento de picos de demanda. Ainda, os autores apontam que outra forma de aumentar o potencial da eólica é aumentar a expansão das fontes despacháveis na expansão, como hidrelétricas com reservatórios e termelétricas flexíveis.

O estudo de (EL-HERI et al., 2016) faz uma análise do impacto energético da variabilidade da produção de energia eólica considerando cenários para a política de operação utilizando o sistema SDDP (Stochastic Dual Dynamic Programming). Os resultados mostram um aumento de custo ao se considerar a variabilidade eólica, mas alterando-se a metodologia de criação da função de custo futuro, pode-se amenizar o impacto. O trabalho sugere estudos com a consideração da variabilidade da produção eólica na simulação final, objetivando considerar o impacto desta fonte no sistema e permitindo a otimização da utilização dos reservatórios hidrelétricos.

O artigo de (CARVALHO et al., 2012) mostra uma metodologia probabilística para avaliar a confiabilidade do suprimento de ponta considerando-se as incertezas da própria demanda de pico do sistema, da produção eólica e na redução da produtibilidade das fontes hidrelétricas com o deplecionamento dos reservatórios. $\mathrm{O}$ trabalho apresenta a variabilidade da produção das eólicas também utilizando o modelo SDDP. Para a representação da variabilidade, adotou-se a premissa de que a distribuição de probabilidade da produção horária das eólicas no Nordeste e Sul do Brasil é normal. O trabalho conclui pela maior necessidade térmica para o atendimento da carga do SIN ao se considerar a variabilidade da produção eólica.

Isto posto, é importante destacar que, até o momento deste estudo apesar de haver trabalhos que tratam a análise da geração eólica estocástica (MACHADO, 2016; CÉSAR et al., 2011; EL- 
HERI et al., 2016; CARVALHO et al., 2012; BEZERRA et al., 2013), não foram encontradas referências que discutem a metodologia de inserção da geração de fontes eólicas representadas por fontes hidráulicas a fio d'água alavancando o modelo PAR (p) para a geração de séries estocásticas no modelo oficial de otimização do setor elétrico (Newave), bem como a análise dos impactos da metodologia. Desta forma, a introdução das séries sintéticas no modelo de otimização do setor elétrico brasileiro pode representar uma contribuição para a literatura e pode subsidiar estudos para a inclusão da geração eólica nos modelos oficiais, dadas as incertezas associadas à geração da fonte. 


\section{PANORAMA DA ENERGIA EÓLICA}

\subsection{Energia eólica no mundo}

A questão ambiental e a alta volatilidade dos preços de barril de petróleo geram uma corrida para o desenvolvimento de energia limpa e renovável. A eólica tem apresentado acelerado crescimento mundial. (GWEC, 2016) mostra que o aumento de geração eólica em 2016 foi de $12,6 \%$, atingindo $487 \mathrm{GW}$ instalados.

Figura 2: Capacidade instalada acumulada de eólicas 2000-2016

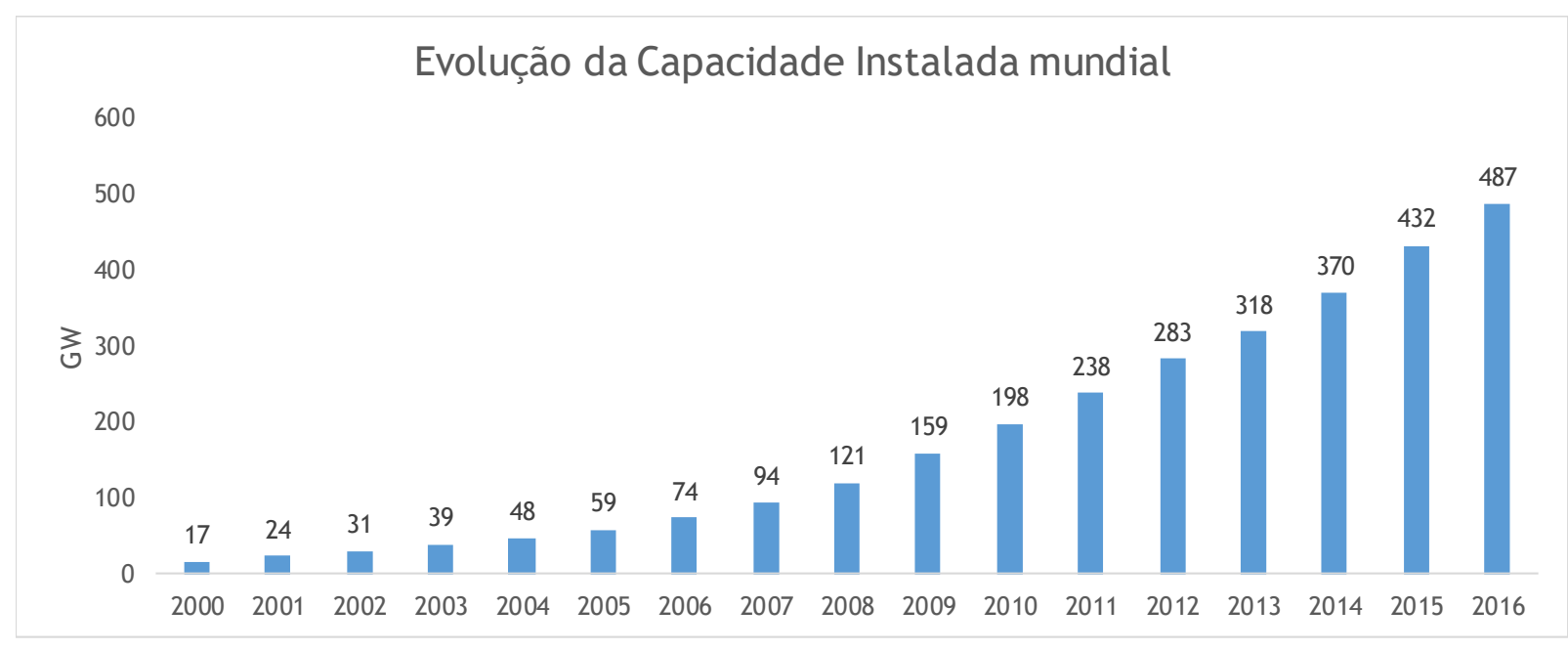

Fonte: GWEC (2016).

A China instalou 23,4 GW em 2016, pouco menos do que os $30 \mathrm{GW}$ de 2015, trazendo o seu acumulado para $169 \mathrm{GW}$ instalados. O Brasil é o quinto maior mercado em 2016, passou para nono lugar no ranking dos dez países com o maior acumulado de capacidade eólica instalada, ultrapassando a Itália. 
Figura 3: 10 maiores países em capacidade eólica instalada e acumulada

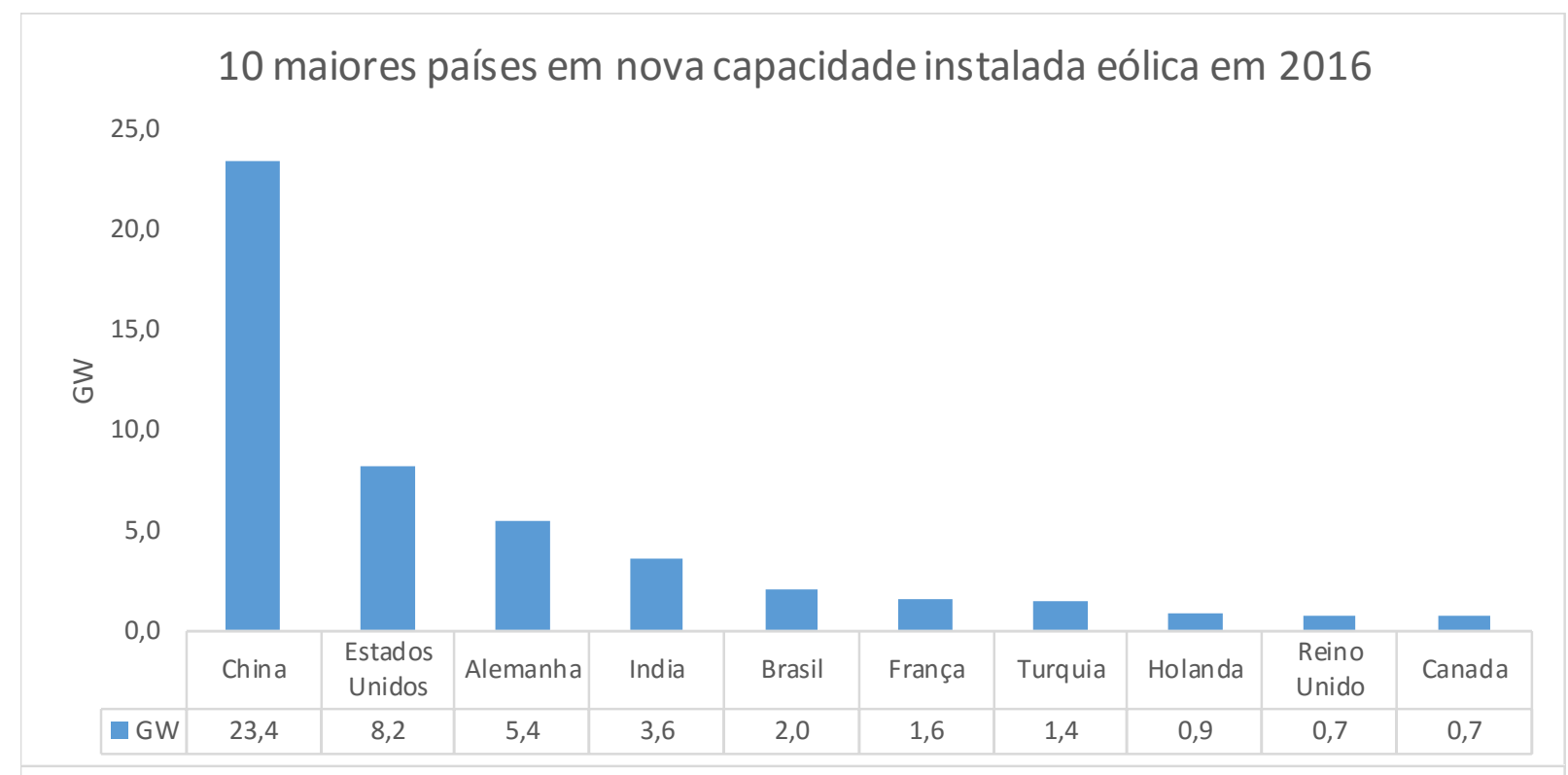

10 maiores países em capacidade acumulada eólica em 2016

180,0

160,0

140,0

120,0

ion,0

80,0

60,0

40,0

20,0

0,0

China

\begin{tabular}{l|l|l|l} 
Unidos & Alemanha India & Espanha
\end{tabular}

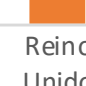

\begin{tabular}{l|l|l|l|l} 
Unido & França & Canadá & Brasil & Itália
\end{tabular}

GW

168,7

82,2

50,0

28,7

23,1

$14,5 \quad 12,1$

11,9

$10,7 \quad 9,3$

Fonte: Elaboração própria, com base em GWEC (2016).

De acordo com (Sawyer e Dyrholm, 2016), as perspectivas econômicas continuam com melhoria na indústria eólica, com recorde de preços em Marrocos (US\$ 30/MWh), leilões competitivos ao redor do mundo e as eólicas offshore também apresentaram redução nos preços na Holanda e Dinamarca. 


\subsection{Energia eólica no Brasil}

Em 1992 foi instalada a primeira turbina eólica em Fernando de Noronha com 225 kW, mas apenas após o desenvolvimento do Programa de Incentivo às Fontes Alternativas de Energia Elétrica (PROINFA) que se permitiu a entrada da energia eólica no Brasil e a adoção dos leilões expandiram a capacidade no país.

Desde então, a energia eólica tem apresentado crescimento importante no sistema elétrico brasileiro. Em 2016, o Brasil alcançou $10 \mathrm{GW}$ instalados com uma cadeia produtiva 80\% nacionalizada, de acordo com a ABEEólica, 2017. No entanto, segundo a Associação, em 2016, devido a recessão do país, houve redução da demanda por energia e houve o cancelamento do leilão de reserva no final do ano, sendo o primeiro ano desde que as eólicas começaram a participar dos leilões em que não houve contratação de energia da fonte.

A eólica representa cerca de $7 \%$ da matriz de capacidade instalada, com aproximadamente 10,8 GW instalados (ANEEL, 2017). A maior participação da potência eólica se concentra na região Nordeste do país, cerca de $80 \%$, sendo os Estados com maior capacidade: Rio Grande do Norte, Bahia e Ceará. O Sul tem aproximadamente o restante da participação, sendo o Rio Grande do Sul o Estado com maior capacidade da região. A região Sudeste apresenta mínima participação. O plano decenal EPE 2024 mostra um crescimento para 12\% de participação da eólica, conforme Figura 4.

Figura 4: Participação da eólica na capacidade instalada em 2016 e projeção para 2024
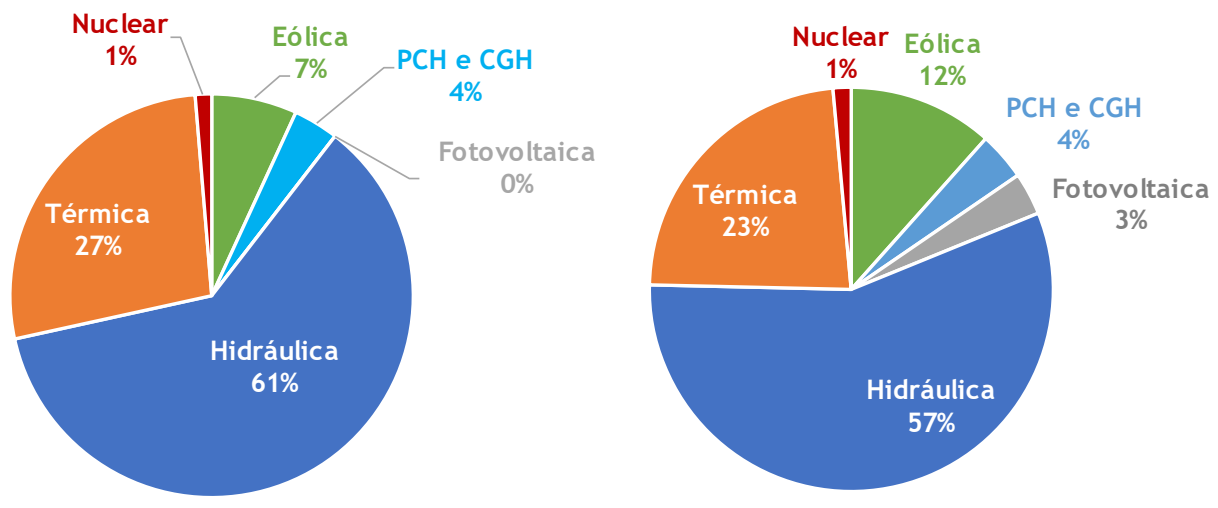

Fonte: Elaboração própria com base nos dados da ANEEL e EPE (2016). 
Devido aos avanços tecnológicos e a curva de aprendizado da energia eólica, o custo e consequentemente o preço da geração apresentou redução até 2012, conforme Figura 5.

Figura 5: Evolução do preço médio de leilão de energia eólica em US\$/MWh

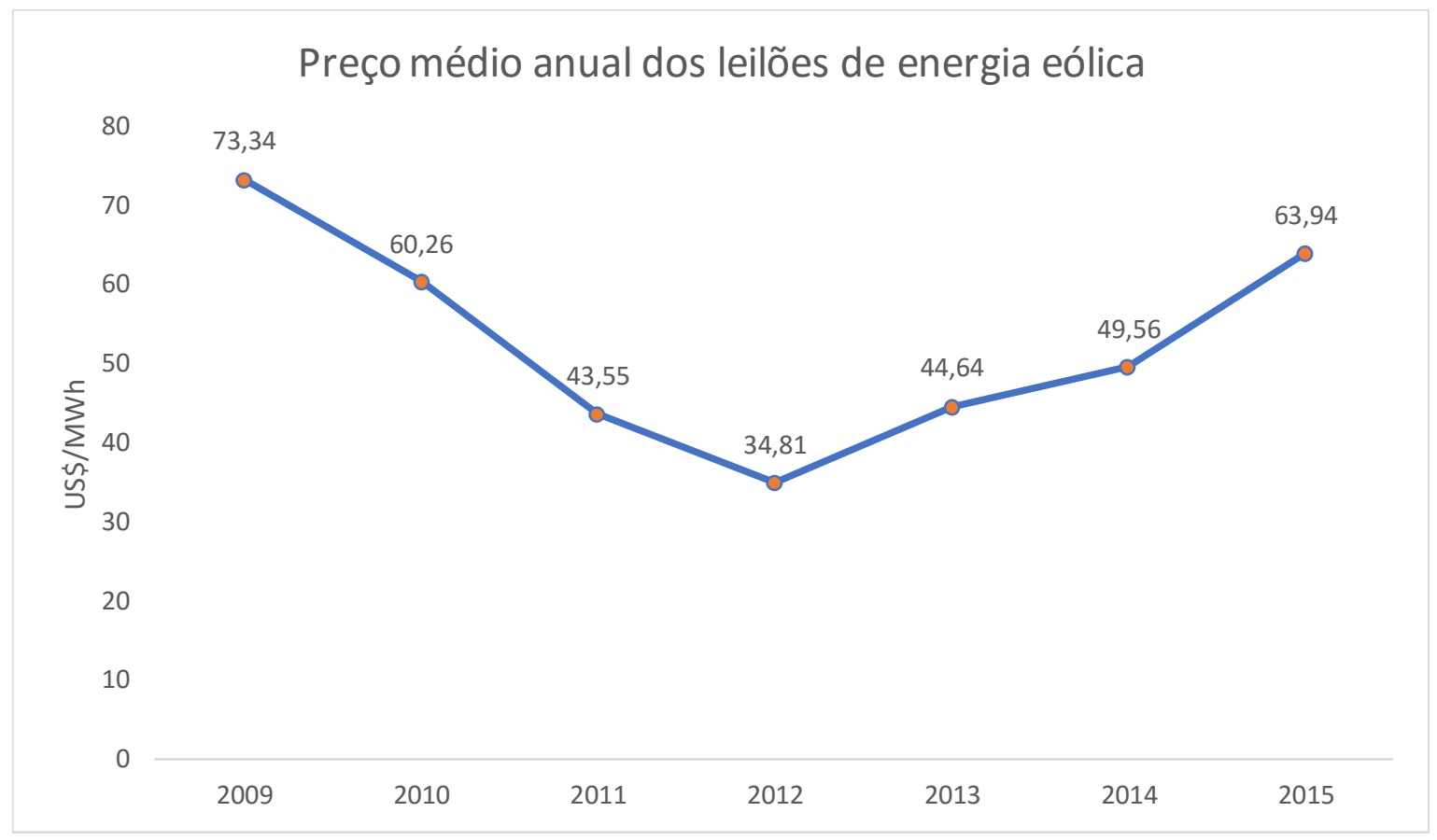

Fonte: Elaboração própria com base nos dados de leilão da CCEE, 2016, atualização do IGP-M e câmbio de 3,24R\$/US\$ em setembro de 2016

Houve aumento do preço de energia eólica no leilão de 2013 devido ao maior risco considerado, uma vez que o risco de conexão à rede de transmissão foi transferido do consumidor para o gerador, além de mudanças como necessidade de índice de produtividade de geração em $\mathrm{P} 90^{6}$, com a entrega de $90 \%$ da garantia física, antes era de $50 \%$.

O potencial eólico Brasileiro é de $143 \mathrm{GW}$, de acordo com o Atlas do Potencial Eólico Brasileiro (AMARANTE et al., 2001). Entretanto, os dados utilizados para este atlas têm referência de valores de 2001, com medições a 50 metros de altura. Hoje as torres podem chegar a 140 metros de altura e estima-se que o potencial brasileiro superaria $300 \mathrm{GW}$, a 100 metros de altura (WITZLER, 2014).

\footnotetext{
${ }^{6} \mathrm{O}$ P90 refere-se ao valor da energia anual com probabilidade de ocorrência igual ou superior a 90\%.
} 


\subsection{Ventos e energia}

O vento é o resultado da continua circulação das camadas de ar na atmosfera, sob a ação da energia do sol e da rotação da terra, conforme Figura 6.

Figura 6: Circulação atmosférica

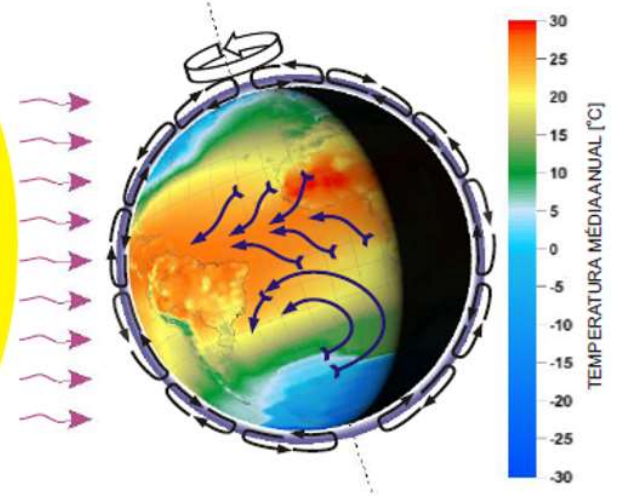

Fonte: Atlas RN (2003).

Os aquecimentos desiguais da superfície terrestre formam os ventos e, desta forma, suas velocidades e direções apresentam tendências sazonais bem definidas ao longo do ano, com características estocásticas. $\mathrm{O}$ vento apresenta grande variação, mas tende a um regime diurno predominante, com influências locais (microescala) e regionais (mesoescala). Em altitudes em torno de $100 \mathrm{~m}$, o vento é afetado pelas condições do relevo e rugosidade do terreno, presença de obstáculos e estabilidade térmica vertical (Atlas RN, 2003).

A turbina eólica capta parte da energia cinética do vento que passa pela área varrida pelo rotor, movimentando um gerador que transforma a energia mecânica em energia elétrica. A potência é função do cubo da velocidade do vento:

$$
P=\frac{1}{2} r A_{r} v^{3} C_{p} h(1)
$$

Onde:

P: Potência em Watts 
r: densidade do ar em $\mathrm{kg} / \mathrm{m} 3$

Ar: área do rotor $\mathrm{p}^{*} \mathrm{D} 2 / 4, \mathrm{D}$ é o diâmetro do rotor

$\mathrm{Cp}$ : coeficiente aerodinâmico de potência do rotor (valor máximo teórico $=0,593$, na prática atinge 0,45 e é variável com a velocidade do vento, rotação e parâmetros de controle da turbina)

h: eficiência do conjunto gerador/transmissões mecânicas e elétricas $(\sim 0,93$ a 0,98$)$

Segundo o Atlas eólico do Ceará:

A absorção de energia cinética reduz a velocidade do vento imediatamente a jusante do disco do rotor; gradualmente essa velocidade se recupera, ao se misturar com as massas de ar predominantes do escoamento livre. Das forças de sustentação aerodinâmica nas pás do rotor resulta uma esteira helicoidal de vórtices, a qual também gradualmente se dissipa. Após alguma distância a jusante da turbina, o escoamento praticamente recupera as condições de velocidade originais; e turbinas adicionais podem ser instaladas, minimizando as perdas de desempenho causadas pela interferência da turbina anterior. Na prática, essa distância varia com a velocidade do vento, condição de operação da turbina, rugosidade de terreno e condição de estabilidade térmica vertical da atmosfera. De modo geral, uma distância considerada segura para a instalação de novas turbinas é da ordem de 10 vezes o diâmetro D quando instalada a jusante, e 5 x D quando instalada ao lado, em relação ao vento predominante.

As curvas de potência fornecidas por fabricantes de turbinas, geralmente medidas por órgãos credenciados e independentes, sempre se referem a velocidades de vento quase instantâneas (médias de 10 minutos) e densidade $\mathrm{r}=1.225 \mathrm{~kg} / \mathrm{m} 3$ (ISA, nível do mar).

\subsection{Atlas eólicos}

\subsubsection{Atlas da Bahia}

De acordo com o Atlas da Bahia 2013, o Estado ocupa posição meridional do Nordeste do Brasil, com aproximadamente $564.733 \mathrm{Km} 2$. A região se encontra entre regimes diferentes de ventos: ventos alísios ${ }^{7}$ ao Norte e mais ao Sul a interação entre o centro de altas pressões Anticiclone Subtropical do Atlântico Sul e as incursões de massas polares.

\footnotetext{
${ }^{7}$ Ventos alísios: ventos típicos de regiões tropicais, dada a diferença da alta pressão nos trópicos e baixa pressão no Equador. As massas de ar no hemisfério Sul giram em torno dos centros de alta pressão no sentido antihorário. Na região Nordeste do Brasil, os ventos alísios vêm da direção Sudeste, principalmente.
} 
Figura 7: Regime de ventos no Estado da Bahia

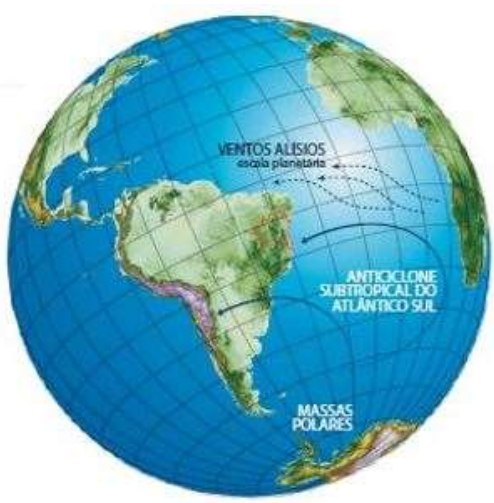

Fonte: Atlas Bahia

A faixa atlântica apresenta área extensa, sem grandes elevações e cobertura vegetal densa. No centro do Estado apresentam-se chapadões de baixa rugosidade, a Oeste o São Francisco abaixando o relevo e o extremo Oeste com altitudes de 1000 metros com agricultura intensiva e pouco rugosa.

Para o cálculo do potencial eólico da Bahia, foi utilizado o modelo de mesoescala (regional): Mesomap (modelo de simulação atmosférica, com base de dados meteorológicos, rede de computadores e sistema de armazenamento), com 156 torres de medição, simulações de 2,5 km por 2,5 km e interpolações para chegar em $200 \mathrm{~m}$ por $200 \mathrm{~m}$, através de modelos de relevo e rugosidade. O Mesomap simula áreas continentais e utiliza base climatológica e dados de reanálise ${ }^{8}$. Esse modelo é capaz de modelar fenômenos meteorológicos como: ondas orográficas, ventos convectivos, brisas marinhas, entre muitos outros.

Após o processamento dos dados e simulações com o Mesomap, comparam-se os resultados com os valores medidos em torres anemométricas e os dados sofrem alguns ajustes estatísticos. A integração dos mapas de velocidade média é realizada com técnicas de geoprocessamento ${ }^{9} \mathrm{e}$ produção de energia com eólicas no estado da arte.

\footnotetext{
${ }^{8}$ Dados de reanálise: Integração de dados de vários sistemas de observação, com modelos numéricos e demais metodologias, que envolvem reanálise e reprocessamento de dados meteorológicos abrangendo períodos históricos de décadas, com métodos modernos e consistentes. O objetivo é a produção de dados que possam ser utilizados para estudos meteorológicos e climatológicos. geográfica.

${ }^{9}$ Técnicas de geoprocessamento: Técnicas matemáticas e computacionais para o tratamento de informação
} 
Foram escolhidas curva de potência dos aerogeradores em 3 faixas de velocidade de vento: baixo (classe C), moderado (classe B) e alto (classe A), conforme Figura 8.

Figura 8: Curvas de Potências consideradas no cálculo do potencial eólico da Bahia

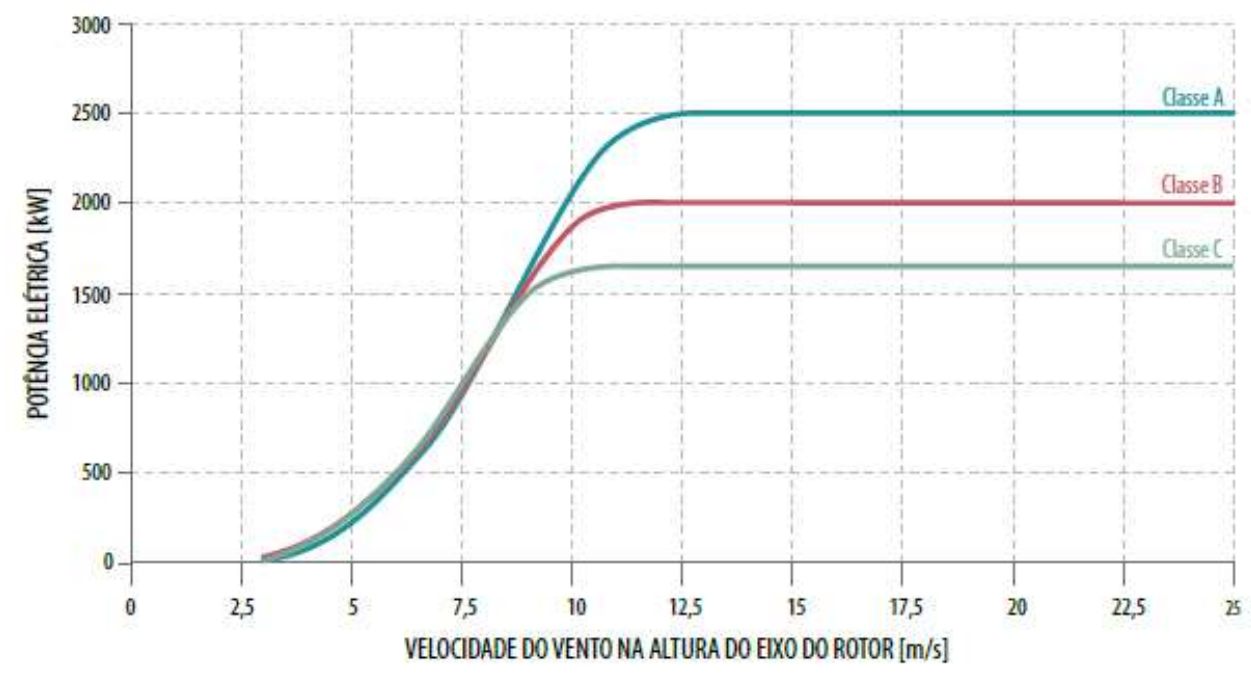

Fonte: Atlas Eólico da Bahia

Áreas onde o desenvolvimento de parques é impossibilitado foram excluídas através de ferramentas de geoprocessamento: áreas de proteção, áreas sobre rios, concentrações urbanas, elevada declividade, etc.

A taxa de ocupação considerada foi de $2,6 \mathrm{MW} / \mathrm{km}^{2}$ e a tabela 1 mostra a potência instalável, o fator de capacidade e a energia anual que poderia ser gerada, por altura e faixa de velocidade, sendo que a integração cumulativa é mostrada ao lado. Em uma faixa de $7 \mathrm{~m} / \mathrm{s}$ de velocidade de vento, a 100 metros de altura e uma área cumulada de aproximadamente $27000 \mathrm{~km}^{2}$, a potência instalável na Bahia é de cerca de $70 \mathrm{GW}$. 
Tabela 1: Potencial de geração eólica na Bahia

\begin{tabular}{|c|c|c|c|c|}
\hline \multicolumn{5}{|c|}{ Potencial Eólico da Bahia } \\
\hline $\begin{array}{c}\text { Altura } \\
(\mathrm{m})\end{array}$ & Vento (m/s) & $\begin{array}{c}\text { Área } \\
\left(\mathrm{km}^{2}\right)\end{array}$ & $\begin{array}{c}\text { Potência Instalável } \\
(\mathrm{GW})\end{array}$ & $\begin{array}{c}\text { Energia Anual } \\
(\mathrm{TWh})\end{array}$ \\
\hline 150 & $>=7 \mathrm{~m} / \mathrm{s}$ & 75180 & 195,2 & 766,5 \\
\hline 120 & $>=7 \mathrm{~m} / \mathrm{s}$ & 44347 & 115,2 & 449,6 \\
\hline 100 & $>=7 \mathrm{~m} / \mathrm{s}$ & 26998 & 70,1 & 273,5 \\
\hline 80 & $>=7 \mathrm{~m} / \mathrm{s}$ & 14866 & 38,6 & 150,4 \\
\hline
\end{tabular}

Fonte: Atlas Eólico da Bahia

De acordo com o Atlas Eólico da Bahia (p.21):

A velocidade do vento apresenta flutuações desde intervalo de tempo inferiores a um minuto (turbulência atmosférica) até intervalo de anos ou décadas (regimes sazonais). Enquanto as primeiras têm caráter fortemente aleatório, as segundas seguem tendências bem definidas para um dado local e possuem baixa variabilidade, possibilitando a previsão da velocidade média de longo prazo em locais onde existem medidas.

\subsubsection{Atlas do Rio Grande do Norte}

Localizado no extremo Nordeste do Brasil, compreende uma área de aproximadamente $53.300 \mathrm{~km}^{2}$. O litoral apresenta $400 \mathrm{~km}$ com grande área de dunas e formações arenosas. O Sudeste do Estado apresenta clima semiúmido com desenvolvimento de vegetação e o restante da região apresenta clima semiárido, com 7 meses de período seco anual, denominado de caatinga.

O Rio Grande do Norte está situado em uma região de predomínio de ventos alísios, resultando em ventos constantes. Nas regiões serranas, os ventos mais intensos são encontrados nos cumes e cristas, onde o escoamento atmosférico é mais acentuado. Nos litorais Norte, Nordeste e nas serras centrais, os ventos médios anuais são mais intensos. Ao longo do litoral ocorrem as brisas marinhas e terrestres, criando ciclo diurno característico. No geral, os ventos mais intensos ocorrem no final da manhã até o meio da tarde. Nas regiões serranas, o vento apresenta maior intensidade durante a noite, madrugada e início da manhã. 
Em geral os ventos mais intensos ocorrem nos meses de final de inverno e primavera (agosto a novembro) e mais brandos no final de verão e outono (fevereiro a maio).

Da mesma forma que no Atlas do potencial eólico da Bahia, no Atlas do Rio grande do Norte foi utilizado o modelo MesoMAP, sendo mapeadas 8 torres anemométricas (este mapa é de 2003), representando as principais regiões do Estado, em um período de 16 meses.

Para velocidades de vento em três alturas, a saber: 50 m, 75 m e 100 m, foram consideradas turbinas eólicas de $500 \mathrm{~kW}, 1,5 \mathrm{MW}$ e 3,0 MW, conforme curvas de potência na Figura 9:

Figura 9: Curvas de Potência das turbinas

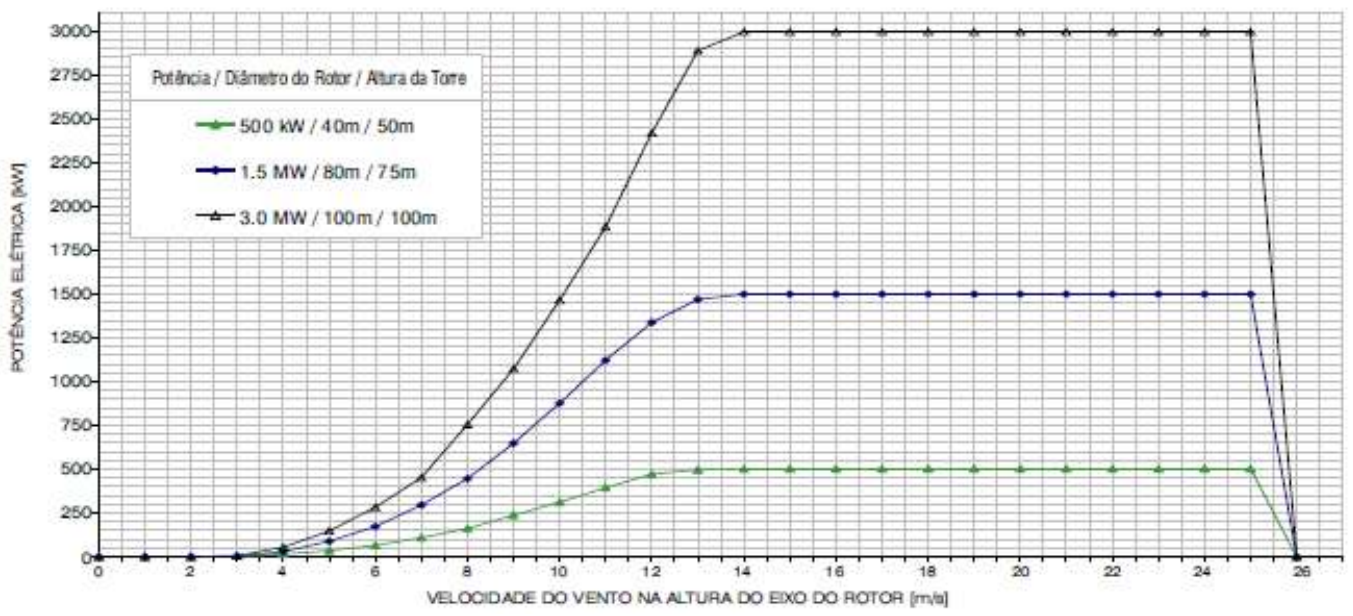

Fonte: Atlas RN

Com os valores das velocidades nas áreas, foi considerado uma taxa de ocupação de 1,5 $\mathrm{MW} / \mathrm{km}^{2}$.

Considerando a faixa de velocidade igual ou acima de $7 \mathrm{~m} / \mathrm{s}$, a potência instalável é de aproximadamente de $27 \mathrm{GW}$, em uma área de cerca de $18.000 \mathrm{~km}^{2}$. A tabela 2 mostra estes resultados: 
Tabela 2: Potencial de geração eólica no Rio Grande do Norte

\begin{tabular}{|c|c|c|c|c|}
\hline \multicolumn{5}{|c|}{ Potencial Eólico do Rio Grande do Norte } \\
\hline $\begin{array}{c}\text { Altura } \\
(\mathrm{m})\end{array}$ & Vento (m/s) & $\begin{array}{c}\text { Área } \\
\left(\mathrm{km}^{2}\right)\end{array}$ & $\begin{array}{c}\text { Potência Instalável } \\
(\mathrm{GW})\end{array}$ & $\begin{array}{c}\text { Energia Anual } \\
(\mathrm{TWh})\end{array}$ \\
\hline 100 & $>=7 \mathrm{~m} / \mathrm{s}$ & 18053 & 27,1 & 69,29 \\
\hline 75 & $>=7 \mathrm{~m} / \mathrm{s}$ & 12954 & 19,4 & 55,90 \\
\hline 50 & $>=7 \mathrm{~m} / \mathrm{s}$ & 6375 & 9,6 & 28,46 \\
\hline
\end{tabular}

Fonte: Atlas Eólico do Rio Grande do Norte

No entanto, para poder comparar com o Atlas da Bahia na altura de $100 \mathrm{~m}$, aplica-se a mesma taxa de ocupação de 2,6 MW/km2, resultando em um potencial de 46,9 GW no Rio Grande do Norte. Os valores são apresentados na Tabela 3:

Tabela 3: Potencial de geração eólica no Rio Grande do Norte com diferente taxa de ocupação

\begin{tabular}{|c|c|c|c|c|}
\hline \multicolumn{5}{|c|}{ Potencial Eólico do Rio Grande do Norte para comparação } \\
\hline $\begin{array}{c}\text { Altura } \\
(\mathrm{m})\end{array}$ & Vento (m/s) & $\begin{array}{c}\text { Área } \\
(\mathrm{km} 2)\end{array}$ & $\begin{array}{c}\text { Potência Instalável } \\
(\mathrm{GW})\end{array}$ & $\begin{array}{c}\text { Energia Anual } \\
(\mathrm{TWh})\end{array}$ \\
\hline 100 & $>=7 \mathrm{~m} / \mathrm{s}$ & 18053 & 46,9 & 131,4 \\
\hline 75 & $>=7 \mathrm{~m} / \mathrm{s}$ & 12954 & 33,7 & 94,3 \\
\hline 50 & $>=7 \mathrm{~m} / \mathrm{s}$ & 6375 & 16,6 & 46,4 \\
\hline
\end{tabular}

Fonte: Elaboração Própria

\subsubsection{Atlas do Ceará}

O Ceará apresenta área territorial de $147.348 \mathrm{~km}^{2}$. Apresenta contínua circulação atmosférica de ventos alísios, que são intensificados pelas brisas marinhas. A movimentação da Zona de Convergência Intertropical ${ }^{10}$ (ZCIT) induz a uma sazonalidade nos regimes de vento. O litoral do Estado apresenta $543 \mathrm{~km}^{2}$ de dunas com ventos intensos e constantes, dada a baixa rugosidade da areia de dunas e acelerações orográficas.

\footnotetext{
${ }^{10}$ Área que circunda a terra próxima ao Equador, onde os ventos dos hemisférios Norte e Sul se encontram.
} 
Os ventos do Ceará são mais intensos durante o dia, conforme Atlas do Estado. Uma exceção pode ser identificada nas áreas de serra, dadas as influências locais de mesoescala.

O modelo utilizado foi o Windmap nas alturas de $50 \mathrm{~m}$ e $70 \mathrm{~m}$ e a taxa de ocupação considerada foi de $2 \mathrm{MW} / \mathrm{km}^{2}$.

Tabela 4: Potencial de geração eólica no Ceará

\begin{tabular}{|c|c|c|c|c|}
\hline \multicolumn{5}{|c|}{ Potencial Eólico do Ceará } \\
\hline $\begin{array}{c}\text { Altura } \\
(\mathrm{m})\end{array}$ & Vento $(\mathrm{m} / \mathrm{s})$ & $\begin{array}{c}\text { Área } \\
\left(\mathrm{km}^{2}\right)\end{array}$ & $\begin{array}{c}\text { Potência Instalável } \\
(\mathrm{GW})\end{array}$ & $\begin{array}{c}\text { Energia Anual } \\
(\mathrm{TWh})\end{array}$ \\
\hline 70 & $>=7 \mathrm{~m} / \mathrm{s}$ & 12426 & 24,9 & 51,9 \\
\hline 50 & $>=7 \mathrm{~m} / \mathrm{s}$ & 2911 & 5,8 & 12,0 \\
\hline
\end{tabular}

Fonte: Atlas Eólico do Ceará

Da mesma forma que foi feito para o atlas do Rio Grande do Norte, aplica-se a taxa de ocupação de 2,6 MW/ $\mathrm{km}^{2}$. Tem-se um potencial de 32,3 GW a 70m no Ceará.

Tabela 5: Potencial de geração eólica no Ceará com diferente taxa de ocupação

\begin{tabular}{|c|c|c|c|c|}
\hline \multicolumn{5}{|c|}{ Potencial Eólico do Ceará } \\
\hline $\begin{array}{c}\text { Altura } \\
(\mathrm{m})\end{array}$ & Vento $(\mathrm{m} / \mathrm{s})$ & $\begin{array}{c}\text { Área } \\
\left(\mathrm{km}^{2}\right)\end{array}$ & $\begin{array}{c}\text { Potência Instalável } \\
(\mathrm{GW})\end{array}$ & $\begin{array}{c}\text { Energia Anual } \\
(\mathrm{TWh})\end{array}$ \\
\hline 70 & $>=7 \mathrm{~m} / \mathrm{s}$ & 12426 & 32,3 & 67,3 \\
\hline 50 & $>=7 \mathrm{~m} / \mathrm{s}$ & 2911 & 7,6 & 15,7 \\
\hline
\end{tabular}

Fonte: Elaboração Própria

\subsubsection{Atlas do Rio Grande do Sul}

O Estado do Rio Grande do Sul é localizado no extremo sul do país, com área de 281.730 $\mathrm{km}^{2}$ segundo o Atlas eólico do Estado. Com pelo menos cinco regiões distintas: (i) planície costeira marcada por lagoas e lagunas, coberta por vegetação de baixa rugosidade, dunas e áreas agrícolas; (ii) nordeste do Estado caracterizado pela Serra Geral, com elevações acima de 1000 metros; (iii) 
região da campanha gaúcha no sudoeste com formas de relevo onduladas que não ultrapassa de 500 metros de altitude; (iv) centro do Estado caracterizado pela Depressão Central que predomina cobertura florestal do norte do rio Jacuí; e (v) o noroeste, caracterizado pela parte sul de planaltos, tipicamente agrícola.

O Estado está em uma zona de transição climatológica, impactado por sistemas intertropicais (massas tropicais) e os extratropicais (massas e frentes do polo Sul). Também apresenta influência de sistemas regionais ou de mesoescala como a baixa do Noroeste argentino ${ }^{11}$ e Baixa do Chaco ${ }^{12}$. A interação entre esses sistemas causa frentes frias cíclicas de curta duração.

Os fenômenos El Niño ${ }^{13}$ e La Niña ${ }^{14}$ que provocam alteração na temperatura do Oceano Pacífico, distorcem o regime pluviométrico, trazendo ou chuvas abundantes ou períodos de estiagem.

A região apresenta diferentes fenômenos meteorológicos, resultando em climatologia única e dinâmica no Estado, com rápidas variações de intensidade e direção de vento. Na Serra Gaúcha, o vento acelera após o pôr do sol e se intensifica durante a madrugada, voltando a patamares mais baixos ao nascer do sol. No litoral, o efeito da brisa se inicia no fim de tarde com o pôr do sol, o ar sobre a areia se esfria e há a circulação da terra para o mar. $\mathrm{O}$ centro e oeste demonstram efeito contrastante, com ventos muito fortes a partir das primeiras horas do pôr do sol, permanecendo desta forma durante toda a madrugada.

Em relação ao regime sazonal mensal, no litoral o potencial se intensifica da primavera até dezembro, no centro-oeste, há o aumento da intensidade do vento a partir do inverno com ápice na primavera, sendo menor no outono.

Para este atlas, também foi utilizado o modelo Mesomap, balizado com medições de 70 torres anemométricas. Os modelos de aerogeradores foram os mesmos considerados para a Bahia,

\footnotetext{
${ }^{11}$ Baixa do Noroeste Argentino: sistema de baixa pressão resultante de fortes fluxos de calor da superfície.

${ }^{12}$ Baixa do Chaco: similar a baixa do Noroeste Argentino, mas localizado mais ao norte, sobre o Paraguai.

${ }^{13}$ El Niño: Fenômeno atmosférico-oceânico representado por aquecimento das águas do Oceano Pacífico Equatorial, alterando o clima regional e global, mudando padrões de vento e regimes de chuva.

${ }^{14}$ La Niña: Fenômeno oposto ao El Niño, representado por resfriamento das águas do Oceano Pacífico Equatorial, intensificando os ventos alísios que sopram na faixa equatorial de leste para oeste.
} 
com classes de vento A, B e C. A taxa de ocupação foi de $2,6 \mathrm{MW} / \mathrm{km}^{2}$. O potencial a $100 \mathrm{~m}$ é de $102,8 \mathrm{GW}$, conforme tabela 6 .

Tabela 6: Potencial de geração eólica no Rio Grande do Sul

\begin{tabular}{|c|c|c|c|c|}
\hline \multicolumn{5}{|c|}{ Potencial Eólico do Rio Grande do Sul } \\
\hline $\begin{array}{c}\text { Altura } \\
(\mathrm{m})\end{array}$ & Vento (m/s) & $\begin{array}{c}\text { Área } \\
(\mathrm{km} 2)\end{array}$ & $\begin{array}{c}\text { Potência Instalável } \\
(\mathrm{GW})\end{array}$ & $\begin{array}{c}\text { Energia Anual } \\
(\mathrm{TWh})\end{array}$ \\
\hline 150 & $>=7 \mathrm{~m} / \mathrm{s}$ & 94342 & 245,3 & 911,0 \\
\hline 100 & $>=7 \mathrm{~m} / \mathrm{s}$ & 39529 & 102,8 & 382,0 \\
\hline
\end{tabular}

Fonte: Atlas Eólico do Rio Grande do Sul

Considerando-se o potencial a 100 metros de altura destes 4 Estados apenas, sendo que o Ceará a 70 metros, ter-se-ia um potencial de $252 \mathrm{GW}$, podendo ser muito maior do que $300 \mathrm{GW}$ no Brasil.

\subsection{Geração eólica no Brasil}

O Nordeste é uma região que tem apresentado necessidade de importação de energia das outras regiões, devido a sua seca severa nos últimos anos. A perspectiva de crescimento de energia eólica faz com que esta fonte ganhe cada vez mais importância. A Figura 10 mostra a participação das diferentes fontes na geração de energia do Nordeste. Em setembro de 2016 a geração eólica foi em média a mais alta do ano, contribuindo com $45 \%$ da geração da região. 
Figura 10: Participação da geração eólica na geração de energia do Nordeste

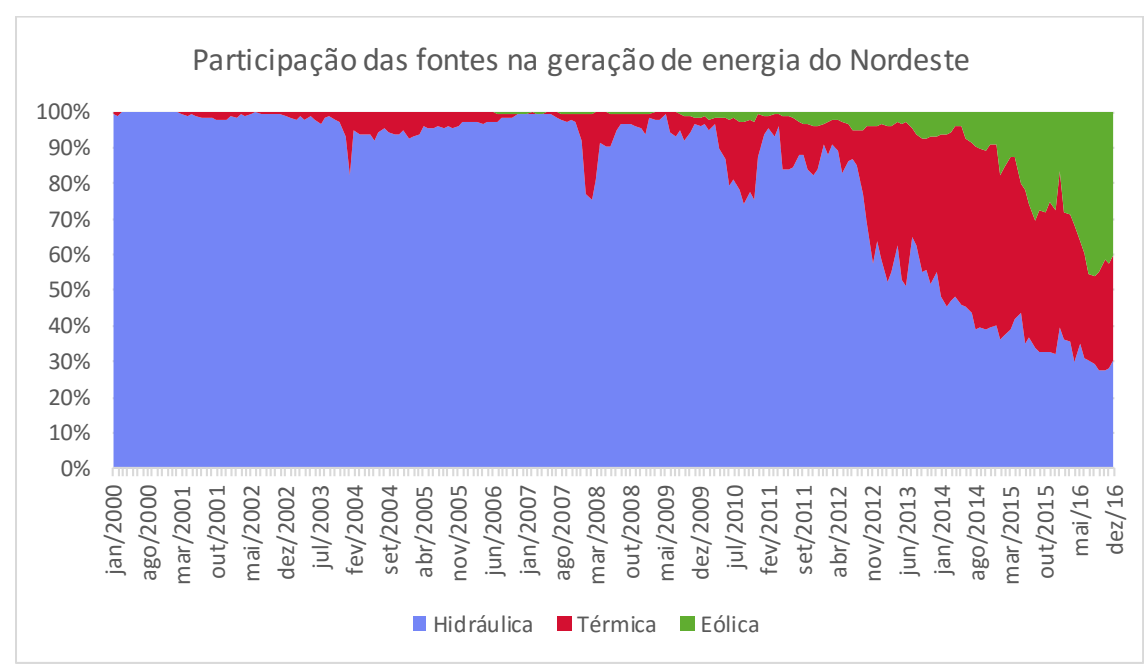

Fonte: Elaboração própria com base nos dados ONS, 2017

Segundo o boletim de geração eólica do ONS, houve um aumento da capacidade instalada do Nordeste a partir de 2014, com geração mensal em torno de 4000 MWm em alguns meses de 2016. No Sul, a maior elevação da capacidade eólica se deu a partir de 2015, com geração em torno de 500 MWm também em alguns meses de 2016. A Figura 11 e Figura 12 mostram a evolução da capacidade instalada e geração eólica, no Nordeste e Sul, respectivamente.

Figura 11: Evolução da capacidade instalada e geração eólica no Nordeste

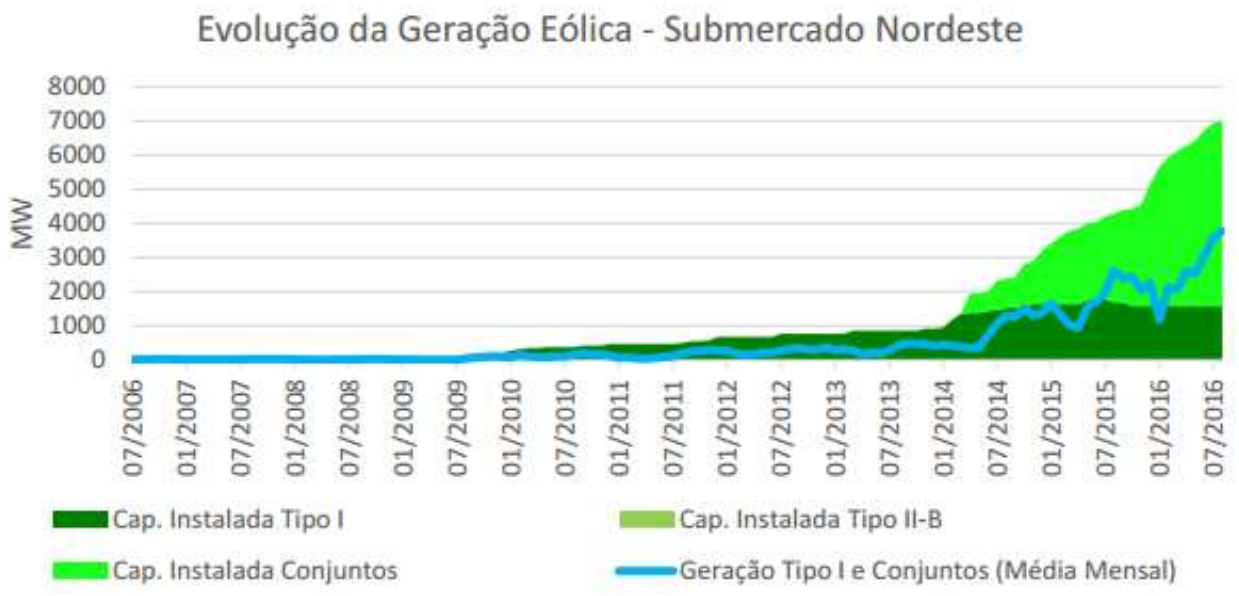

Fonte: ONS, 2016 
Figura 12: Evolução da capacidade instalada e geração eólica no Sul

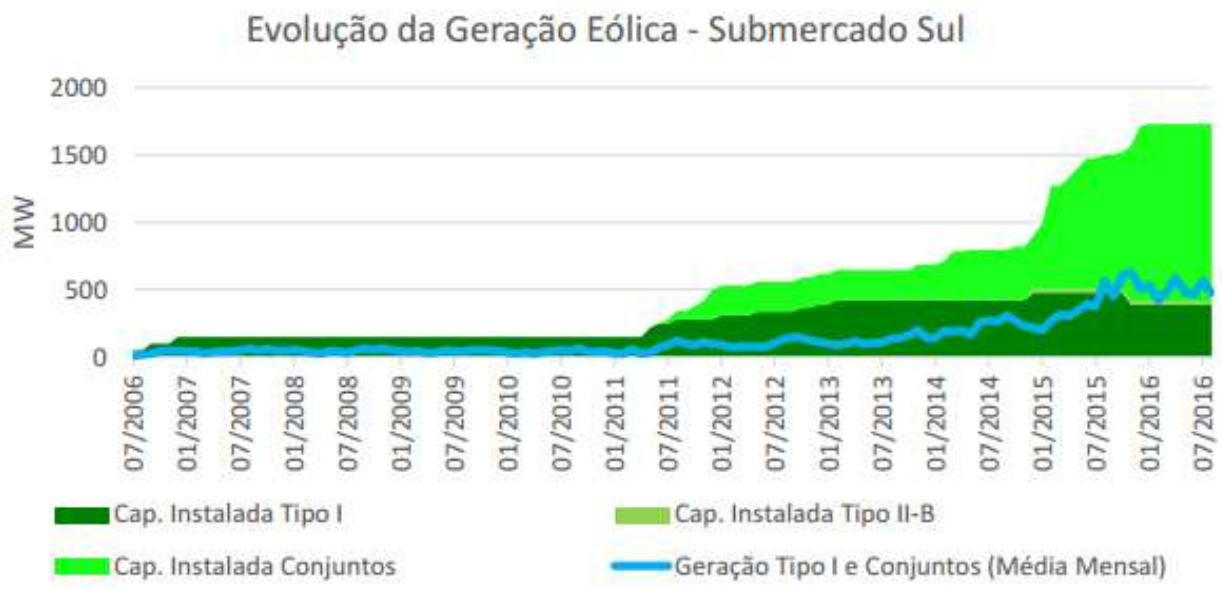

Fonte: ONS, 2016

As usinas Tipo 1 são normalmente conectadas na rede básica, independente da potência líquida injetada no SIN. As usinas tipo II-B, são usinas que não se englobam no Tipo I, mas que se identifica a necessidade de informações ao ONS para representação individualizada nos processos de planejamento e programação/operação. O conjunto de usinas é constituído por um grupo de usinas que totalizam uma injeção de potência significativa e que pelo impacto na rede, necessitase de relacionamento com o ONS. A modalidade da usina é definida a partir da avaliação de impactos tanto na operação eletroenergética do SIN, como na segurança da rede de operação.

De acordo com o boletim do ONS, o estado que gera mais energia eólica atualmente é o Rio Grande do Norte e também com a maior capacidade instalada. A menor capacidade instalada é proveniente de Santa Catarina, em relação aos estados que apresentam geração eólica. A Figura 13 mostra a capacidade instalada e a geração em agosto/16. 
Figura 13: Capacidade instalada e geração eólica por Estado Brasileiro

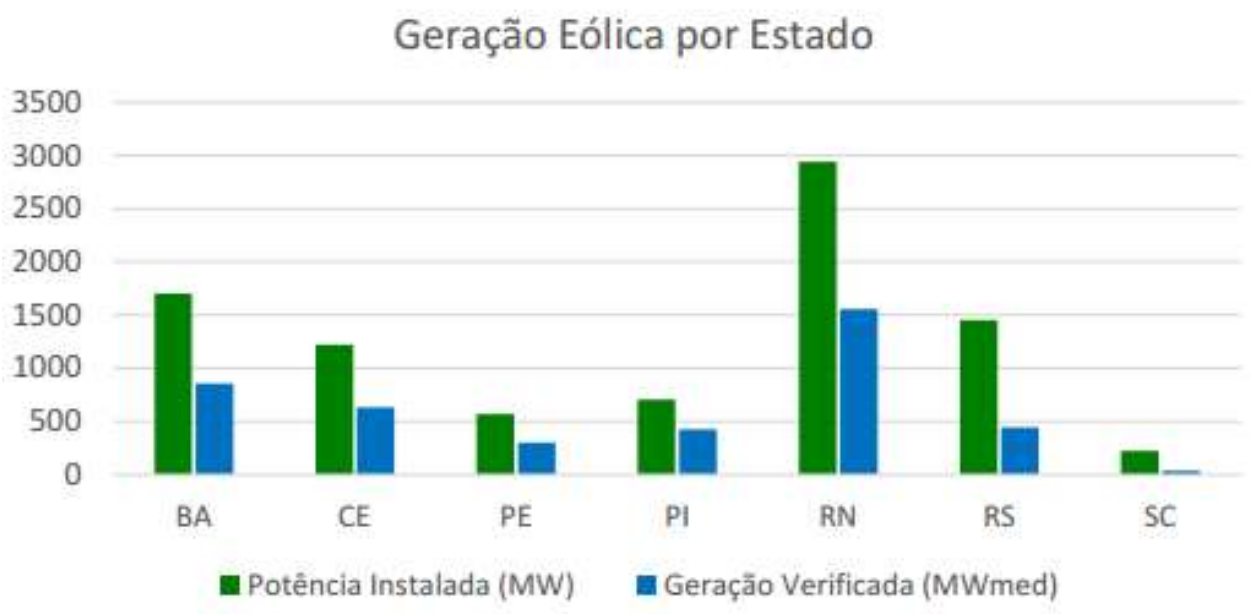

Fonte: Elaboração própria com base nos dados do ONS (2016).

Em agosto, o fator de capacidade médio das eólicas do SIN foi de 48,3\%. A Tabela 7 mostra o fator de capacidade por Estado neste mês.

Tabela 7: Potência instalada, geração eólica e fator de capacidade em ago/16

\begin{tabular}{lrrc}
\hline \multicolumn{1}{c}{ Estado } & $\begin{array}{c}\text { Potência } \\
\text { Instalada (MW) }\end{array}$ & $\begin{array}{c}\text { Geração } \\
\text { Verificada em } \\
\text { (MWm) }\end{array}$ & $\begin{array}{c}\text { Fator de Capacidade } \\
\text { médio (\%) }\end{array}$ \\
\hline Bahia & 1.702 & 858 & $50,4 \%$ \\
Ceará & 1.222 & 632 & $51,7 \%$ \\
Pernambuco & 569 & 302 & $53,1 \%$ \\
Piauí & 706 & 428 & $60,6 \%$ \\
Rio Grande do Norte & 2.939 & 1.555 & $52,9 \%$ \\
Rio Grande do Sul & 1.454 & 445 & $30,6 \%$ \\
Santa Catarina & 222 & 35 & $15,6 \%$ \\
\hline SIN (Sistema Interligado Nacional) & $\mathbf{8 8 1 3}$ & $\mathbf{4 2 5 5}$ & $\mathbf{4 8 , 3 \%}$ \\
\hline
\end{tabular}

Fonte: Elaboração Própria com base em ONS (2016).

Os valores horários mostram que na Bahia, considerando-se os meses de março a agosto de 2016, a geração é maior durante o período noturno. 
Figura 14: Geração horária da Bahia

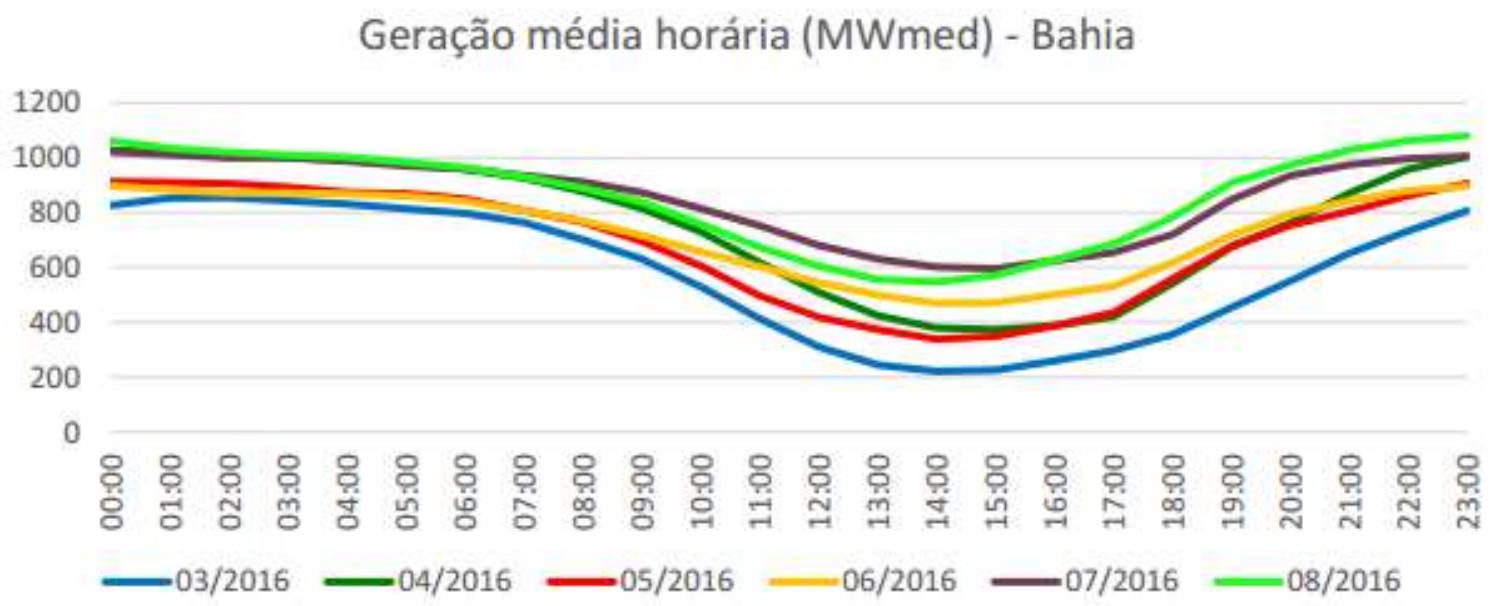

Fonte: ONS, 2016

Diferentemente do Ceará que apresenta maior geração a partir das sete horas da manhã até às 18 horas.

Figura 15: Geração horária do Ceará

\section{Geração média horária (MWmed) - Ceará}

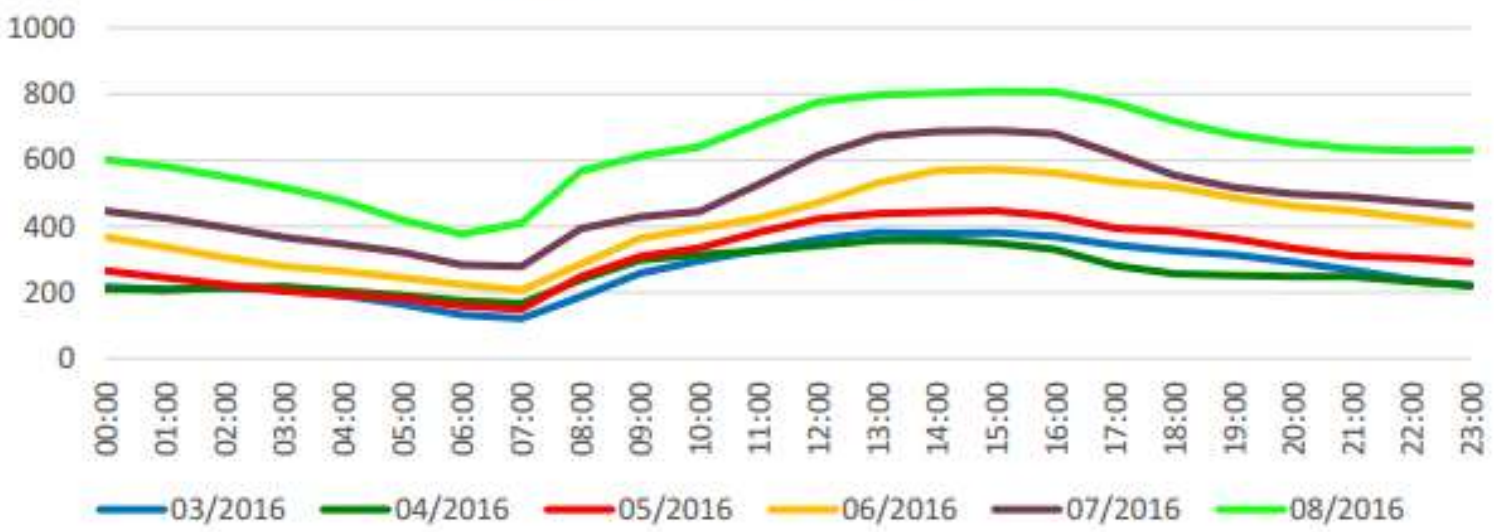

Fonte: ONS, 2016

O Rio Grande do Norte apresenta maior constância quando comparado aos outros estados do Nordeste, mas com picos no início da manhã e final da tarde. 
Figura 16: Geração horária do Rio Grande do Norte

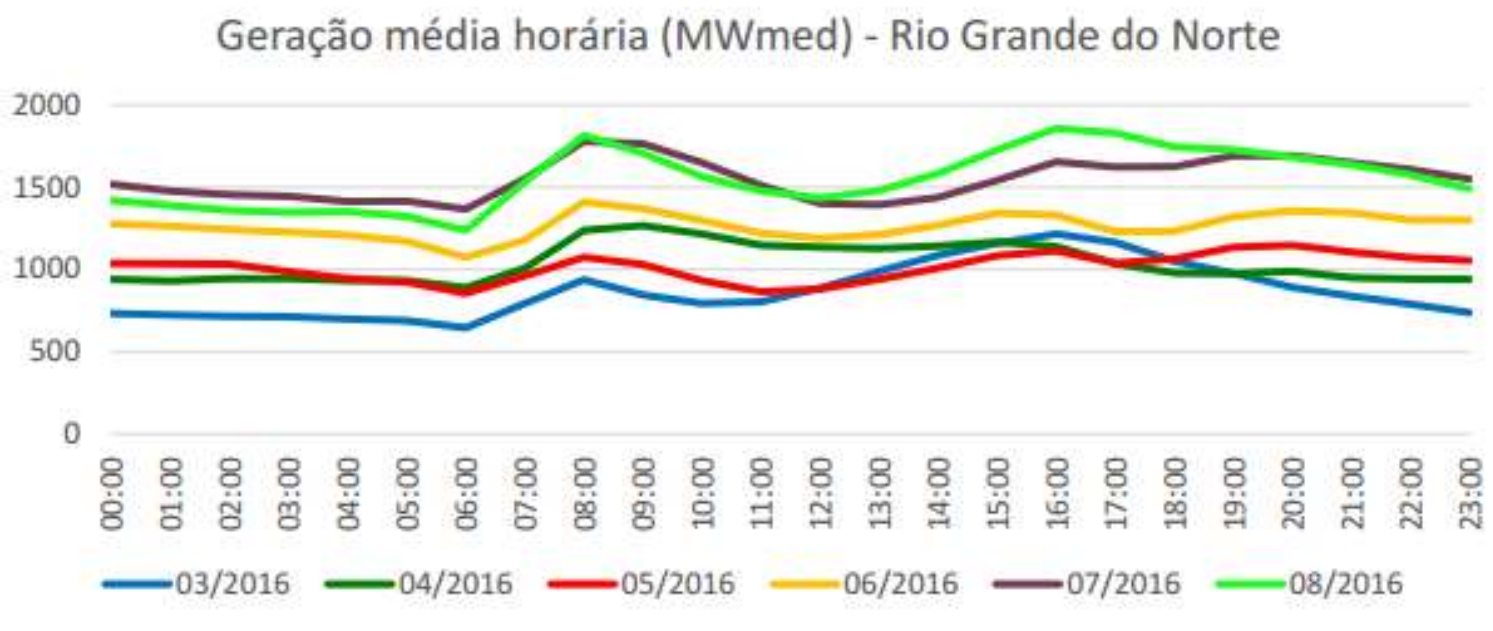

Fonte: ONS, 2016

O Rio Grande do Sul apresenta maior constância durante o dia inteiro, sendo pouco mais elevada no período noturno.

Figura 17: Geração horária do Rio Grande do Sul

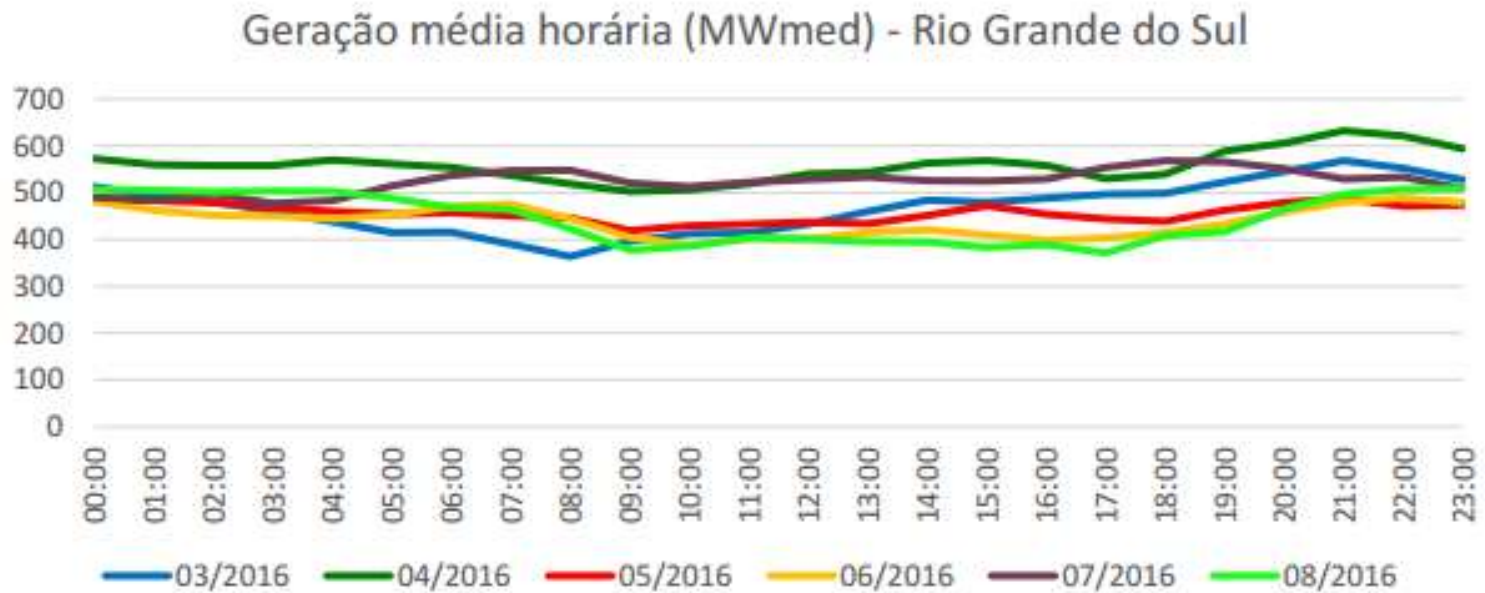

Fonte: ONS, 2016

Em setembro de 2016, o fator de capacidade registrado pelo Rio Grande do Norte foi de praticamente $57 \%$ e todos os Estados do Nordeste apresentaram fator de capacidade acima de $50 \%$. A geração eólica do Nordeste foi capaz de atender 39\% da carga da região neste mesmo mês, 
quando a situação dos níveis dos reservatórios estava se caracterizando por um período de evidente escassez.

Figura 18: Redução dos níveis dos reservatórios do Nordeste e aumento da geração eólica

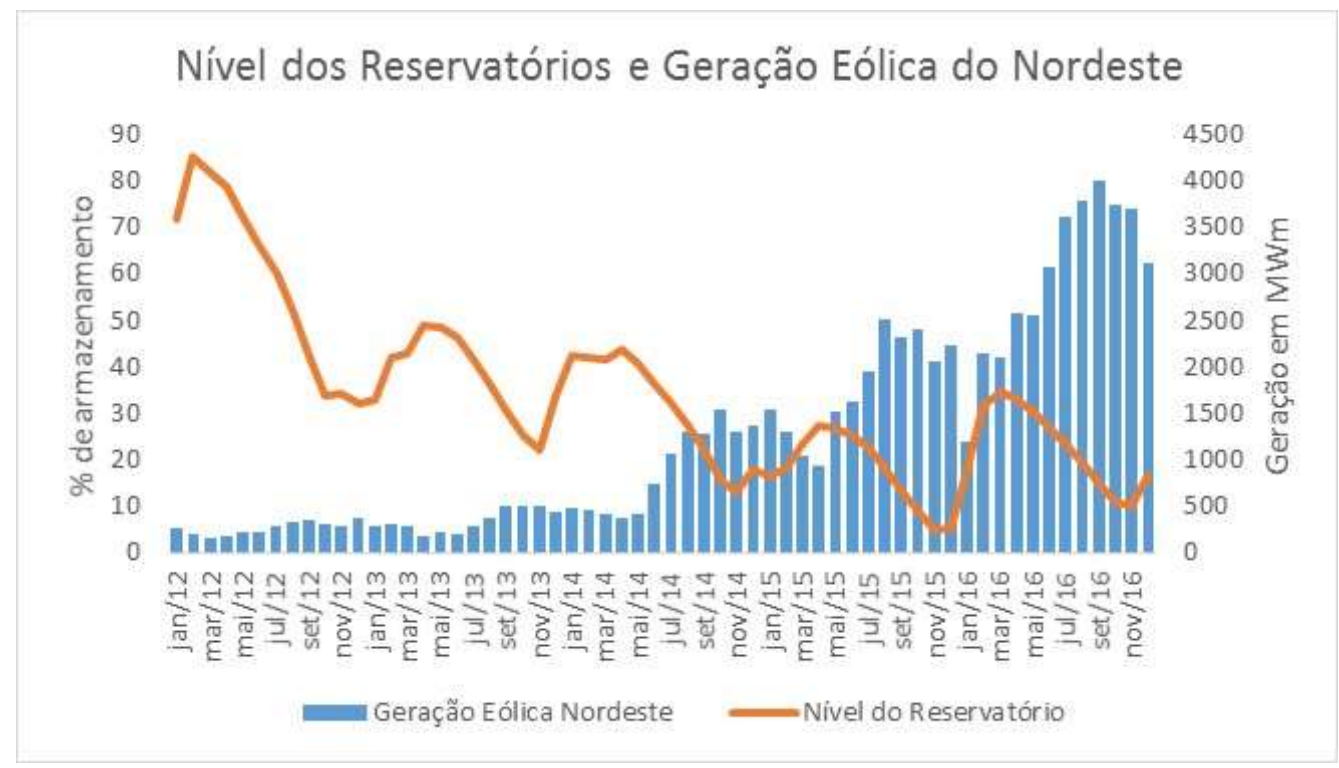

Fonte: Elaboração própria com base nos dados do ONS, 2016

Fazendo-se um comparativo da geração prevista com a realizada durante os meses de janeiro de 2016 a janeiro de 2017, tem-se a Figura 19 e a Figura 20, representando o Nordeste e o Sul, respectivamente. 
Figura 19: Geração eólica prevista e verificada no Nordeste

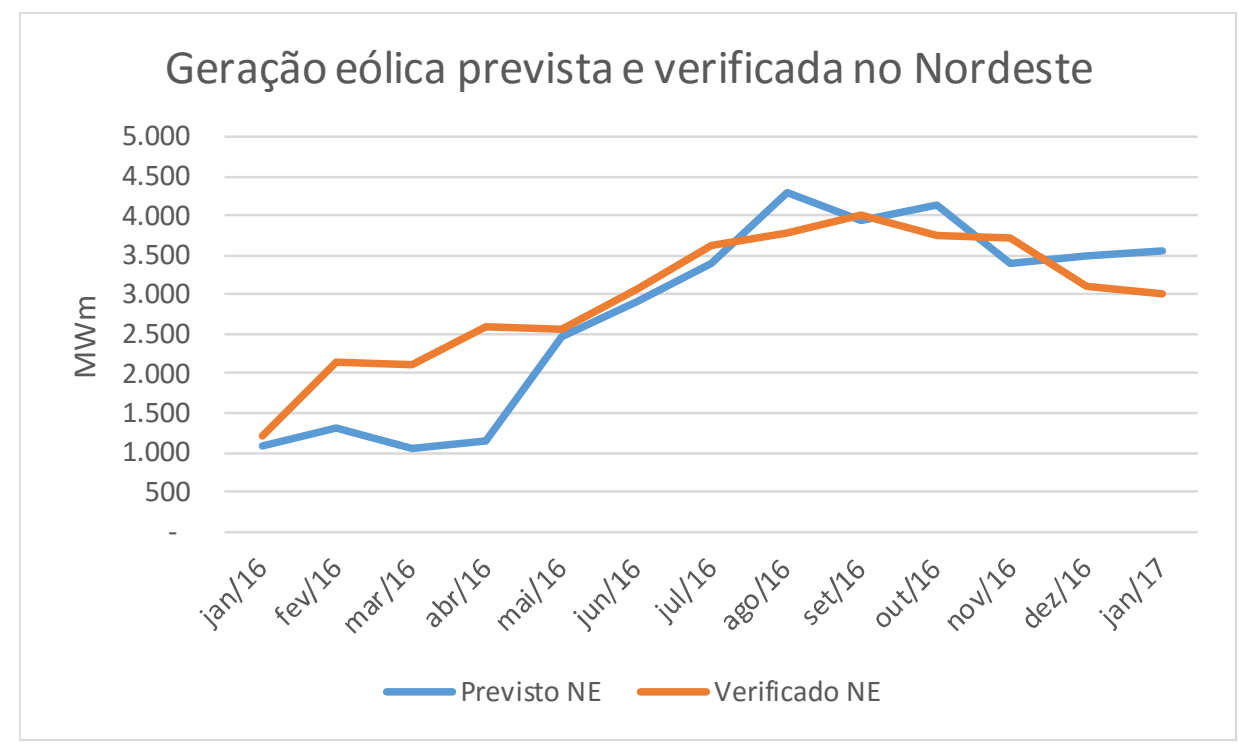

Fonte: Elaboração própria, base ONS 2017

A geração eólica prevista antes de maio de 2016 de usinas existentes considerava o histórico de geração dos últimos 5 anos, ou seja, para fazer a previsão de janeiro de 2016, utilizava-se a média dos últimos 5 janeiros e assim, sucessivamente para todos os meses do ano. De acordo com a Resolução Aneel 440 de 2011 e posterior Resolução Aneel 476 de 2012.

Conforme se verifica na Figura 19 e na Figura 20, os valores previstos de geração eólica ficaram aquém do verificado.

A partir de maio, com a proposta de aprimoramento da metodologia do ONS para estimar os montantes de geração das usinas existentes não simuladas individualmente, completou-se os meses do histórico do último ano com uma estimativa de valores, aplicando-se um fator típico da usina, similar ao utilizado para usinas em expansão. Assim, os montantes de geração que aumentaram durante o ano das usinas existentes, passaram a ser considerados com a metodologia. 
Figura 20: Geração eólica prevista e verificada no Sul

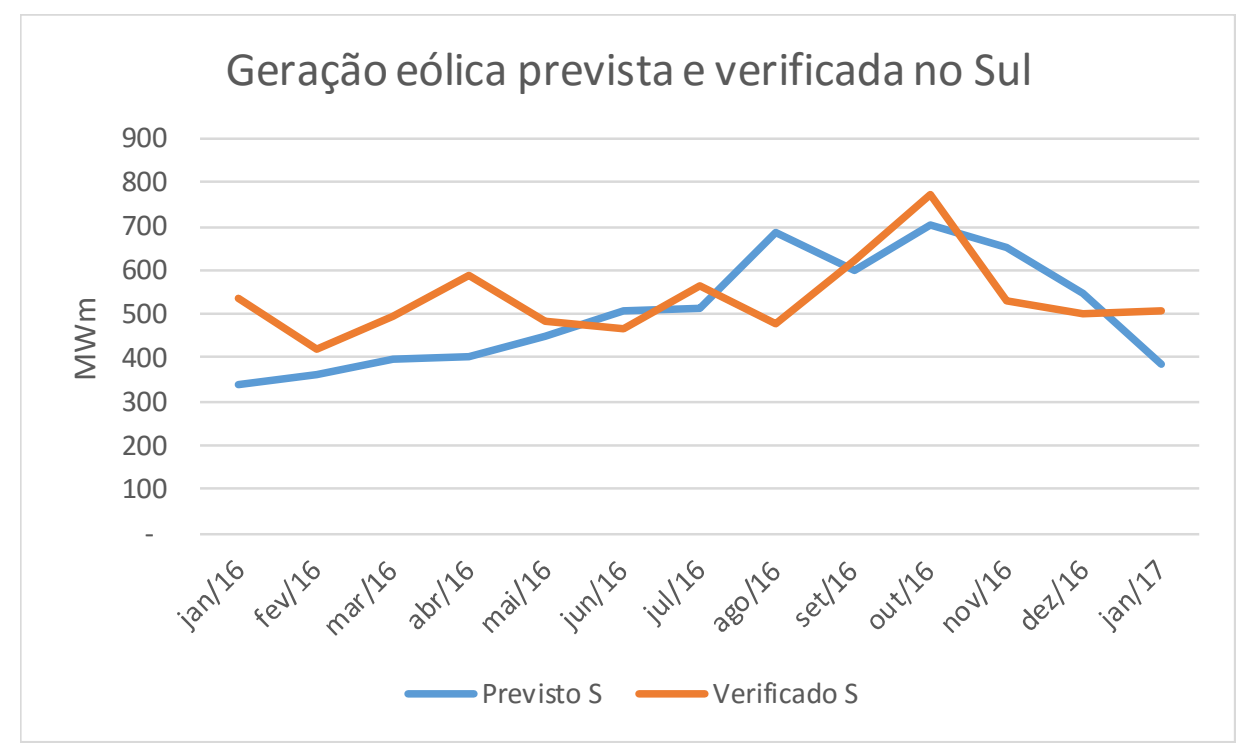

Fonte: Elaboração própria com base em ONS (2017).

A variação percentual da Tabela 8 mostra que antes de maio a diferença da geração verificada em relação à prevista tinha maior variação, mas mesmo assim, a geração eólica verificada em agosto no Sul ficou 30\% menor do que o previsto. Isso mostra o quanto varia a previsão da geração verificada e leva a indagar se em períodos secos, a geração eólica poderia ser maior e ajudar mais o sistema, evitando o maior despacho térmico antecipado desnecessário, dada a sua complementaridade com a geração hidráulica.

Tabela 8: Variação do previsto vs. verificado de geração eólica no Sul e no Nordeste

\begin{tabular}{|c|c|c|c|c|c|c|c|c|c|c|c|c|c|}
\hline & jan/16 & $\mathrm{fev} / 16$ & $\mathrm{mar} / 16$ & $\mathrm{abr} / 16$ & $\mathrm{mai} / 16$ & jun/16 & $\mathrm{jul} / 16$ & ago/16 & set/16 & out/16 & nov/16 & $\mathrm{dez} / 16$ & jan/17 \\
\hline Variação S & $57 \%$ & $15 \%$ & $26 \%$ & $47 \%$ & $8 \%$ & $-8 \%$ & $10 \%$ & $-30 \%$ & $4 \%$ & $10 \%$ & $-18 \%$ & $-8 \%$ & $31 \%$ \\
\hline Variação NE & $10 \%$ & $64 \%$ & $103 \%$ & $123 \%$ & $4 \%$ & $6 \%$ & $6 \%$ & $-12 \%$ & $1 \%$ & $-9 \%$ & $9 \%$ & $-10 \%$ & $-16 \%$ \\
\hline
\end{tabular}

Fonte: Elaboração Própria com base em ONS (2017). 


\section{MODELO NEWAVE}

O Newave foi o modelo utilizado para as simulações dos estudos de caso deste trabalho, assim como para o entendimento dos resultados é necessário o entendimento do funcionamento do modelo.

O planejamento energético do sistema brasileiro utiliza modelos matemáticos aproximados à realidade, com o objetivo de se obter estratégias de despacho de geração, minimizando os custos de operação, sem comprometer a segurança no atendimento de energia. Os custos que se pretende minimizar, são os valores com combustíveis para a geração termelétrica ou o alto preço que representaria o racionamento de energia para a sociedade (KLIGERMAN, 1992).

O modelo Newave desenvolvido pelo Cepel é um programa computacional utilizado com objetivo de realizar o planejamento da operação e expansão do setor elétrico brasileiro. O modelo é utilizado pelo Operador Nacional do Sistema (ONS) para determinação dos despachos das usinas térmicas e hidráulicas para o atendimento da carga do Sistema Interligado Nacional (SIN) e pela Câmara de Comercialização de Energia Elétrica (CCEE) para a formação do preço de energia Preço de Liquidação das Diferenças (PLD). A EPE utiliza o modelo para realizar a expansão do setor, através de leilões de usinas e garantia física.

(KLIGERMAN, 1992) O planejamento da operação em Sistema com predominância hidráulica, tem características complexas, tais como:

- Incertezas das afluências que variam sazonalmente e regionalmente;

- Complexidade do modelo pois apresenta características de acoplamento temporal, sendo que a decisão em um determinado estágio influencia a decisão dos estágios futuros, e espacial, a geração de uma usina pode influenciar o comportamento de outra usina;

- Sistemas de grande porte representados por múltiplos reservatórios e otimização multi-período;

- Função de produção das hidrelétricas e custo de operação das termelétricas é não linear;

- Outros usos para água como navegação, cheias, irrigação, etc. 
O Sistema é representado de maneira agregada em forma de reservatórios equivalentes para reduzir o esforço computacional, para cada submercado, agrega-se os reservatórios em um reservatório equivalente de energia, obtendo-se a capacidade equivalente deste reservatório e as afluências são agregadas em energias afluentes (CCEE \& ONS, 2016). A energia armazenada é a energia que o sistema poderia gerar com o deplecionameto dos reservatórios operados em paralelo, desconsiderando-se afluências adicionais.

Até dezembro de 2015 eram considerados 4 submercados, representados por 4 Reservatórios Equivalentes de Energia (REE's): Sudeste/Centro-Oeste, Sul, Nordeste e Norte. Em janeiro de 2016, o número de REE's passou para nove, sendo 2 na região Norte, 5 na região Sudeste/Centro-Oeste, continuando apenas 1 no Sul e 1 no Nordeste.

O horizonte do modelo é de 5 anos discretizados mensalmente e o objetivo é a construção de política operativa com metas de geração térmica e hidráulica para cada submercado no mês.

\subsection{Otimização do modelo}

O Newave resolve para cada período e cenário de afluência um problema de otimização, minimizando a soma do custo imediato e o custo futuro. $\mathrm{O}$ custo imediato representa o custo de geração de térmicas e eventuais cortes de carga. O custo futuro representa o valor esperado da operação no futuro em função das afluências passadas e reservatórios finais.

Como exemplo de custo imediato, dado um determinado mês, considerando-se apenas a água para atendimento da demanda, o reservatório termina o mês vazio e o custo imediato é "zero", ou por outro lado, atendendo-se a demanda apenas com térmicas, utilizando-se o combustível e tem-se um custo imediato alto. O custo imediato depende do nível dos reservatórios no final do mês. Para o primeiro caso anterior, inicia-se o mês seguinte com o nível do reservatório vazio, necessitando de térmicas para atendimento da demanda, o custo futuro será alto. No segundo caso, com o nível do reservatório cheio no mês seguinte, o custo futuro é menor porque será necessário menos térmicas para atendimento da demanda. 
A decisão ótima resume-se em tomar decisões no presente para que o nível do reservatório no final do mês atinja um volume que resulte no menor custo total. O despacho ótimo é quando o custo imediato é igual ao custo futuro.

Figura 21: Representação gráfica do custo total da operação

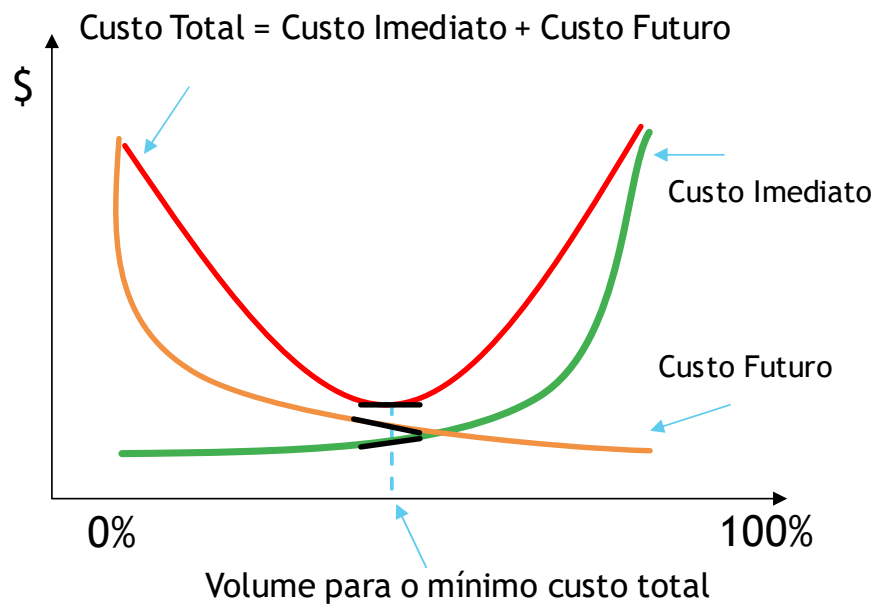

Fonte: Elaboração própria com base em: ONS e CCEE, 2016

A curva de custo futuro é conhecida como função de custo futuro (FCF) e a inclinação dessa curva indica como varia o custo futuro em relação ao volume armazenado, a derivada da FCF é o valor da água. A derivada do custo imediato é o custo da geração das usinas térmicas e de déficit.

O custo imediato é representado pelas despesas com pagamento de combustíveis, de fácil determinação. No entanto, o custo futuro depende das afluências das usinas hidrelétricas, com alto grau de incerteza.

O Newave considera as séries históricas de vazão que se constituem na base do modelo de geração de séries sintéticas de energias afluentes. As afluências são representadas de forma estocástica, uma vez que não se conhece os seus valores para o futuro. A incerteza é representada por árvore de cenários onde cada caminho da árvore é denominado de cenário hidrológico e cada nó é uma possível realização de afluência. As realizações seguem um processo estocástico com propriedades estatísticas do histórico, preservadas na construção da árvore. 
O modelo estatístico que se ajusta ao comportamento das afluências é o PAR (p), que significa "Autoregressivo Periódico de ordem p". Assim, o valor obtido para a variável aleatória em um determinado período é determinado por "p" períodos anteriores. A afluência em um determinado período é obtida pela soma da influência de cada período anterior ao período $\mathrm{p}$, mais um ruído aleatório (CCEE \& ONS, 2015). Detalhes mais aprofundados de modelos autoregressivos são encontrados em (HIPEL \& MCLEOD, 1994; SOUZA \& CAMARGO, 2004 e MACHADO, 2016).

Para o cálculo do custo futuro, conhecendo-se o modelo estocástico, sorteia-se hipóteses de afluências, acompanha-se a evolução do sistema durante 5 anos de cada trajetória correspondente a cada hipótese e calcula-se o custo médio de todas as hipóteses, sendo este o custo futuro médio.

A PDE (Programação Dinâmica Estocástica) estuda a evolução do sistema e traz informações do futuro para o presente. Além do custo futuro médio, encontra-se os custos futuros para qualquer outro estado (nível de armazenamento da usina) de qualquer outro período, dadas diversas hipóteses de afluências. Entretanto, o Sistema brasileiro, é representado por inúmeras usinas e caso estes custos fossem calculados para cada nível de reservatório, ter-se-ia um processo exponencial, pois os estados passariam a ser a combinação dos níveis de armazenamento de todos os reservatórios. A solução para o problema da chamada "maldição da dimensionalidade" ocorreu com a utilização da PDDE: Programação Dinâmica Dual Estocástica. Baseia-se em decomposição de Benders multi-estágio e estocástica. Ao invés de se calcular a função de custo futuro para todos os estados, calcula-se para somente alguns estados. Além do custo futuro, calcula-se também a taxa de variação (derivada do custo futuro) dele ao redor do estado calculado. O conjunto de retas que passam pelos pontos, cuja inclinação corresponde à derivada do custo futuro, é conhecido como função de custo futuro (FCF).

Os estados referidos no parágrafo anterior são escolhidos com simulação da operação, utilizando-se afluências sorteadas por distribuição estatística. No Newave, utiliza-se a árvore incompleta ${ }^{15}$, sendo que todas as hipóteses de afluências se ramificam apenas no início do horizonte e a hipótese permanece até o final do estudo. O estado leva em consideração além do

15 Adota-se a árvore incompleta, caso contrário haveria uma explosão do número de Estados (níveis de armazenamento). 
armazenamento, a afluência anterior. Para cada estado é calculado um custo futuro e sua derivada, representada por um plano.

Figura 22: Sequências de afluências da árvore incompleta

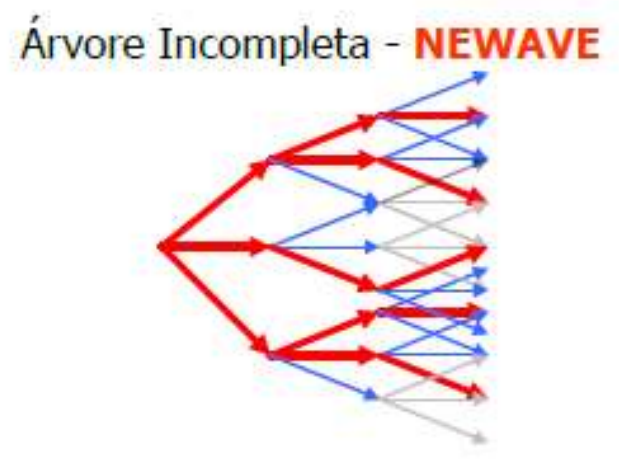

Fonte: ONS e CCEE, 2016

O processo para cálculo da FCF é iterativo e formado por sequências de simulações forward (definem os níveis de armazenamento em cada cenário, partindo do início e chegando ao final do horizonte) e backward (calcula o custo futuro e sua derivada, nos níveis de armazenamento atingidos, partindo do final do horizonte e chegando ao seu início). Na fase forward do Newave, gera-se pontos de armazenamento considerando-se as aproximações das FCF e na fase backward, para que seja calculado o custo futuro em um estado, são sorteadas hipóteses de afluências, denominadas de aberturas. $\mathrm{O}$ custo futuro e derivada são calculados como a média dos custos e derivadas de cada abertura. O método iterativo termina quando o critério de convergência é alcançado, representado pela aproximação do custo futuro estimado com o custo médio simulado (CCEE \& ONS, 2015).

O Newave é um modelo de otimização estocástico que leva em consideração a operação de usinas hidráulicas e termelétricas, a capacidade de expansão, a previsão de carga, os limites das linhas de transmissão entre submercados (por exemplo entre o Sul e o Sudeste) e a incerteza das afluências para determinação do despacho térmico e hidráulico. O modelo considera a oferta de energia eólica, assim como as fontes de biomassa e PCHs abatida diretamente da carga de cada submercado, com previsão determinística. Há a necessidade de realizar uma cenarização, assim como é feito com as vazões, para a geração eólica, representando suas incertezas e sazonalidades. 
$\mathrm{O}$ mecanismo de aversão ao risco CVaR ("Conditional Value at Risk") foi adicionado à função objetivo do modelo em 2013, introduzindo um peso maior para os cenários hidrológicos mais caros, propiciando maior segurança no suprimento de energia.

O Decomp realiza o Planejamento e Operação a Médio Prazo, horizonte de 2 meses. É adaptado ao ambiente de elaboração dos programas mensais de operação do sistema brasileiro. Seu objetivo é determinar as metas de geração de cada usina de um sistema hidrotérmico sujeito a afluências estocásticas, de forma a atender a demanda e minimizar o valor esperado do custo de operação ao longo do período de planejamento. O modelo está formulado como um problema de programação linear, representando as características físicas e as restrições operativas das usinas hidrelétricas de forma individualizada (CEPEL, 2013) e fornece o Custo Marginal da Operação (CMO), que representa quanto custaria atender um acréscimo unitário de carga (1 MWh). O CMO é a base para formação do Preço de Liquidação das Diferenças (PLD) limitado por um preço máximo e mínimo vigente a cada ano. O PLD valora a compra e a venda de energia no mercado de curto prazo, (ou como também denominado no Brasil de "Mercado Spot"), na CCEE.

No Decomp, a hidrologia é considerada parte determinística e parte estocástica. Para cada semana do primeiro mês as afluências são consideradas conhecidas utilizando modelos Previvaz e Cpins. Para os demais meses é considerado o Gevazp. (Manual do Decomp, CEPEL).

O Previvaz foi desenvolvido visando as previsões de afluências semanais, até 6 semanas a frente. A abordagem consiste no uso do valor esperado de modelos de séries temporais. A previsão considera o comportamento sazonal das vazões e também a tendência hidrológica.

A tendência hidrológica é a tendência observada das séries históricas. Valores superiores ou inferiores ao valor normal serem seguidos ou precedidos por valores também superiores ou inferiores à normal.

\subsection{Resultados}

O Newave apresenta resultados de cada uma das 2000 séries sintéticas ou para cada uma das séries históricas de 1931 até o ano mais recente que tenha sido validado e incorporado ao histórico. Os valores de custo marginal de operação, geração térmica e déficit são dados por 
Submercado: Sudeste, Sul, Nordeste e Norte. Já os resultados relacionados à geração hidráulica, níveis de reservatórios e afluências são dados por Reservatório Equivalente de Energia.

Ainda, cabe frisar que os valores dos resultados também são mensais, para o horizonte de até 5 anos, e são fornecidas as médias ou das séries históricas ou sintéticas, dependendo do caso simulado. 


\section{ESTUDO DA ESTATÍSTICA E BASE DE DADOS}

Este capítulo mostra a teoria estatística e sua aplicação na base de dados, tendo como objetivo analisar a sazonalidade da velocidade de vento interanual e estudar a série temporal de geração eólica considerando os diversos dados dos sites em suas localidades, a fim de entender o comportamento ao longo do tempo. Além disso, o capítulo mostra a reconstrução da base de dados históricas para geração eólica que será utilizada na simulação do Newave no capítulo 7 desta tese.

\subsection{Séries temporais}

De acordo com (MUJUMDAR, 2012), o princípio da geração de cenários são os dados históricos que mostram uma ideia do futuro. Com eles, capturam-se as informações essenciais em termos de probabilidade de distribuição, em termos de parâmetros estatísticos e em termos de comportamento estocástico do processo em particular. Utiliza-se dessas informações para gerar dados para o futuro.

Os modelos de geração de cenários reproduzem uma distribuição estatística e persistência das afluências históricas.

Com os dados históricos, calculam-se os parâmetros estatísticos como a média, desviopadrão, coeficientes de correlação e os momentos da distribuição. Dada uma distribuição, o modelo vai gerar dados pertencentes a esta, preservando a média histórica, o desvio-padrão e o coefíciente de correlação. 
Figura 23: Geração de séries com base em dados históricos

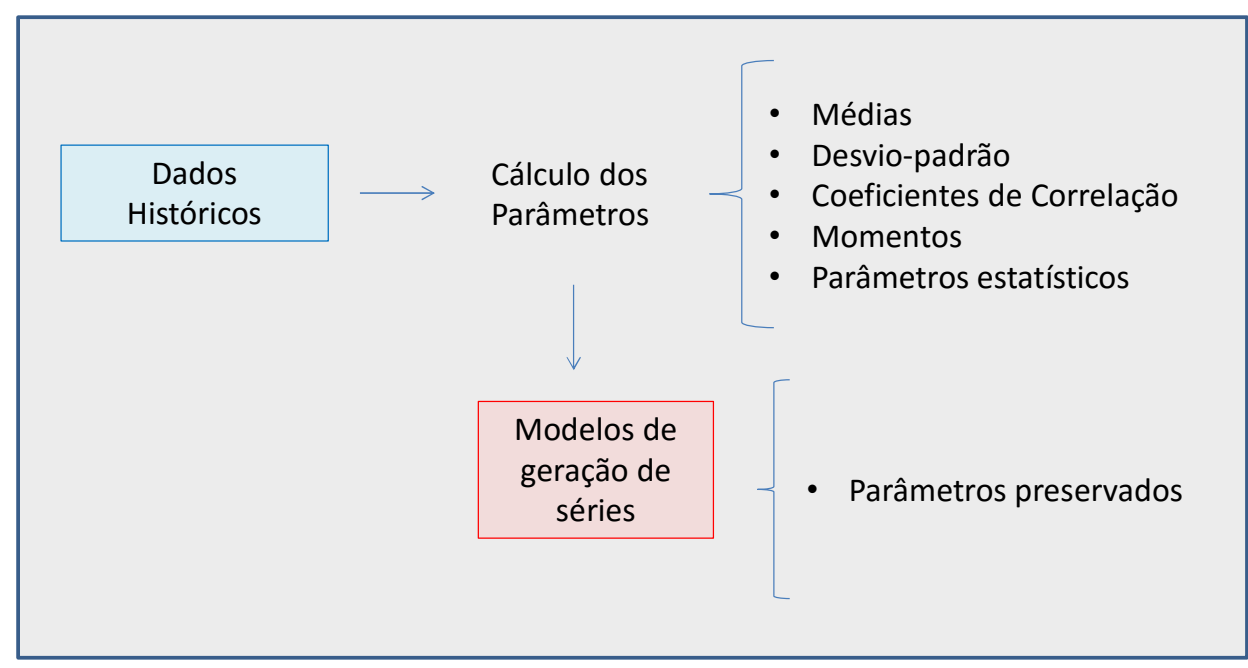

Fonte: Elaboração própria

Um dos métodos mais utilizados para estimar os parâmetros da distribuição é o método dos momentos. O primeiro momento da distribuição é o valor esperado, que em uma amostra representa a média.

$$
X=\frac{\sum_{i=1}^{n} X i}{n}(2)
$$

A moda é o valor com maior frequência e a mediana é o valor que divide a distribuição em duas metades.

A variância é o segundo momento da distribuição, indicando quanto os valores estão dispersos em relação à média. Quanto maior a variância, maior a dispersão. Para uma amostra, temse:

$$
V=\frac{\sum_{i=1}^{n}(X i-\bar{X})^{2}}{n-1}(3)
$$

O desvio padrão é a raiz quadrada da variância. Para uma amostra, tem-se:

$$
S=\sqrt{V}(4)
$$

O coeficiente de variação é dado por:

$$
C_{v}=\frac{S}{\bar{X}}(5)
$$


Para as medidas de simetria, calcula-se o coeficiente de skewness com base no terceiro momento da distribuição.

$$
C_{S}=\frac{n * \sum_{i=1}^{n}(X i-\bar{X})^{3}}{(n-1) *(n-2) * S^{3}}(6)
$$

Para as medidas de pico, calcula-se o coeficiente de Kurtosis, dado pelo quarto momento da distribuição.

$$
K=\frac{n^{2} * \sum_{i=1}^{n}(X i-\bar{X})^{4}}{(n-1) *(n-2) *(n-3) * S^{4}}(7)
$$

Essas medidas proporcionam uma ideia do tipo de distribuição que a amostra pode ser ajustada.

Diferentes funções que ajustam a distribuição de velocidade de vento são utilizadas na literatura como Weibull, Rayleigh e Gaussiana. A distribuição de Weibull se destaca por possibilitar o ajuste dos parâmetros em função do tempo, um mês ou um ano, normalmente.

A distribuição de Weibull é uma distribuição de probabilidade contínua. Uma variável aleatória segue a distribuição de Weibull se a função densidade de probabilidade é dada por:

$$
f(x ; \lambda, k)=\left\{\begin{aligned}
\frac{k}{\lambda} *\left(\frac{x}{\lambda}\right)^{k-1} e^{-\left(\frac{x}{\lambda}\right)^{k}}, & x \geq 0 \\
0, & x<0
\end{aligned}(8)\right.
$$

No entanto, aproximações com histogramas por Weibull podem não evidenciar períodos críticos ou eventos extremos, podendo representar uma limitação do método e merece ser investigado em trabalhos futuros.

A correlação é o maior grau de associação entre duas variáveis aleatórias, $\mathrm{X}$ e $\mathrm{Y}$, por exemplo. Para um coeficiente de correlação positivo, quanto maior o X, maior o Y. Para um coeficiente de correlação negativo, quanto maior o X, menor o valor de Y. O coeficiente de correlação é uma medida de dependência linear.

$$
r=\frac{\sum_{i}^{N}\left(X_{i}-\bar{X}\right) * \sum_{i}^{N}\left(Y_{i}-\bar{Y}\right)}{\sqrt{\sum_{i}^{N}\left(X_{i}-\bar{X}\right)^{2} * \sum_{1}^{N}\left(Y_{i}-\bar{Y}\right)^{2}}}(9)
$$

A covariância captura como duas variáveis se movem juntas. 


$$
\operatorname{Cov}=\frac{\sum_{\mathrm{i}}^{\mathrm{N}}\left(\mathrm{X}_{\mathrm{i}}-\overline{\mathrm{X}}\right) *\left(\mathrm{Y}_{\mathrm{i}}-\overline{\mathrm{Y}}\right)}{\mathrm{n}}(10)
$$

A regressão linear simples depende de apenas duas variáveis aleatórias $\mathrm{X}$ e $\mathrm{Y}$. Especificando um valor de $\mathrm{X}$, pode-se obter o valor de Y pela reta.

Série temporal é o conjunto de observações ordenadas no tempo, podendo ser discretas ${ }^{16}$ ou contínuas ${ }^{17}$. As observações adjacentes são dependentes. Em geral, os intervalos de tempo entre os registros são equidistantes. Pode-se modelar a série para realizar previsões e gerar séries sintéticas.

Séries temporais normalmente são compostas de uma parte determinística e uma parte estocástica:

$$
X_{t}=d_{t}+\varepsilon_{t}(11)
$$

Onde:

Xt Série temporal

dt Componente determinístico

عt Componente estocástico

O componente determinístico é uma combinação de uma média de longo termo, tendência de crescimento ou decrescimento, periodicidade e saltos. As séries temporais podem não apresentar comportamento puramente determinístico, constituindo um processo puramente estocástico.

\footnotetext{
${ }^{16}$ Conjunto de valores que a variável pode assumir é finito.

${ }^{17}$ Conjunto de valores que a variável pode assumir é infinito.
} 
Figura 24: Tipos de séries temporais

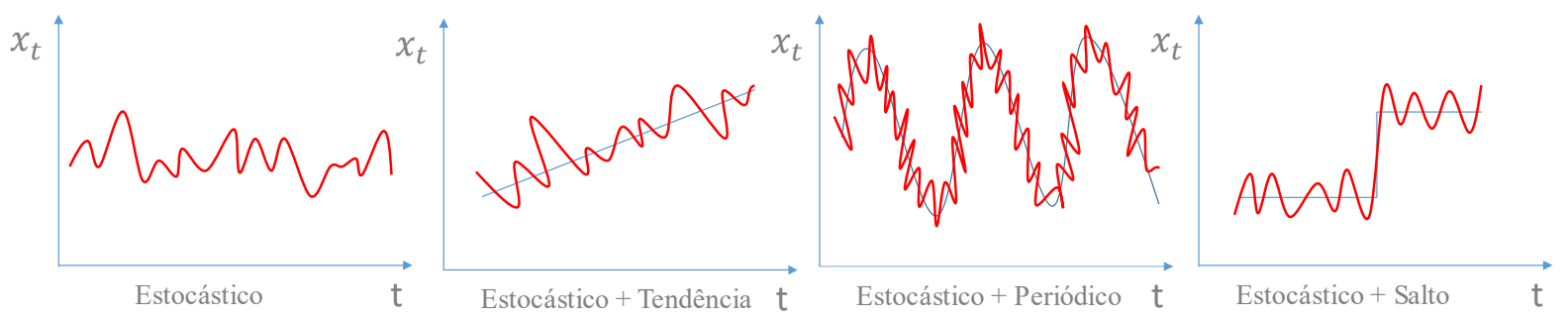

Fonte: Elaboração própria

Uma série sintética é uma série produzida por modelos estocásticos que preserva a propriedade da série original, como média e dispersão dos dados. Cada série sintética tem, usualmente, mesma probabilidade de ocorrer no futuro.

Suposições de série temporal é que seja estacionária, ou seja, se desenvolve no tempo aleatoriamente ao redor de uma média constante. Mas na prática, a maior parte das séries apresentam não estacionariedade, apresentando tendências, sendo um caso que a série flutue ao redor de uma reta com inclinação positiva ou negativa (tendência linear).

Como a maioria das análises estatísticas de séries temporais supõem que sejam estacionárias, é necessário transformar os dados originais, caso não formem uma série estacionária. O mais comum é tomar diferenças sucessivas da série original, até se obter uma série estacionária.

Modelos para descrever séries temporais são processos estocásticos controlados por leis probabilísticas. Um processo estocástico é definido como uma família de variáveis aleatórias definidas em um mesmo espaço de probabilidades.

O primeiro passo em séries temporais é plotar os dados em função do tempo. Principais propriedades podem ser obtidas através de medidas descritivas simples. Exemplos de características presente nas séries: variações sazonais, variações cíclicas, tendências e variações irregulares.

Uma série é estacionária se, a menos das flutuações aleatórias, as observações amostrais não variam com o tempo. As séries não estacionárias podem apresentar saltos bruscos na série temporal, ciclos, ou tendências de crescimentos ou decrescimentos da média. Um teste estatístico 
para avaliar a estacionariedade de uma série é o teste não paramétrico de Spearman. $O$ teste avalia a correlação entre a série e a progressão temporal.

Para uma série com $\mathrm{N}$ dados, define-se o coeficiente rs:

$$
r_{s}=1-\frac{6 * \sum_{t=1}^{N}\left(m_{t}-T_{t}\right)^{2}}{N^{3}-N}(12)
$$

Ordem de classificação $m_{t}$ (1 para o menor valor, 2 para o segundo menor...)

Índice de tempo $T_{t}(1$ para o valor mais antigo a série, 2 para o seguinte e assim sucessivamente até o dado mais recente.

Para $\mathrm{N}>10$

Hipótese $H_{0}$ de que a série não é estacionária, a distribuição pode ser aproximada por uma normal com médias e variâncias:

$$
\begin{aligned}
E\left[r_{s}\right] & =0 \\
\operatorname{Var}\left[r_{s}\right] & =\frac{1}{N-1}(14)
\end{aligned}
$$

A decisão de rejeitar ou não a hipótese é feita com base em T:

$$
T=\frac{r_{s}}{\sqrt{\operatorname{Var}\left[r_{s}\right]}}(15)
$$

A hipótese é rejeitada quando:

$$
|T|>Z_{1}-\frac{\alpha}{2}(16)
$$

Autocovariância

Assumindo o processo estacionário para uma única variável aleatória $\mathrm{X}$ em diferentes períodos de tempo.

$$
\begin{gathered}
\gamma_{k}=\operatorname{Cov}\left(X_{t}, X_{t+k}\right)(17) \\
\gamma_{k}=\in\left[\left(X_{t}-\mu\right)\left(X_{t+k}-\mu\right)\right](18)
\end{gathered}
$$




$$
\gamma_{0}=\sigma_{x}^{2}(19)
$$

Autocorrelação

Mostra a dependência da Variável $X_{t+k}$ em relação a $X_{t}$.

$$
\rho_{k}=\frac{\operatorname{Cov}\left(X_{t}, X_{t+k}\right)}{\sigma X_{t} * \sigma X_{t+k}}=\frac{\gamma_{k}}{\gamma_{0}}(20)
$$

Quando $\mathrm{K}=0, \rho_{0}=1$

Se o processo é estacionário:

$$
\sigma X_{t}=\sigma X_{t+k}(21)
$$

Para uma amostra, a autocovariância é dada por:

$$
\begin{gathered}
C_{k}=\frac{1}{N} * \sum_{t=1}^{n-k}\left(X_{t}-\bar{X}\right) *\left(X_{t+k}-\bar{X}\right)(22) \\
C_{0}=S_{x}^{2}=\sum_{t=1}^{n} \frac{\left(X_{t}-\bar{X}\right)^{2}}{n-1}(23)
\end{gathered}
$$

Para uma amostra, a autocorrelação é dada por:

$$
r_{k}=\frac{C_{k}}{C_{0}}(24)
$$

A autocorrelação indica a memória de um processo estocástico. O gráfico de correlograma $\left(r_{k} X k\right)$ mostra quanto tempo atrás a série "lembra" do que ocorreu em períodos anteriores. Por exemplo, com $\mathrm{k}=12$, está se tratando de um lag de 12 meses por exemplo, identificando que a série depende de um valor de 12 meses atrás, para séries mensais.

A função de auto correlação ou correlograma deve indicar um gráfico conforme Figura 25: 
Figura 25: Exemplo de correlograma

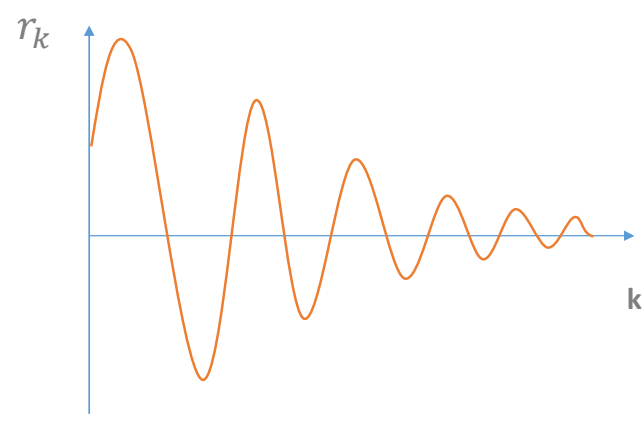

Fonte: Elaboração própria

Se o processo é puramente estocástico, $\rho_{k}$ equivale a zero para todos os valores de k. Como $r_{k}$ é uma estimativa da amostra, os valores não equivalem a zero. Para uma série aleatória, $r_{k}$ tende a uma distribuição normal com média zero e desvio padrão $\frac{1}{\sqrt{N}}$, com $\mathrm{N}$ igual ao número de observações.

Figura 26: Intervalo de confiança

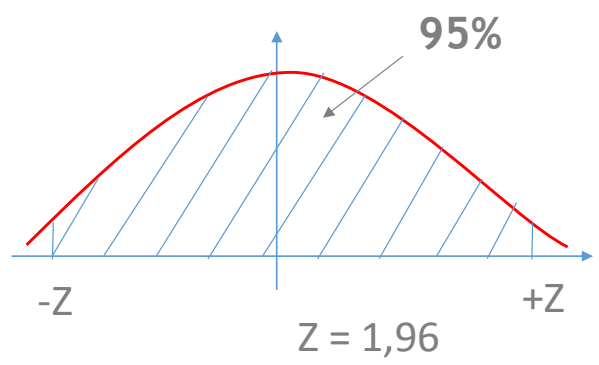

Fonte: Elaboração própria

Com 95\% de confiança:

$$
-\frac{1,96}{\sqrt{N}} \leq r_{k} \leq+\frac{1,96}{\sqrt{N}}(25)
$$

Se rk for maior que esta faixa de valores, este parâmetro é considerado significativo estatisticamente. Caso contrário, se rk ficar dentro da faixa, o processo é puramente estocástico. A Figura 27 mostra um exemplo de um processo puramente estocástico. 
Figura 27: Processo puramente estocástico

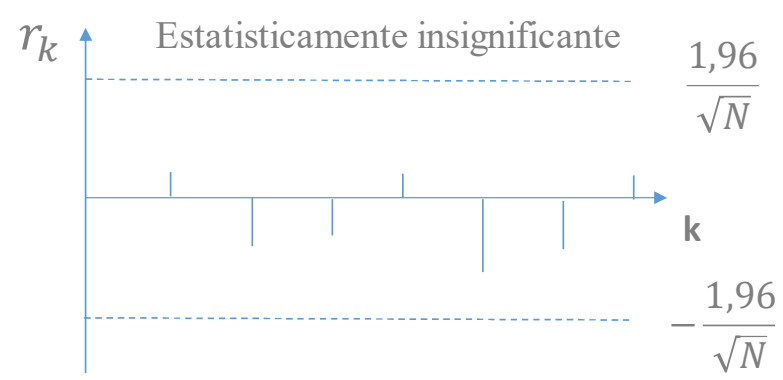

Fonte: Elaboração própria

Já o correlograma seguinte mostra um processo periódico:

Figura 28: Processo periódico

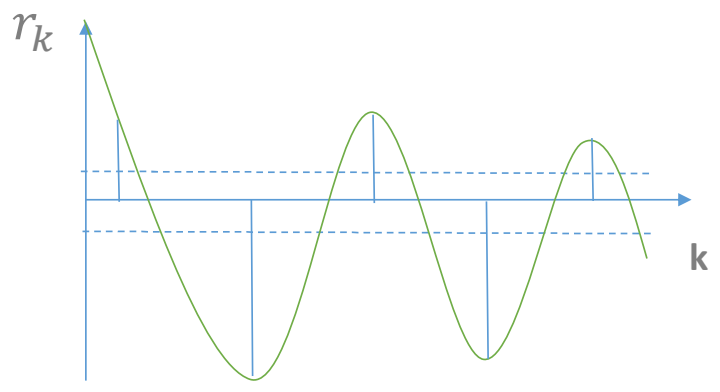

Fonte: Elaboração própria

Periodicidades nos dados podem ser determinadas através de análise da série temporal ou domínio da frequência. O correlograma indica a periodicidade e o espectro indica a significância da periodicidade. Os picos em um diagrama de espectros indicam a periodicidade.

Para o cálculo do espectro utilizam-se as seguintes equações:

$$
f_{k}=\frac{k}{N}(26)
$$

fk: frequência

$$
\begin{aligned}
& \alpha_{k}=\frac{2}{N} \sum_{t=1}^{N} X_{t} \cos \left(2 \pi f_{k} t\right) \\
& \beta_{k}=\frac{2}{N} \sum_{t=1}^{N} X_{t} \sin \left(2 \pi f_{k} t\right)
\end{aligned}
$$




$$
\begin{gathered}
I_{k}=\frac{N}{2}\left[\propto_{k}^{2}+\beta_{k}^{2}\right](29) \\
\omega_{k}=\frac{2 \pi k}{N}(30) \\
P=\frac{2 \pi}{\omega}(31)
\end{gathered}
$$

Abaixo tem-se um diagrama de espectro:

Figura 29: Diagrama de espectro

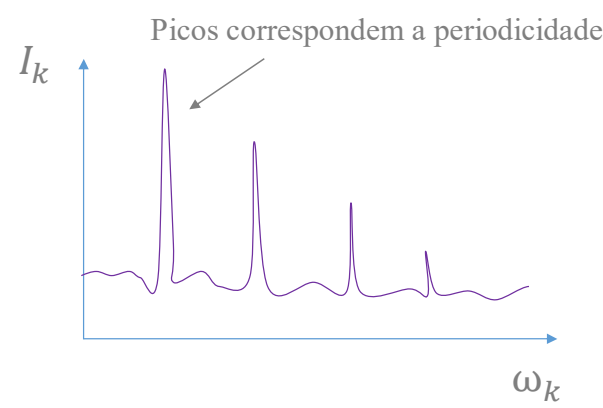

Fonte: Elaboração própria

\subsection{Base de dados}

A principal variável para o levantamento do potencial eólico é a velocidade do vento. Os dados de velocidade de vento têm como base duas fontes:

MERRA: Modern-Era Retrospective Analysis for Research and Applications disponibilizada pela Agência Espacial Americana (NASA); e

VORTEX: Modelo atmosférico de mesoescala online que fornece velocidades de vento para locais onde não existem medições de longo período. 


\subsubsection{Dados do MERRA}

Os dados de magnitude de velocidade de vento do MERRA são horários e disponíveis desde 1980 até 2015. Como não são disponíveis velocidade de vento a 100 metros de altura para o cálculo da geração de energia, utilizou-se os dados de velocidade a 20 e a 50 metros de altura para o cálculo da rugosidade do terreno através da equação:

$$
V=V_{r}\left(\frac{H}{H_{r}}\right)^{n}
$$

Onde:

$\mathrm{V}$ : Velocidade do vento na altura desejada

$V_{r}:$ Velocidade do vento na altura medida

H: Altura desejada

$H_{r}:$ Altura de referência

n: expoente da lei de potência

Tabela 9: Coeficiente de rugosidade para diversos tipos de terreno

\begin{tabular}{lr}
\hline Tipo de Terreno & Coeficiente $\mathbf{n}$ \\
\hline Sem vegetação & 0,10 \\
Grama & 0,12 \\
Cultivado & 0,19 \\
Poucas árvores & 0,23 \\
Muitas árvores, cerca viva ou poucas edificações & 0,26 \\
Florestas & 0,28 \\
Zonas urbanas sem edificações altas & 0,32 \\
\hline
\end{tabular}

Fonte: FADIGAS (2013).

Com os dados disponíveis nestas duas alturas, calculou-se o expoente que determina o fator de rugosidade do terreno. Em seguida, calculou-se para este fator de rugosidade e com os dados em altura e velocidade medidas, a velocidade a 100 metros de altura para as seguintes latitudes e longitudes, dadas na Tabela 10: 
Tabela 10: Latitudes e Longitudes das coordenadas do MERRA

\begin{tabular}{|l|l|r|r|}
\hline Sigla & Nome & Latitude & Longitude \\
\hline CC1 & Coordenada Ceará 1 & 3,5 & 40,625 \\
\hline CC2 & Coordenada Ceará 2 & 3,5 & 39,375 \\
\hline CC3 & Coordenada Ceará 3 & 4,5 & 38,45 \\
\hline CC4 & Coordenada Ceará 4 & 4,5 & 40,625 \\
\hline CC5 & Coordenada Ceará 5 & 4,5 & 39,375 \\
\hline CC6 & Coordenada Ceará 6 & 3 & 41,25 \\
\hline CC7 & Coordenada Ceará 7 & 3 & 40,625 \\
\hline CC8 & Coordenada Ceará 8 & 3 & 40 \\
\hline CRN1 & Coordenada Rio Grande do Norte 1 & 6,5 & 35 \\
\hline CRN2 & Coordenada Rio Grande do Norte 2 & 6 & 36,25 \\
\hline CRN3 & Coordenada Rio Grande do Norte 3 & 5,5 & 36,25 \\
\hline CRN4 & Coordenada Rio Grande do Norte 4 & 5,5 & 35,625 \\
\hline CRN5 & Coordenada Rio Grande do Norte 5 & 6 & 36,875 \\
\hline CRN6 & Coordenada Rio Grande do Norte 6 & 6 & 37,5 \\
\hline CRN7 & Coordenada Rio Grande do Norte 7 & 5 & 37,5 \\
\hline CRN8 & Coordenada Rio Grande do Norte 8 & 5,5 & 37,5 \\
\hline CB1 & Coordenada Bahia 1 & 9,5 & 41,25 \\
\hline CB2 & Coordenada Bahia 2 & 11,5 & 41,25 \\
\hline CB3 & Coordenada Bahia 3 & 10 & 38,75 \\
\hline CB4 & Coordenada Bahia 4 & 9 & 39,375 \\
\hline CB5 & Coordenada Bahia 5 & 14 & 42,5 \\
\hline CB6 & Coordenada Bahia 6 & 11 & 43,75 \\
\hline CB7 & Coordenada Bahia 7 & 12,5 & 38,75 \\
\hline CB8 & Coordenada Bahia 8 & 15 & 39,375 \\
\hline CRS1 & Coordenada Rio Grande do Sul 1 & 29,5 & 50 \\
\hline CRS2 & Coordenada Rio Grande do Sul 2 & 30,5 & 53,75 \\
\hline CRS3 & Coordenada Rio Grande do Sul 3 & 28,5 & 53,75 \\
\hline CRS4 & Coordenada Rio Grande do Sul 4 & 30,5 & 50,625 \\
\hline CRS5 & Coordenada Rio Grande do Sul 5 & 28,8 & 50,625 \\
\hline CRS6 & Coordenada Rio Grande do Sul 6 & 30 & 50,625 \\
\hline CRS7 & Coordenada Rio Grande do Sul 7 & 31,5 & 53,45 \\
\hline CRS8 & Coordenada Rio Grande do Sul 8 & 29 & 53,45 \\
\hline & & & \\
\hline
\end{tabular}

Fonte: MERRA (2016).

\subsubsection{Dados do Vortex}

O Sistema Vortex processa o WRF (Weather Research \& Forecast Model) para micro e macro escala. $\mathrm{O}$ WRF é uma geração numérica para previsão do tempo para finalidade operacional 
e pesquisa atmosférica, fazendo uso de uma ampla variedade de base de dados geofísicas e meteorológicas.

Os dados do Vortex, disponíveis para os estudos no âmbito desta tese, de velocidade de vento horária são desde 1982 até 2014 de 16 coordenadas brasileiras a 100 metros de altura. As coordenadas destes pontos são dadas na Tabela 11:

Tabela 11: Latitude e Longitude das coordenadas do Vortex

\begin{tabular}{|r|l|l|r|r|}
\hline Site & Nome & Estado & Latitude & Longitude \\
\hline 1 & Paracuru & Ceará & 3,423 & 39,043 \\
\hline 2 & Amontada & Ceará & 3,352 & 39,834 \\
\hline 3 & Aracati & Ceará & 4,488 & 37,734 \\
\hline 4 & João Câmara & Rio Grande do Norte & 5,436 & 35,956 \\
\hline 5 & Macau & Rio Grande do Norte & 5,089 & 36,550 \\
\hline 6 & Pedra do Reino & Bahia & 9,487 & 40,880 \\
\hline 7 & Morro do Chapéu & Bahia & 11,537 & 41,158 \\
\hline 8 & Caetité & Bahia & 13,986 & 42,640 \\
\hline 9 & Afrânio & Pernambuco & 8,708 & 41,358 \\
\hline 10 & Araripe & Piauí & 6,817 & 40,660 \\
\hline 11 & Palmar & Rio Grande do Sul & 33,525 & 53,372 \\
\hline 12 & Osório & Rio Grande do Sul & 29,887 & 50,266 \\
\hline 13 & Tramandaí & Rio Grande do Sul & 30,008 & 50,149 \\
\hline 14 & Senandes & Rio Grande do Sul & 32,250 & 52,244 \\
\hline 15 & Coxilha Negra & Rio Grande do Sul & 30,865 & 55,725 \\
\hline 16 & Quilombo & Santa Catarina & 26,727 & 52,725 \\
\hline
\end{tabular}

Fonte: Base de dados Vortex, (WITZLER, 2014).

\subsubsection{Localização geográfica dos dados do MERRA e Vortex}

A partir das latitudes e longitudes das coordenadas das bases MERRA e Vortex, as figuras seguintes mostram as localizações através do software Google Earth.

A Figura 30 mostra a localização das coordenadas do MERRA (CC1 a CC8) e Vortex: Paracuru, Amontada e Aracati 
Figura 30: Localização das coordenadas do Ceará

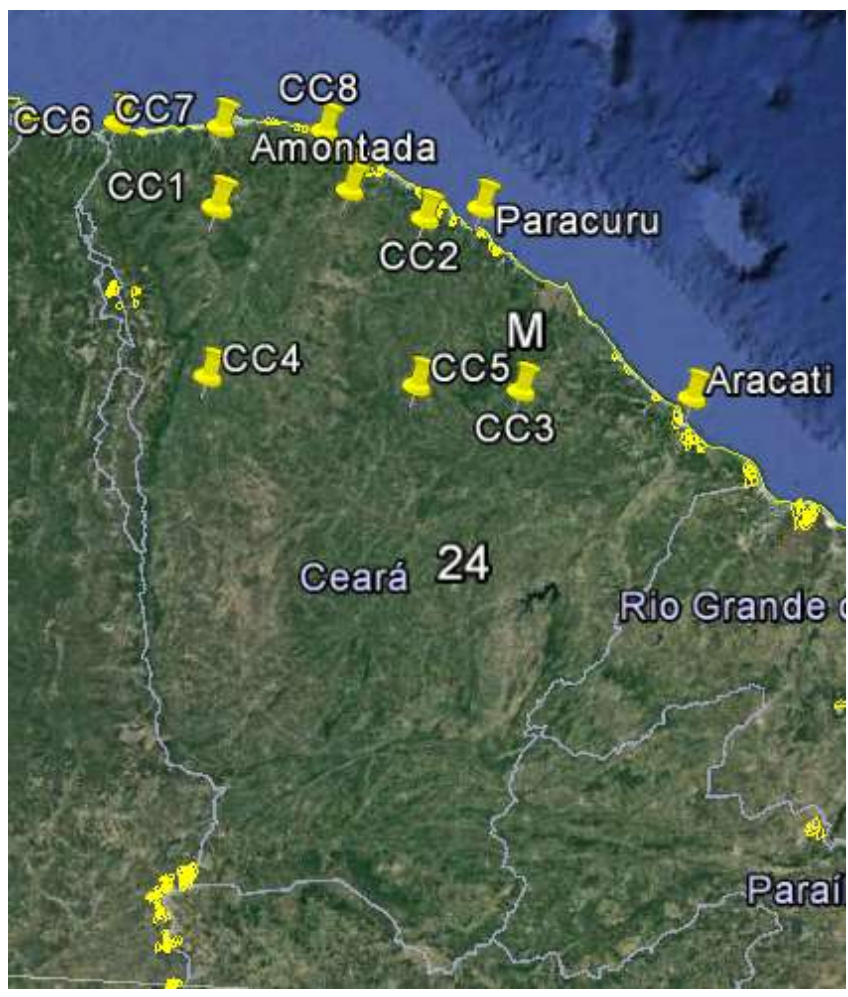

Fonte: Google Earth

A Figura 31 mostra a localização das coordenadas do MERRA (CRN1 a CRN8) e Vortex: João Câmara e Macaú.

Figura 31: Localização das coordenadas do Rio Grande do Norte

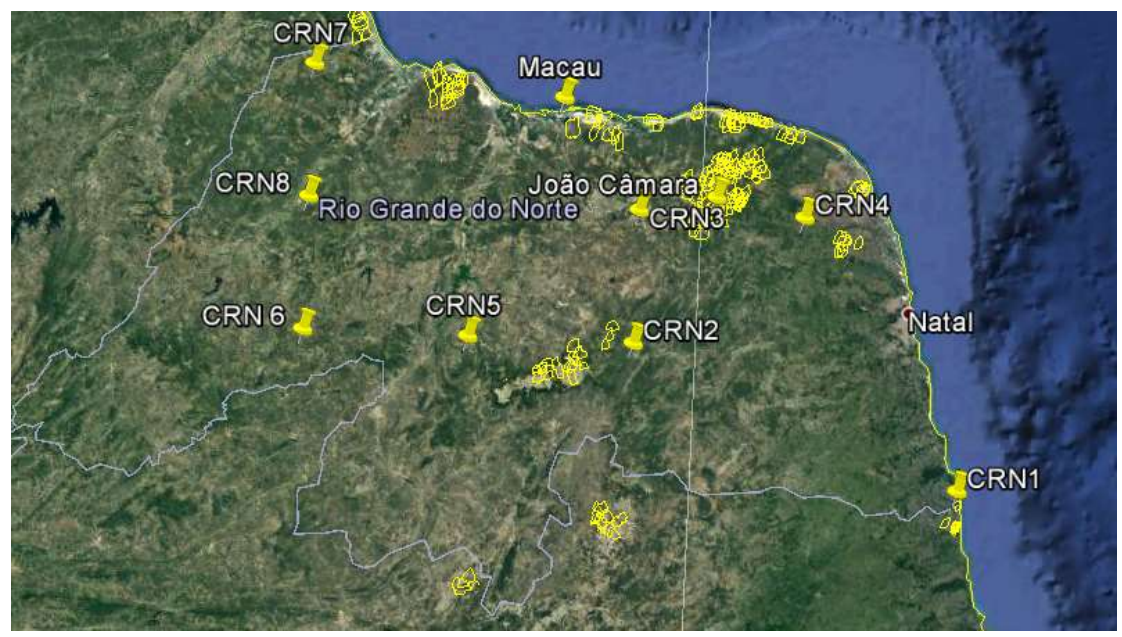

Fonte: Google Earth 
A Figura 32 mostra a localização das coordenadas do MERRA (CB1 a CB8) e Vortex: Pedra do Reino, Morro do Chapéu e Caetité.

Figura 32: Localização das coordenadas da Bahia

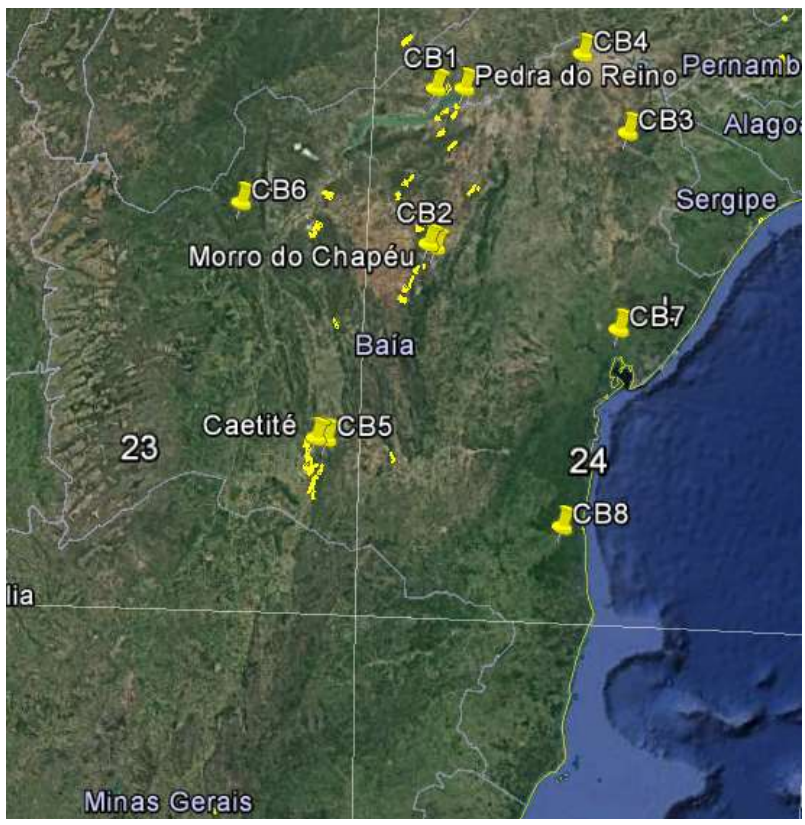

Fonte: Google Earth

A Figura 33 mostra a localização das coordenadas do Vortex: Araripe e Afrânio

Figura 33: Localização das coordenadas de Pernambuco

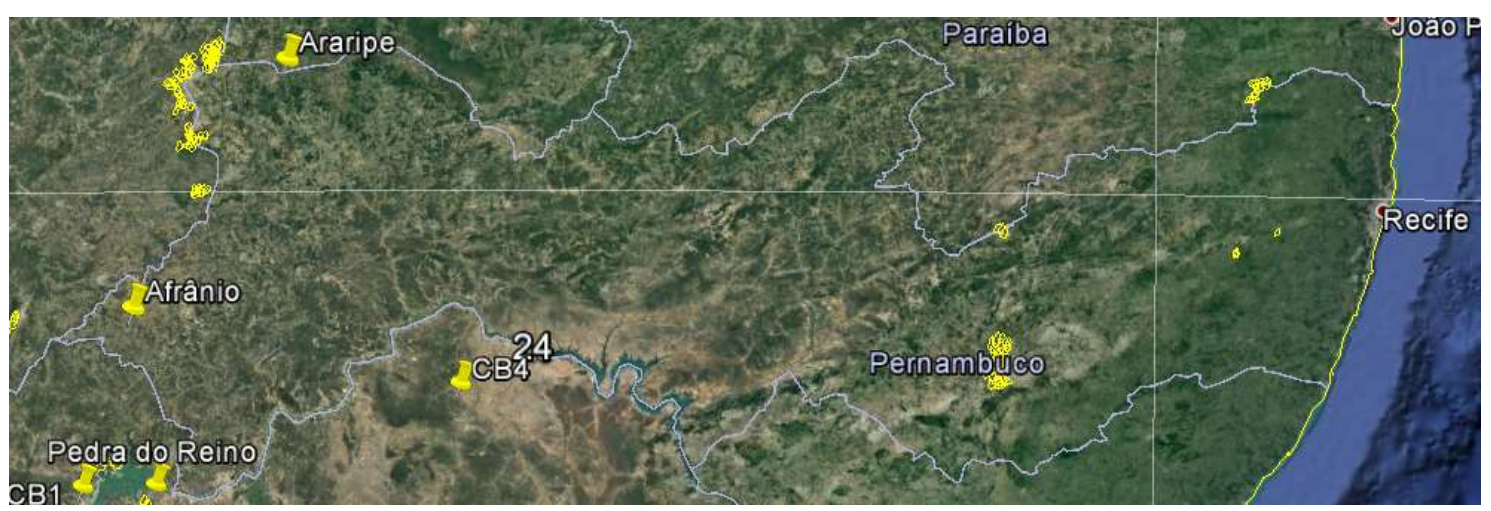

Fonte: Google Earth 
A Figura 34 mostra a localização das coordenadas do MERRA (CRS1 a CB8) e Vortex: Osório, Tramandaí, Estrada de Senandes, Coxilha Negra e Palmar.

Figura 34: Localização das coordenadas do Rio Grande do Sul

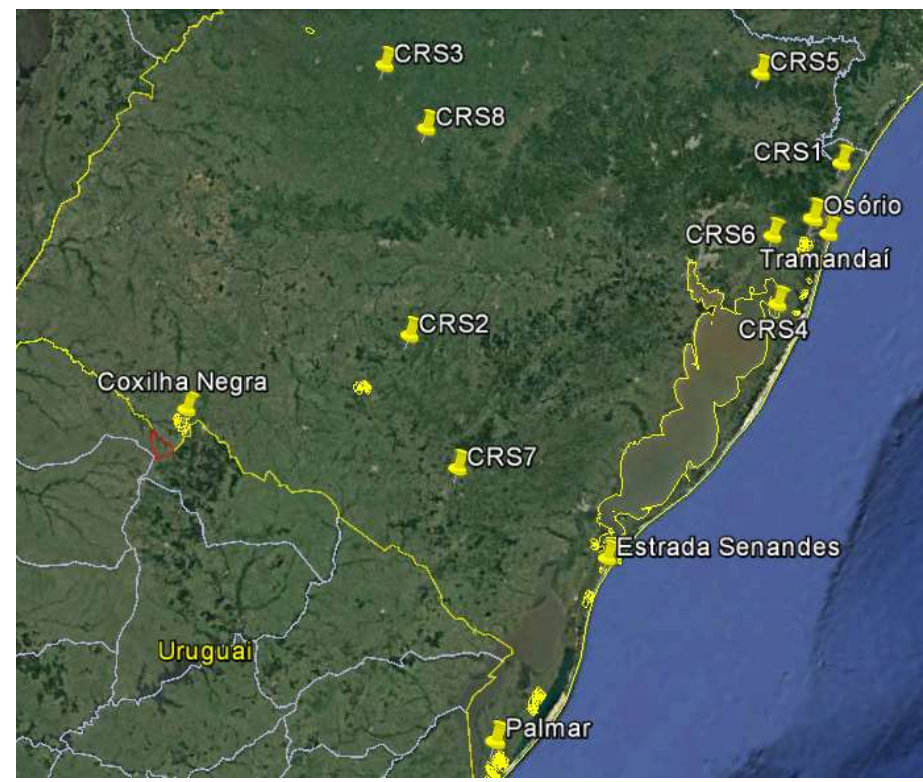

Fonte: Google Earth

A Figura 35 mostra a localização da coordenada do Vortex: Quilombo.

Figura 35: Localização da coordenada de Santa Catarina

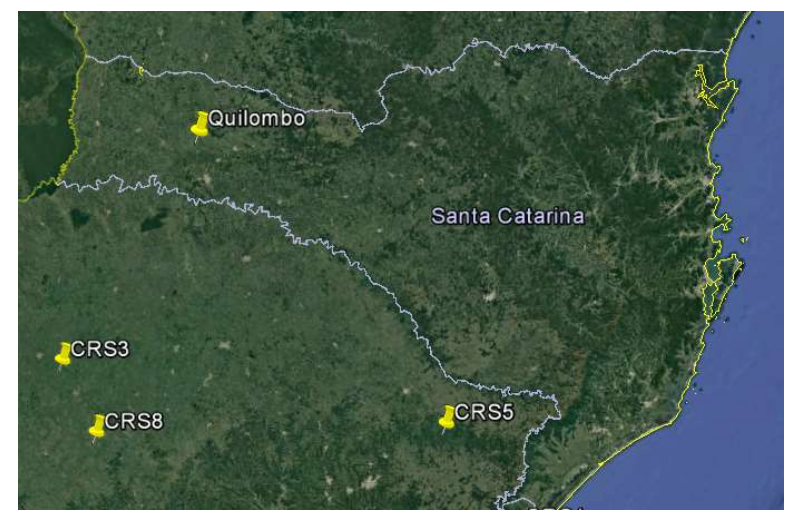

Fonte: Elaboração própria 


\subsubsection{Análise dos dados}

\subsubsection{Boxplot de velocidade mensal dos sites}

Paracuru situa-se no litoral do Ceará, a região possui concentração de parques eólicos principalmente na costa. Analisando-se a periodicidade interanual de Paracuru com os dados de velocidade a 100 metros de altura da base Vortex, verifica-se a sazonalidade na velocidade do vento na Figura 36:

Figura 36: Boxplot da coordenada de Paracuru

\section{Boxplot Paracuru mensal}

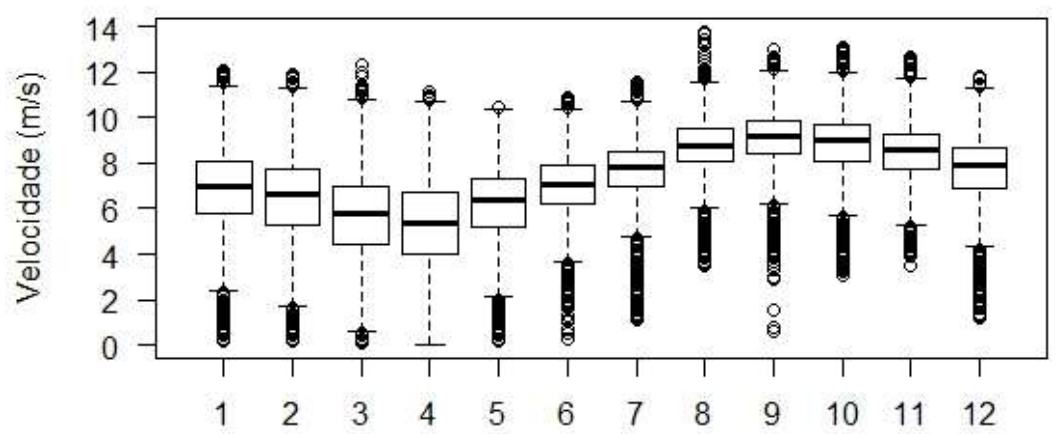

Fonte: Elaboração própria

No Apêndice A estão as sazonalidades de todos os sites da Vortex. Verifica-se através das figuras que no Ceará a sazonalidade entre os sites da Vortex é semelhante, com maior potencial de geração eólica no segundo semestre, com as maiores velocidades entre agosto e novembro. As velocidades máximas ficam em torno de $15 \mathrm{~m} / \mathrm{s}$.

Os diagramas de boxplot do Rio Grande do Norte são parecidos com os do Ceará, com maior velocidade entre agosto e novembro. Já os diagramas da Bahia apresentam bastante variabilidade entre si, com maiores variações de velocidade dentro do mês.

As coordenadas de Pernambuco apresentam sazonalidade definida, com maior potencial de geração eólica entre julho e outubro. 
No Sul a sazonalidade não é definida, todos os meses apresentam medianas semelhantes e os picos de velocidades são maiores do que no Nordeste, atingindo cerca de $30 \mathrm{~m} / \mathrm{s}$ de velocidade máxima.

Esta análise mostra que com dados elevados de velocidade de vento no segundo semestre dos anos no Nordeste, há complementaridade com a geração hidráulica, uma vez que é menor no segundo semestre dos anos. Já no Sul, isso não ocorre, uma vez que não há variação definida das velocidades do vento durante os meses dos anos.

\subsubsection{Boxplot entre as coordenadas Vortex}

Analisando-se as diferentes coordenadas do Vortex, verificou-se que o site Paracuru, em relação as coordenadas do Ceará (Amontada e Aracati), representa variação semelhante. A mediana é próxima principalmente com relação a Amontada e a variação dos dados também é semelhante.

Verifica-se através da Figura 37 que as coordenadas da Bahia (Pedra do Reino, Morro do Chapéu e Caetité) apresentam variabilidade entre si, como também as de Pernambuco (Afrânio e Araripe). Novamente pode se observar a variabilidade das coordenadas do Sul e os picos de velocidades de vento. Quilombo em Santa Catarina apresenta a menor mediana entre as coordenadas, mas atinge picos de $20 \mathrm{~m} / \mathrm{s}$. 
Figura 37: Diagrama de Boxplot das coordenadas do Vortex

\section{Boxplot Coordenadas Vortex}

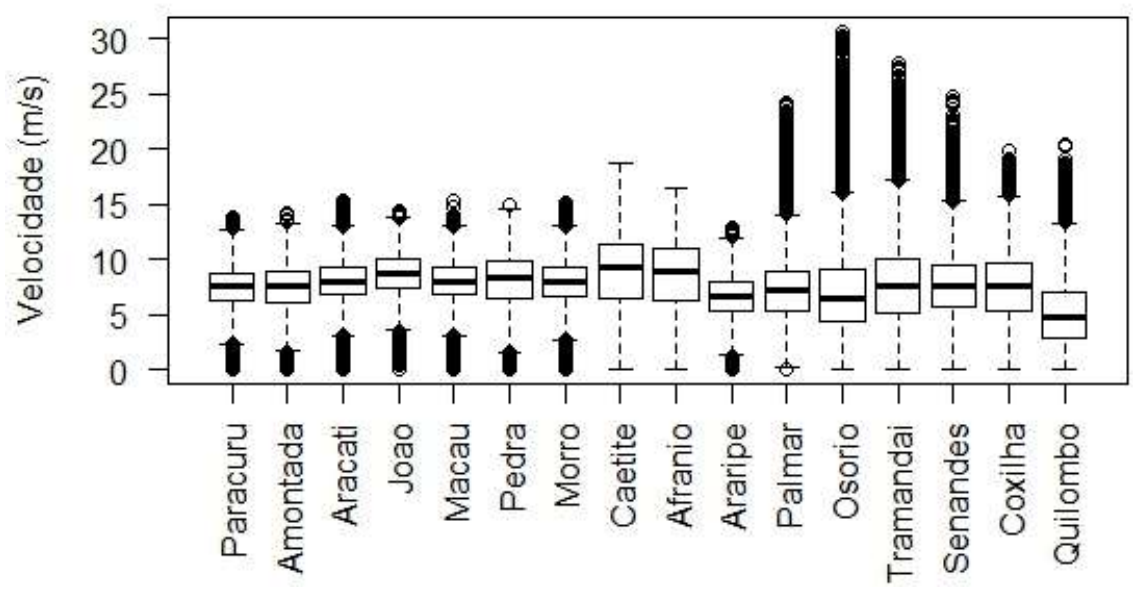

Fonte: Elaboração própria

\subsubsection{Correlação entre bases}

Considerando-se a correlação entre as coordenadas, a correlação de Paracuru é de 0,85 com Aracati e 0,92 com Amontada. Combinando-se base de dados diferentes, a maior correlação é com as coordenadas 7 e 8 , com correlação em 0,62 e 0,66, respectivamente. As coordenadas 7 e 8 , assim como Paracuru se encontram no litoral Cearense.

Figura 38: Correlação entre as coordenadas do Ceará com base MERRA e Vortex

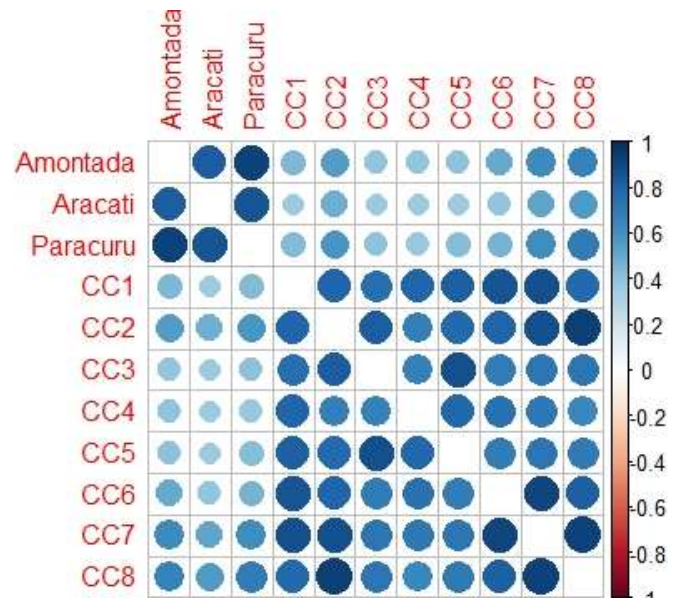

Fonte: Elaboração própria 
As correlações entre as coordenas do Rio Grande do Norte da Vortex são altas entre si, mas diminuem quando comparadas com os valores da base MERRA. No caso da Bahia, não há alta correlação nem dentro da mesma base, mostrando grande variabilidade entre os dados. Já entre as coordenadas do Rio Grande do Sul, as correlações são altas entre Tramandaí e Osório e entre as coordenadas do MERRA, são altas entre CRS8 com CRS3 e CRS6 com CRS4.

Figura 39: Correlação entre as bases Vortex e MERRA

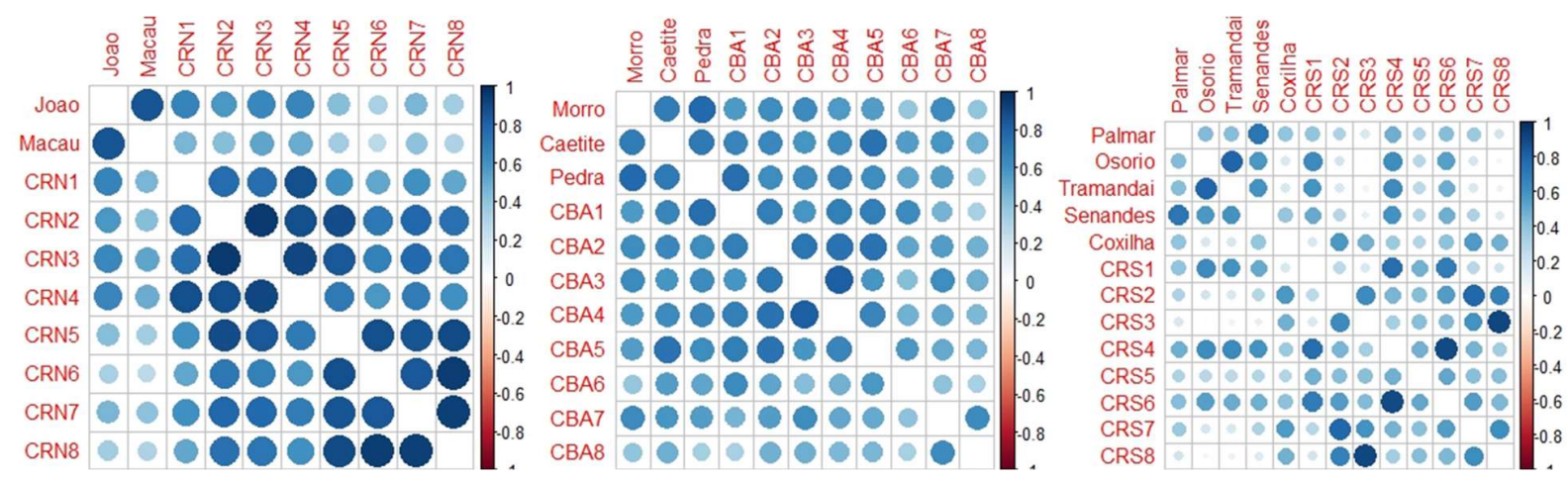

Fonte: Elaboração própria

O objetivo de se analisar as duas bases de dados era de aumentar a quantidade de sites do trabalho, apresentando uma maior abrangência entre as "bacias eólicas". No entanto, dado que as correlações entre as coordenadas das duas bases não representaram altos valores, mostrando-se independência entre si na maioria dos casos, este trabalho considera para a inserção dos dados no Newave, a base de dados de velocidade de vento proveniente da base do Vortex. Sugere-se em trabalhos futuros, uma análise de coordenadas de diferentes bases e de dados reais de anemômetros, a fim de se aumentar a confiabilidade do estudo.

\subsubsection{Histograma das velocidades}

A distribuição de Weibull ajustada nos dados de velocidade da coordenada de Paracuru: 
Figura 40: Histograma de Paracuru e ajuste da distribuição de Weibull

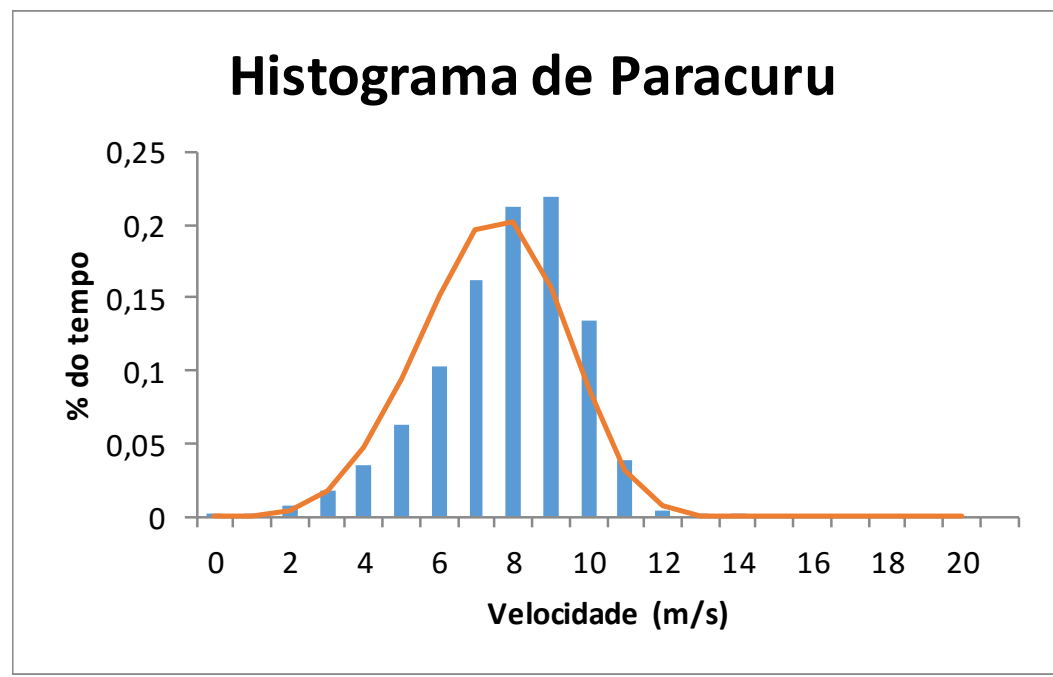

Fonte: Elaboração própria

O Apêndice B mostra o histograma de todas as coordenadas da base Vortex. As coordenadas do Ceará e Rio Grande do Norte apresentam histograma semelhante. A Bahia e Pernambuco apresentam variações. No Sul, apesar de apresentar as maiores velocidades de pico, estas ocorrem poucas vezes, sendo que as menores velocidades ocorrem mais vezes, mostrando um dos motivos do fator de capacidade do Sul ser menor do que no Nordeste.

\subsubsection{Geração eólica}

A partir dos dados de velocidade horária das coordenadas da base do Vortex, calculou-se através da curva da turbina GE de potência nominal de $2.300 \mathrm{~kW}$ e diâmetro do rotor de 94 metros encontrada no catálogo do software (windPRO 2.9, 2015), identificada na Figura 41, a energia gerada em cada velocidade com a turbina.

A função polinomial da curva de potência para energia é a seguinte:

$$
y=0,0462 x^{6}-2,1484 x^{5}+39,016 x^{4}-355,22 x^{3}+1743,9 x^{2}-4313,3 x+
$$

$4173,1(33)$

Onde:

$\mathrm{x}$ : velocidade do vento $\mathrm{em} \mathrm{m} / \mathrm{s}$ 
y: energia em Wh

Figura 41: Curva de potência da turbina eólica

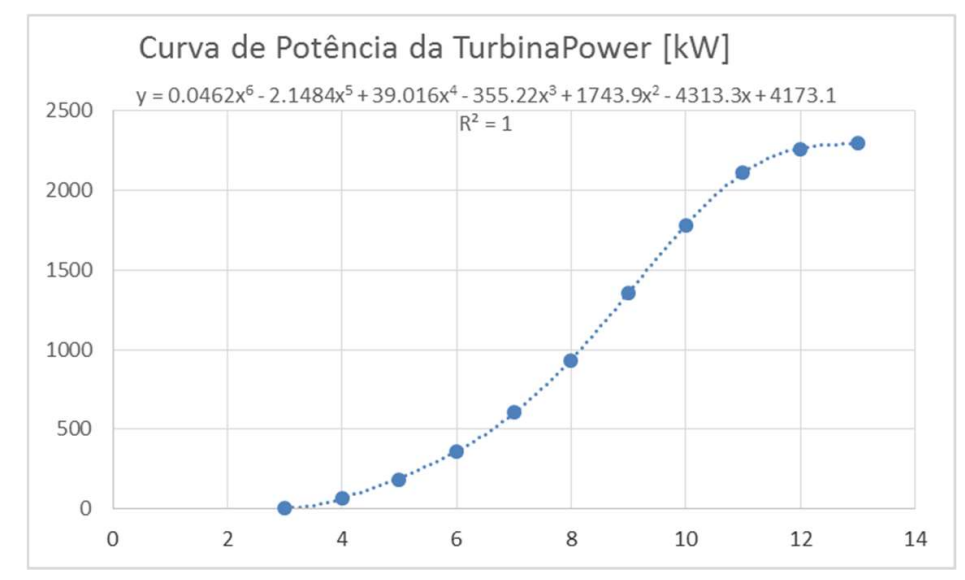

Fonte: Elaboração própria com base no windPRO 2.9, 2015

Para as velocidades menores do que $3 \mathrm{~m} / \mathrm{s}$ e maiores do que $25 \mathrm{~m} / \mathrm{s}$ foram consideradas gerações de energia nulas, para as velocidades entre $12 \mathrm{~m} / \mathrm{s}$ e $25 \mathrm{~m} / \mathrm{s}$, a geração considerada foi a máxima de $2.300 \mathrm{KWh}$. Em seguida, a partir dos dados horários de geração de energia, foi realizada uma média mensal de geração para a turbina considerada em cada uma das coordenadas.

A série temporal do potencial de geração de energia eólica da coordenada de Paracuru é apresentada na Figura 42.

Figura 42: Série temporal da geração eólica em Paracuru

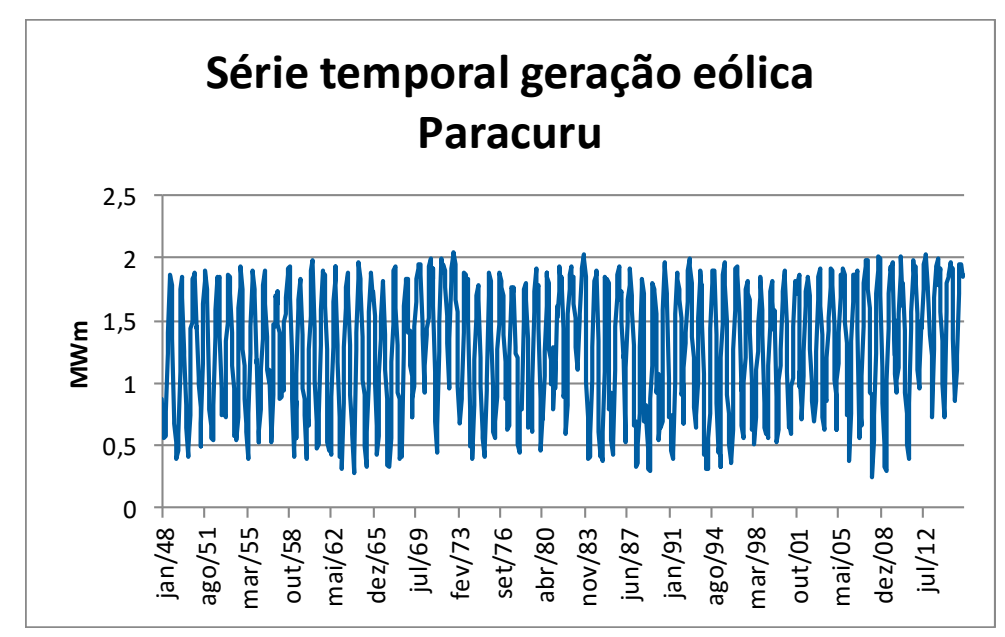

Fonte: Elaboração própria 
A Figura 43 mostra o correlograma da coordenada de Paracuru e verifica-se que existe uma periodicidade nos dados e que estão além dos limites de significância.

Figura 43: Correlograma de Paracuru

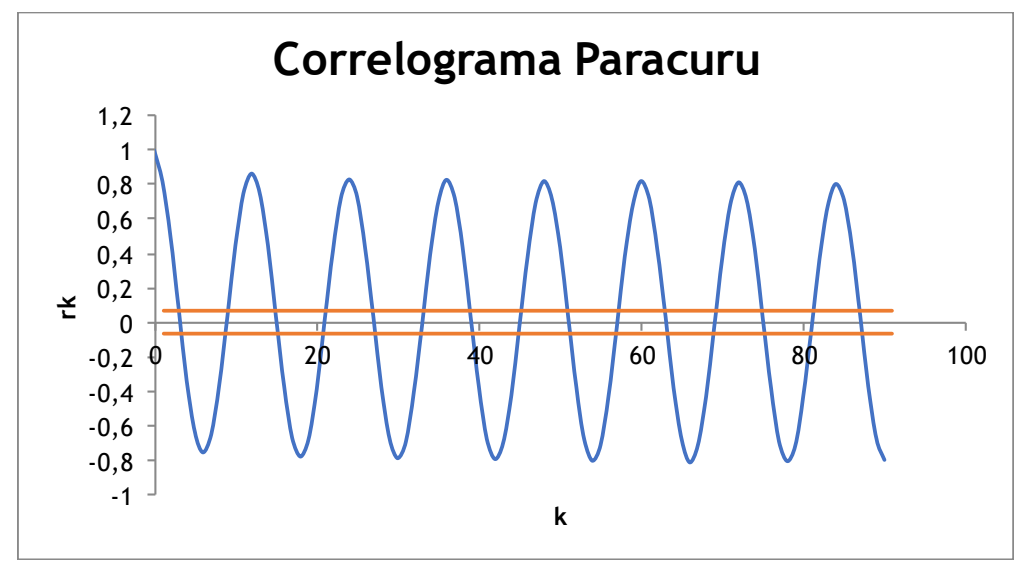

Fonte: Elaboração própria

A Figura 44 mostra o espectro no domínio da frequência. Verifica-se um pico para Ik de 168, o que equivale a uma periodicidade de 12 meses.

Figura 44: Espectro de Paracuru

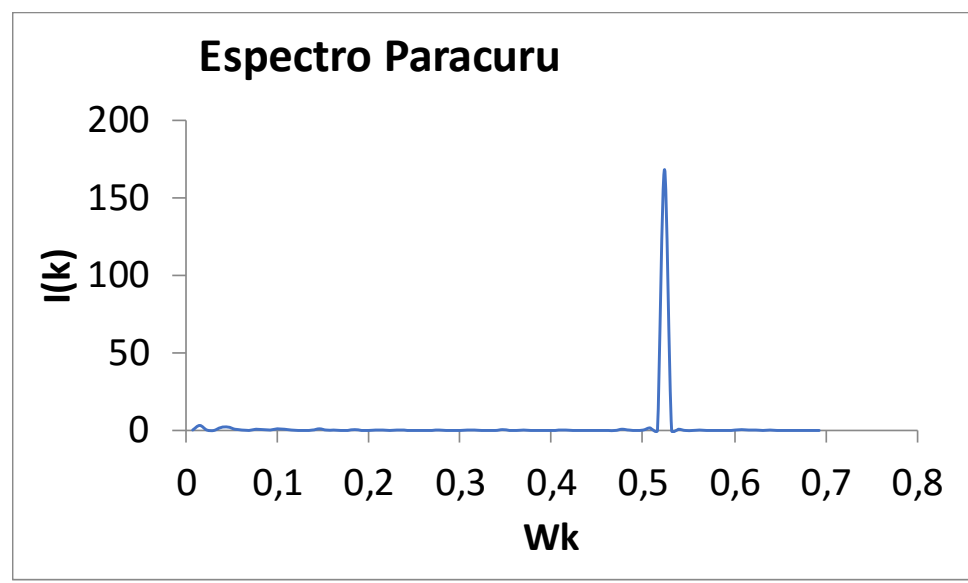

Fonte: Elaboração própria

$\mathrm{Na}$ análise desta primeira coordenada foi confirmada a periodicidade anual. O Apêndice $\mathrm{C}$ mostra os espectros para as demais coordenadas, sendo que todas apresentaram periodicidade de 12 meses. 


\subsection{Metodologia de reconstrução da base de velocidade de vento}

A metodologia da reconstrução das séries históricas de dados de velocidade de vento e geração de energia eólica teve como base o trabalho de (WITZLER, 2014). Para isso, utilizou-se duas bases de dados: Vortex e NOAA, uma vez que esta última apresenta valores desde 1948.

A base de dados do Vortex contempla a magnitude da velocidade de vento de hora em hora para os anos de 1982 a 2014 (em alguns sites utilizou-se base até 2015 ou 2016) de 10 em 10 metros de altura, com início em 50 metros até 150 metros. A base de dados do NOAA apresenta valores de velocidade de vento diária de 1948 a 2010 a 10 metros de altura.

As séries foram transformadas para uma mesma base de comparação, considerando os anos comuns nas duas séries, sendo esses os anos de 1982 a 2010. Além disso, os dados da base Vortex foram transformados em valores de médias diárias. Com as bases paralelas, foi possível estabelecer uma análise comparativa entre as séries NOAA e Vortex. Foram consideradas todas as séries com correlação maior do que 0,8 .

Em seguida fez-se a extrapolação vertical, passando da velocidade a 10 metros do NOAA para a velocidade à altura do rotor do aerogerador utilizado, que é de 120 metros (a partir deste momento, é considerada esta altura na tese). Para isso, utilizou-se a série horária de velocidade de vento da base Vortex para as alturas de 50 metros a 150 metros, sendo então calculado o gráfico e a equação que descreve a variação da velocidade de vento com o aumento da altura, conforme Figura 45. Após a determinação da curva, calculou-se o fator de extrapolação para transformar os valores a 10 metros do NOAA em 120 metros.

$$
\alpha=\frac{v(120)-\left(v(10)-\overline{v_{N O A A}}\right)}{\overline{v_{N O A A}}}(34)
$$

Onde:

$\alpha$ : Fator de extrapolação

$v(h)$ : Velocidade do Vortex em função da altura

$\overline{v_{N O A A}}:$ Velocidade média do NOAA a 10 metros 
Figura 45: Curva logarítmica da velocidade horária do Vortex e a altura

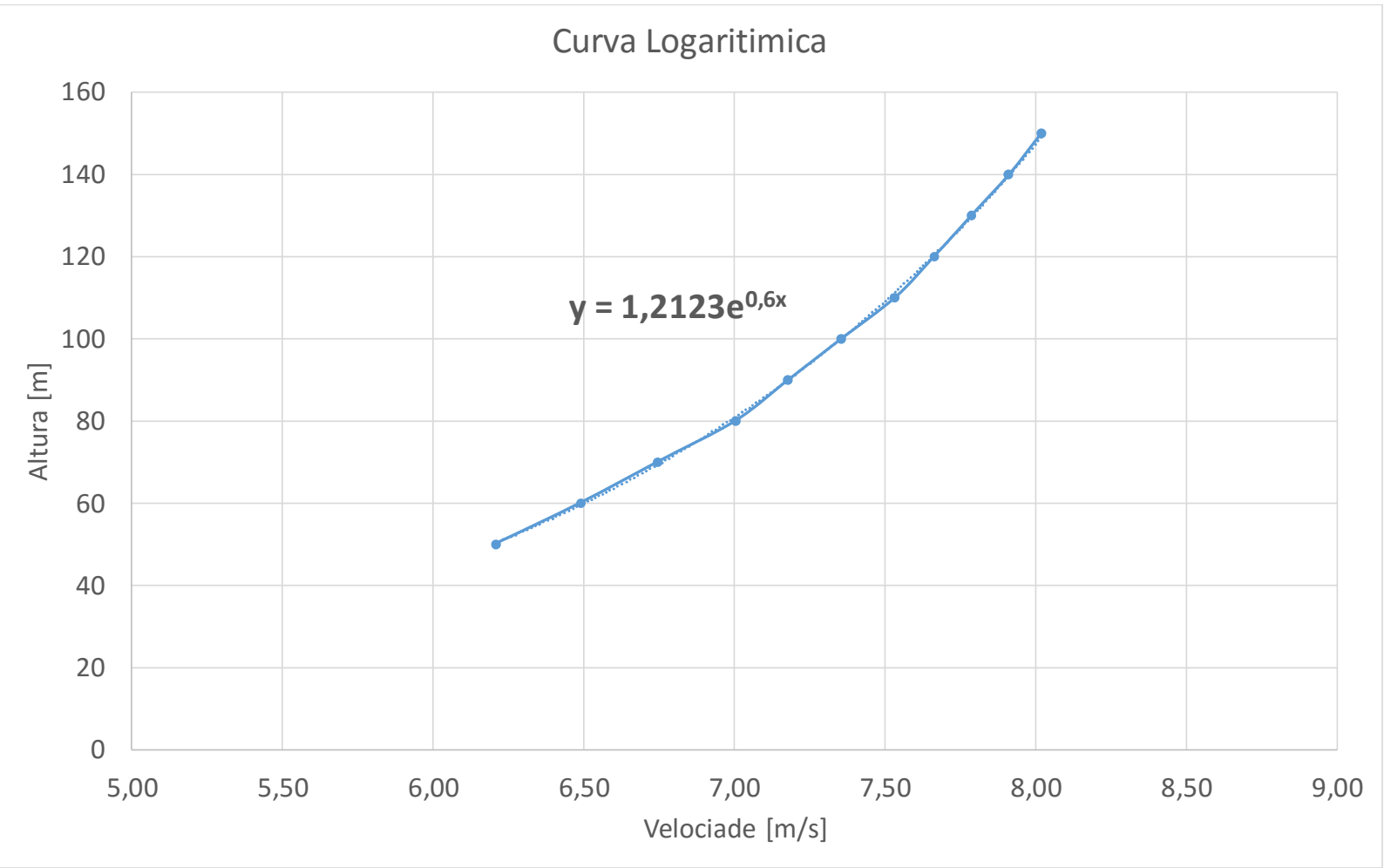

Fonte: WITZLER, 2014

Em seguida, determinou-se o desvio padrão típico $\left(\sigma_{m}\right)$ por mês da base Vortex e com base nos valores de velocidades médias horárias $\left(V_{m}\right)$ plotou-se a distribuição de Weibull $p_{m}(v)$ para cada mês, considerando-se os 30 meses do histórico.

$$
\begin{gathered}
k_{m}=\left(\frac{\sigma_{m}}{\overline{V_{m}}}\right)^{-1,086}(35) \\
\frac{c_{m}}{\overline{V_{m}}}=\left(0,568+\frac{0,433}{k_{m}}\right)^{-\frac{1}{k_{m}}}(36) \\
p_{m}(v)=\left[\frac{k_{m}}{c_{m}}\right] *\left(\frac{v}{c_{m}}\right)^{k_{m}-1} * e^{-\left(\frac{v}{c_{m}}\right)^{k_{m}}}(37)
\end{gathered}
$$

A partir das 12 curvas de Weibull com a base Vortex, uma para cada mês, construiu-se a distribuição de Weibull conforme Figura 46, para cada dia da série do NOAA, com base na sua velocidade diária e na distribuição do Vortex. 
Figura 46: Distribuição de Weibull

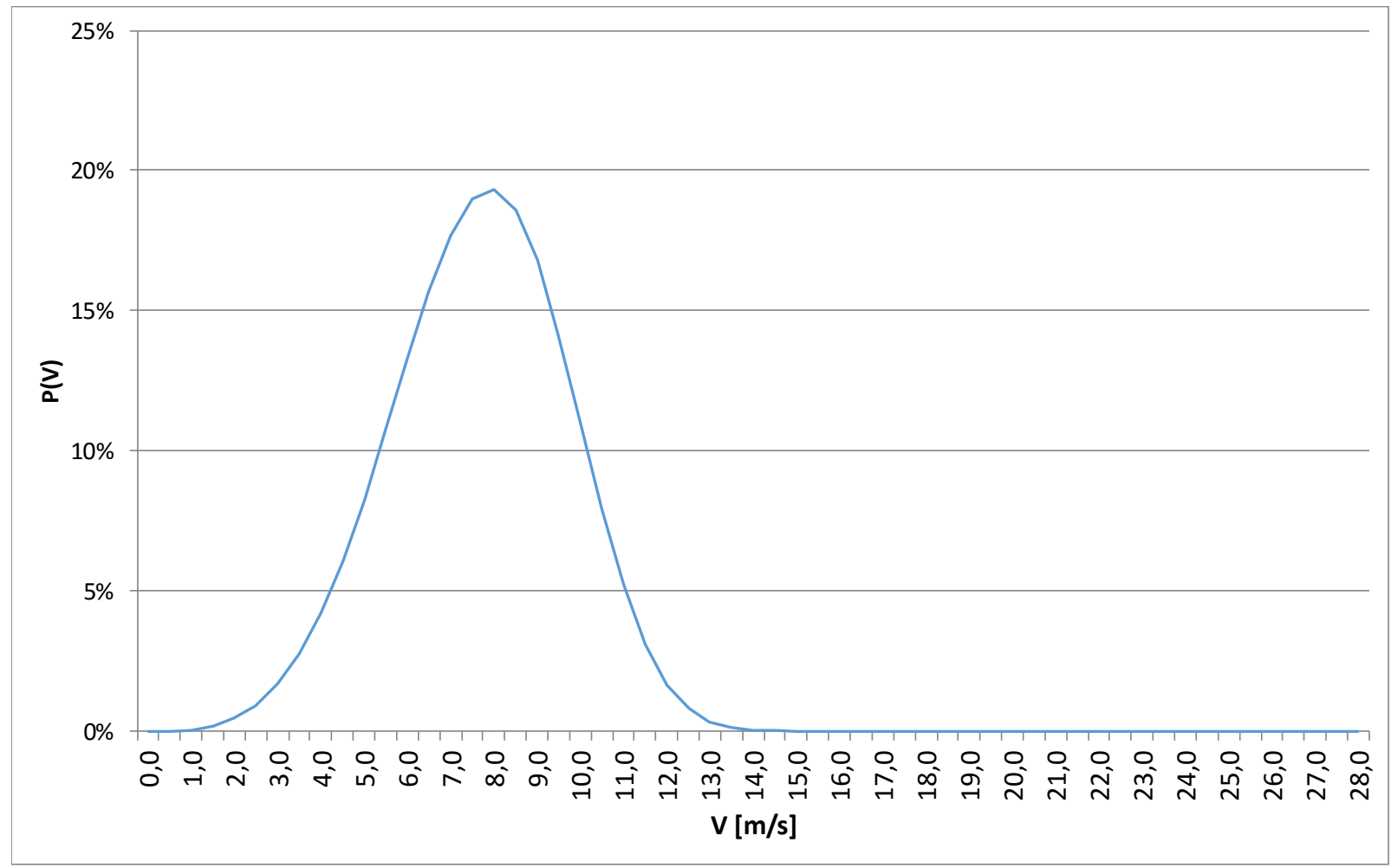

Fonte: WITZLER, 2014

Para cada distribuição de Weibull diária de 1948 a 2010, calculou-se a energia diária gerada com a potência da turbina escolhida para cada site.

$$
E_{\text {gerada }}=\sum_{1}^{24} p_{d}(v) * \operatorname{Pot}_{\text {turbina }}(v)(38)
$$

Onde:

$p_{d}(v):$ Distribuição diária de Weibull

$\operatorname{Pot}_{\text {turbina }}(v)$ : Curva de Potência da turbina em função da velocidade

Como a velocidade de vento do NOAA desde 1948 é mensal, precisou-se da curva de Weibull para transformar os dados em base horária. Esta premissa simplificadora foi adotada pela indisponibilidade de dados horários, mas apresenta uma limitação do trabalho, uma vez que a distribuição de Weibull deixa de fora alguns valores devido as aproximações, podendo perder os valores extremos. 
A Figura 47 mostra exemplos de curvas de turbina utilizadas na análise:

Figura 47: Curvas de potência de turbinas

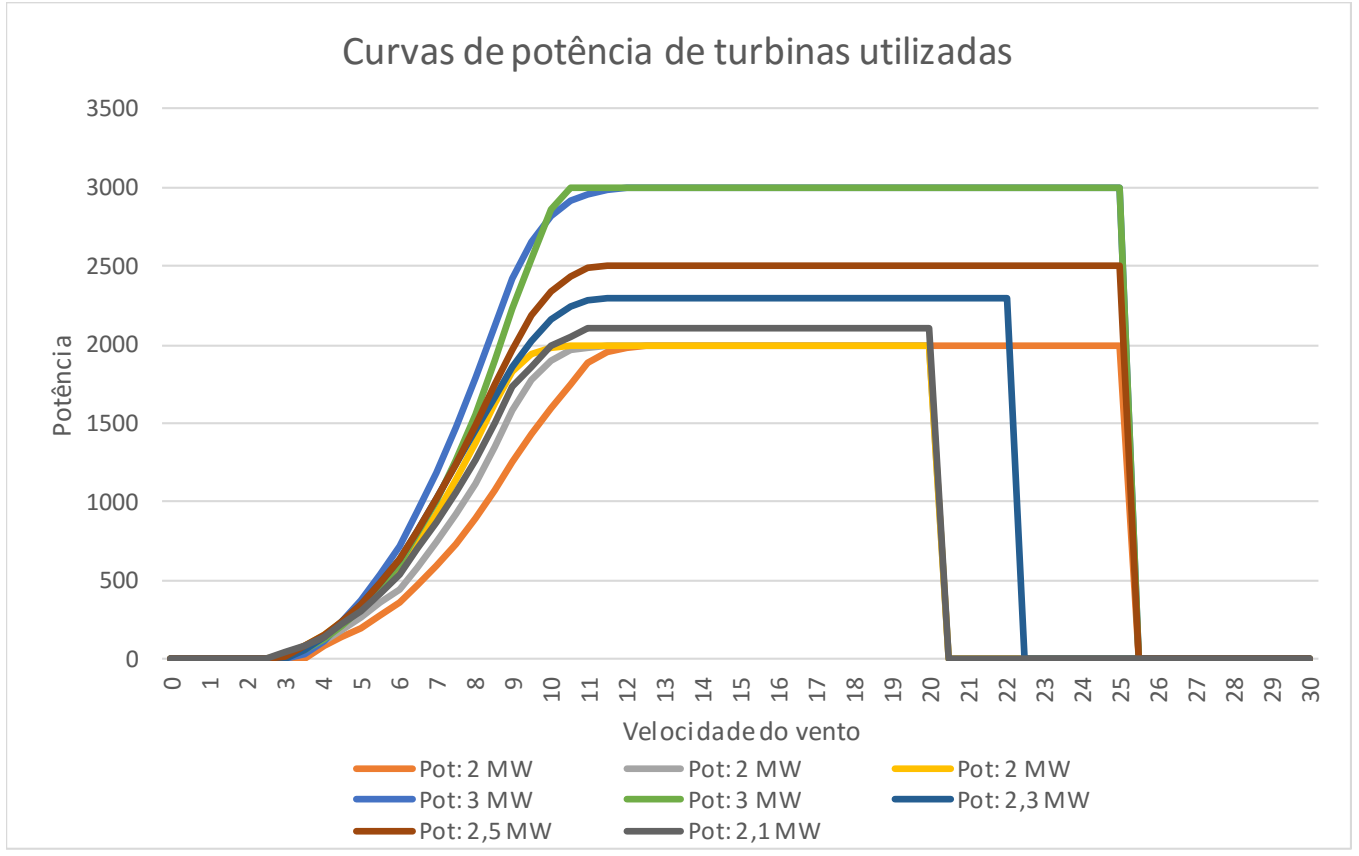

Fonte: WITZLER, 2014

As curvas de turbinas consideradas no trabalho são otimizadas, ou seja, foram consideradas as curvas que apresentaram o maior fator de capacidade por região. A adoção desta premissa se justifica pela indisponibilidade de curvas de turbinas reais utilizadas no Brasil à ocasião da elaboração deste documento.

Com base nos valores de geração diária em MWh, fez-se uma soma de todos os dias do mês para transformar em dados mensais. 


\section{INSERÇÃO DA GERAÇÃO EÓLICA ESTOCÁSTICA}

\subsection{Usinas não simuladas}

Conforme mencionado anteriormente, a geração das pequenas usinas (PCHs, eólicas e biomassas), também denominadas como usinas não simuladas, são abatidas da carga a ser atendida pelo Newave para em seguida acontecer a otimização hidrotérmica do sistema. Os valores abatidos da carga são determinísticos, considerando-se implicitamente que a geração média de cada mês ocorrerá ao longo de todo o período de simulação, considerando dessa forma a estratégia de despacho pela geração média mensal. A geração determinística é feita pelo Operador Nacional do Sistema, com base na geração dos últimos 5 anos das respectivas fontes, em cada submercado, considerando-se também a expansão da oferta do sistema. A inserção da geração eólica estocástica no Newave tem como benefício suprir uma deficiência na metodologia atualmente empregada, representando a variabilidade da fonte eólica e a complementaridade da hidráulica com a eólica no Nordeste do Brasil.

Em relação a região Nordeste, a geração eólica representa em média $92 \%$ das usinas não simuladas, dados do PMO de agosto de 2016. A Figura 48 mostra esta relação durante os 5 anos de estudo:

Figura 48: Geração eólica e total das usinas não simuladas no Nordeste

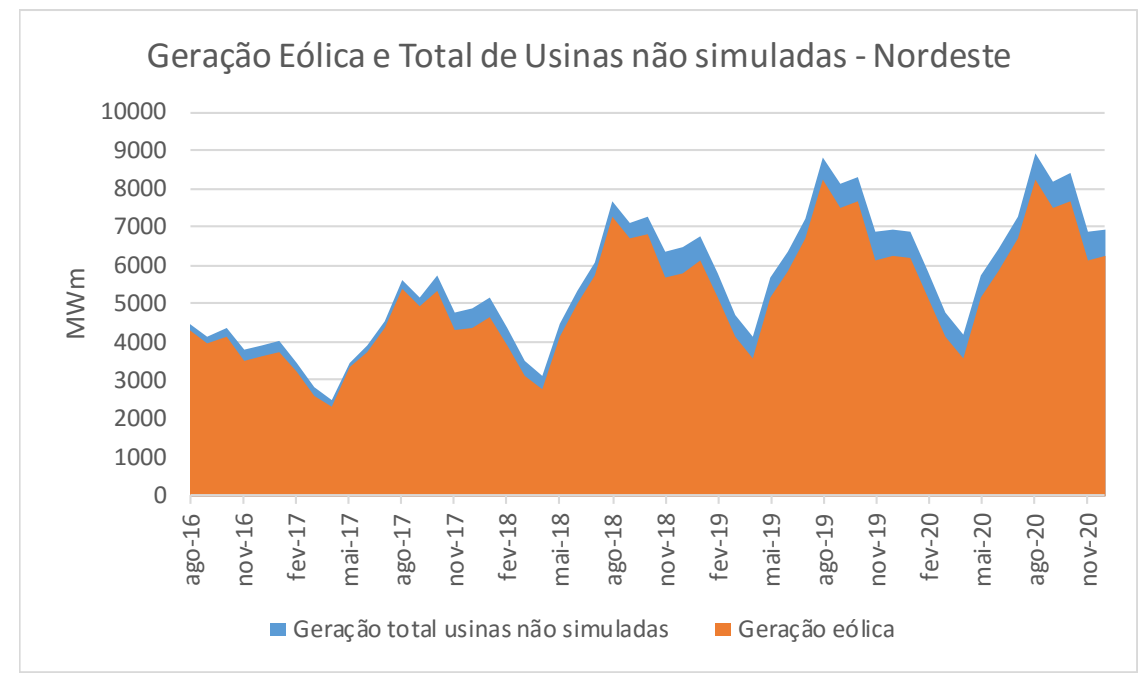

Fonte: Elaboração própria, base CCEE 2016 
Da mesma forma, considerando-se para a região Sul, as eólicas representam em média 34\% da geração das usinas não simuladas, conforme Figura 49:

Figura 49: Geração eólica e total das usinas não simuladas no Sul

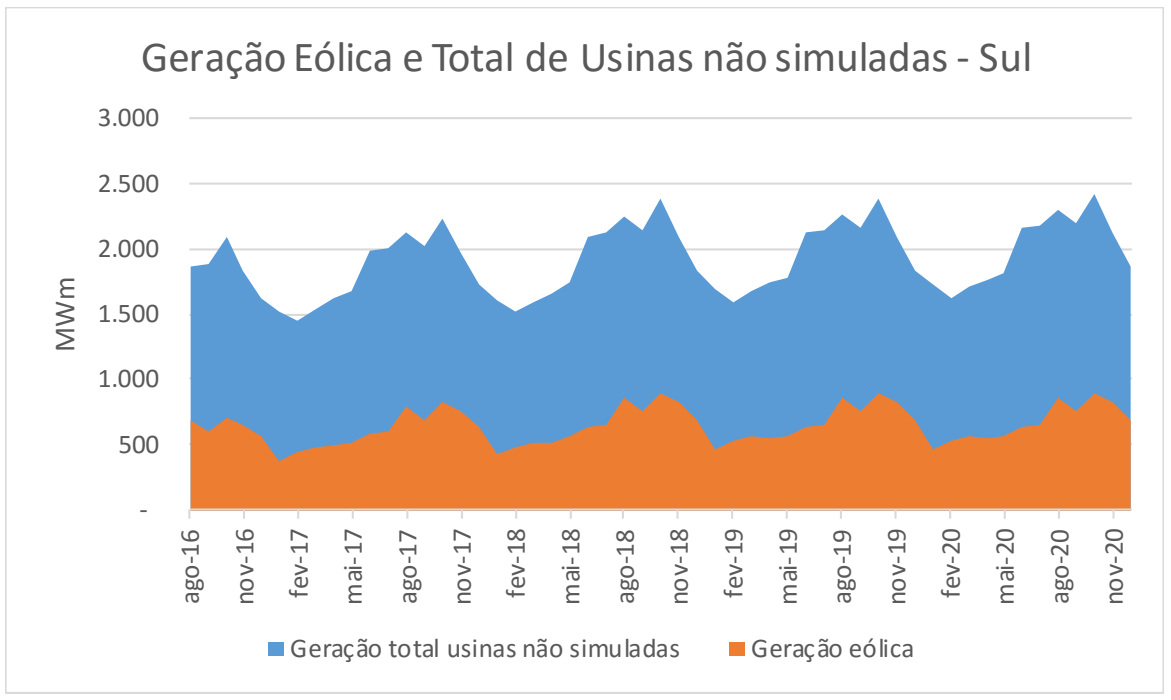

Fonte: Elaboração própria, base CCEE 2016

Estes valores de geração eólica determinística foram excluídos dos dados de entrada do programa, para fins deste estudo, na medida em que, no momento seguinte, se considerou a reinserção dessa capacidade de produção através das usinas hidráulicas a fio d' água.

Os valores médios anuais são dados na Figura 50 e Figura 51, para o Nordeste e Sul, respectivamente: 
Figura 50: Geração anual eólica e total das usinas não simuladas no Nordeste Média anual das gerações no Nordeste das usinas não simuladas

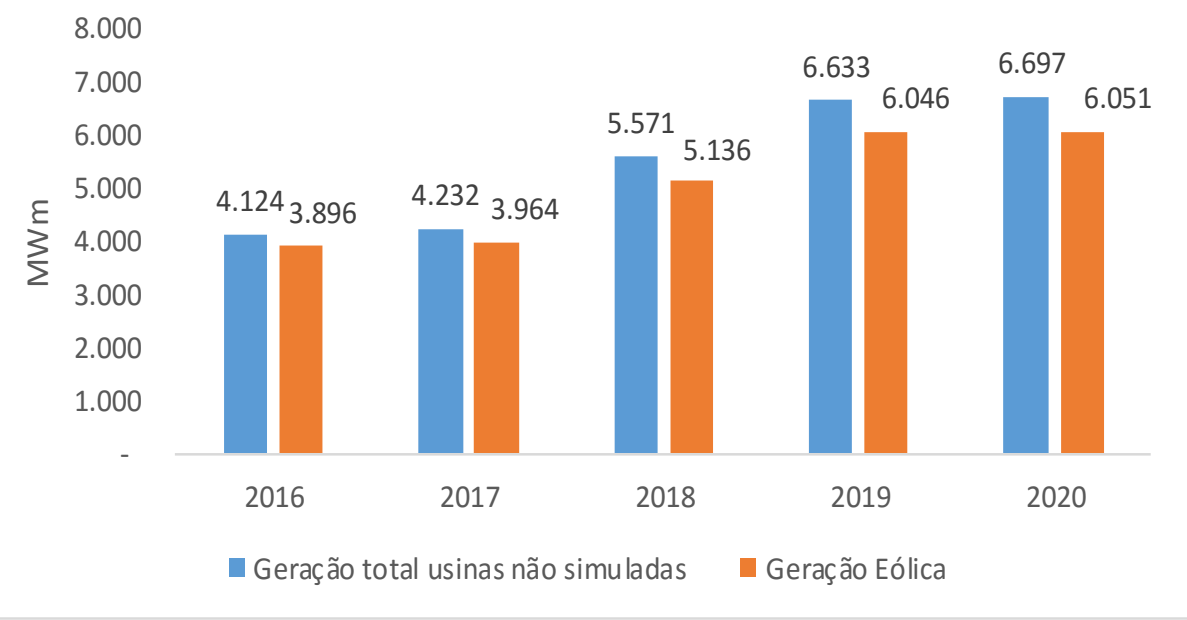

Fonte: Elaboração própria, base ONS 2016

Figura 51: Geração anual eólica e total das usinas não simuladas no Sul

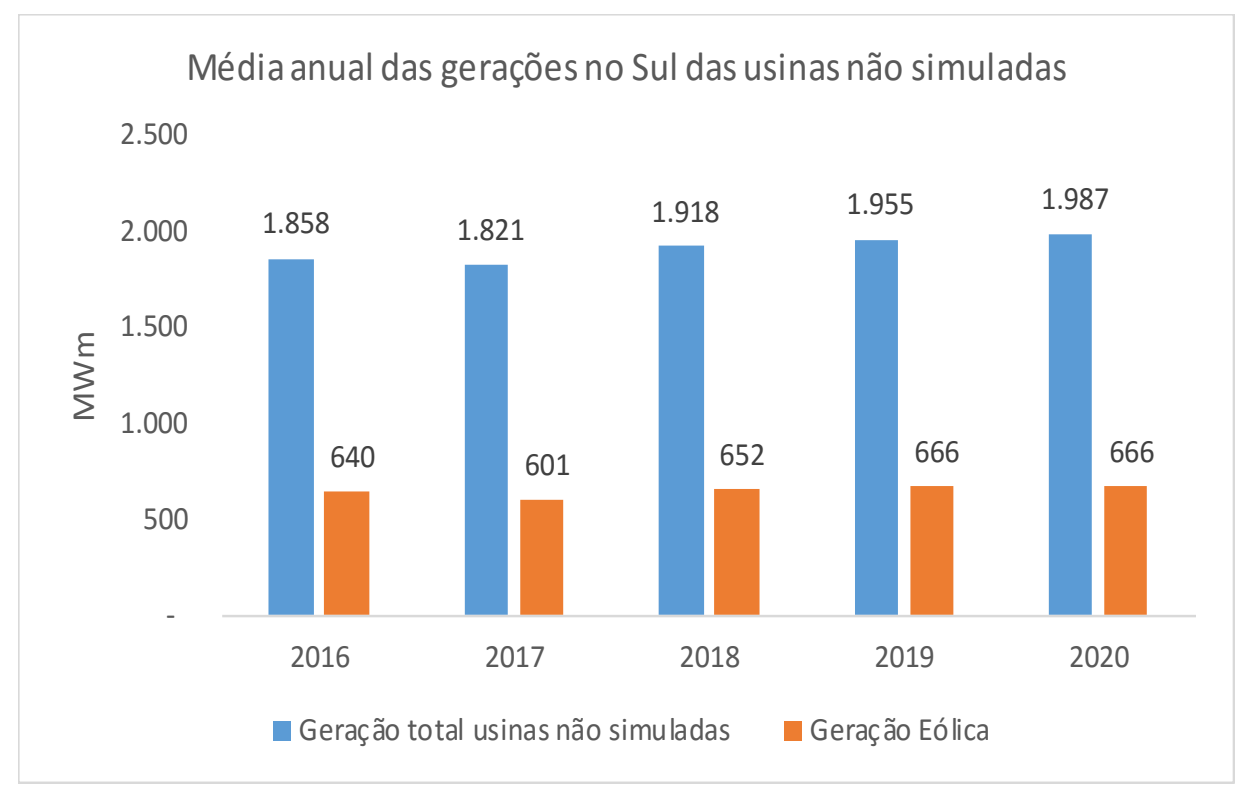

Fonte: Elaboração própria, base ONS 2016 


\subsection{Capacidade instalada dos Estados e expansão}

As capacidades instaladas por Estado e a respectiva expansão, considerando os leilões realizados até agosto/16, estão na Figura 52:

Figura 52: Capacidade eólica instalada por Estado e a respectiva expansão

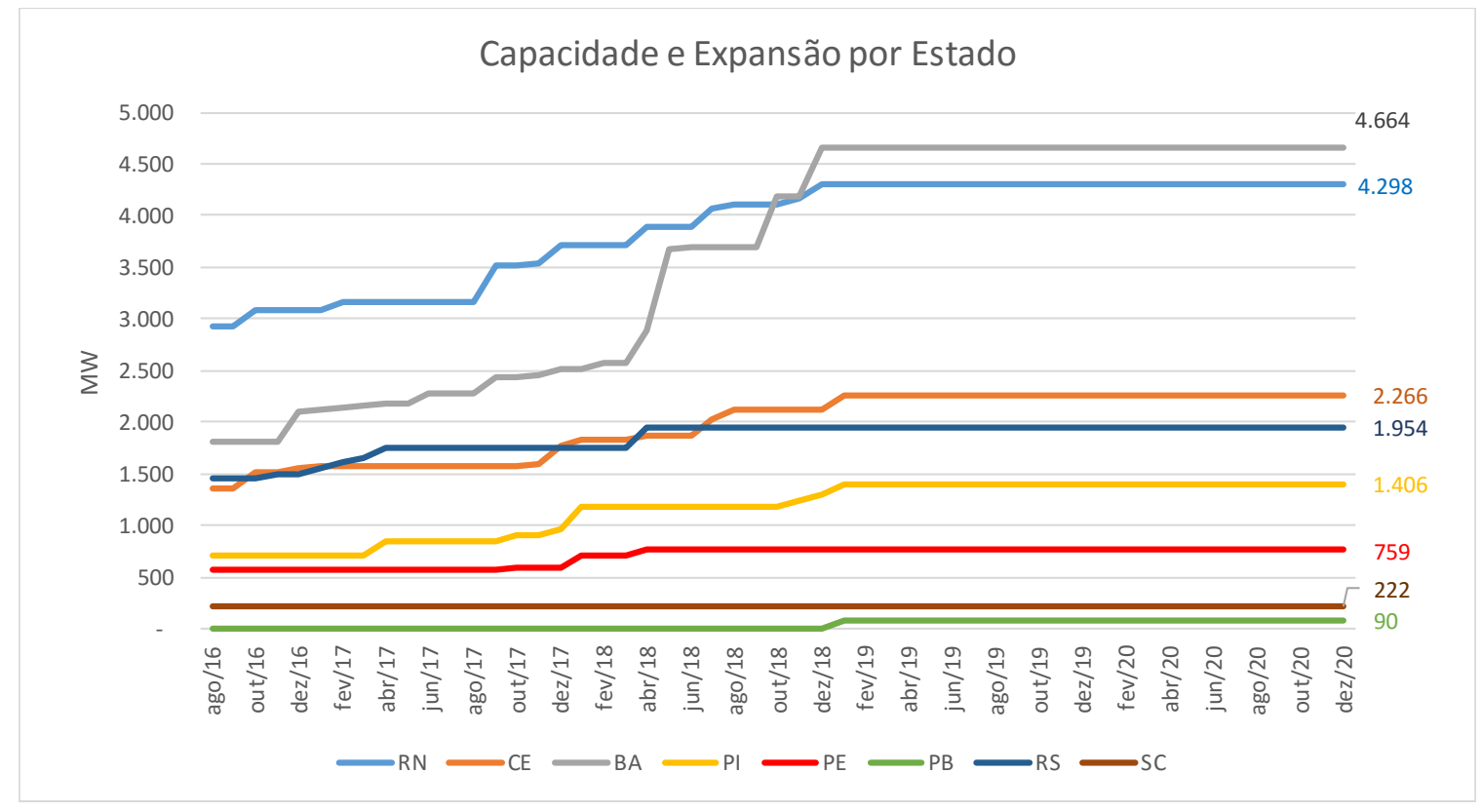

Fonte: Elaboração própria, base ONS 2016

O Estado com maior capacidade instalada em 2016 é o Rio Grande do Norte com aproximadamente $3 \mathrm{GW}$ instalados, mas deverá ser superado em 2018 pela Bahia, que tende a ser o Estado com maior capacidade instalada e maior crescimento. A Paraíba não apresenta nenhuma capacidade instalada em 2016, mas começa a ganhar participação em 2019.

Santa Catarina não apresenta aumento da capacidade instalada durante todo o horizonte e o Rio Grande do Sul apresenta crescimentos próximos ao do Ceará.

De forma agregada e anual, a Figura 53 e Figura 54 mostram o crescimento da eólica, para o Nordeste e Sul respectivamente: 
Figura 53: Capacidade eólica instalada no Nordeste e expansão

\section{Capacidade Instalada Nordeste e Expansão}

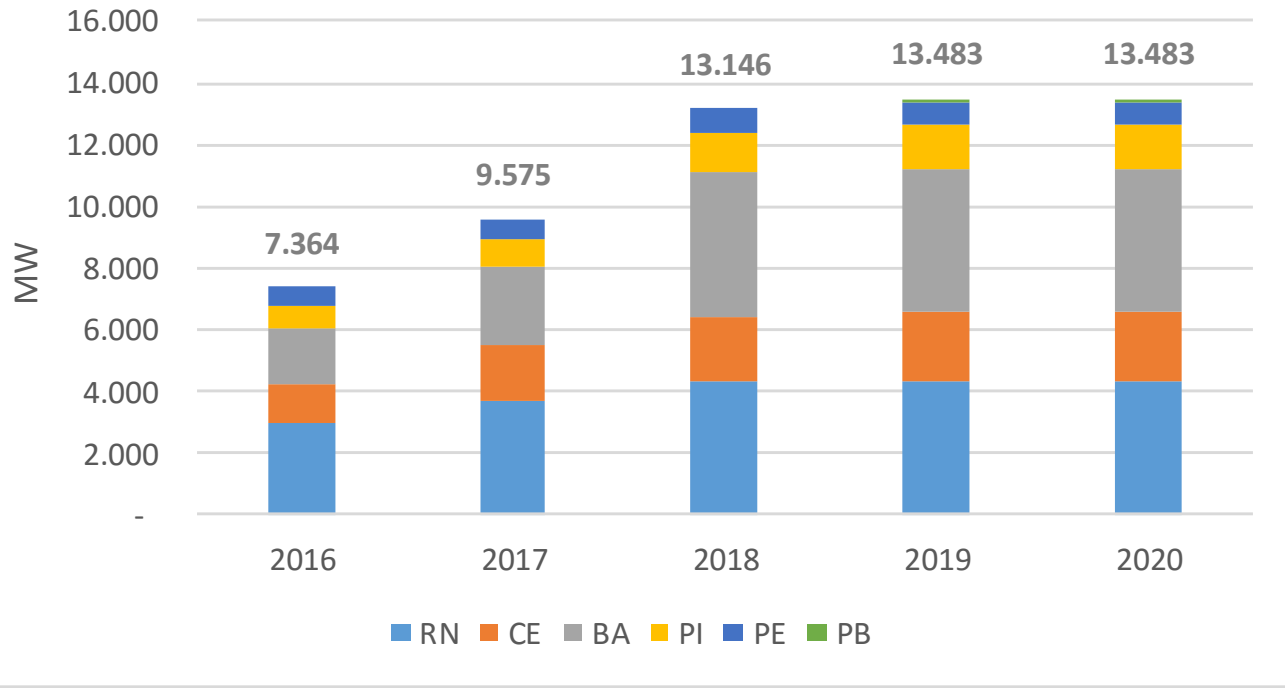

Fonte: Elaboração própria, base ONS 2016

Figura 54: Capacidade eólica instalada no Sul e expansão

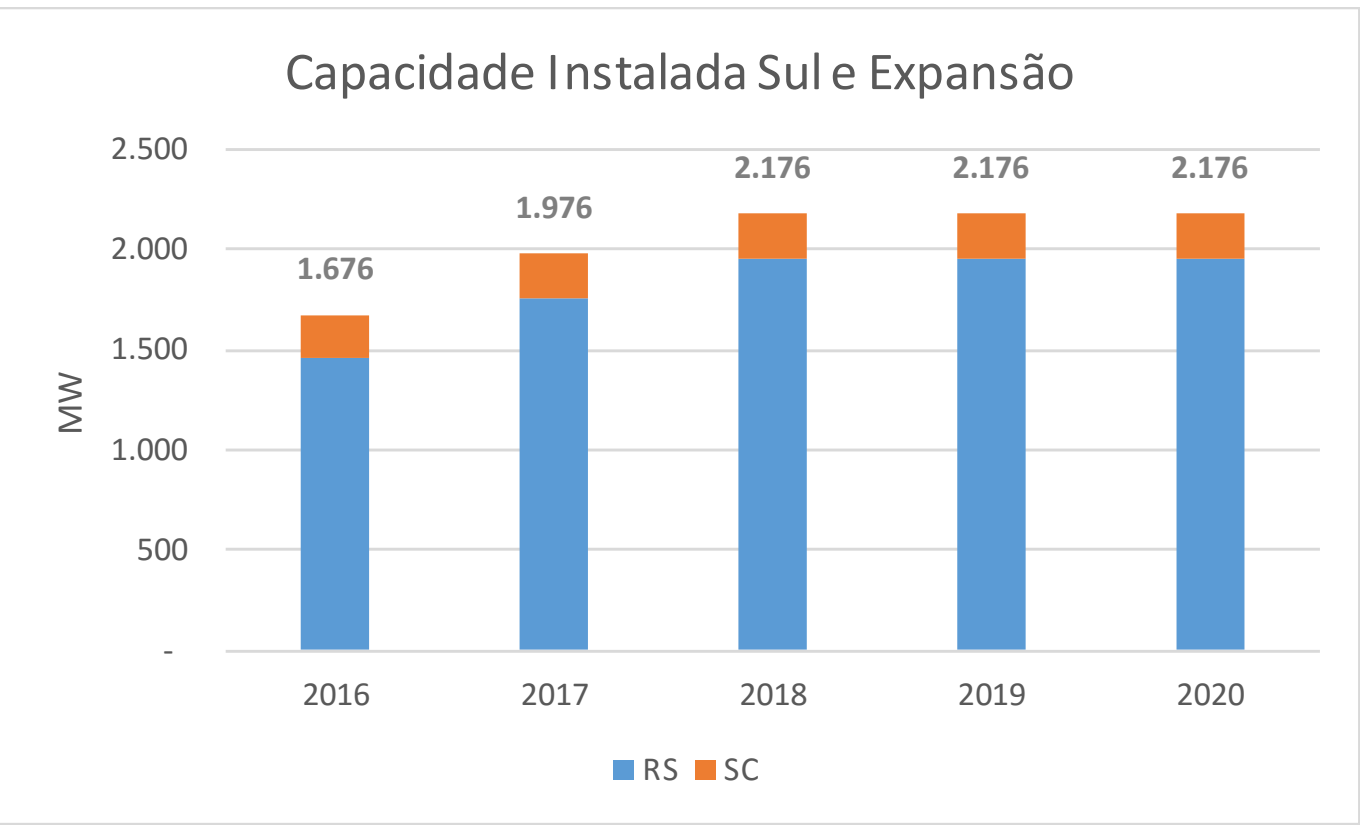

Fonte: Elaboração própria, base ONS 2016 


\subsection{Fator de capacidade}

O fator de capacidade médio anual da região Nordeste é superior ao da região Sul. A média anual dos Estados do Nordeste registram valores iguais ou maiores do que $40 \%$ considerando a geração verificada das usinas de cada Estado pela respectiva capacidade instalada. Na região Sul, o fator de capacidade do Rio Grande do Sul, de 33\% é superior ao de Santa Catarina, com 14\%. A Figura 55 mostra o fator de capacidade médio de cada Estado.

Figura 55: Fator de capacidade médio anual dos Estados

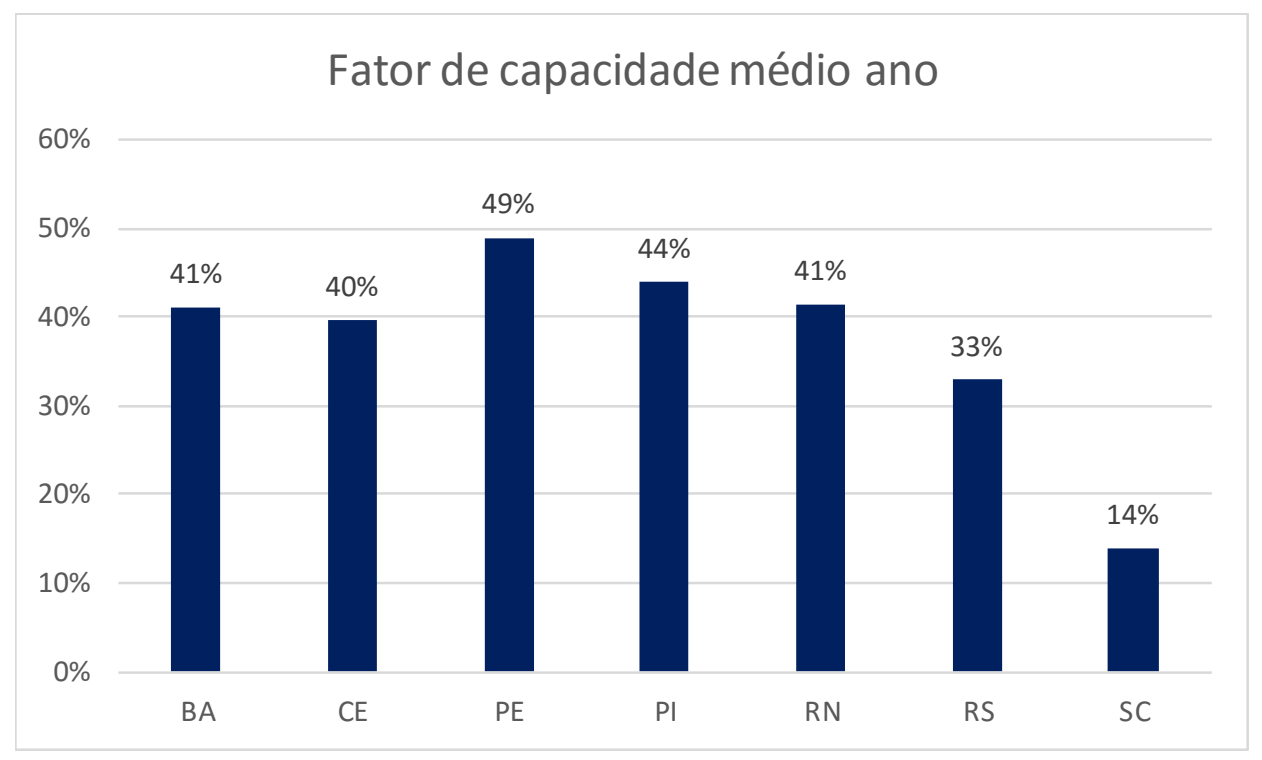

Fonte: Elaboração própria, base ONS 2016

Considerando-se a sazonalidade entre os meses, verifica-se no histórico de setembro de 2015 a agosto de 2016, que janeiro é o mês com menor fator de capacidade do Nordeste e os meses de julho a outubro apresentam os maiores valores, atingindo mais de $60 \%$ em alguns Estados. No Sul, o fator de capacidade não sofre tanta variação, com valores entre 30 e $40 \%$ no Rio Grande do Sul e 10 a 18\% em Santa Catarina. A Figura 56 e Figura 57 mostram o fator de capacidade mensal dos Estados do Nordeste e Sul, respectivamente. 
Figura 56: Fator de capacidade mensal do Nordeste

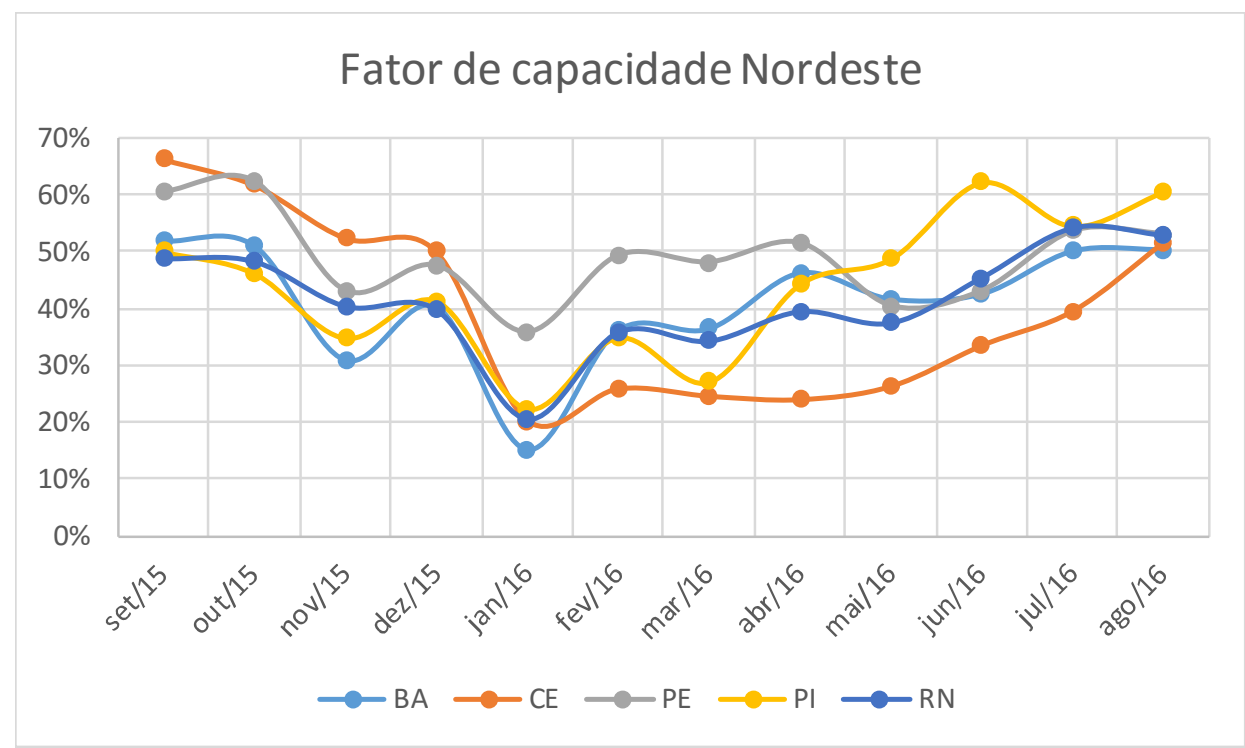

Fonte: Elaboração própria, base ONS 2016

Figura 57: Fator de capacidade mensal do Sul

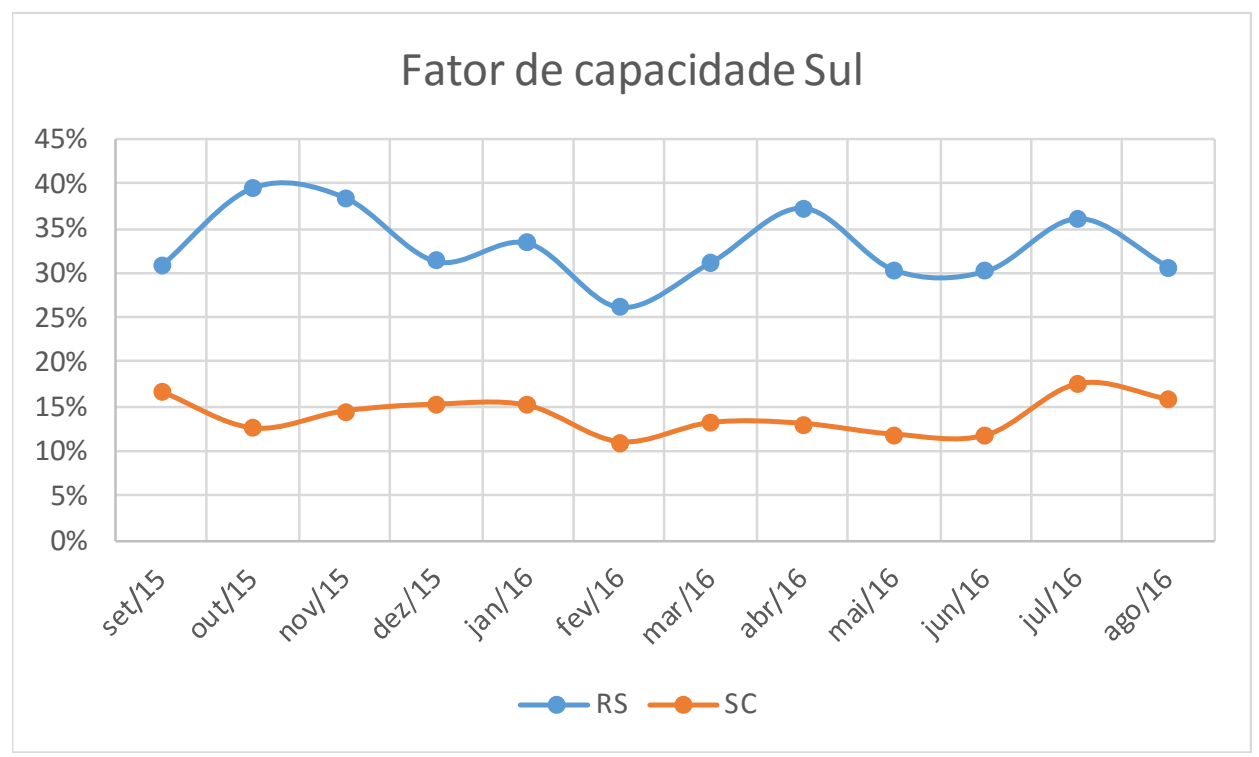

Fonte: Elaboração própria, base ONS 2016 


\subsection{Variabilidade da geração eólica}

Como há variabilidade na velocidade dos ventos, existe diferença na geração diária de energia eólica que pode causar necessidade térmica adicional para atendimento da carga. A Figura 58 mostra a geração eólica diária na região Nordeste, sendo que em alguns dias a geração atinge aproximadamente 5000 MWmédios e em dias seguintes, gera-se 1500 MWmédios.

Figura 58: Geração eólica diária do Nordeste

\section{Geração Eólica Diária no Nordeste}

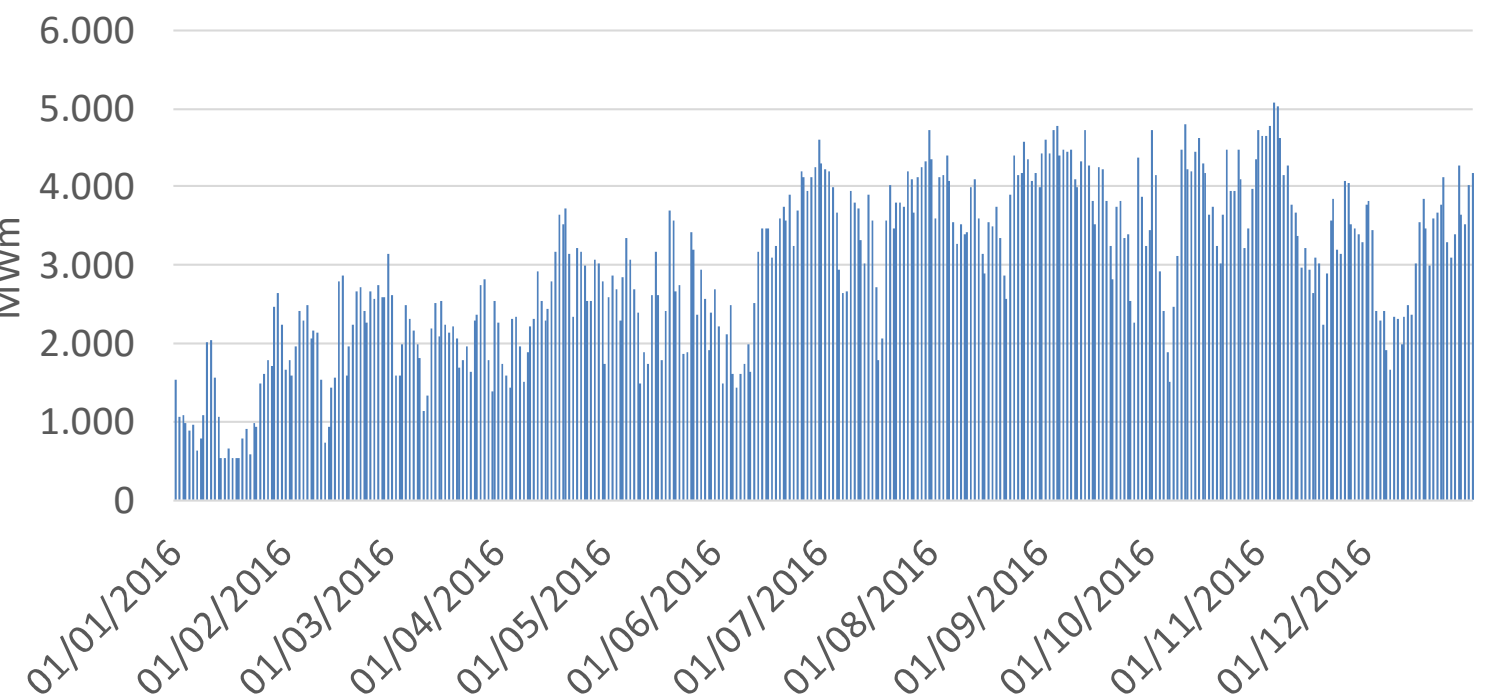

Fonte: Elaboração própria, base ONS 2016

No Sul também ocorre variabilidade, conforme pode ser observado na Figura 59. 
Figura 59: Geração eólica diária do Sul

Geração Eólica Diária no Sul

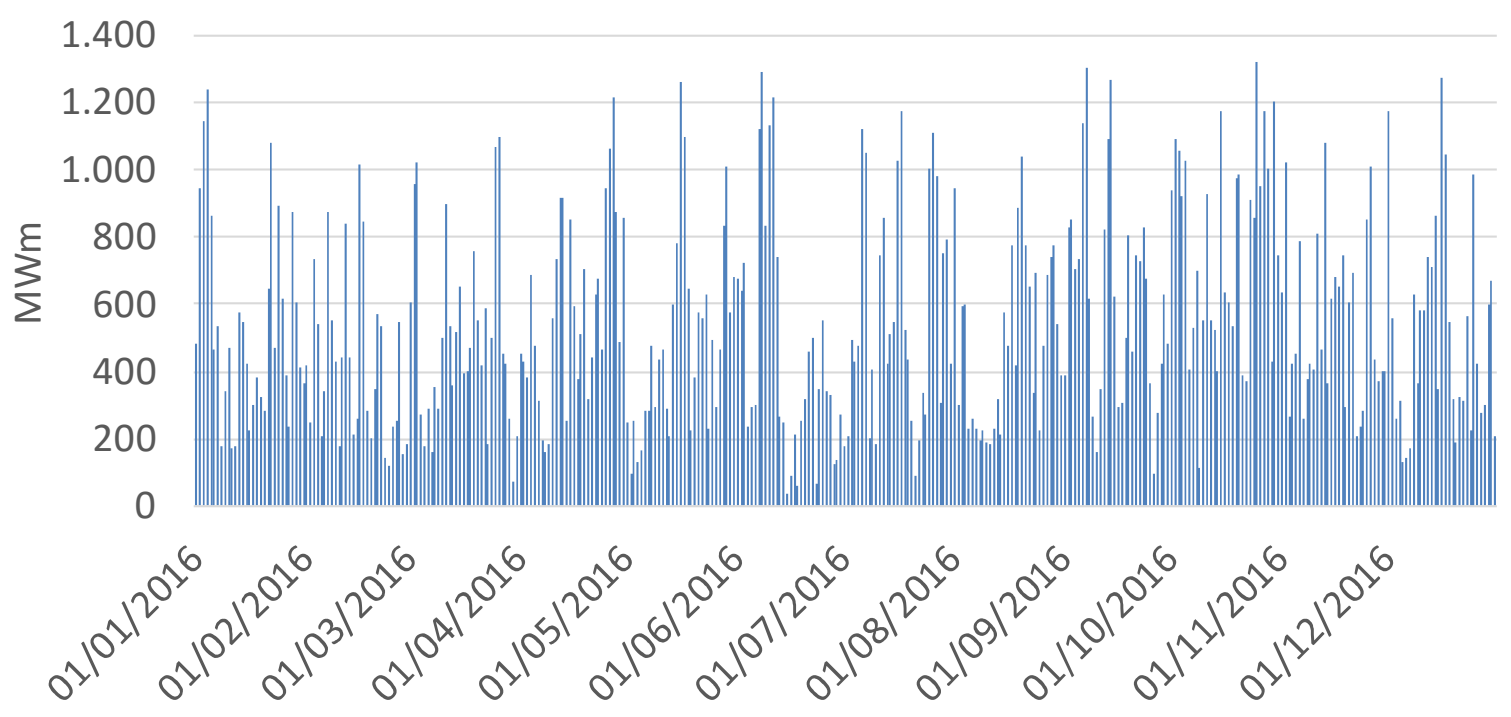

Fonte: Elaboração própria, base ONS 2016 


\section{INSERÇÃO DOS DADOS DE ENERGIA EÓLICA NO MODELO NEWAVE}

Neste capítulo são apresentados os dados de entrada do deck (conjunto de arquivos) do Newave de agosto de 2016, utilizado como base para as simulações, além das alterações realizadas no deck e os respectivos resultados das simulações. Inicialmente serão apresentadas as particularidades em relação a introdução dos Reservatórios Equivalentes de Energia (REEs) utilizadas para a representação da energia eólica estocástica. Em seguida, serão apresentadas simulações identificando-se as diferenças em relação ao deck determinístico oficial, por meio da análise do CMO, geração hidráulica, térmica e eólica.

\subsection{Metodologia}

O Newave conta com 4 submercados e 9 Reservatórios Equivalentes de Energia (REEs), são eles: Paraná, Itaipu, Madeira, Teles Pires e Sudeste (5 REEs no Submercado Sudeste); Norte e Belo Monte (2 REEs no submercado Norte); submercado Nordeste (1 REE) e Submercado Sul (1 REE). 
Figura 60: Reservatórios Equivalentes de Energia

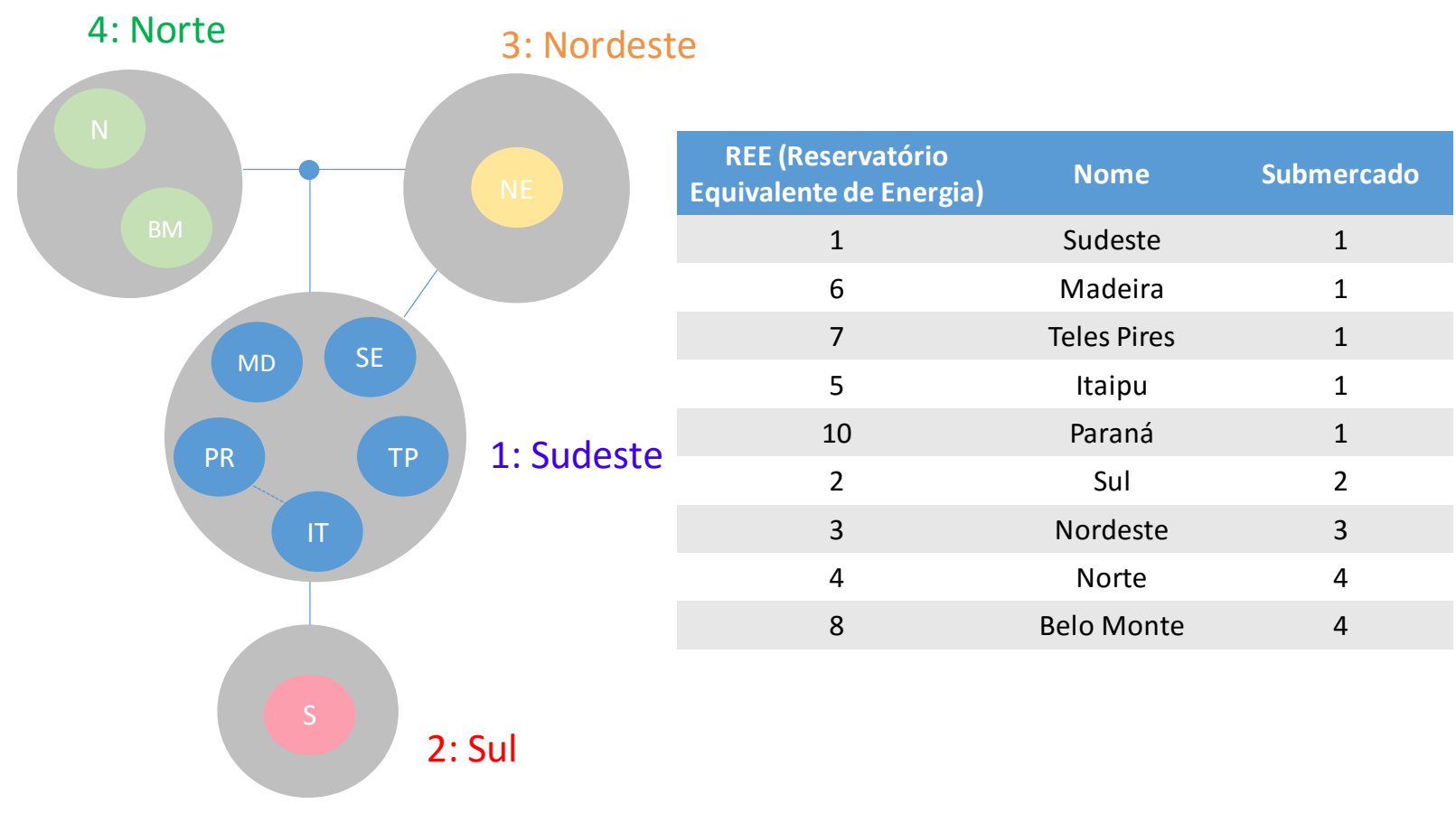

Fonte: Elaboração própria com base em (CCEE; ONS, 2015).

A capacidade do Newave é de até 15 REEs. Desta forma, são incluídos 4 REEs na região Nordeste, aqui denominadas de: RN (Rio Grande do Norte), CE (Ceará), PI+PE (Piauí + Pernambuco) e BA (Bahia), além de 2 REEs na região Sul: SC (Santa Catarina) e RS (Rio Grande do Sul). Estes REEs representam as principais "bacias eólicas".

A nova representação dos Submercados e REEs é dada na Figura 61: 
Figura 61: Nova representação dos Reservatórios Equivalentes de Energia

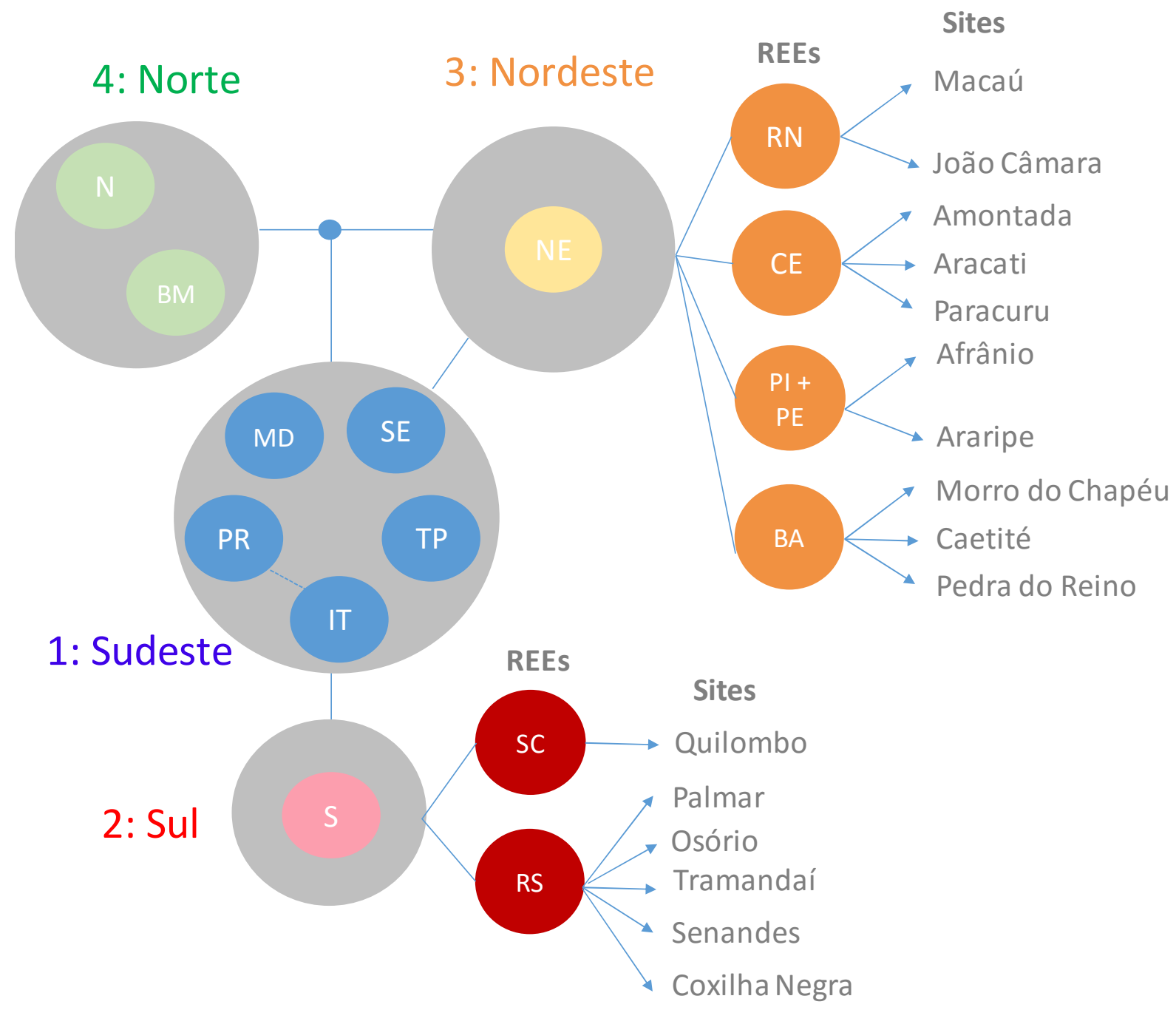

Fonte: Elaboração própria

Cada novo REE contém "um conjunto de rios" que representam os sites eólicos e as respectivas usinas eólicas são equivalentes a usinas a fio d'água, ligadas ao respectivo submercado como se tivessem transmissão de capacidade infinita. Como no Newave a geração de séries sintéticas através do modelo PAR (p) é limitada à geração hidráulica e o modelo apresenta código fonte fechado, não possibilitando a inserção de séries sintéticas de geração eólica, utilizou-se neste trabalho desta premissa simplificadora de representação da eólica como hidráulica a fio d'água. $\mathrm{O}$ detalhamento da alteração da usina eólica para hidráulica é mostrado nos arquivos de entrada neste capítulo. 
Com base na localização das eólicas em operação e em construção disponibilizadas pela ABEEólica (informação pessoa $1^{18}$ de YAMAMOTO, 2017), verificou-se os sites da base de dados Vortex que ficam mais próximos destas localidades e assim, foram definidas as quantidades de máquinas para cada site, com proporções das localidades, conforme Tabela 12.

Tabela 12: Localizações próximas das usinas em operação e em construção consideradas na simulação

\begin{tabular}{lcc}
\hline Bahia & Operação & Construção \\
Morro do Chapéu & $13 \%$ & $15 \%$ \\
Caetité & $60 \%$ & $68 \%$ \\
Pedra do Reino & $27 \%$ & $17 \%$ \\
\hline & & \\
\hline Ceará & Operação & Construção \\
Amontada & $51 \%$ & $57 \%$ \\
Aracati & $16 \%$ & $33 \%$ \\
Paracuru & $32 \%$ & $10 \%$ \\
\hline & & \\
\hline Rio Grande do Norte & Operação & Construção \\
Macaú & $25 \%$ & $0 \%$ \\
João Câmara & $75 \%$ & $100 \%$ \\
\hline & & \\
\hline Piauí + Pernambuco & Operação & Construção \\
Afrânio & $43 \%$ & $17 \%$ \\
Araripe & $57 \%$ & $83 \%$ \\
\hline & & \\
\hline Rio Grande do Sul & Construção \\
Palmar & $39 \%$ & $68 \%$ \\
Osório & $20 \%$ & $0 \%$ \\
Tramandaí & $20 \%$ & $32 \%$ \\
Senandes & $11 \%$ & $0 \%$ \\
Coxilha Negra & & \\
\hline Santa Catarina & & \\
Quilombo & $100 \%$ & \\
\hline & & \\
\hline
\end{tabular}

Fonte: Elaboração Própria com base em (informação pessoal de YAMAMOTO, 2017).

\footnotetext{
${ }^{18}$ YAMAMOTO, S. K. Mensagem recebida por<sandro@abeeolica.org.br> em 27 jan. 2017.
} 


\subsection{Dados de entrada}

Conforme mencionado anteriormente, o modelo Newave apresenta um conjunto de arquivos de dados de entrada, o qual é denominado de deck. Para este estudo foi utilizado o deck de dados de agosto de 2016 oficial disponível no site da CCEE.

Os arquivos do deck que foram modificados para a inserção dos Reservatórios Equivalentes de Energia e respectivas usinas com geração eólicas fictícias modeladas através de usinas a fio d' água foram: SISTEMA, REE, CONFHD, MODIF, POSTOS, VAZPAST, VAZOES e HIDR.

\subsubsection{SISTEMA}

$O$ arquivo SISTEMA.DAT apresenta informações de custo de déficit, limites de intercâmbio, mercado de energia e geração de usinas não simuladas.

Conforme citado antes, os valores de geração de usinas não simuladas representam a média dos últimos cinco anos das usinas eólicas, biomassa e PCHs, adicionados das novas gerações da expansão dessas usinas e o ajuste das usinas do último ano. Como estes valores são determinísticos, ou seja, o modelo conta que estes valores serão gerados e abatidos da carga antes da otimização do sistema, estes valores de eólicas são excluídos do deck e se considerou a reinserção dessa capacidade de produção através de usinas hidráulicas a fio d' água nos reservatórios equivalentes de energia.

Desta forma, o arquivo SISTEMA permanece com a geração de usinas não simuladas contemplando as usinas a biomassa e PCHs para o Sul e Nordeste, sendo que para os demais submercados, todas as fontes (incluindo as eólicas) continuam neste arquivo. Não são separadas as fontes eólicas das regiões Norte e Sudeste porque há um limite de reservatórios equivalentes no Newave e estes submercados são pouco representativos em relação a geração de usinas não simuladas eólicas, quando comparados com os submercados Sul e Nordeste. Apenas 0,2\% da geração das usinas não simuladas no Sudeste são representadas por eólicas. No Norte, apesar da representação da geração eólica ser de mais de 30\% a partir de 2018, dentro da própria região, o 
montante total mensal máximo de eólica no Norte é de apenas $110 \mathrm{MWm}$ enquanto que no Nordeste e Sul chegam a 9000 MWm e 900 MWm, respectivamente.

\subsubsection{REE}

Este arquivo começou a fazer parte do deck do Newave a partir de janeiro de 2016 quando começaram a ser divididos os reservatórios equivalentes dentro dos submercados.

A Figura 62 mostra a esquerda os Reservatórios Equivalentes utilizados no deck de agosto de 2016 e a parte da direita mostra a inserção dos 4 Reservatórios Equivalentes na região Nordeste (Submercado 3: Ceará, Bahia, Piepe e RN) e 2 Reservatórios Equivalentes na região Sul (Submercado 2: SC e RS), modelados para este trabalho.

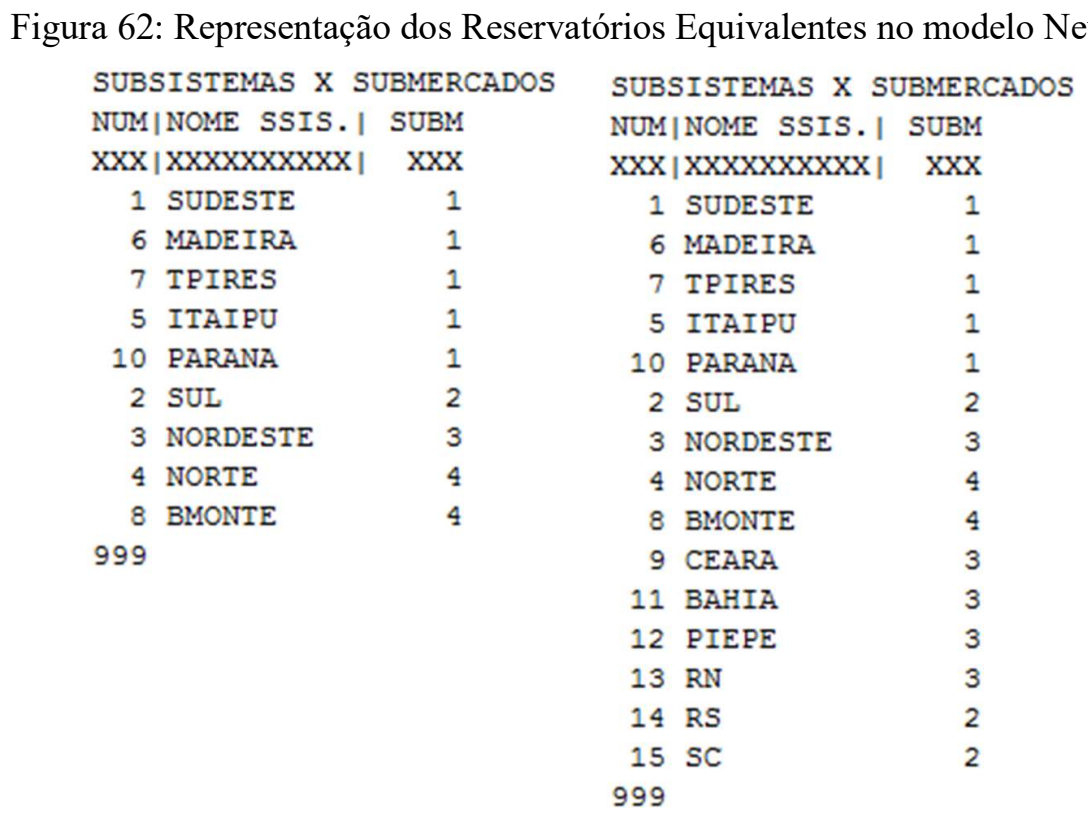

Fonte: Newave, agosto 2016 e elaboração própria

\subsubsection{CONFHD}

O arquivo CONFHD.DAT apresenta informações de cadastro das usinas hidrelétricas como o nome, o número, o posto, usina a jusante, o reservatório equivalente a que pertence, o volume inicial do reservatório, se a usina está considerada como existente ou em expansão dentro do deck 
e o histórico de anos considerados de vazões (os valores do histórico de vazões de 1931 a 2014 são considerados no arquivo VAZOES.DAT que será detalhado mais à frente neste estudo).

A Figura 63 mostra como foram inseridas as usinas eólicas representadas por hidráulicas a fio d' água dentro do arquivo, sendo criados números para usinas e postos, cada uma dentro do seu respectivo Reservatório Equivalente de Energia. Por exemplo, as usinas Amontada, Aracati e Paracuru estão todas no REE 9 (Ceará) dentro do Submercado 3 (Nordeste). Os postos representam cada site eólico e a respectiva expansão. A nomenclatura "ENTCE1" representa a entrada de uma nova usina no Ceará, assim como "ENTBA1" representa a entrada de uma nova usina na Bahia. O valor considerado de volume inicial é "zero" porque não possuem reservatório, uma vez que são usinas a fio d' água, considerando-se também que não possuem usina a jusante, sendo este valor considerado como "zero".

Figura 63: Representação dos Reservatórios Equivalentes com sites eólicos e expansão

\begin{tabular}{|c|c|c|c|c|c|c|c|c|c|}
\hline NUM & NOME & POSTO & JUS & REE & V.INIC & U.EXIS & MODIF & INIC.HIST & FIM HIST \\
\hline $\mathrm{xxxx}$ & $\mathrm{xxxxxxxx \times xxx}$ & $\mathrm{xxxx}$ & $\mathrm{xxxx}$ & $\mathrm{xxxx}$ & $\mathrm{xxx} \cdot \mathrm{xx}$ & $\mathrm{xxxx}$ & $\mathrm{xxxx}$ & $\mathrm{xxxx}$ & $\mathrm{xxxx}$ \\
\hline 3 & AMONTADA & 3 & 0 & 9 & 0.00 & EX & 1 & 1931 & 2014 \\
\hline 177 & ARACATI & 177 & 0 & 9 & 0.00 & EX & 1 & 1931 & 2014 \\
\hline 179 & PARACURU & 179 & 0 & 9 & 0.00 & EX & 1 & 1931 & 2014 \\
\hline 67 & ENTCE1 & 67 & 0 & 9 & 0.00 & $\mathrm{NE}$ & 0 & 1931 & 2014 \\
\hline 68 & ENTCE2 & 68 & 0 & 9 & 0.00 & NE & 0 & 1931 & 2014 \\
\hline 69 & ENTCE3 & 69 & 0 & 9 & 0.00 & $\mathrm{NE}$ & 0 & 1931 & 2014 \\
\hline 79 & ENTCE 4 & 79 & 0 & 9 & 0.00 & $\mathrm{NE}$ & 0 & 1931 & 2014 \\
\hline 84 & ENTCE 5 & 84 & 0 & 9 & 0.00 & $\mathrm{NE}$ & 0 & 1931 & 2014 \\
\hline 87 & ENTCE 6 & 87 & 0 & 9 & 0.00 & $\mathrm{NE}$ & 0 & 1931 & 2014 \\
\hline 5 & MORROCHAP & 5 & 0 & 11 & 0.00 & EX & 1 & 1931 & 2014 \\
\hline 185 & CAETITE & 185 & 0 & 11 & 0.00 & $\mathrm{EX}$ & 1 & 1931 & 2014 \\
\hline 200 & PEDRAREIN & 200 & 0 & 11 & 0.00 & $\mathrm{EX}$ & 1 & 1931 & 2014 \\
\hline 96 & ENTBA1 & 96 & 0 & 11 & 0.00 & $\mathrm{NE}$ & 0 & 1931 & 2014 \\
\hline 106 & ENTBA2 & 106 & 0 & 11 & 0.00 & NE & 0 & 1931 & 2014 \\
\hline 136 & ENTBA3 & 136 & 0 & 11 & 0.00 & $\mathrm{NE}$ & 0 & 1931 & 2014 \\
\hline 137 & ENTBA 4 & 137 & 0 & 11 & 0.00 & $\mathrm{NE}$ & 0 & 1931 & 2014 \\
\hline 140 & ENTBA5 & 140 & 0 & 11 & 0.00 & $\mathrm{NE}$ & 0 & 1931 & 2014 \\
\hline 142 & ENTBA6 & 142 & 0 & 11 & 0.00 & $\mathrm{NE}$ & 0 & 1931 & 2014 \\
\hline 146 & ENTBA7 & 146 & 0 & 11 & 0.00 & $\mathrm{NE}$ & 0 & 1931 & 2014 \\
\hline 13 & AFRANIO & 13 & 0 & 12 & 0.00 & EX & 1 & 1931 & 2014 \\
\hline 212 & ARARIPE & 212 & 0 & 12 & 0.00 & EX & 1 & 1931 & 2014 \\
\hline 147 & ENTPEEPI1 & 147 & 0 & 12 & 0.00 & $\mathrm{NE}$ & 0 & 1931 & 2014 \\
\hline 150 & ENTPEEPI2 & 150 & 0 & 12 & 0.00 & $\mathrm{NE}$ & 0 & 1931 & 2014 \\
\hline 151 & ENTPEEPI3 & 151 & 0 & 12 & 0.00 & $\mathrm{NE}$ & 0 & 1931 & 2014 \\
\hline 152 & ENTPEEPI 4 & 152 & 0 & 12 & 0.00 & NE & 0 & 1931 & 2014 \\
\hline 153 & ENTPEEPI 5 & 153 & 0 & 12 & 0.00 & NE & 0 & 1931 & 2014 \\
\hline 157 & ENTPEEPI 6 & 157 & 0 & 12 & 0.00 & NE & 0 & 1931 & 2014 \\
\hline
\end{tabular}

Fonte: Newave, agosto 2016 e elaboração própria 


\subsubsection{MODIF}

O arquivo MODIF.DAT representa as alterações dos dados das usinas hidrelétricas. São quatro variáveis que podem sofrer alterações neste arquivo: canal de fuga, volume máximo dos reservatórios para consideração dos volumes de espera, o volume mínimo dos reservatórios e a vazão mínima variável no tempo. Mais uma vez, como neste estudo estamos trabalhando com usinas a fio d' água, somente a variável de vazão mínima será considerada.

A Figura 64 mostra a representação deste arquivo com as usinas criadas nos submercados Nordeste e Sul com as respectivas vazões mínimas do histórico, representadas pelas gerações eólicas reconstruídas de menor valor.

Figura 64: Representação das vazões mínimas das usinas com sites eólicos

\begin{tabular}{|c|c|c|}
\hline P. CHAVE & MODIFICACOES E INDICES & \\
\hline $\mathrm{xxxxxxxx}$ & 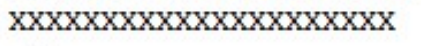 & \\
\hline USINA & 3 & AMONTADA \\
\hline VAZMIN & 161 & \\
\hline USINA & 177 & ARACATI \\
\hline VAZMIN & 48 & \\
\hline USINA & 179 & PARACURU \\
\hline VAZMIN & 161 & \\
\hline USINA & 5 & MORROCHAP \\
\hline VAZMIN & 665 & \\
\hline USINA & 185 & CAETITE \\
\hline VAZMIN & 665 & \\
\hline USINA & 200 & PEDRAREIN \\
\hline VAZMIN & 665 & \\
\hline USINA & 13 & AFRANIO \\
\hline VAZMIN & 178 & \\
\hline USINA & 212 & ARARIPE \\
\hline VAZMIN & 178 & \\
\hline USINA & 19 & MACAU \\
\hline VAZMIN & 594 & \\
\hline USINA & 208 & JOAOCAME \\
\hline VAZMIN & 594 & \\
\hline USINA & 36 & PALMAR \\
\hline VAZMIN & 472 & \\
\hline USINA & 213 & OSORIO \\
\hline VAZMIN & 472 & \\
\hline USINA & 214 & TRAMANDAI \\
\hline VAZMIN & 48 & \\
\hline USINA & 218 & SENANDES \\
\hline
\end{tabular}

Fonte: Newave, agosto 2016 e elaboração própria 


\subsubsection{POSTOS}

$\mathrm{O}$ arquivo POSTOS.DAT representa o cadastro com os nomes e anos inicial e final dos registros dos postos fluviométricos. Este arquivo é binário e é necessário um software disponibilizado no site do ONS denominado de "vazedit" para transformá-lo em texto, inserção dos dados dos postos, posterior alteração para binário e reinserção no deck de dados.

A Figura 65 mostra o software vazedit e a Figura 66 mostra a tela do arquivo POSTOS.DAT considerando a inserção das usinas eólicas.

Figura 65: Gerador de arquivos binário e texto para alteração das informações no deck

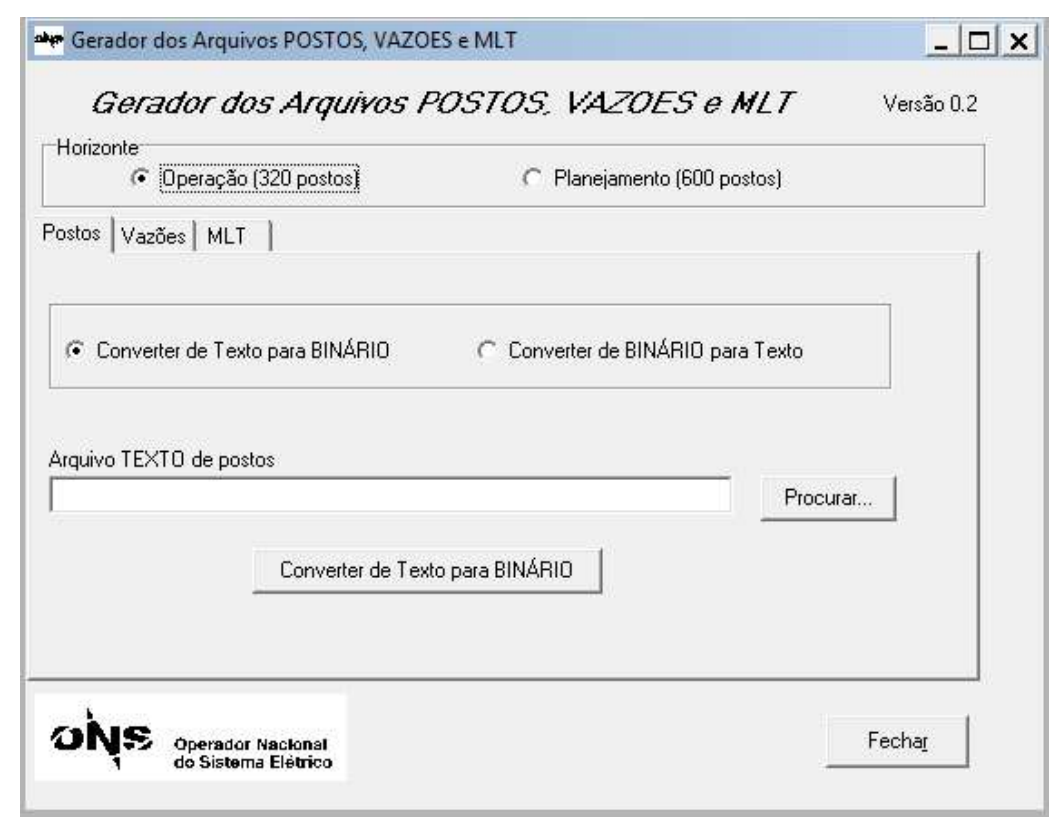

Fonte: ONS (2016). 
Figura 66: Tela do arquivo POSTOS.DAT considerando a inserção das eólicas

$\begin{array}{rlll}1 & \text { CAMARGOS } & 1931 & 2014 \\ 2 & \text { ITUTINGA } & 1931 & 2014 \\ 3 & \text { AMONTADA } & 1931 & 2014 \\ 5 & \text { MORROCHAP } & 1931 & 2014 \\ 6 & \text { FURNAS } & 1931 & 2014 \\ 7 & \text { M. DE MORAES } & 1931 & 2014 \\ 8 & \text { ESTREITO } & 1931 & 2014 \\ 9 & \text { JAGUARA } & 1931 & 2014 \\ 10 & \text { IGARAPAVA } & 1931 & 2014 \\ 11 & \text { VOLTA GRANDE } & 1931 & 2014 \\ 12 & \text { P. COLOMBIA } & 1931 & 2014 \\ 13 & \text { AFRANIO } & 1931 & 2014 \\ 14 & \text { CACONDE } & 1931 & 2014 \\ 15 & \text { E. DA CUNHA } & 1931 & 2014 \\ 16 & \text { A.S.OLIVEIRA } & 1931 & 2014 \\ 17 & \text { MARIMBONDO } & 1931 & 2014 \\ 18 & \text { A. VERMELHA } & 1931 & 2014 \\ 19 & \text { MACAU } & 1931 & 2014 \\ 20 & \text { BOCAINA } & 1931 & 2014 \\ 22 & \text { BATALHA } & 1931 & 2014 \\ 23 & \text { CORUMBA III } & 1931 & 2014 \\ 24 & \text { EMBORCACAO } & 1931 & 2014 \\ 25 & \text { NOVA PONTE } & 1931 & 2014 \\ 28 & \text { CAPIM BRANC2 } & 1931 & 2014 \\ 31 & \text { ITUMBIARA } & 1931 & 2014 \\ 32 & \text { CACH.DOURADA } & 1931 & 2014\end{array}$

Fonte: Newave, agosto 2016 e elaboração própria

\subsubsection{VAZPAST}

O arquivo VAZPAST.DAT representa as vazões passadas recentes por posto fluviométrico, que são as vazões afluentes mensais que serão utilizadas como condição inicial para a geração de séries sintéticas.

A Figura 67 mostra a tela do arquivo vazpast considerando a inserção das usinas eólicas no Nordeste e Sul. Os valores de cada coluna representam os meses (de janeiro a dezembro, neste caso janeiro a agosto de 2016 e setembro a dezembro de 2015, uma vez que são os últimos doze meses do histórico para este estudo).

A partir dos dados de ENA eólica calculados com base nos dados de velocidade de vento do Vortex para as coordenadas de cada Estado, além da reconstrução de séries históricas até 2016, 
verifica-se a Energia Natural Afluente histórica da fonte eólica. Também são consideradas as entradas de eólicas no horizonte a fim de se avaliar também a expansão do Sistema.

Figura 67: Tela do arquivo VAZPAST.DAT considerando a inserção das eólicas

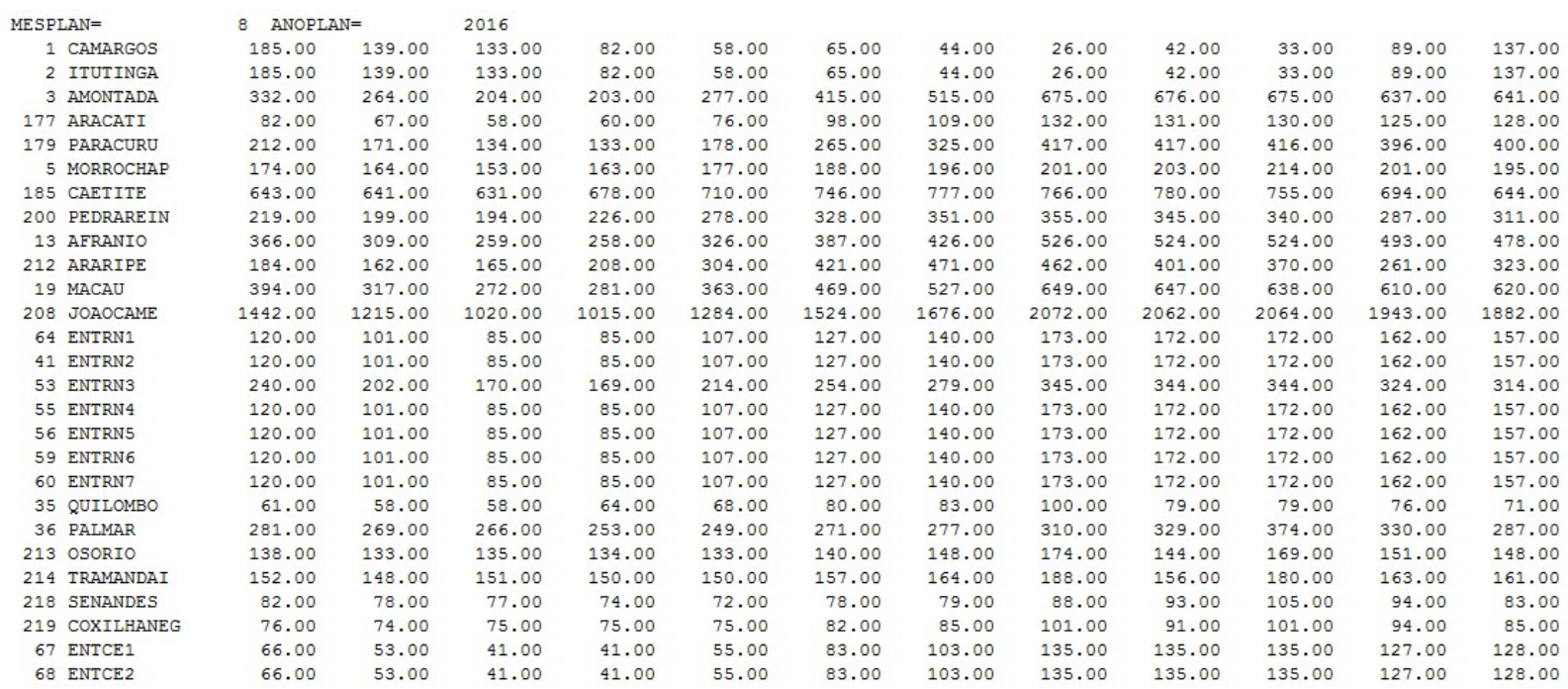

Fonte: Newave, agosto 2016 e elaboração própria

\subsubsection{VAZOES}

O arquivo VAZOES.DAT representa as vazões naturais do histórico desde 1931 até o último mês do histórico. Este arquivo também é binário e necessita do mesmo software "vazedit" utilizado anteriormente para abertura do arquivo de postos.

Como o Newave considera os dados históricos de vazões desde 1931 a 2014 (para a simulação de agosto de 2016), verificou-se, a partir do histórico de afluências do Nordeste, os anos calendário, do período histórico em que não se dispunha de séries reconstruídas de velocidade do vento, que fossem hidrologicamente mais parecidos aos anos do período 1948 a 2014. A partir de então, utilizou-se os valores de geração eólica reconstruídos para associar um perfil de vento aos anos do período histórico até 1947, associando-se a cada um desses anos um perfil de vento correspondente ao ano hidrológico, pós 1947, mais semelhante, do ponto de vista de hidrologia, ao ano do período de lacuna, permitindo assim compor a base de dados desde o início do horizonte. Fez-se o mesmo procedimento para a região Sul. Esta simplificação foi necessária, dado que os valores disponibilizados de velocidades de vento são a partir de 1948. 
A Figura 68 mostra os dados de vazões reconstruídos para o histórico de geração eólica. A primeira coluna representa o posto da usina, em seguida o ano do histórico e as 12 colunas seguintes as vazões do histórico para cada posto em cada mês.

Figura 68: Tela do arquivo VAZOES.DAT considerando a inserção das eólicas

\begin{tabular}{|c|c|c|c|c|c|c|c|c|c|c|c|}
\hline 31931 & 261 & 217 & 180 & 172 & 274 & 458 & 535 & 634 & 626 & 638 & 568 \\
\hline 31932 & 328 & 201 & 179 & 130 & 157 & 309 & 342 & 580 & 645 & 624 & 586 \\
\hline 31933 & 395 & 289 & 300 & 208 & 218 & 298 & 407 & 569 & 608 & 589 & 607 \\
\hline 31934 & 525 & 377 & 314 & 370 & 510 & 482 & 600 & 676 & 701 & 711 & 606 \\
\hline 31935 & 357 & 327 & 217 & 140 & 192 & 360 & 453 & 510 & 623 & 617 & 466 \\
\hline 31936 & 278 & 143 & 155 & 129 & 108 & 404 & 494 & 640 & 685 & 616 & 510 \\
\hline 31937 & 295 & 170 & 206 & 228 & 339 & 380 & 424 & 566 & 596 & 658 & 631 \\
\hline 31938 & 409 & 270 & 208 & 246 & 336 & 516 & 629 & 654 & 592 & 619 & 504 \\
\hline 31939 & 239 & 130 & 139 & 98 & 282 & 430 & 543 & 607 & 649 & 588 & 440 \\
\hline 31940 & 345 & 296 & 205 & 342 & 385 & 470 & 571 & 643 & 631 & 660 & 644 \\
\hline 31941 & 142 & 153 & 96 & 99 & 183 & 249 & 488 & 614 & 658 & 658 & 657 \\
\hline 31942 & 345 & 296 & 205 & 342 & 385 & 470 & 571 & 643 & 631 & 660 & 644 \\
\hline 31943 & 199 & 129 & 145 & 120 & 205 & 363 & 444 & 637 & 613 & 631 & 620 \\
\hline 31944 & 314 & 333 & 216 & 184 & 339 & 402 & 594 & 622 & 582 & 567 & 474 \\
\hline 31945 & 337 & 370 & 191 & 169 & 301 & 497 & 488 & 582 & 554 & 596 & 503 \\
\hline 31946 & 199 & 129 & 145 & 120 & 205 & 363 & 444 & 637 & 613 & 631 & 620 \\
\hline 31947 & 261 & 217 & 180 & 172 & 274 & 458 & 535 & 634 & 626 & 638 & 568 \\
\hline 31948 & 291 & 196 & 178 & 186 & 259 & 416 & 470 & 633 & 639 & 607 & 457 \\
\hline 31949 & 226 & 170 & 128 & 147 & 199 & 361 & 481 & 596 & 634 & 572 & 421 \\
\hline 31950 & 274 & 208 & 129 & 155 & 247 & 486 & 497 & 628 & 646 & 652 & 488 \\
\hline 31951 & 345 & 327 & 266 & 156 & 224 & 384 & 555 & 617 & 654 & 598 & 568 \\
\hline 31952 & 261 & 217 & 180 & 172 & 274 & 458 & 535 & 634 & 626 & 638 & 568 \\
\hline 31953 & 316 & 244 & 253 & 254 & 242 & 446 & 499 & 640 & 636 & 588 & 474 \\
\hline 31954 & 318 & 189 & 191 & 173 & 238 & 459 & 543 & 603 & 668 & 604 & 426 \\
\hline 31955 & 296 & 219 & 200 & 127 & 249 & 413 & 488 & 619 & 653 & 599 & 578 \\
\hline 31956 & 401 & 183 & 169 & 198 & 261 & 367 & 453 & 608 & 652 & 558 & 458 \\
\hline 31957 & 337 & 370 & 191 & 169 & 301 & 497 & 488 & 582 & 554 & 596 & 503 \\
\hline
\end{tabular}

Fonte: Newave, agosto 2016 e elaboração própria

A Figura 69 mostra o histórico reconstruído da geração de energia eólica em Paracuru e considerando a similaridade de 1931 e 2015. 
Figura 69: Histórico reconstruída de geração eólica

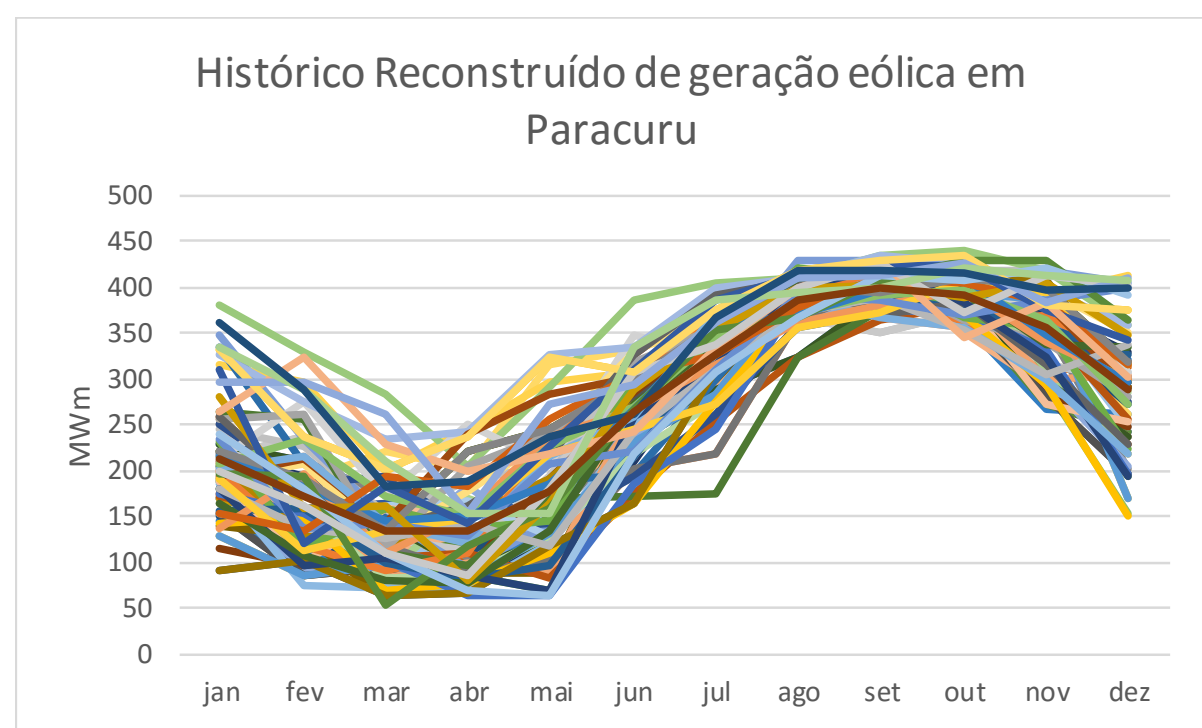

Fonte: Elaboração própria

\subsubsection{HIDR}

$\mathrm{O}$ arquivo HIDR.DAT representa os dados das usinas hidroelétricas. Este arquivo também é binário e necessita do software "hydroedit" disponível no site do ONS para inserção de novas usinas. A usina Ceará foi introduzida no modelo Newave de agosto de 2016, assim como as demais usinas dos reservatórios equivalentes, considerando como base as características da usina fio d' água de Jupiá.

As informações de cotas das usinas e polinômios foram as mesmas da consideração de usinas a fio d'água existentes no modelo, sem consideração de evaporação e dado que o rendimento considerado foi de "um" e altura de "um" metro de queda d'água, a potência é proporcional a "vazão" da usina, conforme Equação 4:

$$
P=\eta Q H \text { (39) }
$$

Onde:

P: Potência

$\eta:$ Rendimento 
Q: vazão

H: altura

Figura 70: Tela do hydroedit para leitura e inserção de novas usinas

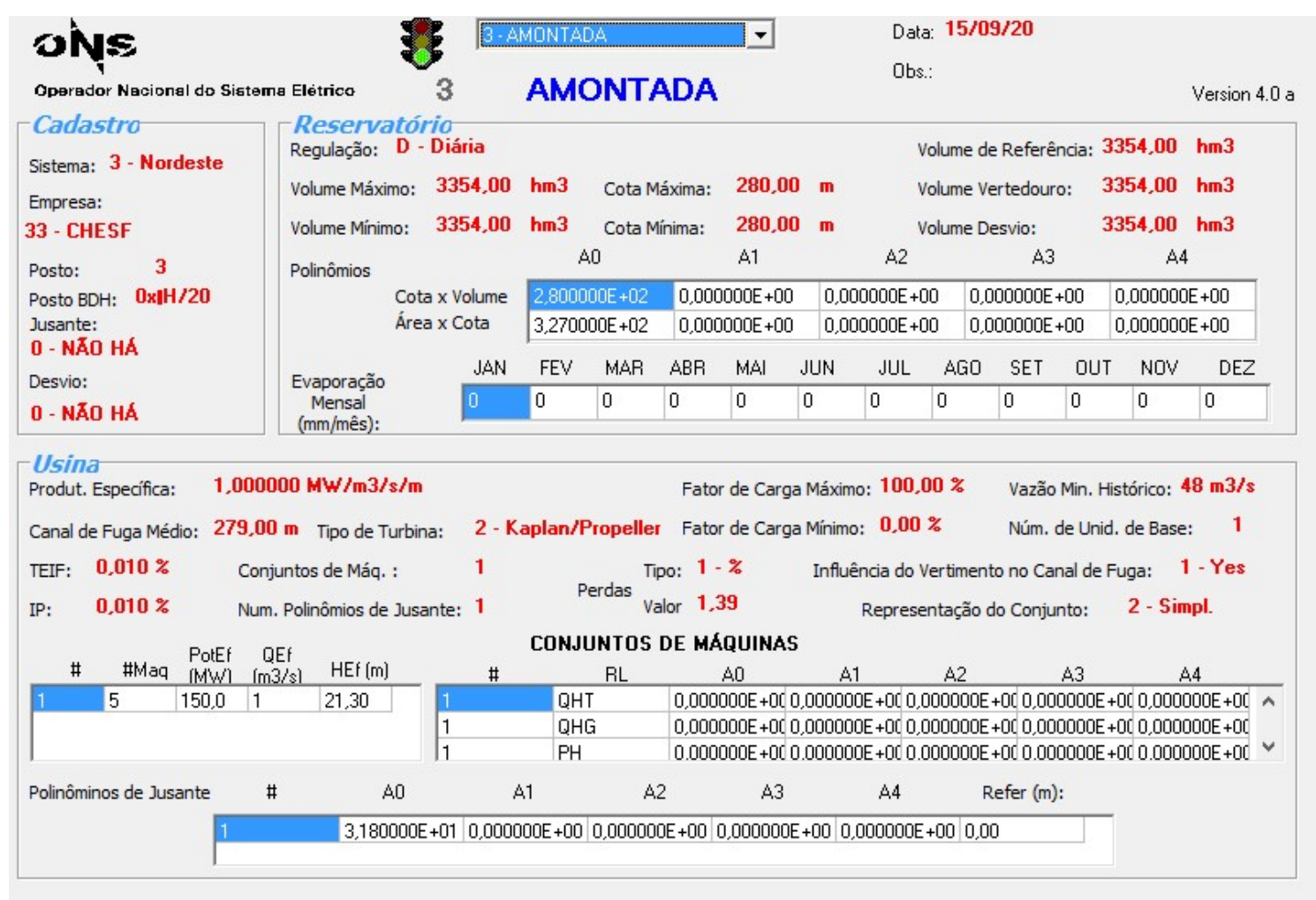

Fonte: ONS (2016).

A Figura 71 mostra a capacidade instalada inserida nos Reservatórios Equivalentes de Energia criados através do arquivo Hidr.dat 
Figura 71: Capacidade eólica inserida no Newave

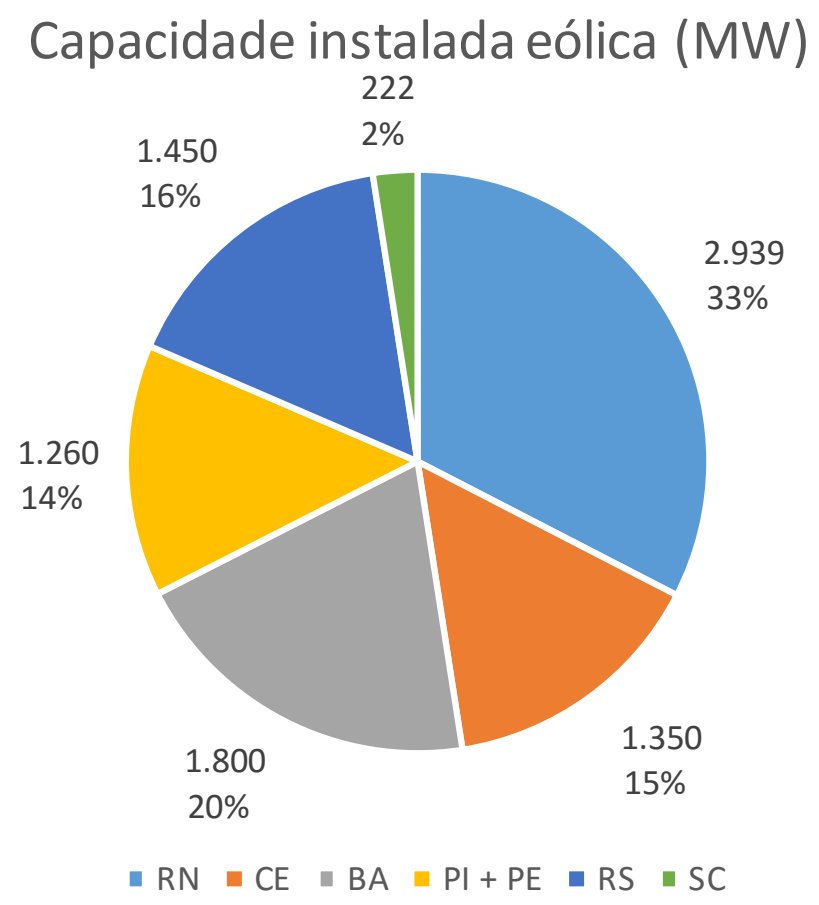

Fonte: Elaboração Própria

Além disso, a expansão é feita com valores aproximados da capacidade considerada do Nordeste e Sul pelo Departamento de Monitoramento do Sistema Elétrico (DMSE) conforme Figura 72 e Figura 73, respectivamente, uma vez que as potências das máquinas apresentam os mesmos valores e o que varia é a quantidade de máquinas a entrar por usina. 
Figura 72: Expansão do Nordeste

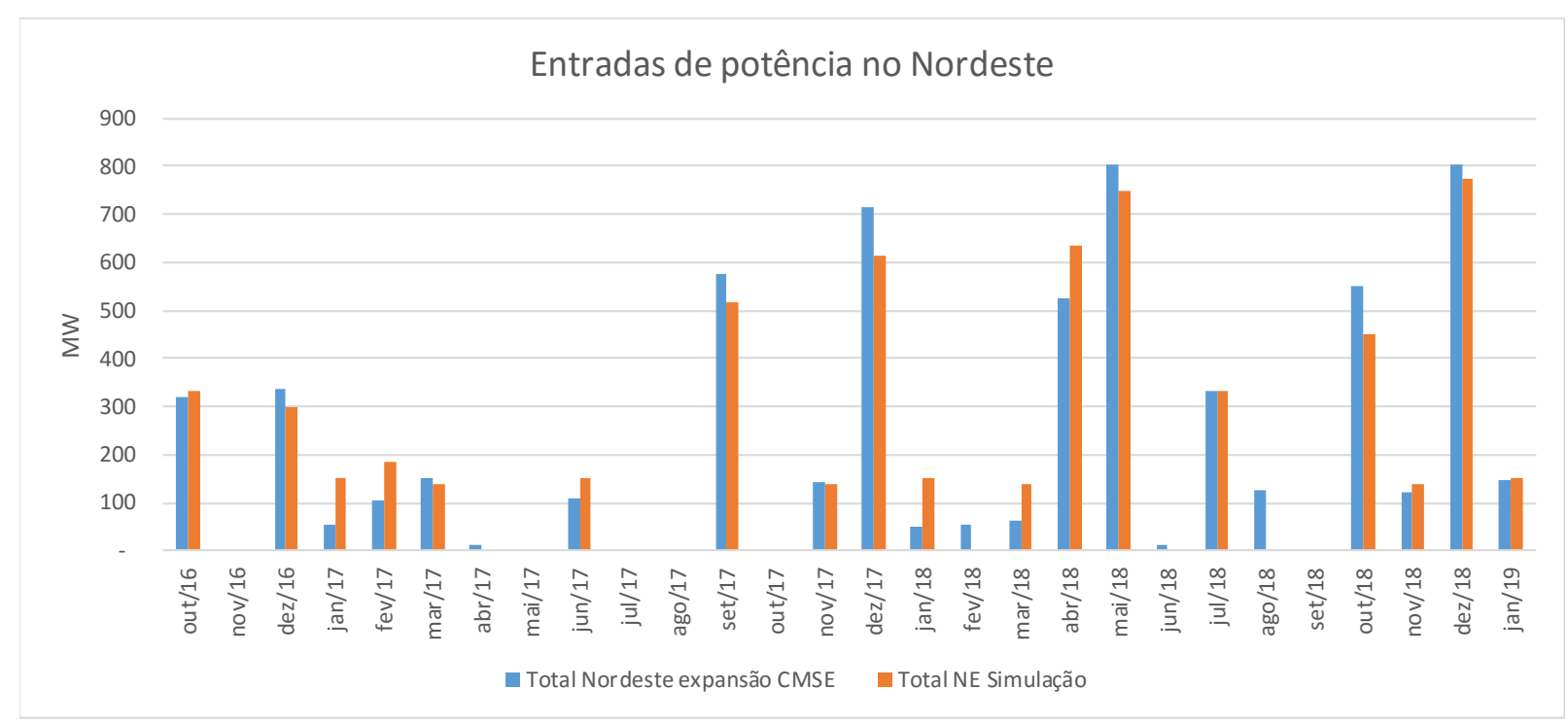

Fonte: Elaboração Própria

Figura 73: Expansão do Sul

Entradas de potência no Sul

250

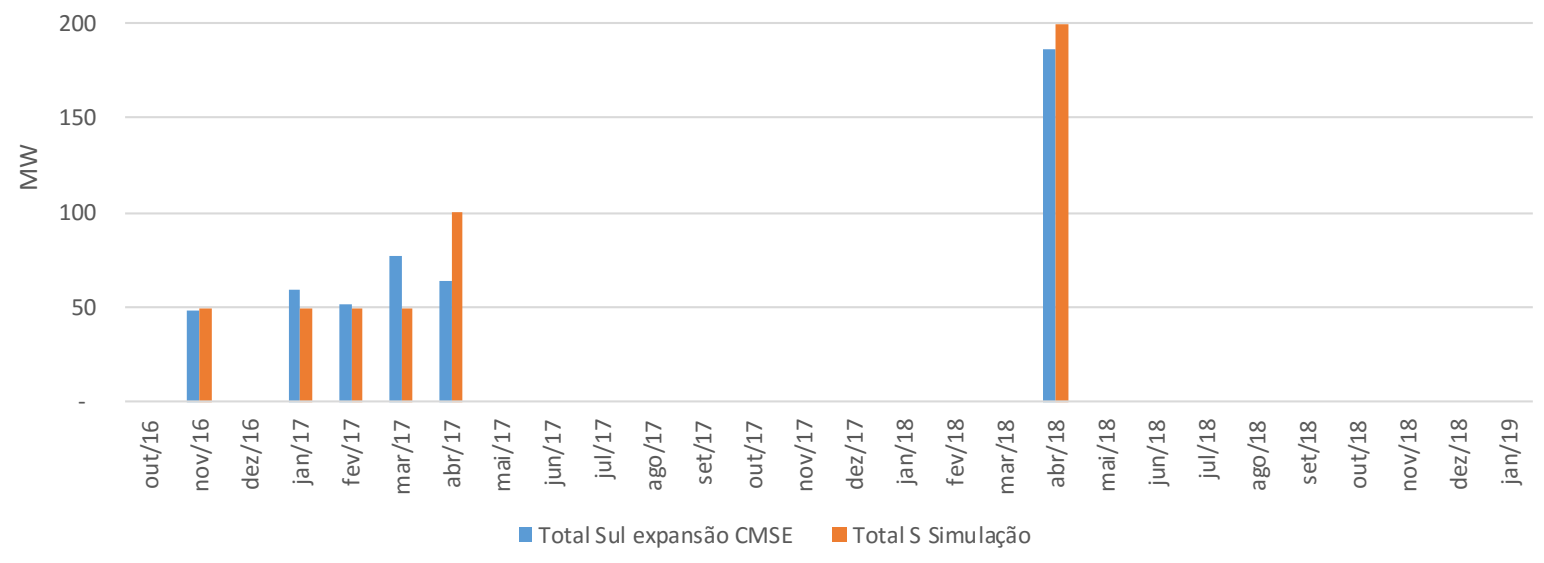

Fonte: Elaboração Própria 


\subsection{Cenários de simulações}

As simulações do modelo Newave são as seguintes, considerando o deck de agosto de 2016:

1) Caso denominado "Simulações eólicas históricas": séries históricas com turbinas otimizadas, 4 REEs no Nordeste e 2 no Sul de geração eólica. Este caso é comparado com as séries oficiais de agosto/16 considerando o deck com séries históricas e geração eólica determinística.

2) Caso denominado "Simulação crítico históricas": a partir do caso 1, com nível de reservatório inicial para todos os submercados de agosto de 2014 (crítico - Tabela 13) e aumento de carga em $8 \%$ em todos os submercados. Apesar dos níveis dos reservatórios em agosto de 2014 ser maior nos submercados Sul, Nordeste e Norte do que em 2016, é menor no Sudeste que representa 70\% dos reservatórios do SIN. Desta forma, o cenário é considerado crítico. Este caso é comparado com as séries oficiais de agosto, mas considerando os mesmos níveis de reservatórios iniciais de agosto de 2014 e aumento de carga também em $8 \%$ para todos os submercados.

Tabela 13: Níveis dos reservatórios iniciais em agosto de 2014, 2015 e 2016

\begin{tabular}{|c|c|c|c|}
\hline & $\begin{array}{c}\text { Nível dos } \\
\text { reservatórios } \\
\text { em 31/07/2014 }\end{array}$ & $\begin{array}{c}\text { Nível dos } \\
\text { reservatórios } \\
\text { em 31/07/2015 }\end{array}$ & $\begin{array}{c}\text { Nível dos } \\
\text { reservatórios em } \\
31 / 07 / 2016\end{array}$ \\
\hline SE & $\mathbf{3 4 , 4 0 \%}$ & $37,40 \%$ & $51,50 \%$ \\
\hline S & $\mathbf{9 0 , 5 0 \%}$ & $96,80 \%$ & $88,10 \%$ \\
\hline NE & $\mathbf{3 2 , 3 0 \%}$ & $22,50 \%$ & $23,30 \%$ \\
\hline N & $\mathbf{8 4 , 9 0 \%}$ & $\mathbf{7 5 , 6 0 \%}$ & $54,40 \%$ \\
\hline
\end{tabular}

Fonte: ONS (2016).

3) Caso denominado "Capacidade eólica aumentada": com base no caso 1, considerando aumento da capacidade eólica em 10 vezes, próxima da capacidade instalada hidráulica, com a manutenção das térmicas.

4) Caso denominado "Simulações eólicas sintéticas": idem ao caso 1, mas considerando as séries sintéticas. 


\subsection{Resultados e Análises}

Os principais resultados que se deseja observar com o suporte destes casos são:

- A complementaridade da eólica com a hidráulica, verificando-se em períodos de hidrologia desfavorável, se a eólica contribui efetivamente mais nestes períodos;

- Se a metodologia estocástica consegue mostrar a variabilidade da eólica;

- Se em períodos críticos, com baixas afluências e carga elevada, a geração eólica é mais elevada do que em um cenário médio nas simulações;

- Se com o aumento "em dez vezes" da capacidade eólica, esta ajuda mais o sistema, uma vez que a eólica representa aproximadamente $9 \%$ da capacidade hidráulica;

- Avaliar o ganho adicional de informação e conhecimento considerando-se as séries sintéticas.

Dois períodos do histórico foram considerados para a apuração e análise dos resultados. O primeiro refere-se aos anos de 1951 a 1955 que apresentam no geral baixas afluências no Nordeste (ENA hidráulica) com a maioria dos meses abaixo da média histórica e média de geração eólica reconstruída (ENA eólica) com alguns meses abaixo da média histórica, de acordo com a Figura 74.

Figura 74: ENA hidráulica e ENA eólica do Nordeste de 1951 a 1955
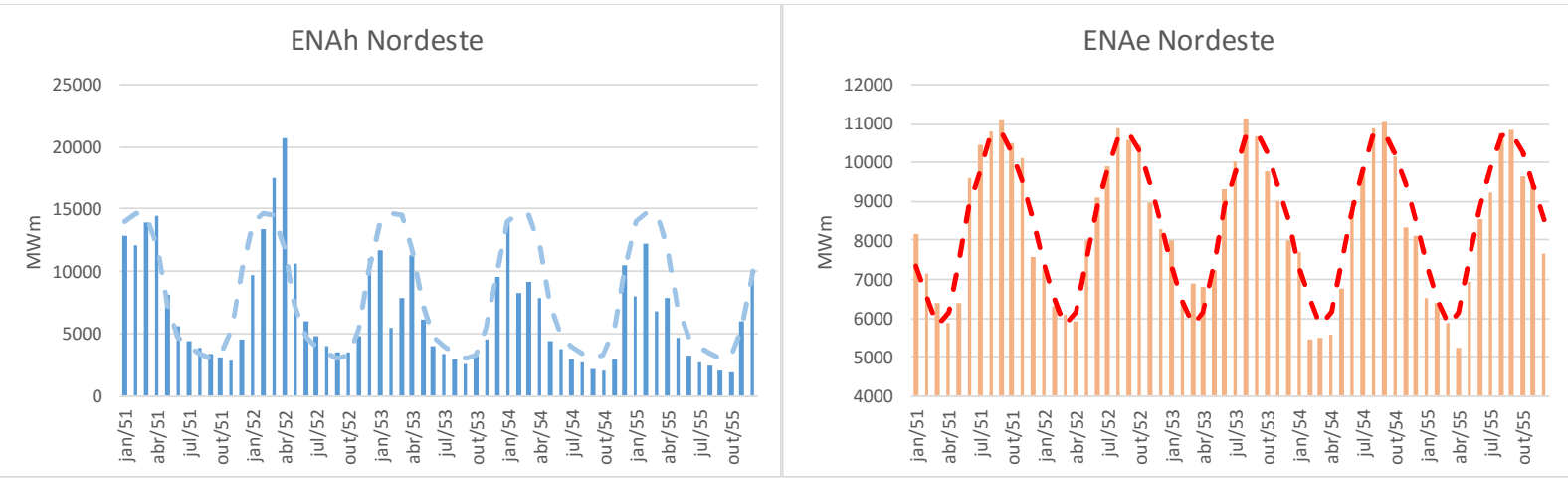

Fonte: Elaboração própria com base na ENA do Nordeste com dados do ONS e reconstrução das séries eólicas deste trabalho 
O segundo período apurado é referente aos anos de 2010 a 2014, representados por ENA hidráulica do Nordeste abaixo da média histórica na maior parte do período e ENA eólica acima da média.

Figura 75: ENA hidráulica e ENA eólica do Nordeste de 2010 a 2014
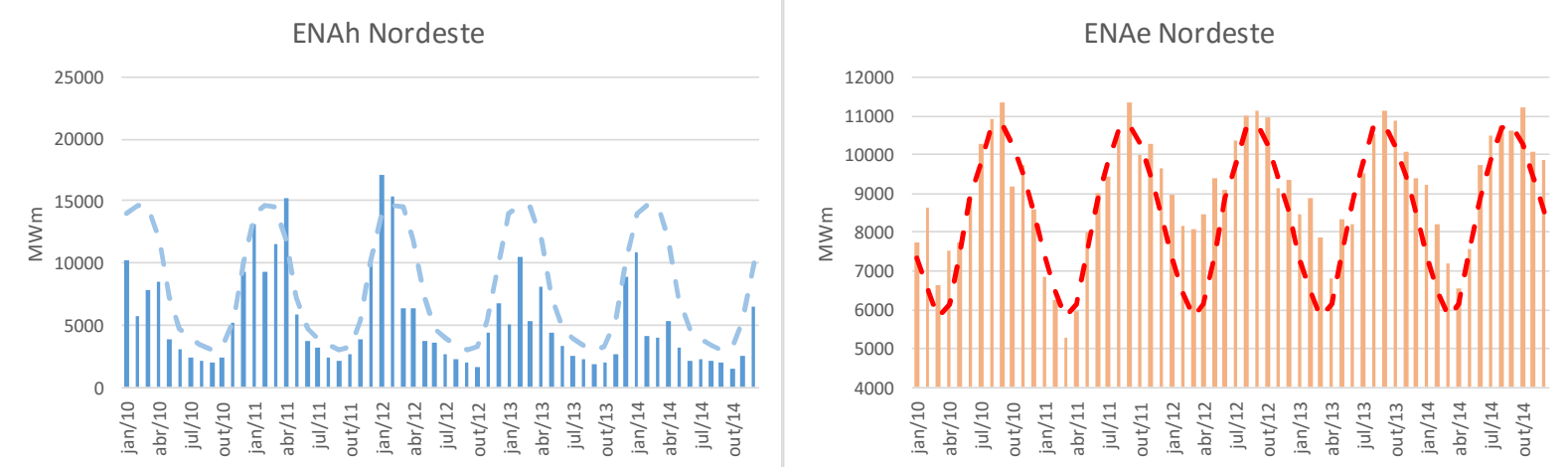

Fonte: Elaboração própria com base na ENA do Nordeste com dados do ONS e reconstrução das séries eólicas deste trabalho

Em relação ao caso com séries sintéticas, são apurados os valores médios mensais, uma vez que as séries sintéticas apresentam 2000 sequências de resultados de ENA (ao invés de valores do histórico de 1931 a 2014) para o horizonte de até 5 anos discretizados mensalmente.

\subsubsection{Caso 1}

Neste primeiro estudo de caso, considerou-se as usinas eólicas separadas em Reservatórios Equivalentes de Energia, com sites eólicos em cada região com séries históricas. A consideração das turbinas eólicas são otimizadas e representam os maiores fatores de capacidade por região.

\subsubsection{Análise de mês específico}

A Tabela 14 mostra o CMO e as gerações hidráulicas, térmicas e eólicas para os quatro submercados, considerando-se o caso oficial e a simulação com as eólicas em reservatórios equivalentes em um mês específico, no caso agosto do quarto ano. As três primeiras colunas de valores da tabela representam o caso oficial com séries históricas. A quarta coluna até a sexta 
representam os valores da simulação. As três primeiras colunas, referem-se, respectivamente: média de agosto de 2019 (simulação de 2016 a 2020, sendo que agosto de 2019 representa agosto do quarto ano), média de agosto de 1954 (simulação de 1951 a 1955) e média de agosto de 2013 (simulação de 2010 a 2014). As demais colunas apresentam a análise dos mesmos meses, mas considerando o cenário da simulação.

Tabela 14: Análise de CMO e geração em agosto do quarto ano

\begin{tabular}{|c|c|c|c|c|c|c|}
\hline Agosto quarto ano & Oficial média & Oficial 1951-1955 & Oficial 2010-2014 & Simulação média & Simulação 1951-1955 & Simulação 2010-2014 \\
\hline CMO Sudeste (R\$̦/MWh) & 27,75 & 152,14 & 5,51 & 8,70 & 46,85 & 1,84 \\
\hline CMO Sul (R\$/MWh) & 27,27 & 152,13 & 5,50 & 8,41 & 46,86 & 1,84 \\
\hline CMO Nordeste (R\$/MWh) & 21,46 & 85,15 & 5,50 & 1,17 & - & - \\
\hline CMO Norte (R\$̧/MWh) & 24,46 & 114,43 & 5,51 & 6,94 & 43,76 & 1,49 \\
\hline Geração Hidráulica SE & 25.965 & 23.088 & 27.885 & 25.801 & 28.764 & 21.857 \\
\hline Geração Hidráulica S & 11.711 & 11.373 & 13.736 & 10.302 & 6.660 & 13.634 \\
\hline Geração Hidráulica NE & 4.879 & 5.675 & 3.788 & 4.483 & 4.410 & 4.373 \\
\hline Geração Hidráulica N & 5.894 & 5.728 & 3.289 & 6.674 & 7.104 & 7.104 \\
\hline Geração Hidráulica SIN & 48.449 & 45.864 & 48.698 & 47.261 & 46.937 & 46.968 \\
\hline Geração Térmica SE & 2.866 & 3.828 & 2.709 & 2.735 & 2.879 & 2.709 \\
\hline Geração Térmica S & 807 & 976 & 779 & 780 & 779 & 779 \\
\hline Geração Térmica NE & 584 & 715 & 572 & 572 & 572 & 572 \\
\hline Geração Térmica N & 1.261 & 2.585 & 1.209 & 1.209 & 1.209 & 1.209 \\
\hline Geração Térmica SIN & 5.519 & 8.103 & 5.269 & 5.296 & 5.439 & 5.269 \\
\hline Geração Eólica S & 868 & 868 & 868 & 1.049 & 1.051 & 1.154 \\
\hline Geração Eólica NE & 8.262 & 8.262 & 8.262 & 9.492 & 9.670 & 9.706 \\
\hline Geração Eólica SIN & 9.130 & 9.130 & 9.130 & 10.541 & 10.721 & 10.860 \\
\hline
\end{tabular}

Fonte: Elaboração Própria

Analisando-se a tabela, verifica-se que em agosto do quarto ano, a simulação apresenta valores de CMOs menores quando comparados com os valores oficiais. Considerando-se o caso oficial na média, a geração hidráulica do SIN é de 48.449 MWm, no caso da simulação, a geração diminui para 47.261 MWm. A geração térmica também diminui de 5.519 MWm no oficial para 5.296 MWm na simulação. A geração eólica aumenta de $9.130 \mathrm{MWm}$ para $10.541 \mathrm{MWm}$. Consequentemente, com maior geração eólica, há uma menor necessidade térmica, diminuindo-se os custos marginais da operação. No caso dos anos de 1951 a 1955, que representam os anos secos, a geração hidráulica é menor por ser um período seco, a geração eólica é maior dada a sua complementaridade, necessitando de menor geração térmica e reduzindo-se os custos marginais. Já para o período de 2010 a 2014, como os ventos são maiores no período, a geração eólica é ainda maior, reduzindo-se ainda mais a geração térmica e os custos marginais ficam próximos de zero.

Nem sempre a geração eólica do Nordeste é maior na simulação. Conforme pode ser observado na Tabela 15, através dos meses de fevereiro do último ano, sendo eles: fevereiro de 
2020, fevereiro de 1955 e fevereiro de 2014. Como o mês em análise é fevereiro, mês com baixa geração eólica, a geração eólica da simulação na média no Nordeste é de $3.952 \mathrm{MWm}$, enquanto que no caso oficial, a geração é de 5.174 MWm. Mesmo assim, o custo marginal da operação na simulação é menor do que no oficial, uma vez que a maior geração eólica de meses anteriores, gerou menor quantidade de hidrelétricas, represando mais água nos reservatórios. Consequentemente, há uma maior geração hidráulica do que no caso oficial e menor geração térmica. Com isso, os CMOs ficam menores. Em relação aos anos de 1951 a 1955 e 2010 a 2014, há uma maior geração eólica por serem períodos secos do histórico, o que faz com que os custos marginais da operação fiquem mais baratos do que o mesmo período do caso oficial.

Tabela 15: Análise de CMO e geração em fevereiro do quinto ano

\begin{tabular}{|c|c|c|c|c|c|c|}
\hline Fevereiro quinto ano & Oficial média & Oficial 1951-1955 & Oficial 2010-2014 & Simulação média & Simulação 1951-1955 & Simulação 2010-2014 \\
\hline CMO Sudeste (R\$/MWh) & 23,60 & 415,86 & 65,22 & 9,04 & 104,67 & 22,20 \\
\hline CMO Sul (R\$/MWh) & 24,19 & 415,87 & 65,21 & 9,04 & 104,67 & 22,20 \\
\hline CMO Nordeste (R\$/MWh) & 7,96 & 99,14 & - & 2,43 & 3,51 & - \\
\hline CMO Norte (R\$/MWh) & 8,03 & 99,14 & - & 2,46 & 3,50 & - \\
\hline Geração Hidráulica SE & 44.125 & 31.604 & 29.940 & 43.490 & 35.507 & 38.137 \\
\hline Geração Hidráulica S & 6.386 & 7.516 & 13.462 & 7.062 & 6.765 & 5.053 \\
\hline Geração Hidráulica NE & 6.152 & 3.772 & 3.852 & 7.692 & 4.156 & 4.163 \\
\hline Geração Hidráulica N & 7.310 & 15.474 & 16.599 & 6.880 & 15.467 & 13.834 \\
\hline Geração Hidráulica SIN & 63.974 & 58.364 & 63.854 & 65.124 & 61.894 & 61.188 \\
\hline Geração Térmica SE & 2.880 & 7.186 & 2.945 & 2.747 & 3.843 & 2.845 \\
\hline Geração Térmica S & 1.065 & 1.242 & 1.199 & 1.054 & 1.231 & 1.041 \\
\hline Geração Térmica NE & 594 & 715 & 572 & 574 & 572 & 572 \\
\hline Geração Térmica N & 1.267 & 2.272 & 1.209 & 1.218 & 1.209 & 1.209 \\
\hline Geração Térmica SIN & 5.806 & 11.414 & 5.925 & 5.593 & 6.855 & 5.667 \\
\hline Geração Eólica S & 529 & 529 & 529 & 814 & 731 & 1.000 \\
\hline Geração Eólica NE & 5.174 & 5.174 & 5.174 & 3.952 & 6.002 & 7.627 \\
\hline Geração Eólica SIN & 5.704 & 5.704 & 5.704 & 4.766 & 6.733 & 8.627 \\
\hline
\end{tabular}

Fonte: Elaboração Própria

Conforme mencionado antes da Tabela 15, com o aumento da geração eólica, há uma menor geração hidráulica, represando-se mais água nos reservatórios. A Figura 76 mostra o aumento dos níveis dos reservatórios no Sudeste e no Nordeste considerando a simulação com os reservatórios equivalentes de energia. 
Figura 76: Nível dos reservatórios dos submercados caso oficial vs. Simulação Caso 1

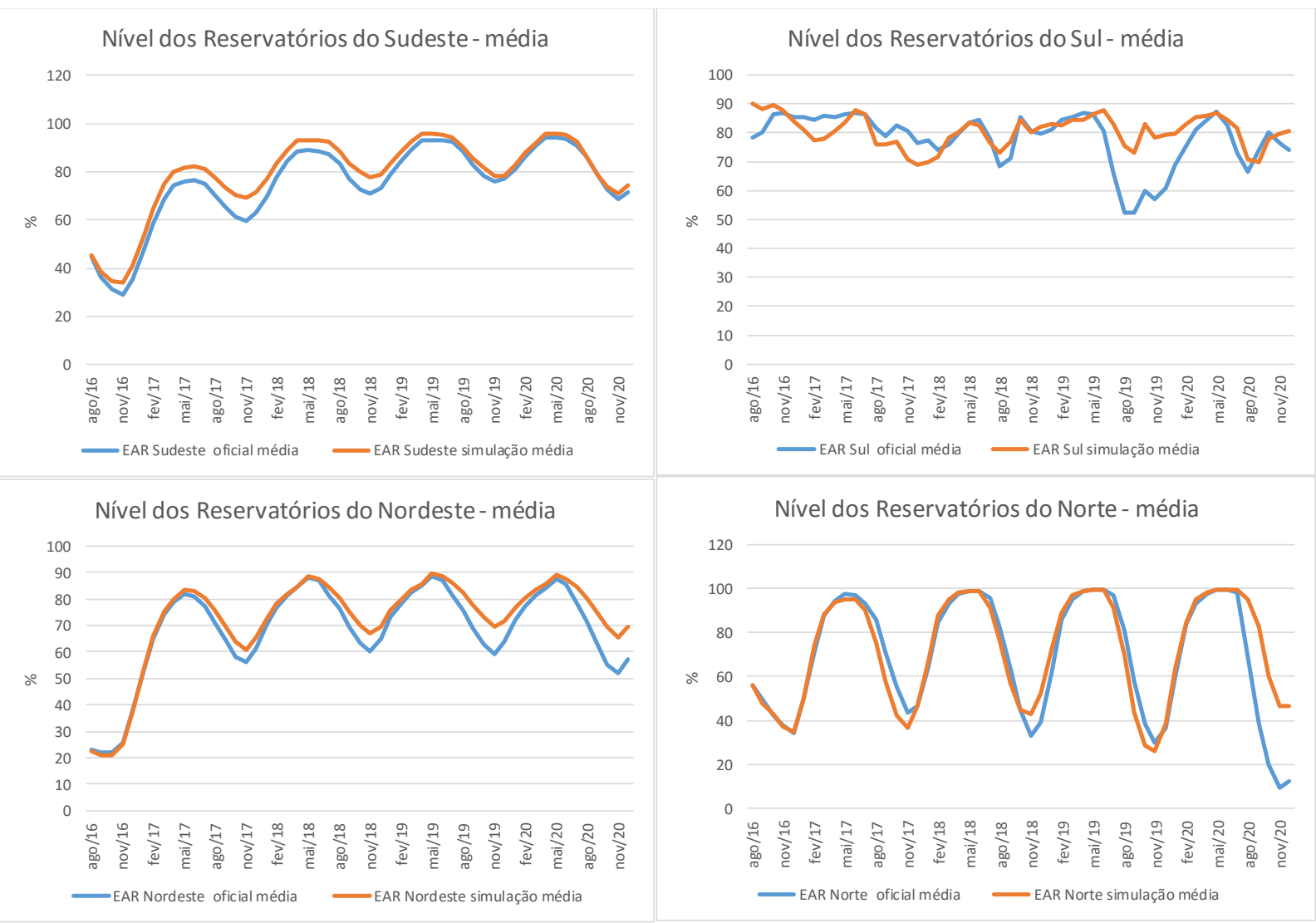

Fonte: Elaboração Própria

\subsubsection{Custo marginal de operação anual do caso 1}

Comparando-se os resultados de custo marginal de operação (CMO) anual das séries do caso 1 com as simulações oficiais históricas, verifica-se que a simulação com eólicas em reservatório equivalente apresenta valores menores do que com as séries históricas oficiais em praticamente todo o horizonte, exceto no primeiro ano.

A Figura 77 mostra o CMO médio anual dos submercados Sudeste, Sul, Nordeste e Norte considerando as séries oficiais com a simulação com eólicas estocásticas do caso 1 . 
Figura 77: CMO médio anual dos submercados com séries oficiais vs. Simulação caso 1

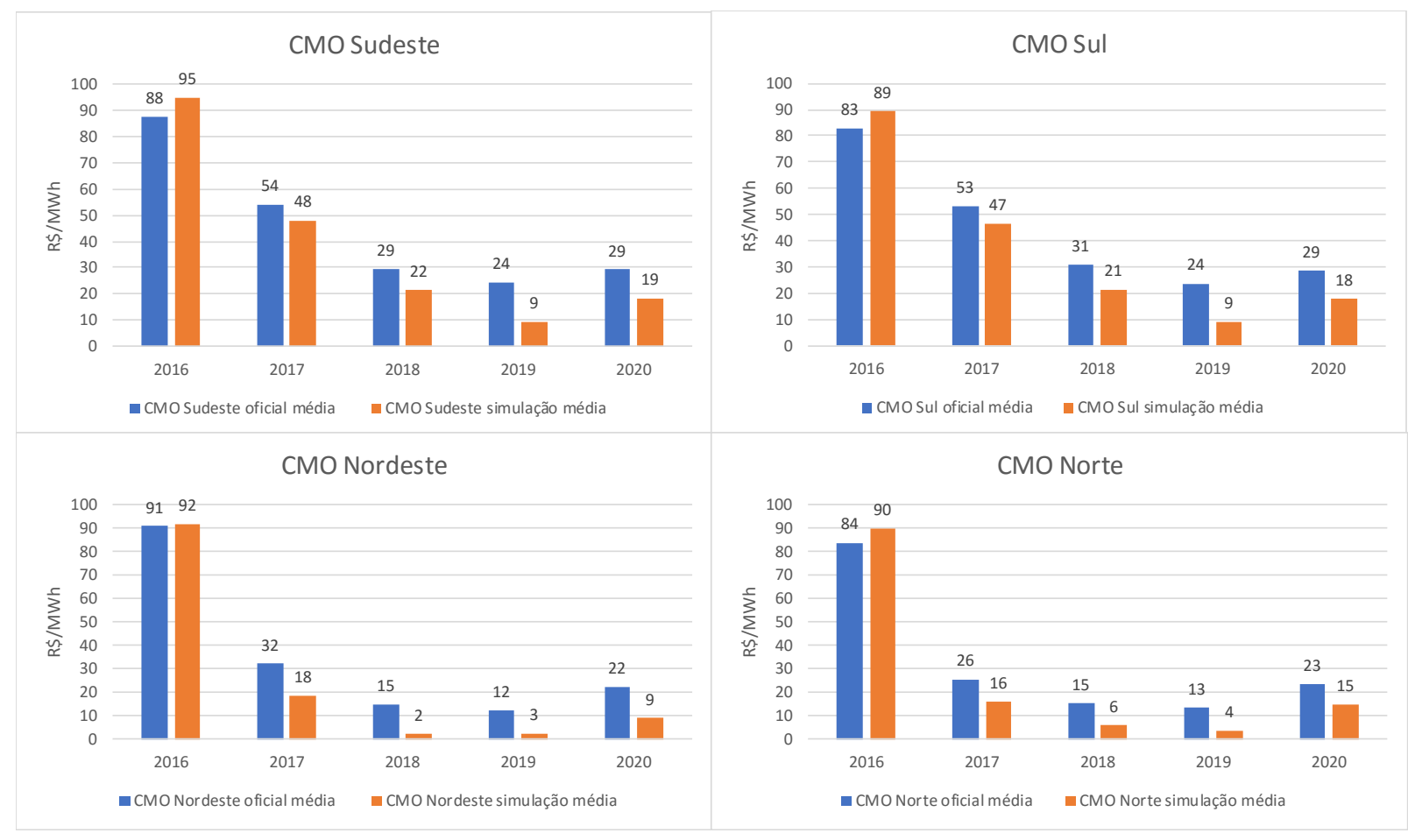

Fonte: Elaboração própria

\subsubsection{Custo marginal de operação mensal do caso 1}

O CMO mensal mostra em geral uma redução dos valores da simulação com eólicas comparando-se com os valores das séries oficiais. As Figura 78, Figura 79 e Figura 80 mostram os custos marginais mensais dos submercados, as barras em cinza mostram a diferença entre os valores oficiais e das simulações no eixo vertical secundário, na mesma unidade do eixo vertical principal. As figuras dos demais casos também apresentam a diferença no eixo vertical secundário. 
Figura 78: CMO médio mensal dos submercados com séries oficiais vs. Simulação caso 1

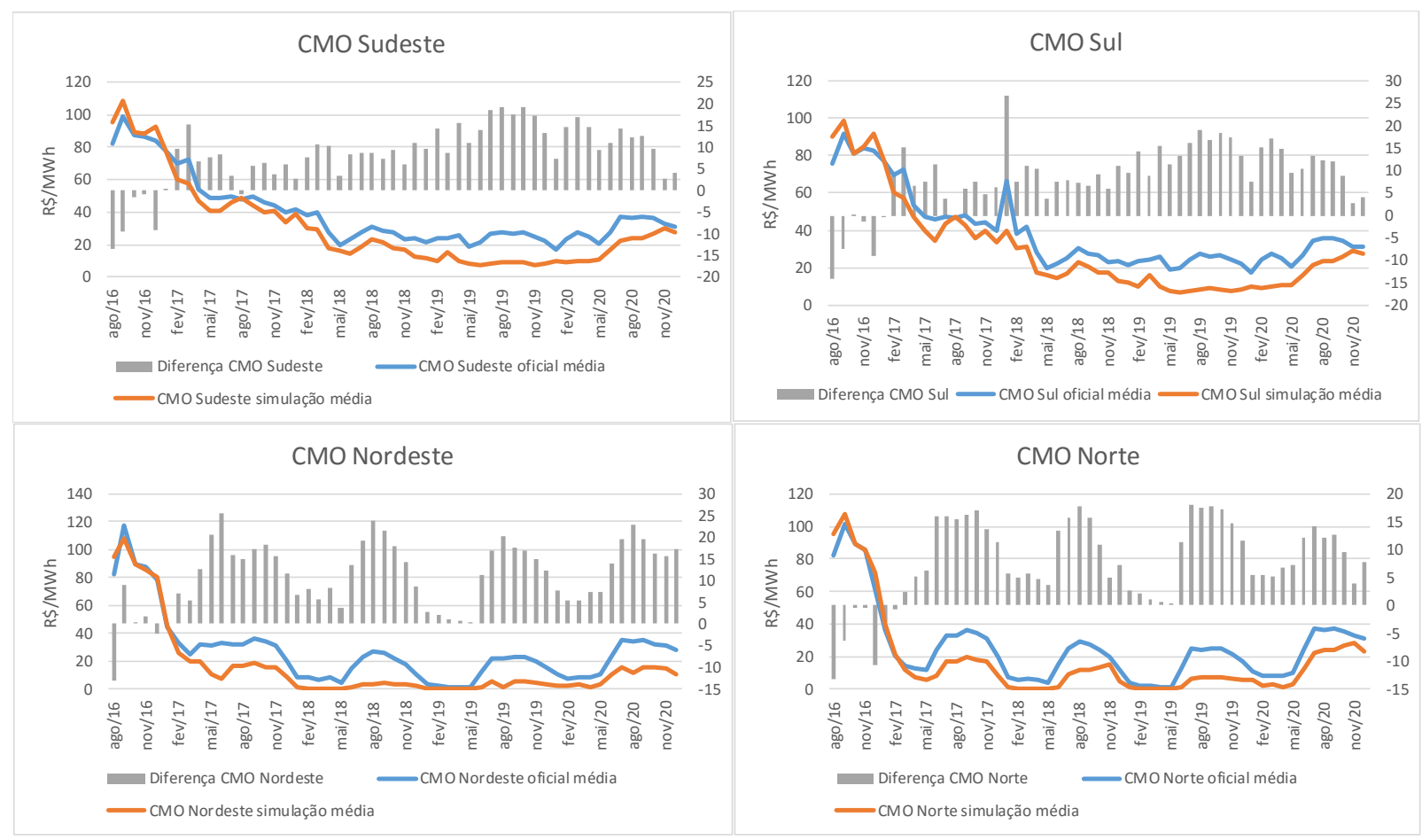

Fonte: Elaboração própria

Verifica-se através da Figura 79 que considerando o período seco de 1951 a 1955, período não favorável de ventos, que os CMOs da simulação oficial são bem mais elevados em todos os submercados na maior parte do período. Dada a complementaridade da hidráulica com a eólica, mesmo em períodos secos, a simulação representa custos marginais menores. 
Figura 79: CMO médio mensal dos submercados com séries oficiais vs. Simulação caso 1 (1951-1955)

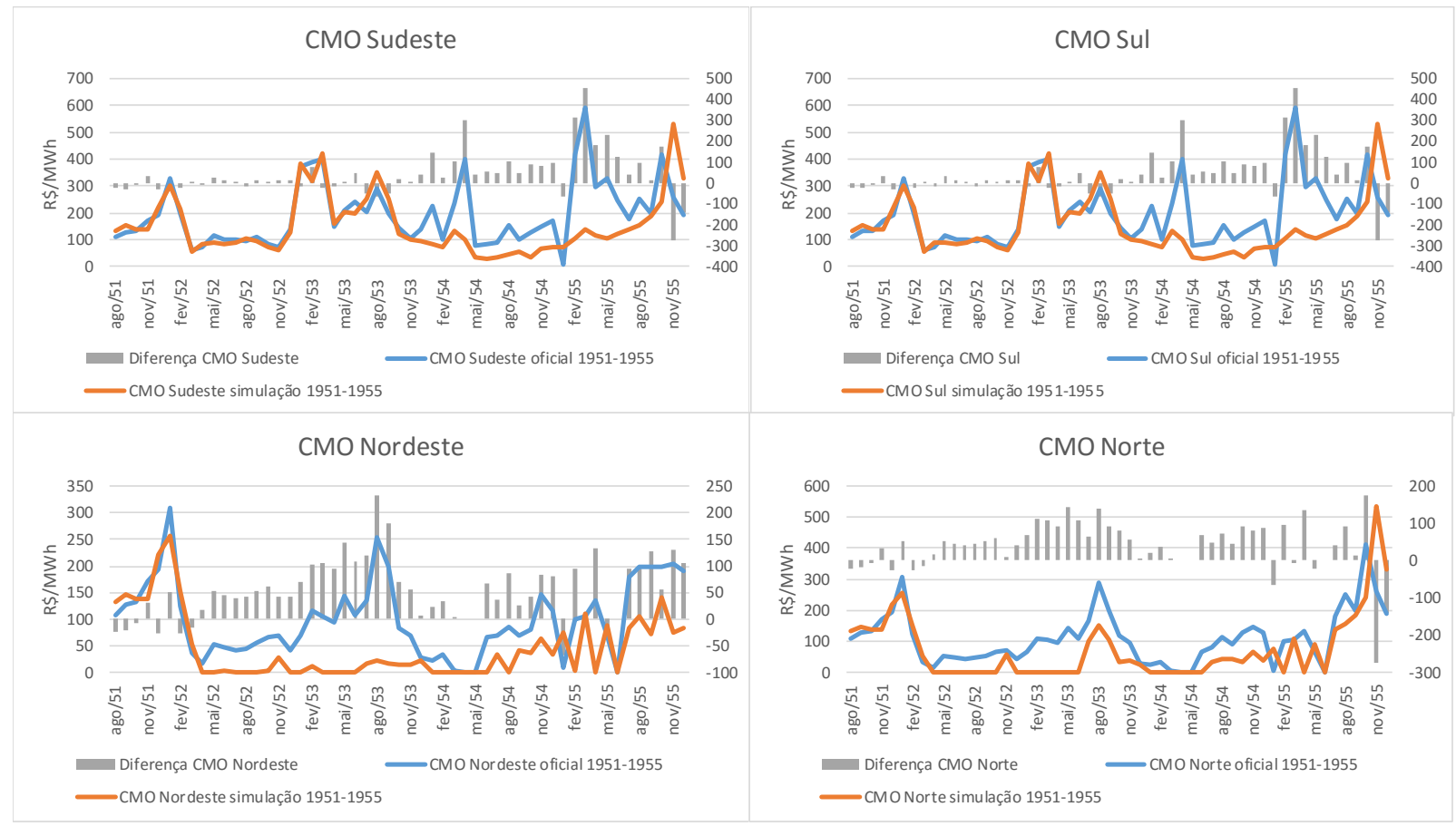

Fonte: Elaboração própria

Considerando o período de 2010 a 2014 que apresentou ENAs do Nordeste abaixo da média, mas condições mais favoráveis de vento, os CMOs são mais reduzidos em relação ao caso de 1951 a 1955. Entretanto, na simulação com eólicas os valores ficam ainda mais baixos.

As reduções de CMOs demonstram que com a simulação considerando as eólicas separadas em Reservatórios Equivalentes de Energia, há uma maior complementaridade da hidráulica com a eólica, necessitando de menor geração térmica. Dessa forma, os custos marginais da operação reduzem. 
Figura 80: CMO médio mensal dos submercados com séries oficiais vs. Simulação caso 1 (2010-2014)

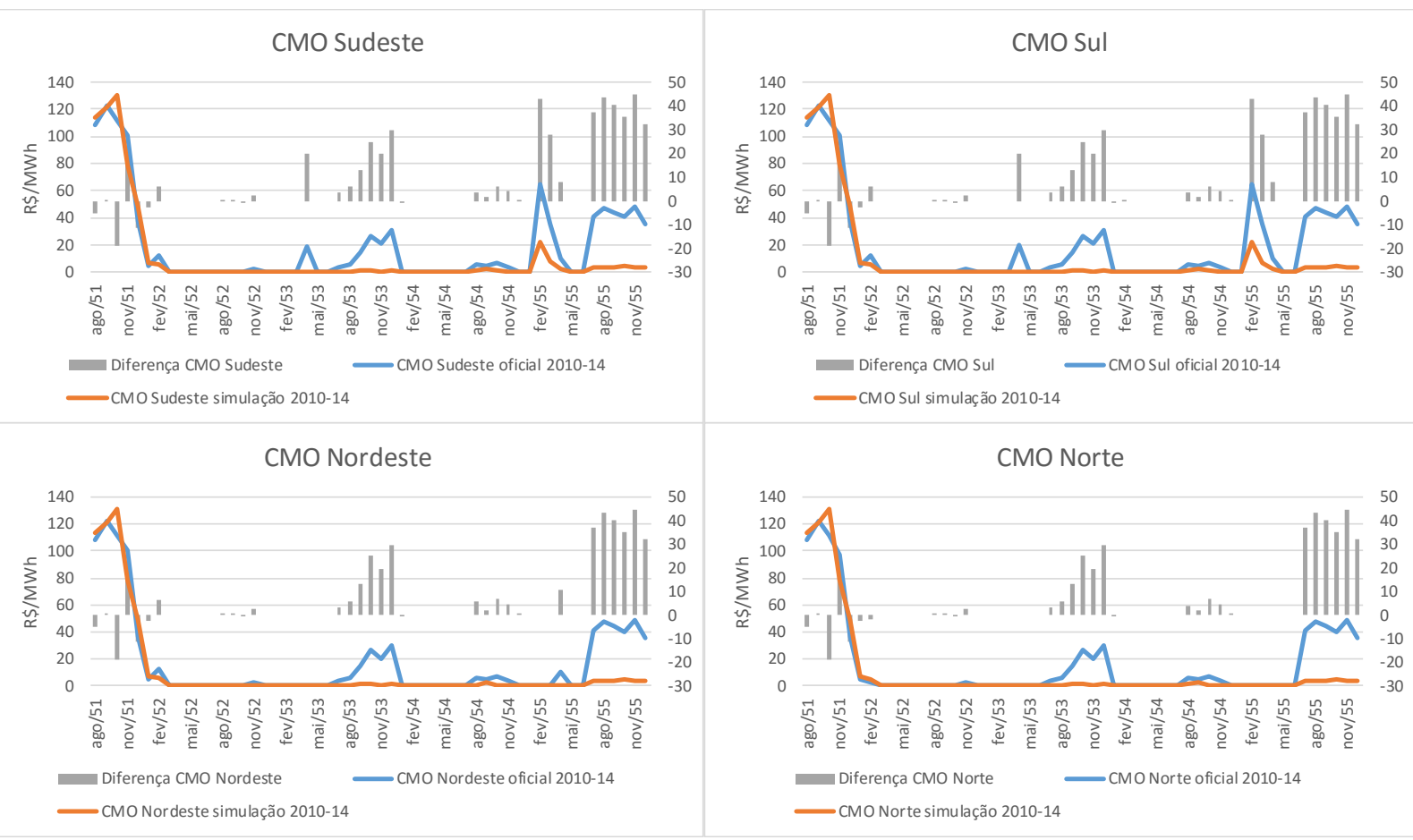

Fonte: Elaboração própria

\subsubsection{Geração hidráulica do caso 1}

Nas regiões Sudeste e Norte, na maior parte do tempo, considerando a média da simulação, os valores de geração hidráulica são maiores no caso oficial do que com a representação eólica. $\mathrm{O}$ Sul não tem um comportamento definido. Já o Nordeste apresenta geração hidráulica maior no caso oficial de maio a novembro e menor de dezembro a abril, do que na simulação. Isso mostra que na simulação com eólicas em REEs, a geração eólica do Nordeste é maior no período seco dado a sua complementaridade com a hidráulica, necessitando de menor geração hidráulica. 
Figura 81: Geração hidráulica anos médios oficial vs. Simulação caso 1

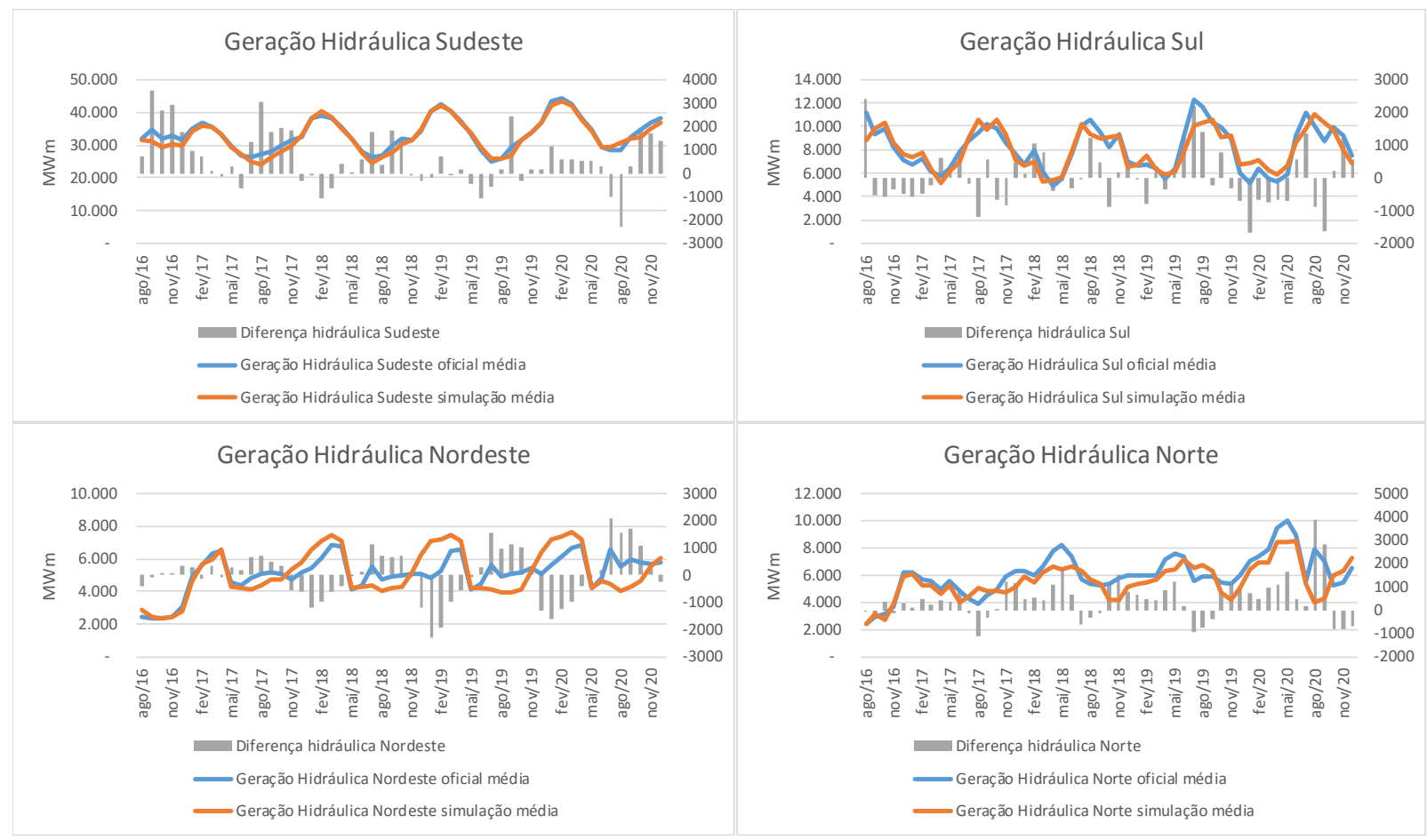

Fonte: Elaboração própria

De forma geral no SIN, há um aumento da geração hidráulica no deck oficial do que na simulação eólica, conforme Figura 82.

Figura 82: Geração hidráulica do SIN anos médios oficial vs. Simulação caso 1

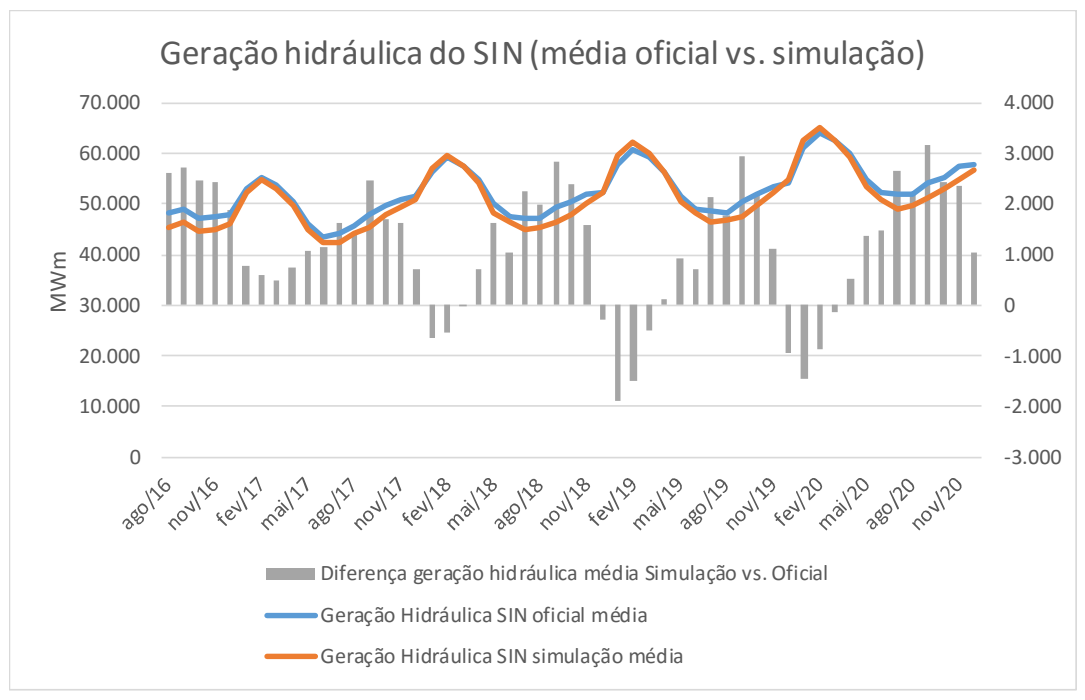

Fonte: Elaboração própria 
Considerando os de 1951 a 1955 em alguns meses em relação à média, a geração hidráulica é reduzida devido a ser um período seco do histórico.

Figura 83: Geração hidráulica oficial vs. Simulação caso 1 (1951-1955)

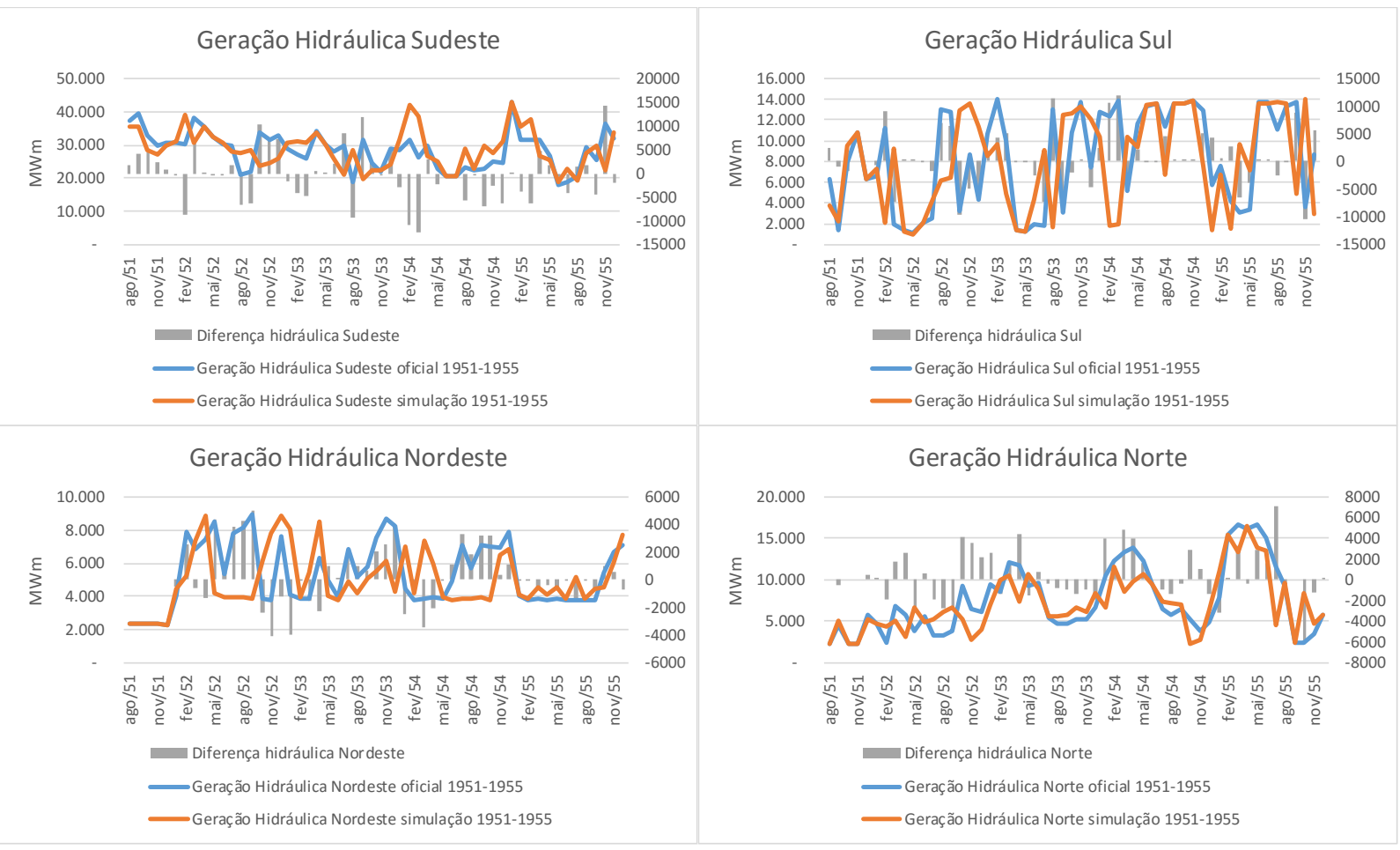

Fonte: Elaboração própria

No SIN, a geração hidráulica da simulação é menor do que no caso oficial na maior parte do período considerando os anos de 1951 a 1955. 
Figura 84: Geração hidráulica no SIN oficial vs. Simulação caso 1 (1951 a 1955)

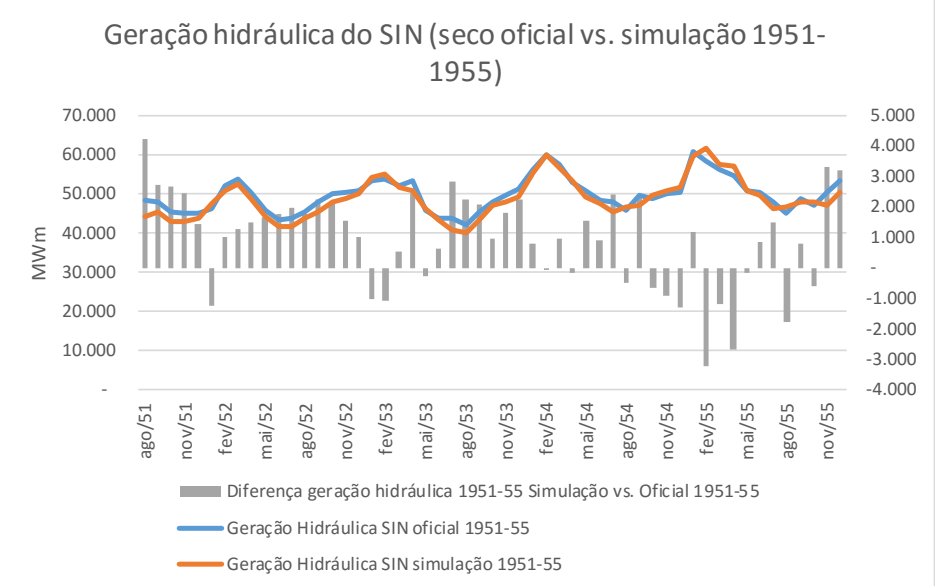

Fonte: Elaboração própria

Considerando os anos de 2010 a 2014, a geração hidráulica tende a ser também maior no caso oficial do que na simulação.

Figura 85: Geração hidráulica oficial vs. Simulação caso 1 (2010-2014)

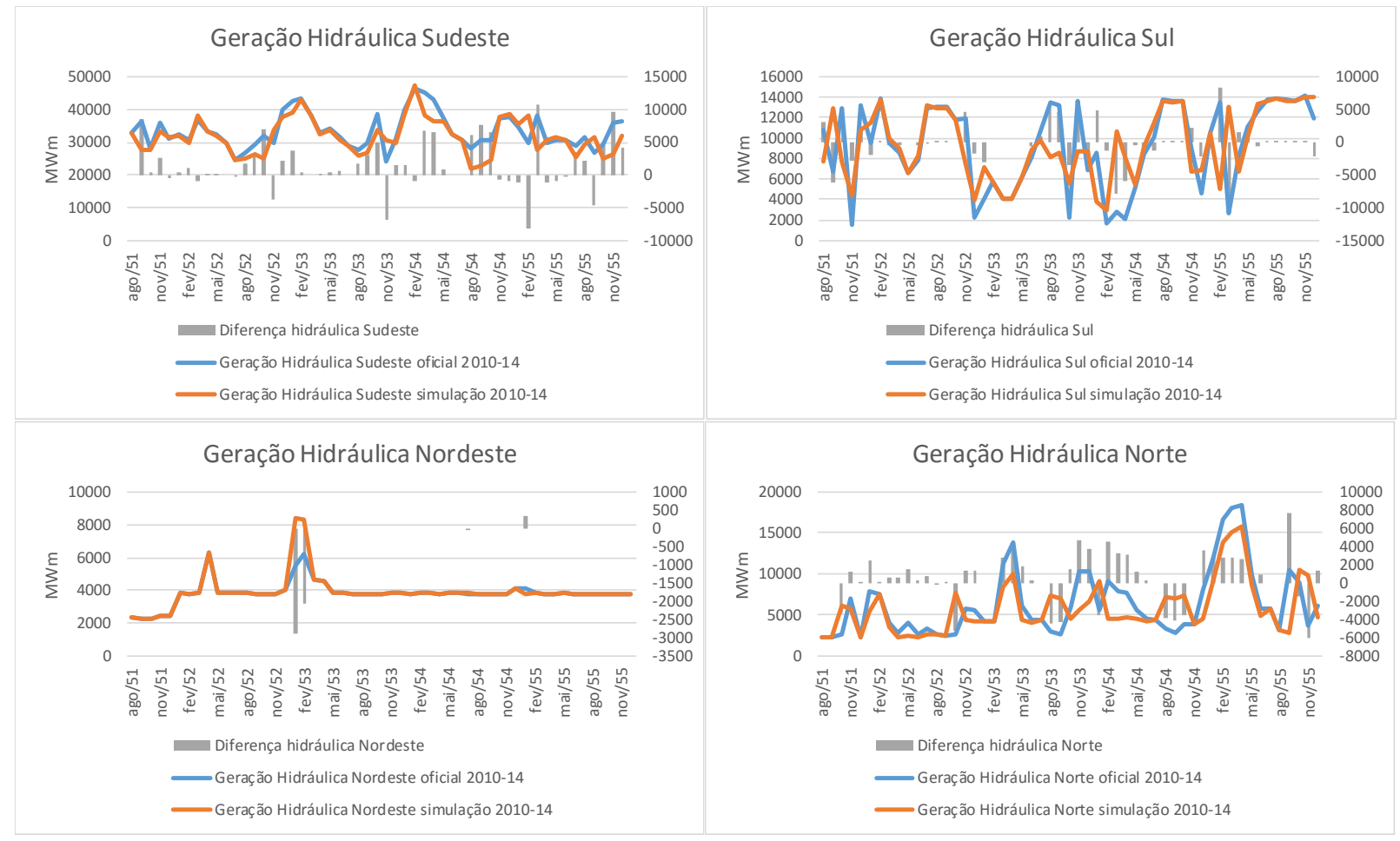

Fonte: Elaboração própria 
Considerando para o SIN, a maior geração hidráulica do caso oficial fica ainda mais nítida.

Figura 86: Geração hidráulica no SIN oficial vs. Simulação caso 1 (2010 a 2014)

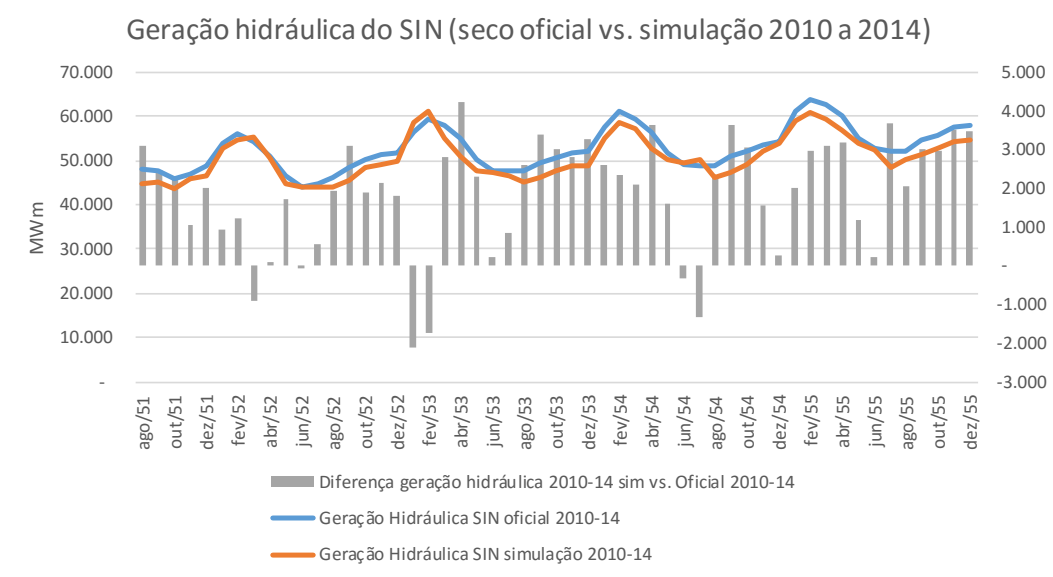

Fonte: Elaboração própria

Assim, com a redução da geração hidráulica considerando a simulação com REEs, dada a complementaridade com as eólicas, os níveis dos reservatórios apresentam replecionamento.

\subsubsection{Geração térmica do caso 1}

Em relação a geração térmica, pode-se verificar na Figura 87, que é maior no caso oficial do que no caso com simulação eólica. 
Figura 87: Geração térmica anos médios oficial vs. Simulação caso 1

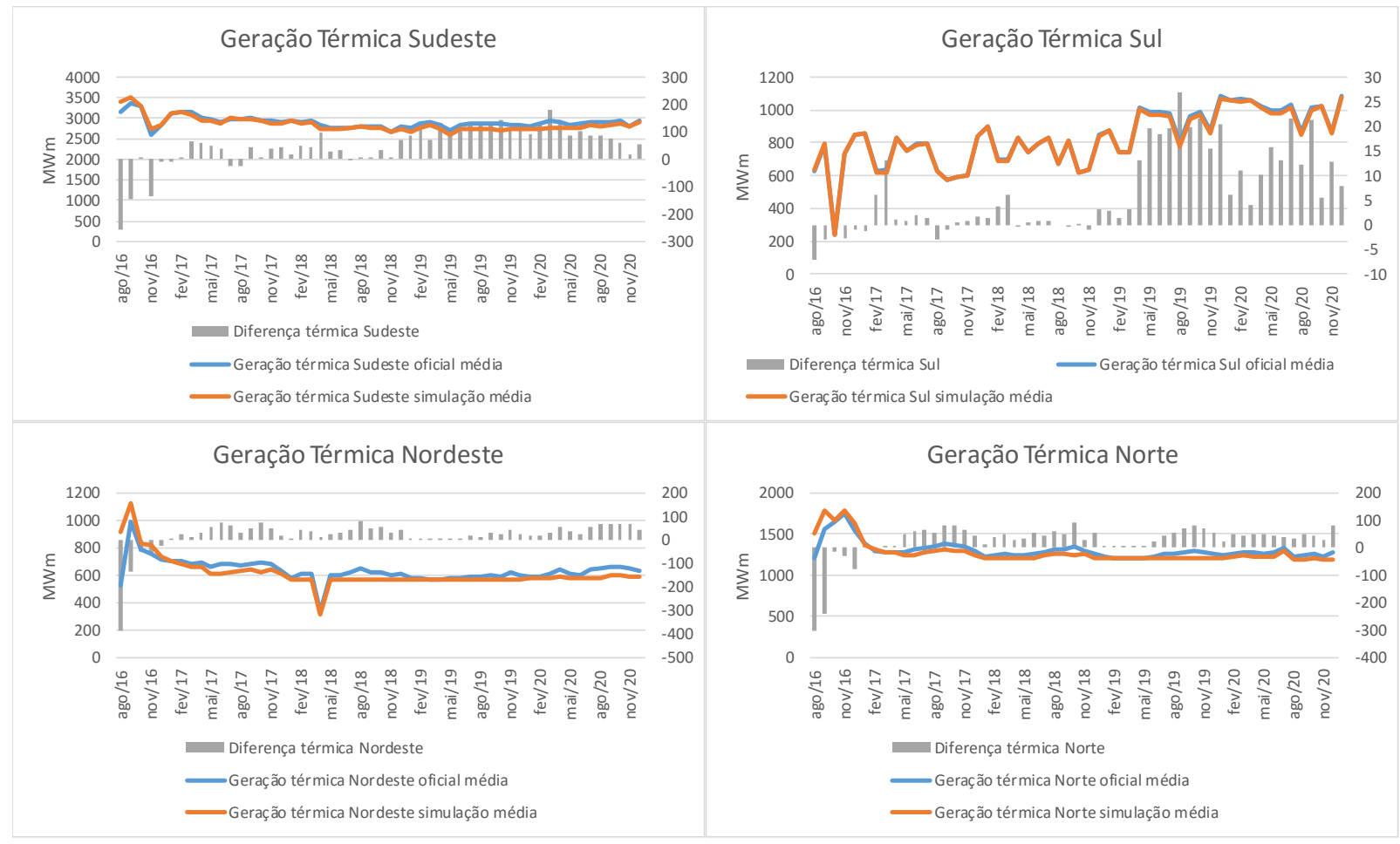

Fonte: Elaboração própria

No SIN, verifica-se uma maior geração térmica no caso oficial do que na simulação conforme Figura 88.

Figura 88: Geração térmica oficial no SIN vs. Simulação caso 1 (média)

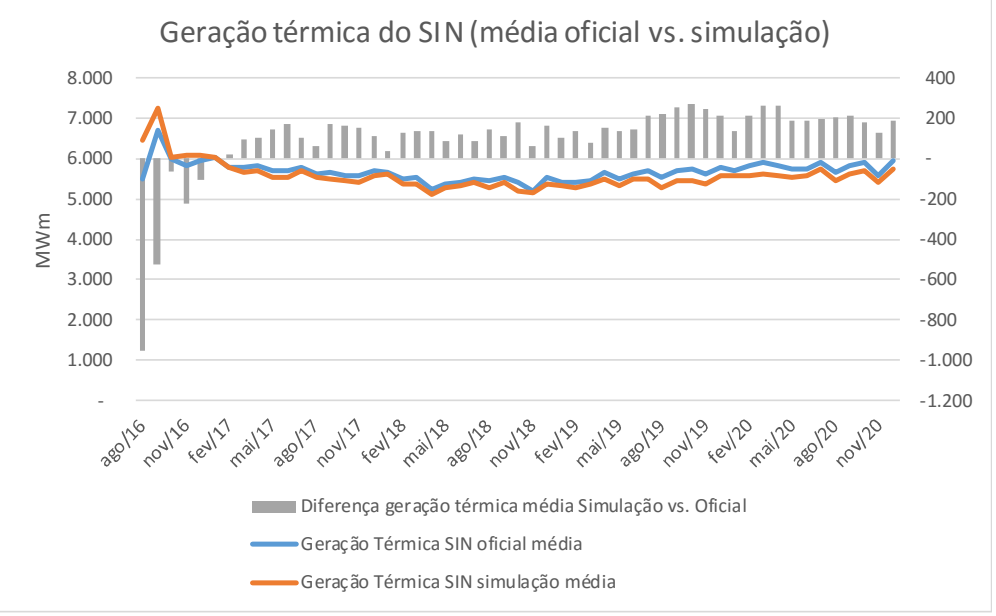

Fonte: Elaboração própria 
Considerando-se os anos de 1951 a 1955, a geração térmica também é maior no caso oficial do que na simulação eólica.

Figura 89: Geração térmica oficial vs. Simulação caso 1

(1951 a 1955)

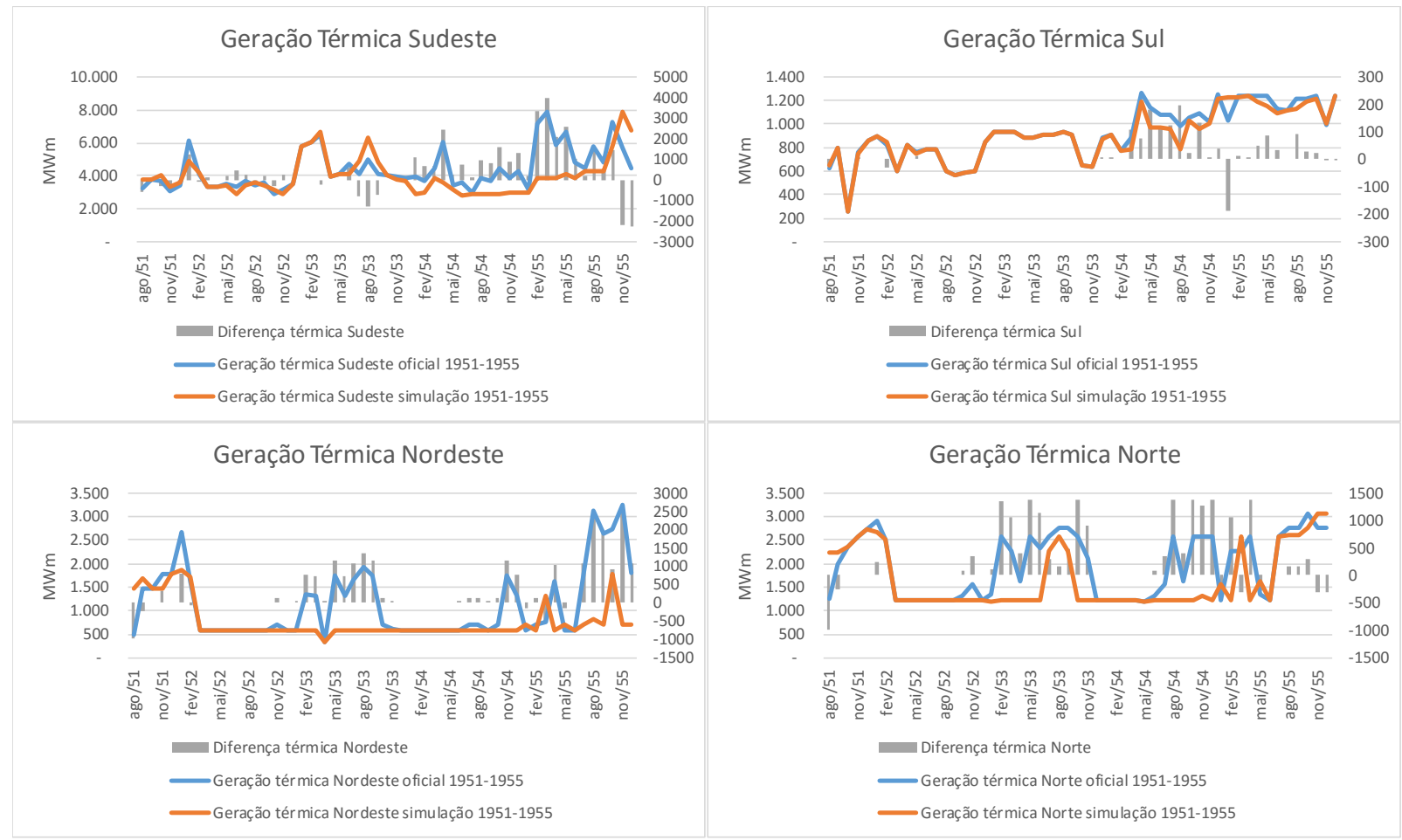

Fonte: Elaboração própria

Considerando para o SIN, a geração térmica apresenta valores mais altos no caso oficial do que na simulação. 
Figura 90: Geração térmica oficial no SIN vs. Simulação caso 1 (1951 a 1955)

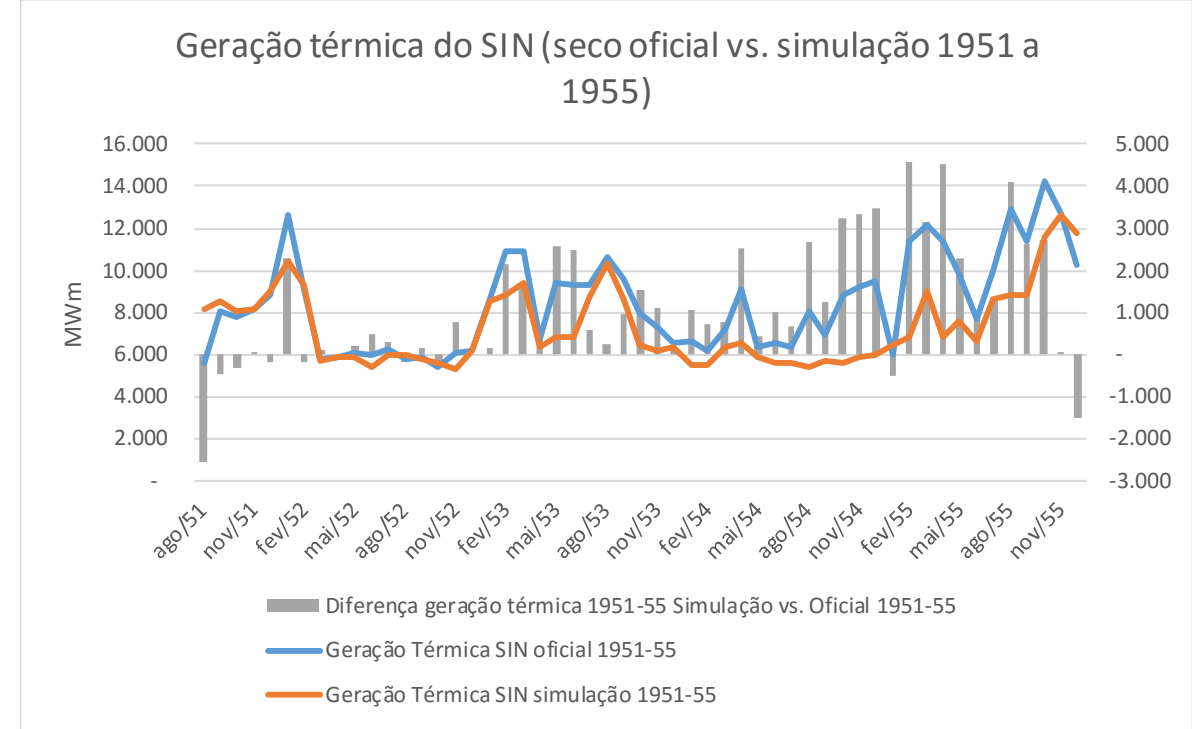

Fonte: Elaboração Própria

Para o período de 2010 a 2014, a diferença de geração térmica é pequena, mas o deck oficial continua com valores maiores do que na simulação na maior parte do período. 
Figura 91: Geração térmica oficial vs. Simulação caso 1

(2010 a 2014)

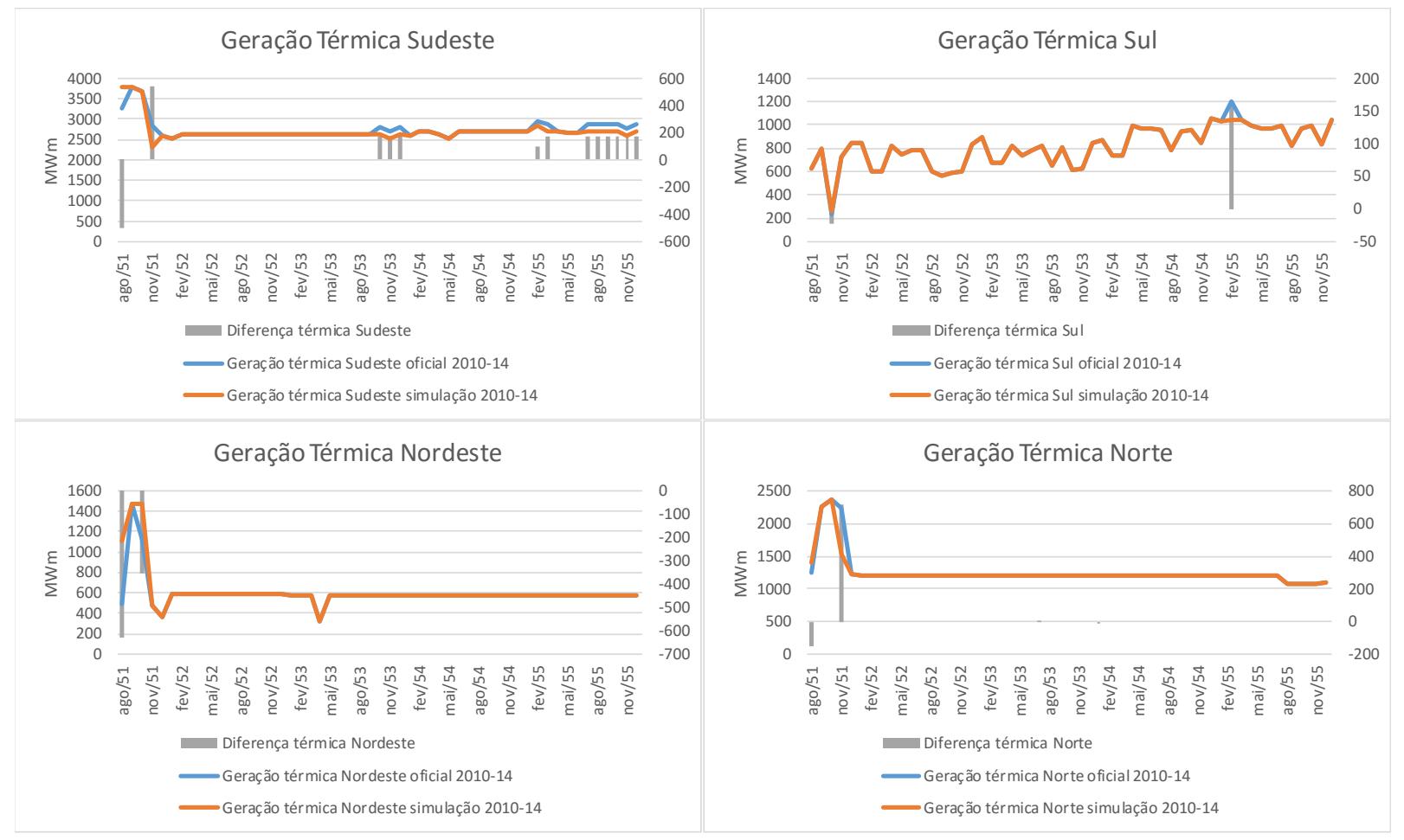

Fonte: Elaboração Própria

Mais uma vez no SIN, a geração térmica do oficial é maior do que na simulação. 
Figura 92: Geração térmica oficial no SIN vs. Simulação caso 1 (2010 a 2014)

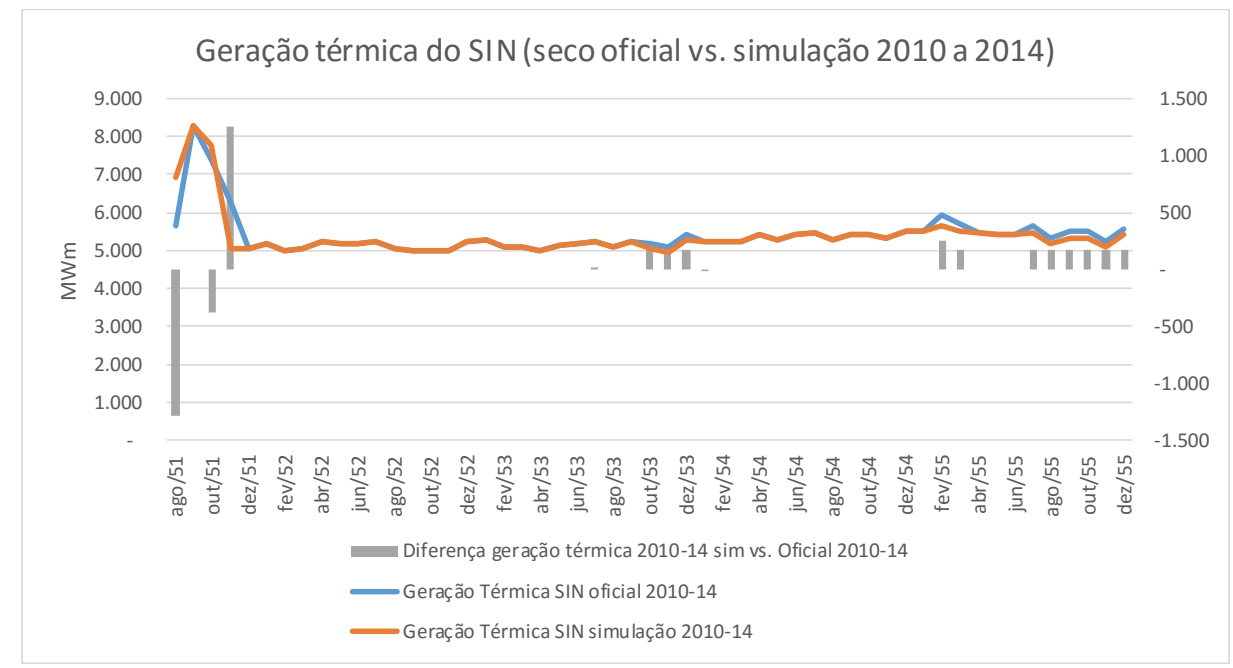

Fonte: Elaboração Própria

\subsubsection{Geração eólica do caso 1}

Em relação a geração eólica, verifica-se que a simulação apresentou a sazonalidade esperada do Nordeste, juntamente com o crescimento da geração ao longo do horizonte devido ao incremento de capacidade instalada. O que fica mais evidenciado na simulação é que no período seco (maio a novembro), a geração eólica da simulação é maior do que os valores determinísticos oficiais e no período úmido (dezembro a abril) há maior geração eólica na série oficial determinística.

Já no Sul, houve maior geração eólica no caso com simulação em reservatório equivalente, uma vez que foram utilizadas turbinas otimizadas. 
Figura 93: Geração Eólica séries históricas vs. Simulação caso 1 (média)
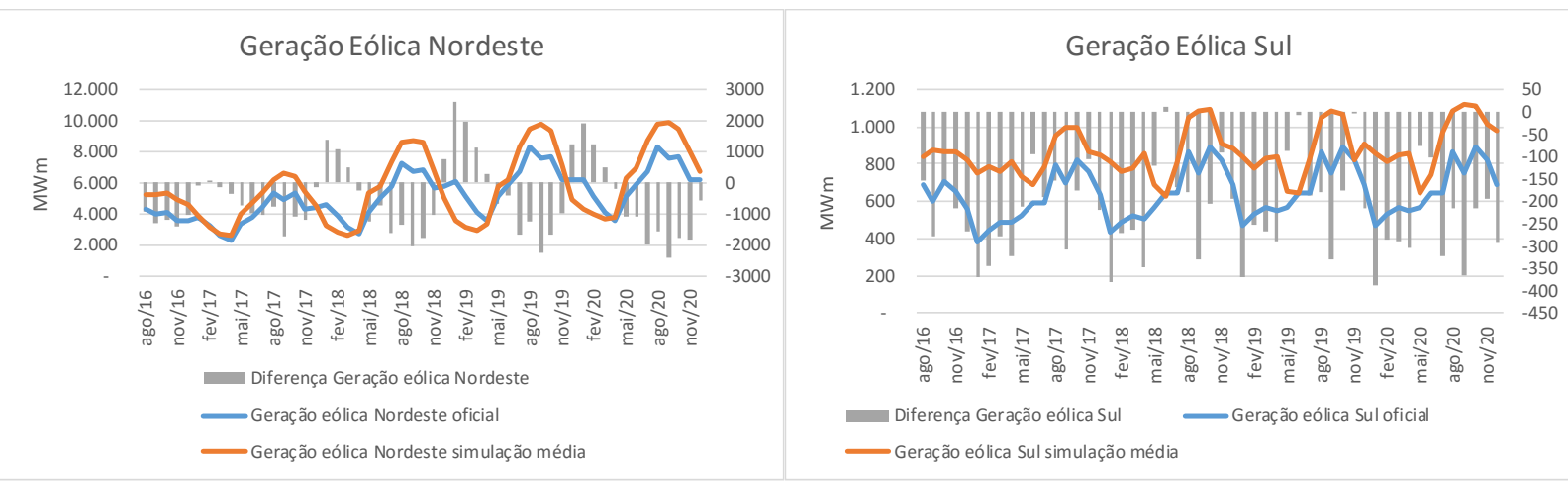

Fonte: Elaboração própria

Considerando os anos secos de 1951-1955, a geração eólica é maior praticamente em todo o período no Nordeste e no Sul com a simulação em reservatórios equivalentes, conforme Figura 94.

Figura 94: Geração Eólica séries históricas vs. Simulação caso 1 (1951 a 1955)
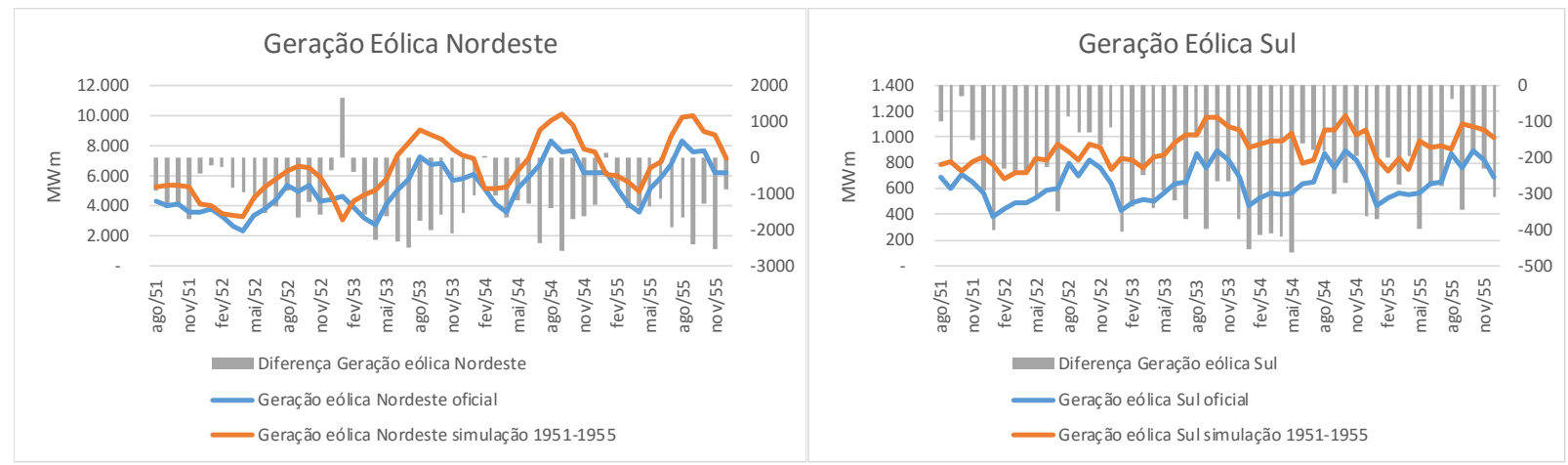

Fonte: Elaboração própria

\subsubsection{Complementaridade do caso 1}

Há uma evidente complementaridade eólica com a hidráulica no Nordeste considerando a média das séries, o que ajuda a manter os custos marginais menores em períodos secos. Na região Sul, não se verifica esta complementaridade. 
Figura 95: Geração Eólica no Nordeste e no Sul (média) caso 1
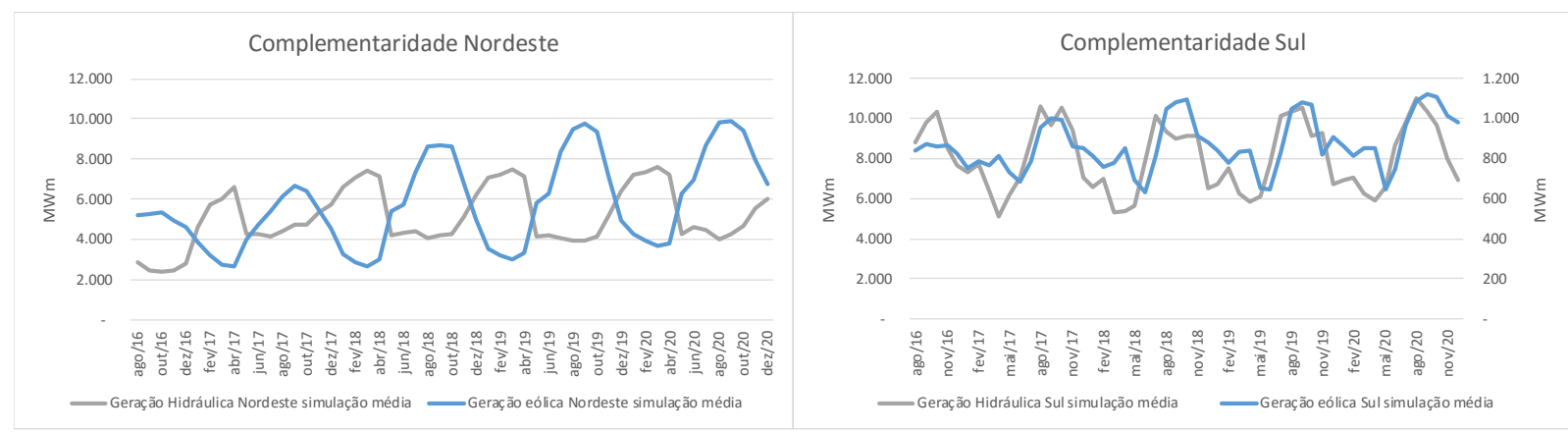

Fonte: Elaboração própria

Ao se considerar o deck oficial, conforme Figura 96, a complementaridade da hidráulica com a eólica não é tão evidente no Nordeste e no Sul continua não se observando essa complementaridade.

Figura 96: Geração Eólica no Nordeste e no Sul oficial caso 1

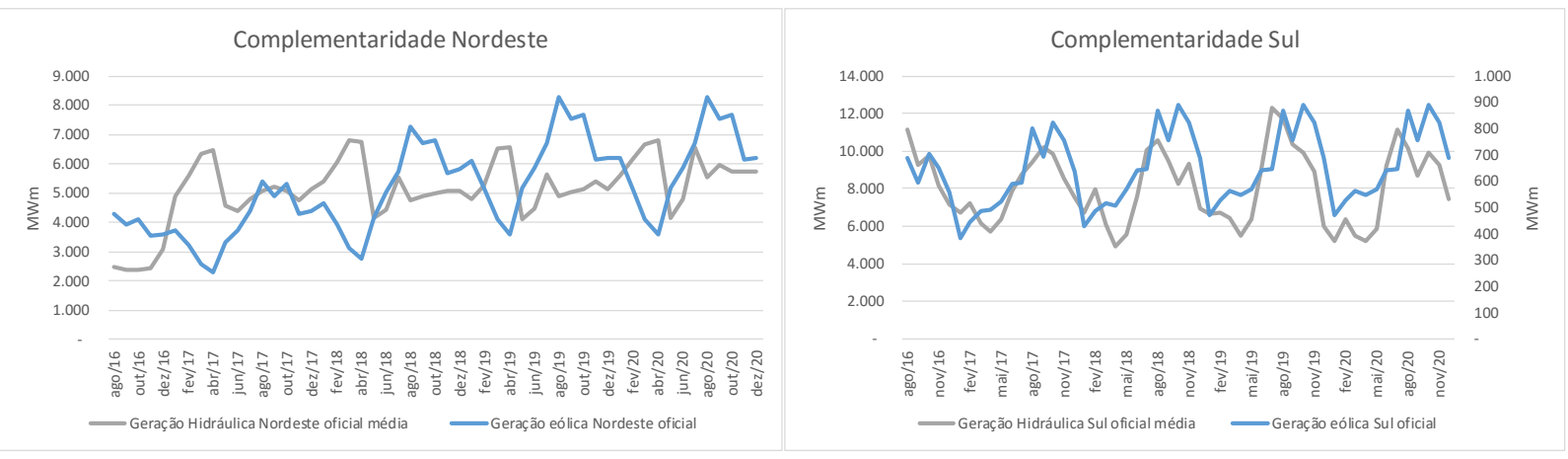

Fonte: Elaboração própria

\subsubsection{Conclusões do caso 1}

Este caso mostrou que com a simulação eólica em Reservatórios Equivalentes de Energia, houve uma maior complementaridade da geração eólica com a geração hidráulica, notou-se uma maior geração eólica nos períodos secos dos anos, necessitando de menor geração térmica e consequente redução dos custos marginais. A consideração das eólicas em séries históricas pôde mostrar em cada cenário, o comportamento em relação a geração hidráulica, mostrando a 
variabilidade da fonte de acordo com as condições de hidrologia, o que não é identificado em séries determinísticas, que sempre apresenta um valor constante, só variando a sazonalidade e o incremento das capacidades.

\subsubsection{Caso 2}

No segundo estudo de caso, a partir do caso 1, considera-se nível de reservatório inicial de agosto de 2014 e aumento de carga em 8\% em todos os submercados. Este caso é comparado com as séries oficiais de agosto, com os mesmos níveis de reservatórios iniciais de agosto de 2014 e aumento de carga também em $8 \%$ para todos os submercados.

\subsubsection{Análise de mês específico}

A Tabela 16 mostra o $\mathrm{CMO}$ e as gerações hidráulicas, térmicas e eólicas para os submercados, considerando-se o caso oficial crítico e a simulação com as eólicas em reservatórios equivalentes também crítico em agosto do quarto ano. As colunas são representadas da mesma forma que no caso 1.

Tabela 16: Análise de CMO e geração em agosto do quarto ano

\begin{tabular}{|c|c|c|c|c|c|c|}
\hline Agosto quarto ano & Oficial crítico média & Oficial crítico 1951-1955 & Oficial crítico 2010-2014 & Simulação média & Simulação 1951-1955 & Simulação 2010-2014 \\
\hline CMO Sudeste (R\$/MWh) & 165,10 & 805,15 & 67,57 & 110,79 & 445,60 & 41,86 \\
\hline CMO Sul (R\$/MWh) & 160,39 & 805,14 & 67,57 & 108,04 & 445,59 & 41,85 \\
\hline CMO Nordeste (R\$/MWh) & 88,60 & 177,52 & 66,41 & 27,10 & 74,83 & 38,41 \\
\hline CMO Norte (R\$/MWh) & 112,19 & 273,99 & 67,57 & 66,20 & 152,41 & 38,41 \\
\hline Geração Hidráulica SE & 28.732 & 19.246 & 29.877 & 28.146 & 21.112 & 25.670 \\
\hline Geração Hidráulica S & 10.627 & 13.753 & 13.997 & 10.599 & 13.771 & 13.896 \\
\hline Geração Hidráulica NE & 6.216 & 5.523 & 6.687 & 5.028 & 4.818 & 4.851 \\
\hline Geração Hidráulica N & 5.676 & 6.057 & 3.289 & 7.115 & 6.222 & 7.934 \\
\hline Geração Hidráulica SIN & 51.251 & 44.578 & 53.851 & 50.888 & 45.922 & 52.351 \\
\hline Geração Térmica SE & 4.305 & 9.046 & 2.962 & 3.775 & 7.213 & 2.879 \\
\hline Geração Térmica S & 1.020 & 1.466 & 883 & 958 & 1.231 & 779 \\
\hline Geração Térmica NE & 995 & 1.752 & 587 & 593 & 715 & 572 \\
\hline Geração Térmica N & 2.021 & 2.750 & 1.309 & 1.559 & 2.585 & 1.209 \\
\hline Geração Térmica SIN & 8.341 & 15.013 & 5.741 & 6.884 & 11.744 & 5.439 \\
\hline Geração Eólica S & 868 & 868 & 868 & 1.084 & 1.051 & 1.154 \\
\hline Geração Eólica NE & 8.262 & 8.262 & 8.262 & 9.865 & 10.004 & 9.777 \\
\hline Geração Eólica SIN & 9.130 & 9.130 & 9.130 & 10.949 & 11.055 & 10.931 \\
\hline
\end{tabular}

Fonte: Elaboração Própria 
Analisando-se a tabela, verifica-se que em agosto do quarto ano, a simulação apresenta valores de CMOs maiores quando comparados com os valores do caso 1, logicamente porque o cenário é mais crítico, necessitando de maior geração de energia. De qualquer forma, os casos da simulação apresentaram valores de CMO menores do que o caso oficial crítico do caso 2. As gerações hidráulicas e térmicas foram maiores do que no caso 1. A geração eólica foi um pouco maior no Nordeste do que no caso 1 , mas não deveria ser muito diferente, uma vez que desde o primeiro caso, como a geração deriva do mesmo histórico, já deveriam produzir o máximo.

Analisando-se a Tabela 17 para o caso de fevereiro do último ano, percebe-se a mesma geração eólica do que no caso 1 para o período seco de 1951 a 1955 e 2010 a 2014.

Tabela 17: Análise de CMO e geração em fevereiro do quinto ano

\begin{tabular}{|c|c|c|c|c|c|c|}
\hline Fevereiro último ano & Oficial crítico médic & 1951-1955 & 010-2014 & édia & Simulação 1951-1955 & Simulação 2010-2014 \\
\hline CMO Sudeste (R\$/MWh') & 114,87 & $1.469,34$ & 282,63 & 79,81 & 623,50 & 265,66 \\
\hline CMO Sul (R\$/MWh) & 119,47 & $1.469,34$ & 282,64 & 82,39 & 626,76 & 265,66 \\
\hline CMO Nordeste (R\$/MWI & 34,32 & 188,42 & 109,39 & 11,95 & 89,70 & 32,53 \\
\hline CMO Norte (R\$/MWh) & 39,73 & 188,42 & 109,38 & 15,67 & 89,70 & 32,52 \\
\hline Geração Hidráulica SE & 44.975 & 33.150 & 40.950 & 45.025 & 40.437 & 40.479 \\
\hline Geração Hidráulica S & 8.054 & 8.620 & 5.053 & 7.879 & 2.044 & 5.053 \\
\hline Geração Hidráulica NE & 6.001 & 3.754 & 3.796 & 7.217 & 4.101 & 4.119 \\
\hline Geração Hidráulica N & 10.039 & 15.439 & 16.183 & 9.148 & 16.477 & 15.389 \\
\hline Geração Hidráulica SIN & 69.069 & 60.963 & 65.981 & 69.268 & 63.059 & 65.039 \\
\hline Geração Térmica SE & 3.715 & 9.165 & 5.167 & 3.556 & 8.488 & 5.167 \\
\hline Geração Térmica S & 1.120 & 1.477 & 1.242 & 1.104 & 1.242 & 1.242 \\
\hline Geração Térmica NE & 820 & 1.799 & 1.302 & 626 & 715 & 572 \\
\hline Geração Térmica N & 1.429 & 2.750 & 2.461 & 1.273 & 1.621 & 1.209 \\
\hline Geração Térmica SIN & 7.085 & 15.191 & 10.173 & 6.559 & 12.065 & 8.190 \\
\hline Geração Eólica S & 529 & 529 & 529 & 895 & 731 & 1.000 \\
\hline Geração Eólica NE & 5.174 & 5.174 & 5.174 & 5.141 & 6.002 & 7.627 \\
\hline Geração Eólica SIN & 5.704 & 5.704 & 5.704 & 6.036 & 6.733 & 8.627 \\
\hline
\end{tabular}

Fonte: Elaboração Própria

A Figura 97 mostra que a diferença da geração no Nordeste é mínima considerando o caso 1 para o caso 2, como deveria ser uma vez que se está obtendo a geração eólica do mesmo histórico reconstruído nos dois casos. 
Figura 97: Geração eólica do Nordeste e do Sul caso 1 vs. Caso 2
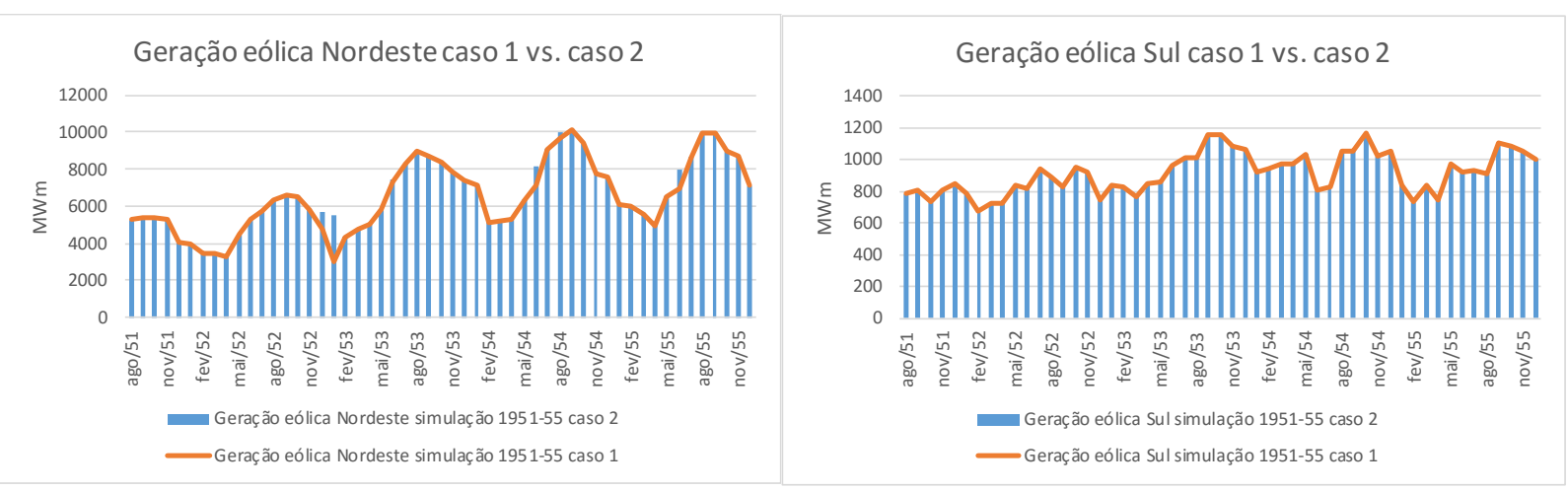

Fonte: Elaboração Própria

\subsubsection{Custo marginal de operação anual do caso 2}

Considerando o cenário de simulação crítico, há um aumento nos custos marginais de operação anuais tanto no caso da simulação eólica quanto com o caso oficial, agora com a mesma partida e aumento de carga do cenário crítico. No entanto, assim como no primeiro estudo de caso, os CMOs com a simulação eólica tendem a ficar mais baixos do que com eólicas determinísticas a partir do segundo ano. 
Figura 98: CMO médio anual dos submercados com séries oficiais vs. Simulação caso 2

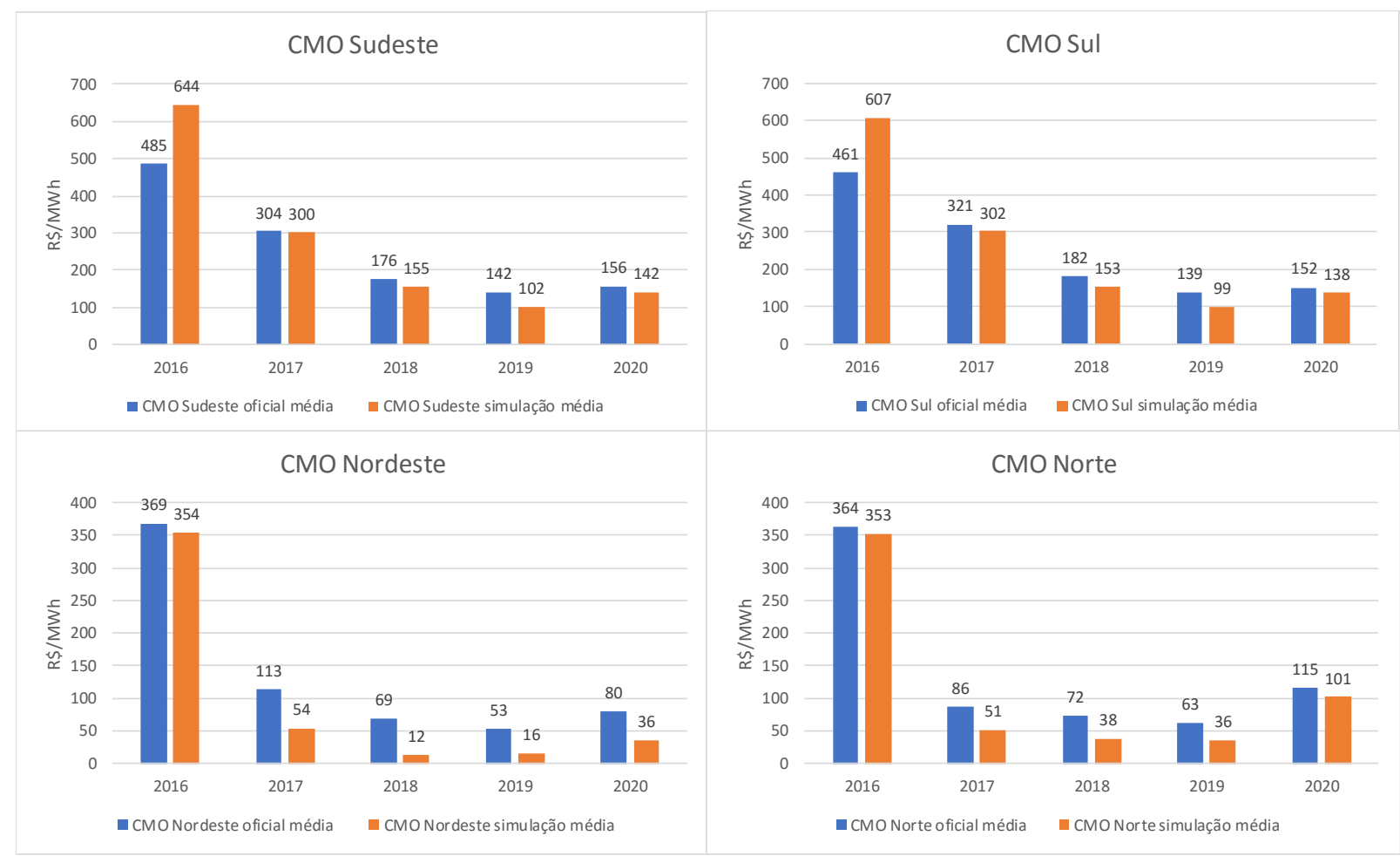

Fonte: Elaboração própria

\subsubsection{Custo marginal de operação mensal do caso 2}

O CMO mensal mostra em geral valores mais baixos da simulação eólica do que com as séries oficiais. A Figura 99 e a Figura 100 mostram os custos marginais mensais dos submercados considerando a média dos valores e o ano seco de 1951-55. 
Figura 99: CMO médio mensal dos submercados com séries oficiais vs. Simulação caso 2

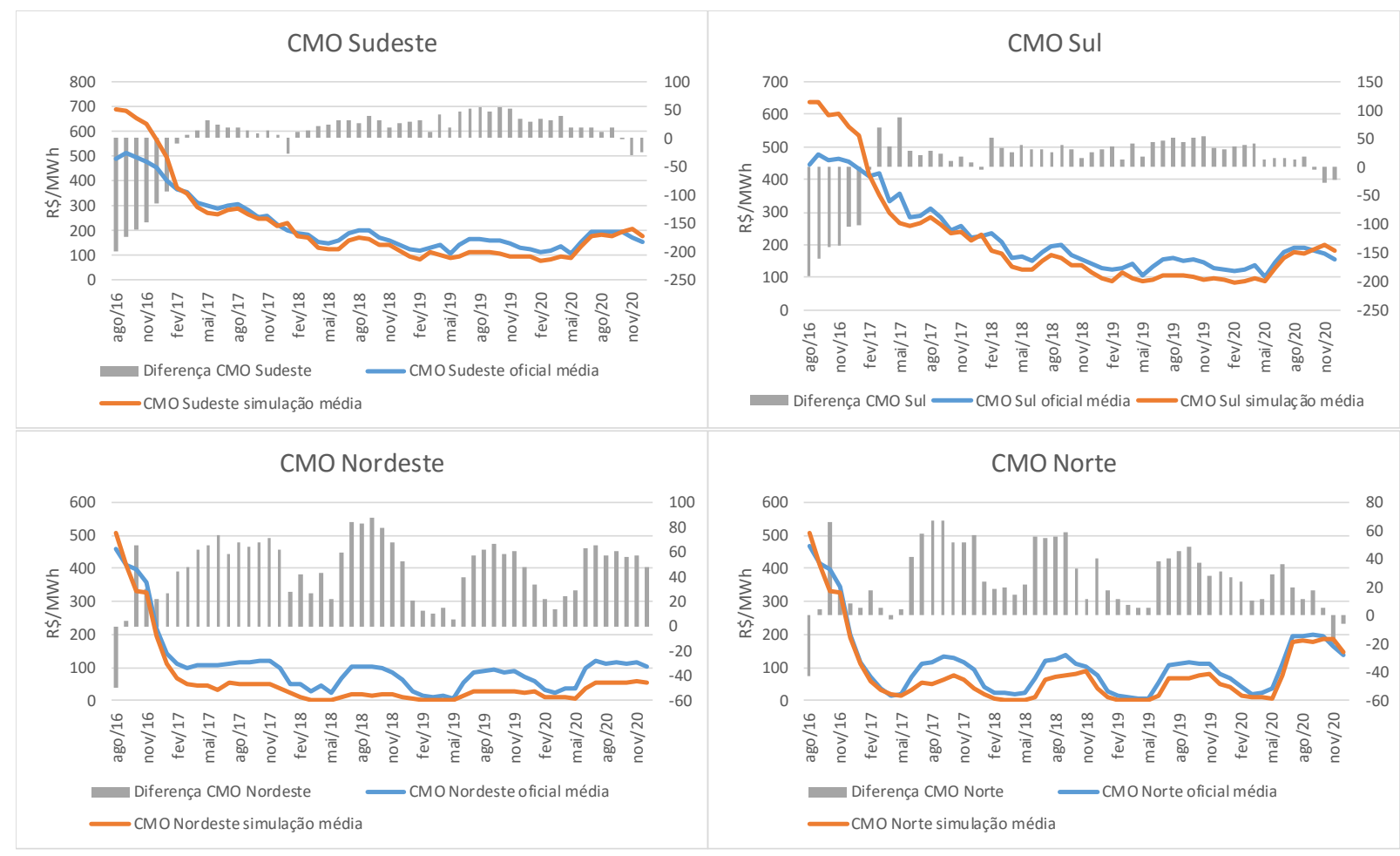

Fonte: Elaboração própria

No caso seco de 1951 a 1955, os custos marginais do caso crítico se elevam. No entanto, os valores da simulação com eólicas resultam significativamente mais baixos do que com as séries oficiais, conforme Figura 100, enfatizando novamente a complementaridade no caso de eólicas com séries temporais. 
Figura 100: CMO médio mensal dos submercados com séries oficiais vs. Simulação caso 2 (1951-1955)

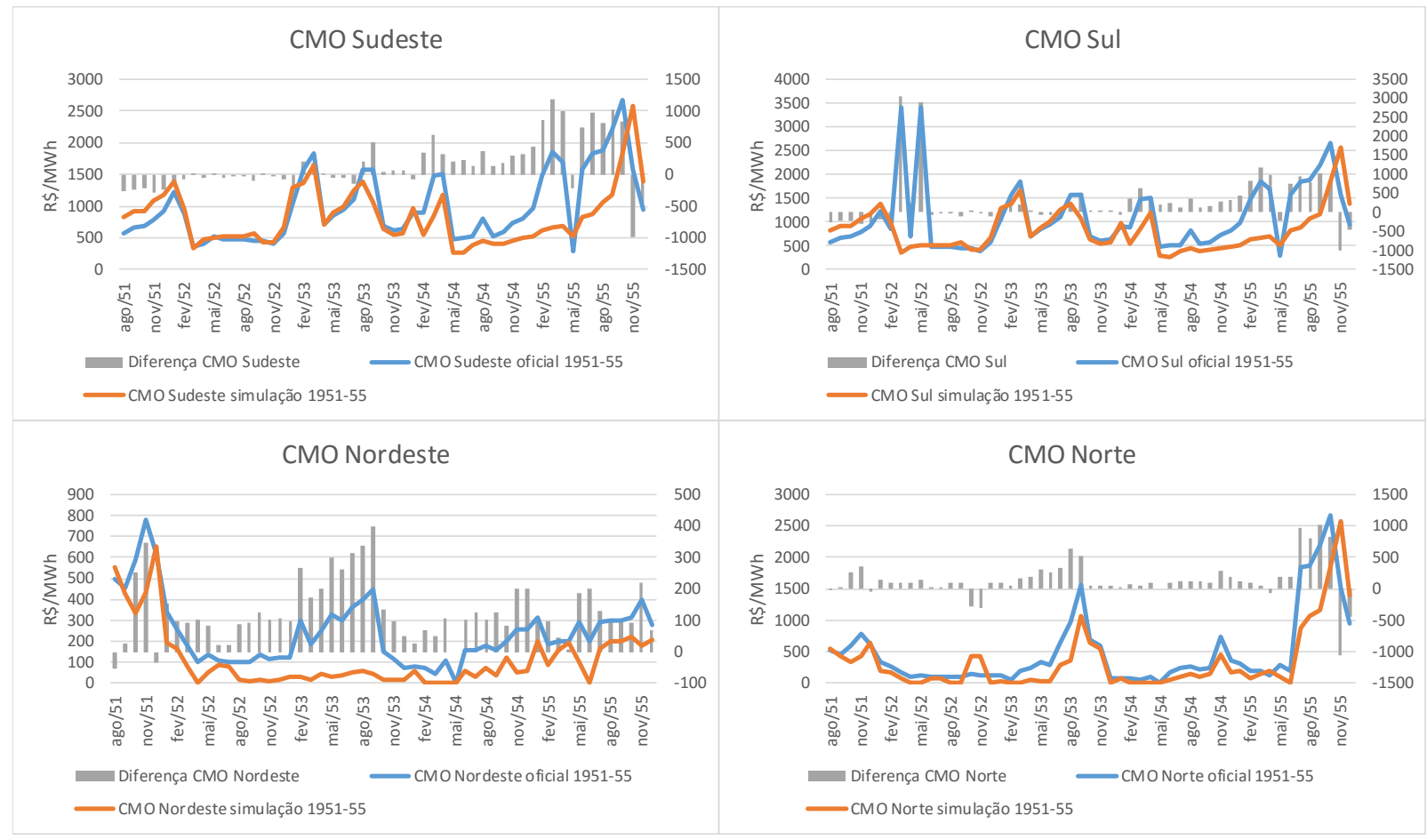

Fonte: Elaboração própria

\subsubsection{Geração hidráulica do caso 2}

A geração hidráulica no Sudeste com a simulação do caso 2 apresentou valores menores do que a série oficial na maioria das séries. No entanto, no Nordeste, a geração hidráulica ficou maior na simulação do que na série oficial no período úmido, complementada no período seco por maior geração eólica. 
Figura 101: Geração hidráulica anos médios oficial vs. Simulação caso 2

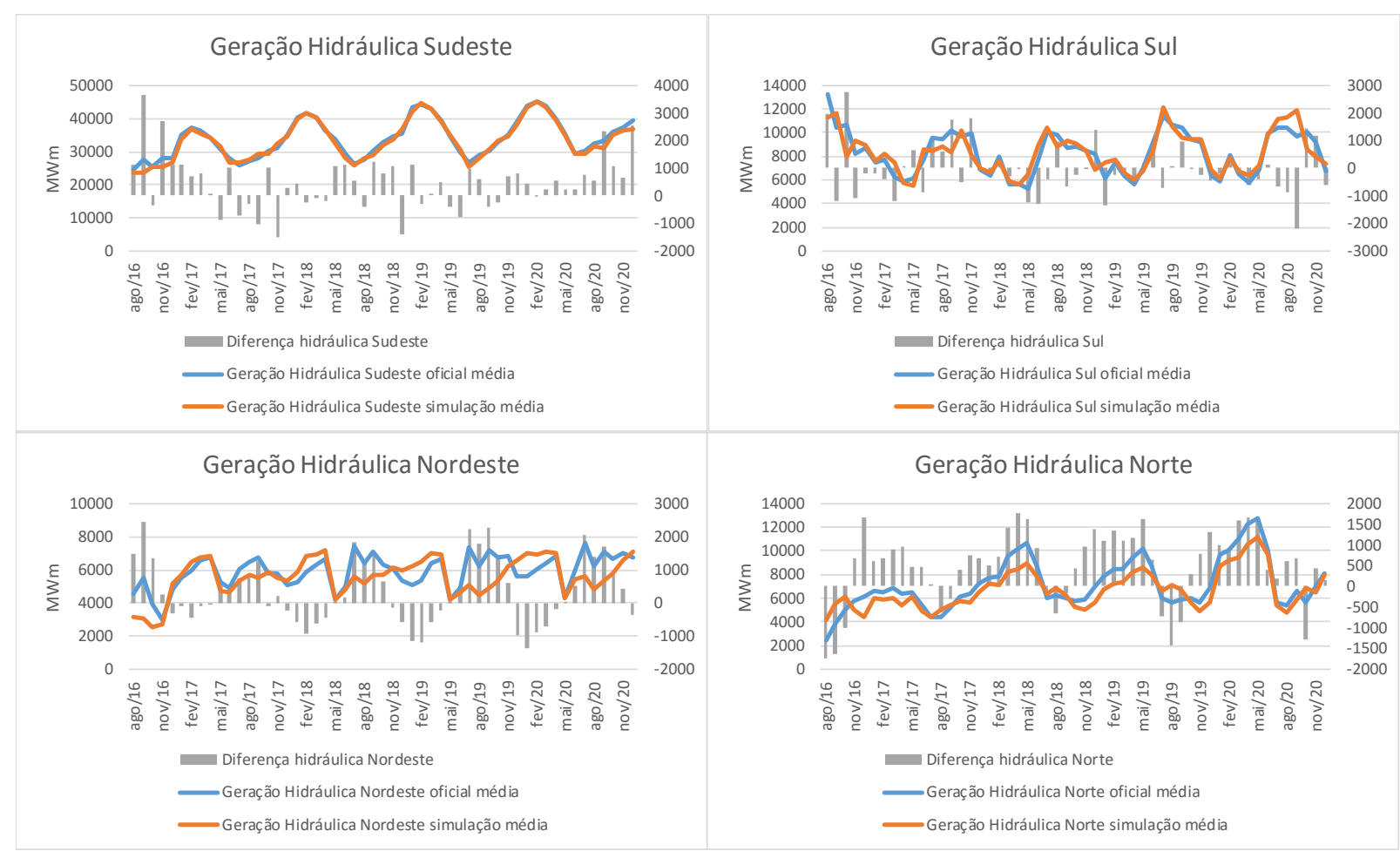

Fonte: Elaboração própria

Considerando os anos secos, a geração hidráulica do cenário oficial crítico continua sendo maior na maior parte dos casos do que da simulação com eólicas explicitadas. No entanto, há uma redução da geração em relação aos valores médios pelo período ser seco. 
Figura 102: Geração hidráulica oficial vs. Simulação caso 2 (1951 a 1955)

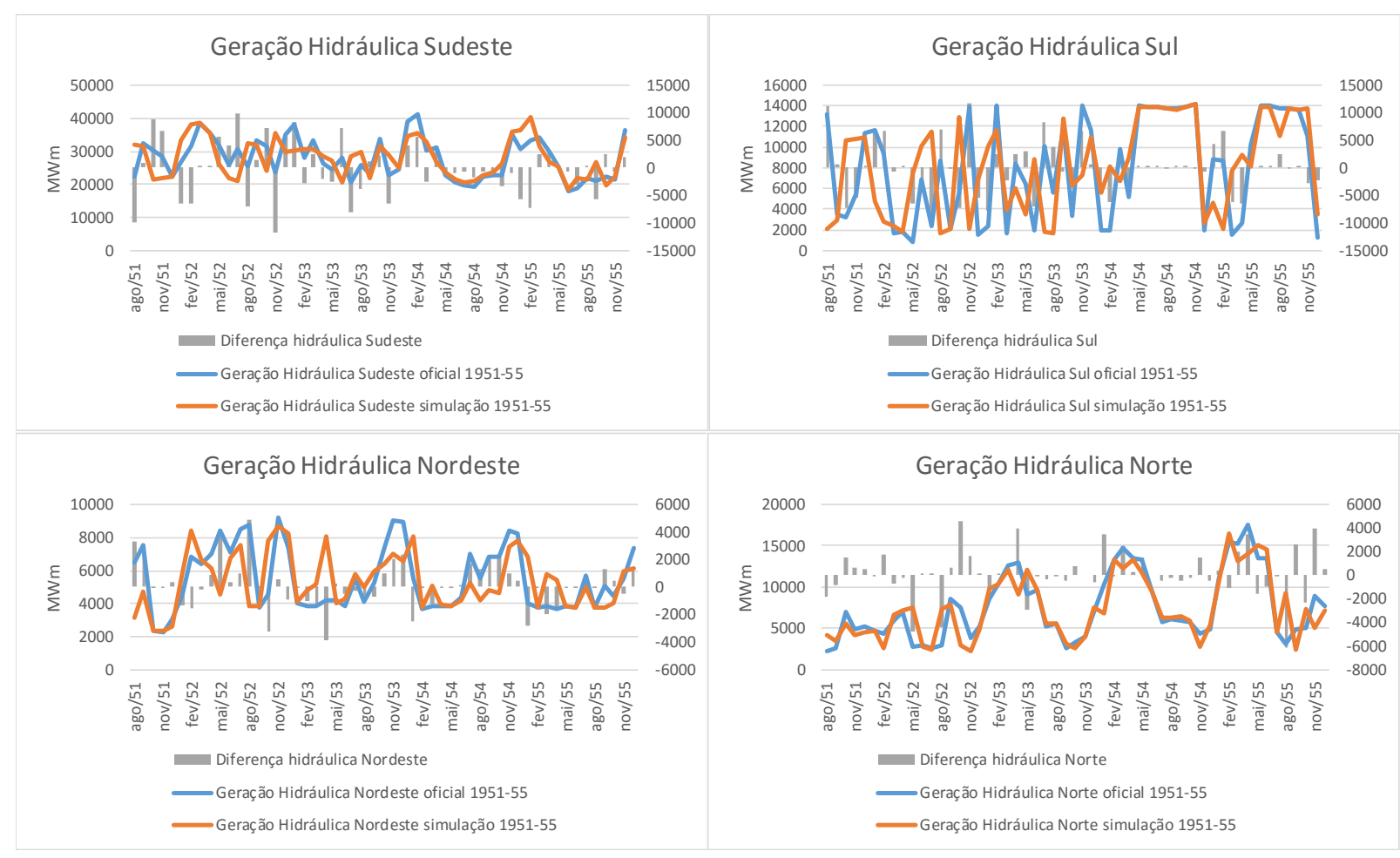

Fonte: Elaboração própria

\subsubsection{Geração térmica do caso 2}

Em relação a geração térmica, pode-se verificar na Figura 103, que a geração térmica do caso oficial crítico é maior do que da simulação na maior parte do período, em todos os submercados. 
Figura 103: Geração térmica anos médios oficial vs. Simulação caso 2

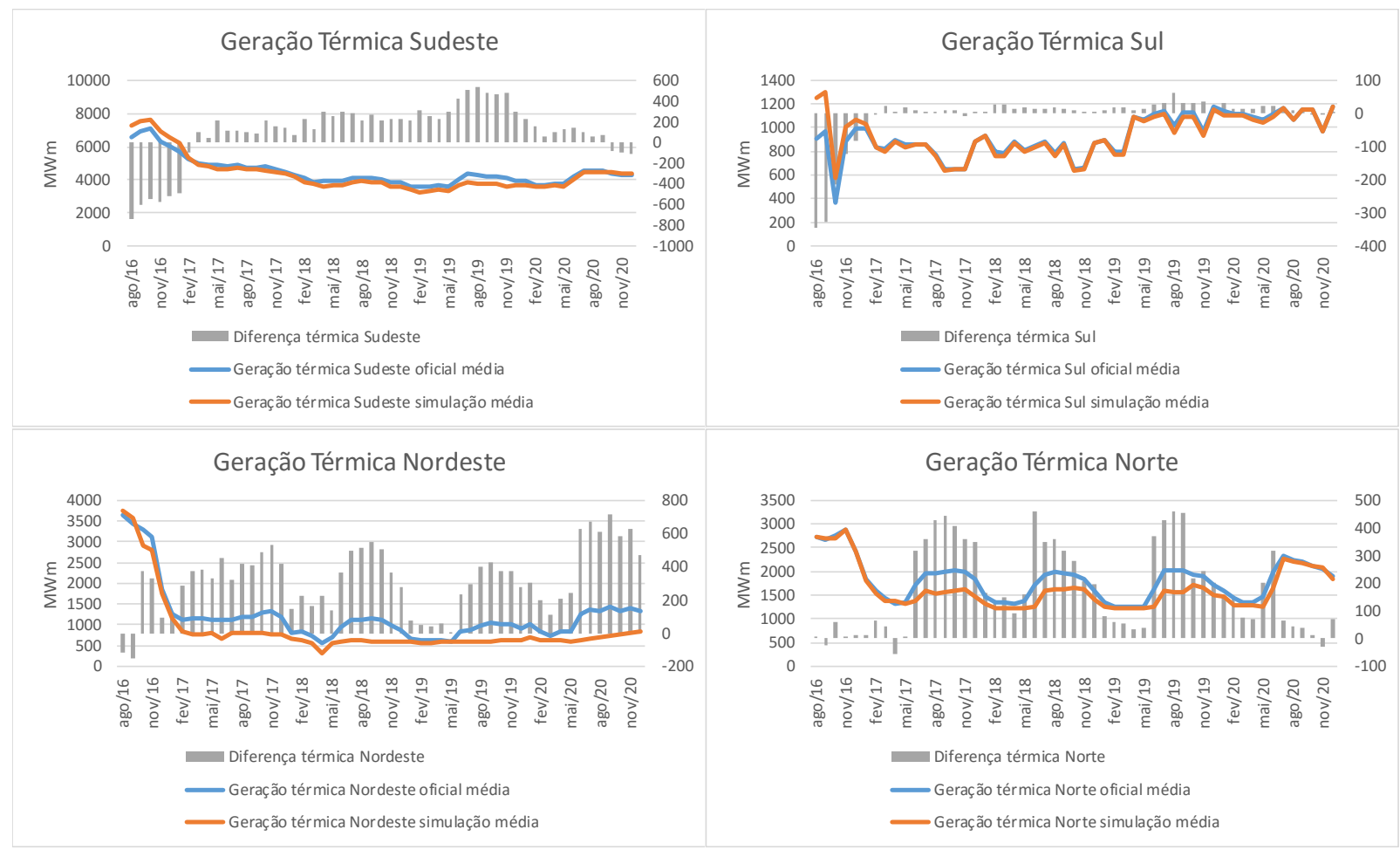

Fonte: Elaboração própria

No período de 1951 a 1955 a geração térmica é maior também no caso oficial crítico do que na simulação na maior parte do tempo. Além disso, a geração térmica é maior por ser o período seco. 
Figura 104: Geração térmica crítico oficial vs. Simulação caso 2 (1951 a 1955)

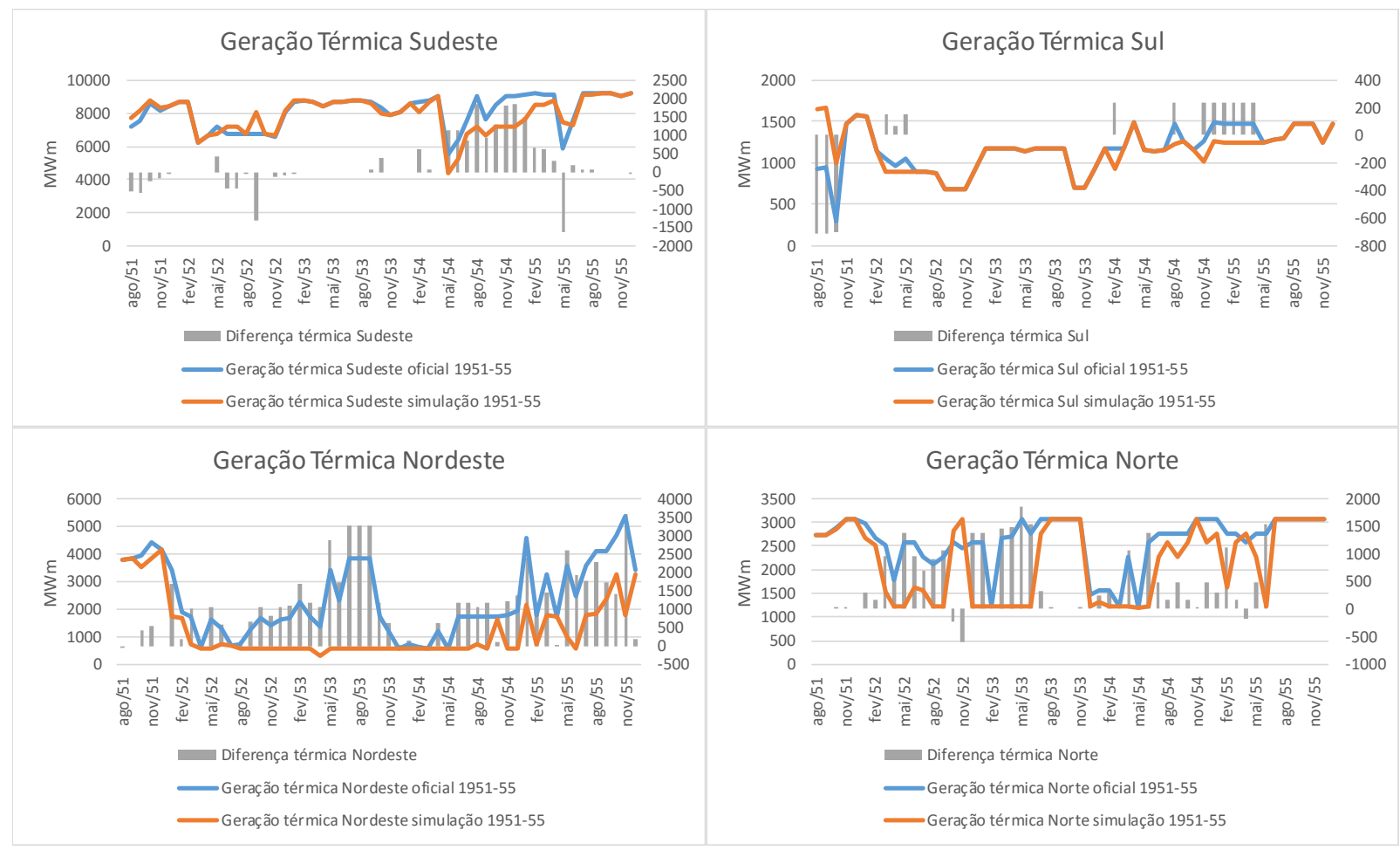

Fonte: Elaboração própria

\subsubsection{Geração eólica do caso 2}

Verifica-se na simulação que há um aumento da geração eólica em todo o horizonte, tanto no Nordeste quanto no Sul.

Figura 105: Geração Eólica séries históricas vs. Simulação caso 2

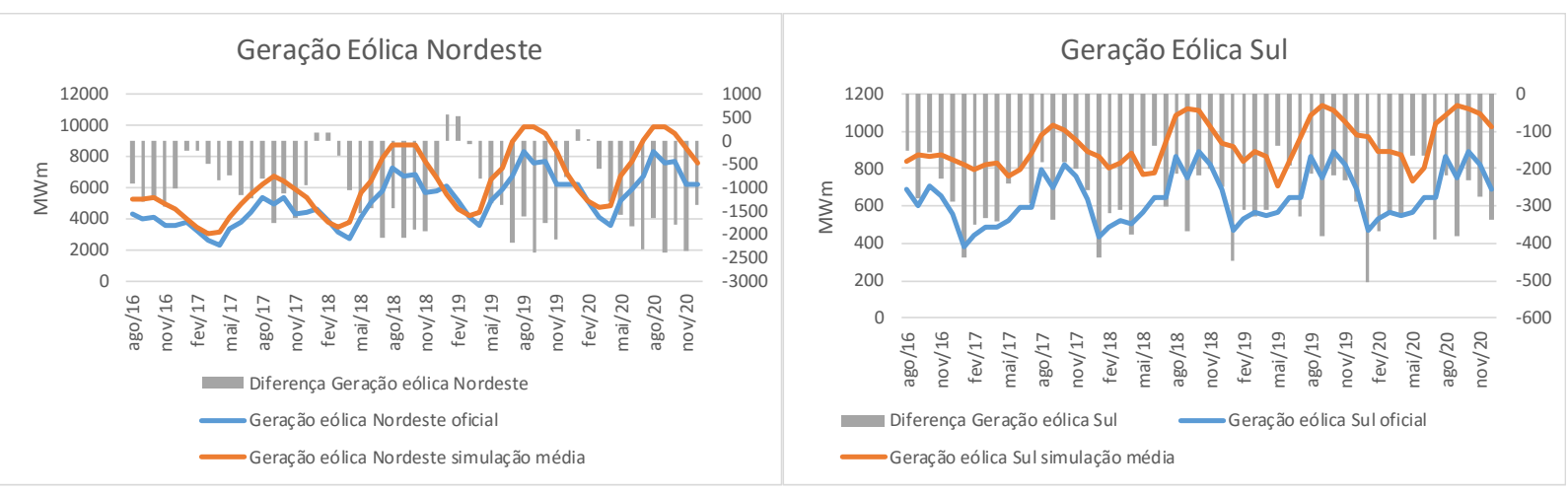

Fonte: Elaboração própria 
Considerando os anos secos de 1951-1955, também há uma tendência de aumento da geração eólica na simulação por serem turbinas otimizadas e se estar representando a complementaridade.

Figura 106: Geração Eólica séries históricas vs. Simulação caso 2 (1951 a 55)
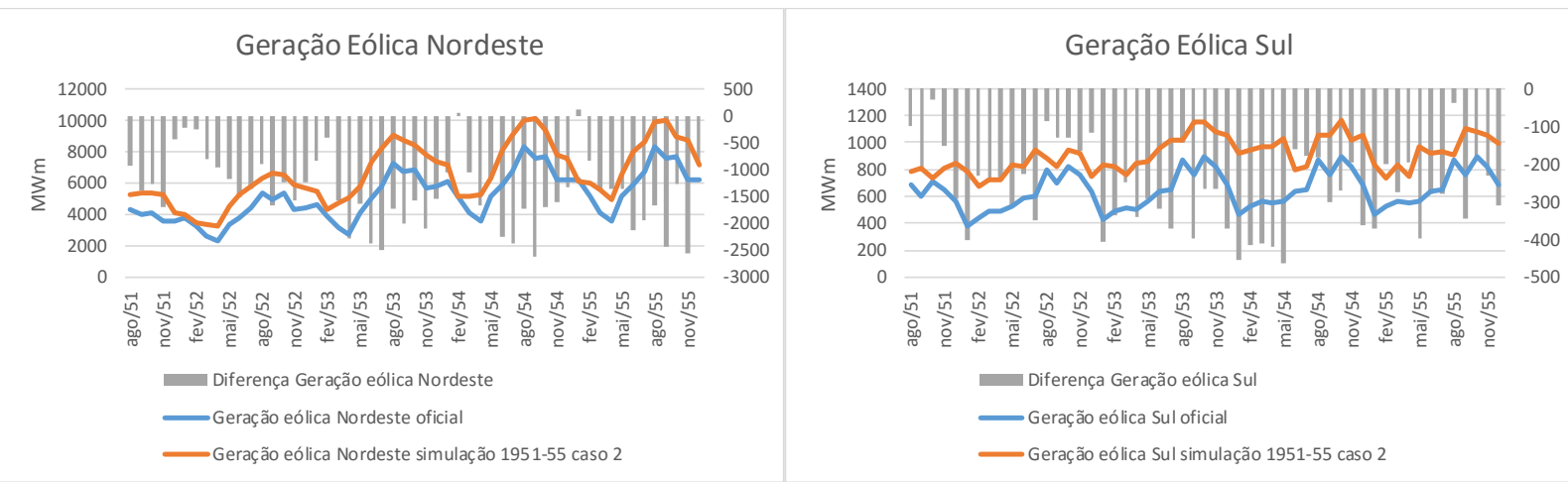

Fonte: Elaboração própria

\subsubsection{Complementaridade do caso 2}

A complementaridade da hidráulica do Nordeste com a eólica não apresentou a mesma sazonalidade do que no caso 1, uma vez que a geração hidráulica apresentou distorções por ser um período crítico.

Figura 107: Geração Eólica no Nordeste e no Sul (média) caso 2

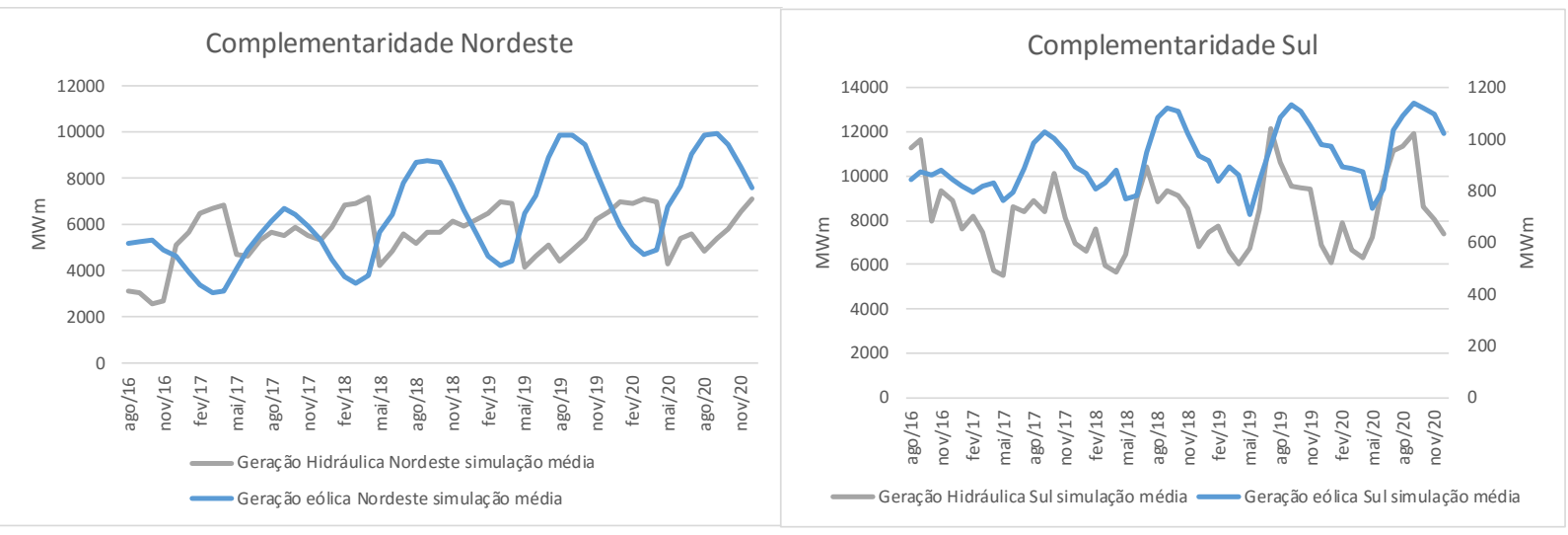

Fonte: Elaboração própria 
Ao se considerar os anos secos, há uma maior geração eólica, mas a complementaridade é distinta daquela que ocorre em um período hidrológico de severidade média.

Figura 108: Geração Eólica no Nordeste e no Sul (1951-55) caso 2
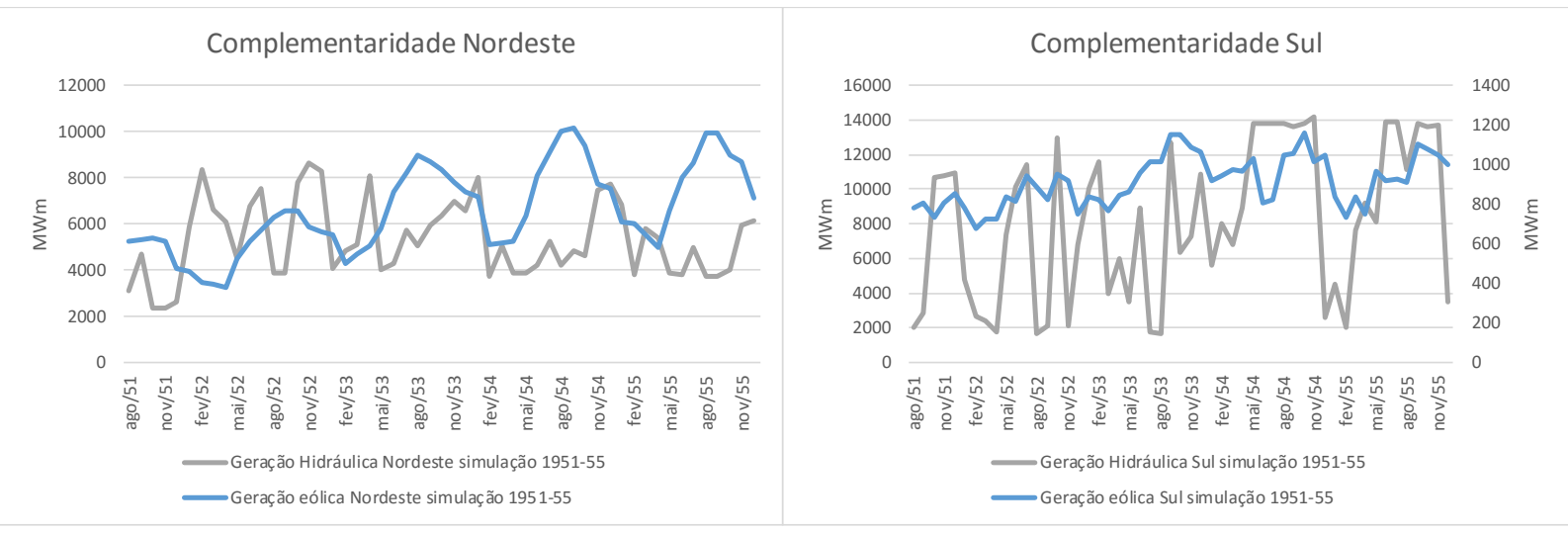

Fonte: Elaboração própria

\subsubsection{Conclusões do caso 2}

Apesar deste cenário ser mais crítico, praticamente não há alteração na geração eólica em relação ao caso anterior, posto que a fonte eólica é não despachável e, portanto, não é variável de decisão do modelo, sendo considerada determinística para cada série do histórico, de tal forma que o modelo estabelece uma geração em cada período analisado, representando, com o auxílio de um artifício, as plantas eólicas como usinas a fio d' água. O que aumentou neste cenário foi o despacho hidráulico, que mesmo com níveis dos reservatórios mais baixos no Sudeste, houve disponibilidade maior, assim como aumento do despacho térmico dado o aumento de carga, consequentemente houve elevação dos custos marginais de operação. No entanto, os valores dos custos marginais da simulação ficaram menores do que no caso oficial, mostrando a necessidade da representação estocástica para contribuir com a complementaridade na otimização do sistema.

\subsubsection{Caso 3}

Neste terceiro caso de simulação, a ideia hipotética é de acrescentar aproximadamente a mesma capacidade instalada de usinas hidráulicas em eólicas, mantendo-se a capacidade termelétrica, a fim de se verificar a complementaridade da hidráulica. Neste caso há a necessidade 
de aumento de carga, caso contrário haveria uma oferta muito grande para uma carga pequena em termos relativos, e ter-se-ia custos marginais nulos, sem a necessidade de despachos térmicos na maior parte do tempo. Como o aumento da capacidade eólica foi no Nordeste e Sul, aumentou-se a carga destes submercados apenas.

Uma vez que a capacidade eólica instalada em agosto/16 é de 9.021 MW e a capacidade hidráulica no SIN é de $91.788 \mathrm{MW}$, de acordo com o deck do Newave de agosto de 2016, aumentou-se a capacidade eólica em dez vezes, para 90.212 MW, proporcional por submercado. Para isso, aumentou-se a carga do Sul em aproximadamente $6.000 \mathrm{MWm}$ e a carga do Nordeste em 37.000 MWm, de acordo com a Figura 109.

Figura 109: Aumento da carga do Sul e Nordeste para simulação de aumento de eólicas
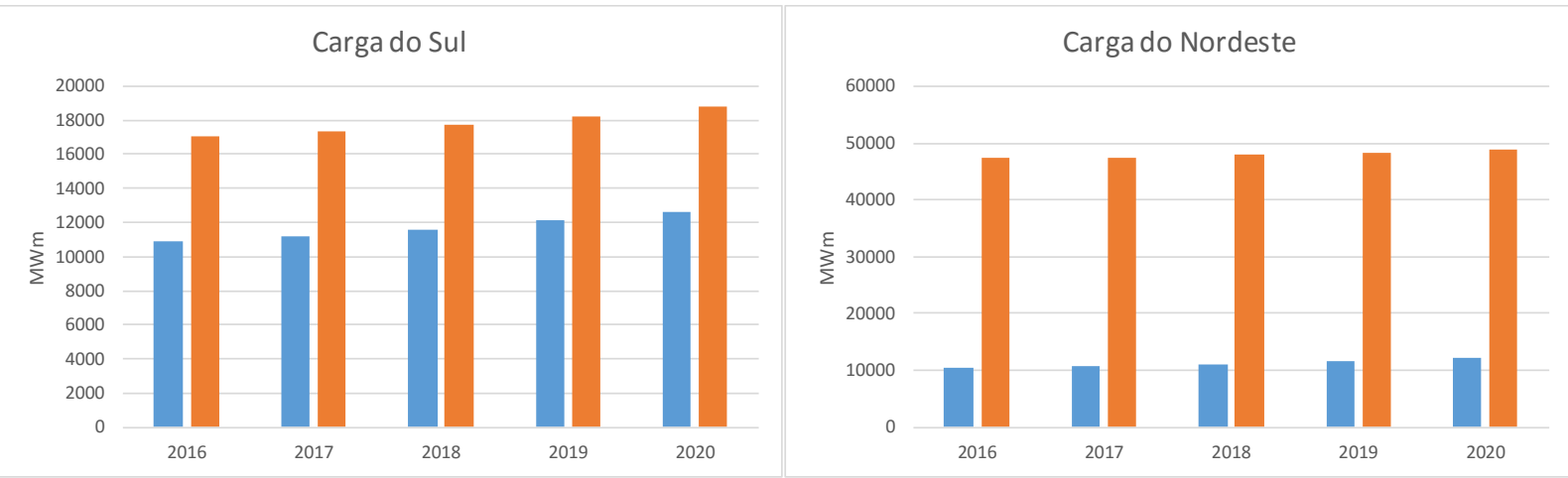

Fonte: Elaboração Própria

\subsubsection{Análise de mês específico}

A Tabela 18 mostra o $\mathrm{CMO}$ e as gerações hidráulicas, térmicas e eólicas para os submercados, considerando-se a simulação hipotética com as eólicas em reservatórios equivalentes em um mês específico, no caso agosto do quarto ano. As três primeiras colunas de valores da tabela representam apenas o caso da simulação com séries históricas, não apresentando o caso oficial. 
Tabela 18: Análise de CMO e geração em agosto do quarto ano

\begin{tabular}{|c|c|c|c|}
\hline Agosto quarto ano & Simulação média & Simulação 1951-1955 & Simulação 2010-2014 \\
\hline CMO Sudeste (R\$/MWh) & 1,19 & 0,03 & 0,11 \\
\hline CMO Sul (R\$/MWh) & 1,18 & 0,03 & 0,11 \\
\hline CMO Nordeste (R\$/MWh) & - & - & - \\
\hline CMO Norte (R\$/MWh) & 0,22 & 0,03 & 0,08 \\
\hline Geração Hidráulica SE & 24.702 & 25.776 & 21.138 \\
\hline Geração Hidráulica S & 10.311 & 12.775 & 12.484 \\
\hline Geração Hidráulica NE & 4.216 & 3.803 & 3.788 \\
\hline Geração Hidráulica N & 6.209 & 2.992 & 7.104 \\
\hline Geração Hidráulica SIN & 45.438 & 45.346 & 44.514 \\
\hline Geração Térmica SE & 2.729 & 2.709 & 2.709 \\
\hline Geração Térmica S & 782 & 779 & 779 \\
\hline Geração Térmica NE & 572 & 572 & 572 \\
\hline Geração Térmica N & 1.209 & 1.209 & 1.209 \\
\hline Geração Térmica SIN & 5.291 & 5.269 & 5.269 \\
\hline Geração Eólica S & 8.578 & 8.347 & 9.166 \\
\hline Geração Eólica NE & 47.943 & 48.188 & 48.197 \\
\hline Geração Eólica SIN & 56.521 & 56.536 & 57.363 \\
\hline
\end{tabular}

Fonte: Elaboração Própria

Uma vez que agosto é um mês de elevada geração eólica, a maior parte da carga é atendida por esta geração, com geração hidráulica e térmica parecida com a simulação oficial do caso 1 . Analisando-se a tabela, verifica-se que em agosto do quarto ano, a simulação apresenta valores de CMOs quase nulos em todos os submercados.

No entanto, conforme pode ser observado na Tabela 19, através dos meses de fevereiro do último ano, a geração eólica é muito menor do que no período seco dos anos. Isso torna necessário o despacho térmico mais caro do Nordeste para o atendimento da carga, além de um deplecionamento nos reservatórios, dada a também necessidade de despacho hidráulico. O limite de recebimento de energia entre os submercados é atingido e o Nordeste fica com preços muito elevados no cenário médio. No período de 1951-1955, como o período é seco, o Newave recolhe geração hidráulica no Sudeste e Sul, em detrimento de um maior despacho térmico nestes submercados e uma geração eólica no Nordeste maior, dado o aumento desta geração por ser um fevereiro seco do histórico. Contudo, considerando o período de 2010 a 2014, em que foi seco, mas houve mais ventos do que na média, houve uma menor geração hidráulica e térmica, justamente porque a eólica pôde contribuir bem mais para o atendimento da carga e os custos marginais ficaram quase nulos. 
Tabela 19: Análise de CMO e geração em fevereiro do quinto ano

\begin{tabular}{lrrr}
\hline \multicolumn{1}{c}{ Fevereiro quinto ano } & Simulação média & Simulação 1951-1955 & Simulação 2010-2014 \\
\hline CMO Sudeste (R\$/MWh) & 2,51 & 100,56 & 0,04 \\
CMO Sul (R\$/MWh) & 2,52 & 100,57 & 0,04 \\
CMO Nordeste (R\$/MWh) & 469,30 & 100,56 & - \\
CMO Norte (R\$/MWh) & 2,43 & 100,56 & - \\
\hline Geração Hidráulica SE & 44.326 & 41.340 & 32.542 \\
Geração Hidráulica S & 7.032 & 5.429 & 10.033 \\
Geração Hidráulica NE & 7.559 & 8.334 & 3.852 \\
Geração Hidráulica N & 8.695 & 12.881 & 11.631 \\
Geração Hidráulica SIN & $\mathbf{6 7 . 6 1 2}$ & $\mathbf{6 7 . 9 8 4}$ & $\mathbf{5 8 . 0 5 9}$ \\
\hline Geração Térmica SE & 2.716 & 3.586 & 2.693 \\
Geração Térmica S & 1.046 & 1.231 & 1.041 \\
Geração Térmica NE & 1.900 & 744 & 572 \\
Geração Térmica N & 1.231 & 2.007 & 1.209 \\
Geração Térmica SIN & $\mathbf{6 . 8 9 3}$ & $\mathbf{7 . 5 6 7}$ & $\mathbf{5 . 5 1 5}$ \\
\hline Geração Eólica S & 7.407 & 5.691 & 7.910 \\
Geração Eólica NE & 36.572 & 37.241 & 46.999 \\
Geração Eólica SIN & $\mathbf{4 3 . 9 7 9}$ & $\mathbf{4 2 . 9 3 2}$ & $\mathbf{5 4 . 9 0 9}$ \\
\hline
\end{tabular}

Fonte: Elaboração Própria

\subsubsection{Custo marginal de operação mensal}

A simulação mostra que na média, os CMOs tendem a ficar nulos, exceto no Nordeste que dado o aumento de carga, em períodos com redução eólica devido à sazonalidade, a complementaridade não é suficiente para o atendimento da carga, ocorrendo déficits no sistema. Além disso, em períodos desfavoráveis hidrologicamente, como a série de 1951-1955, há também necessidade de maior despacho térmico durante o período, porém menor do que no caso médio. Considerando o período de 2010 a 2014, verifica-se uma complementaridade ainda maior, com maior geração eólica e menor necessidade de despachos térmicos, dados os custos marginais baixos praticamente em todo o período, conforme Figura 110. 
Figura 110: CMO mensal na média e anos secos caso 3

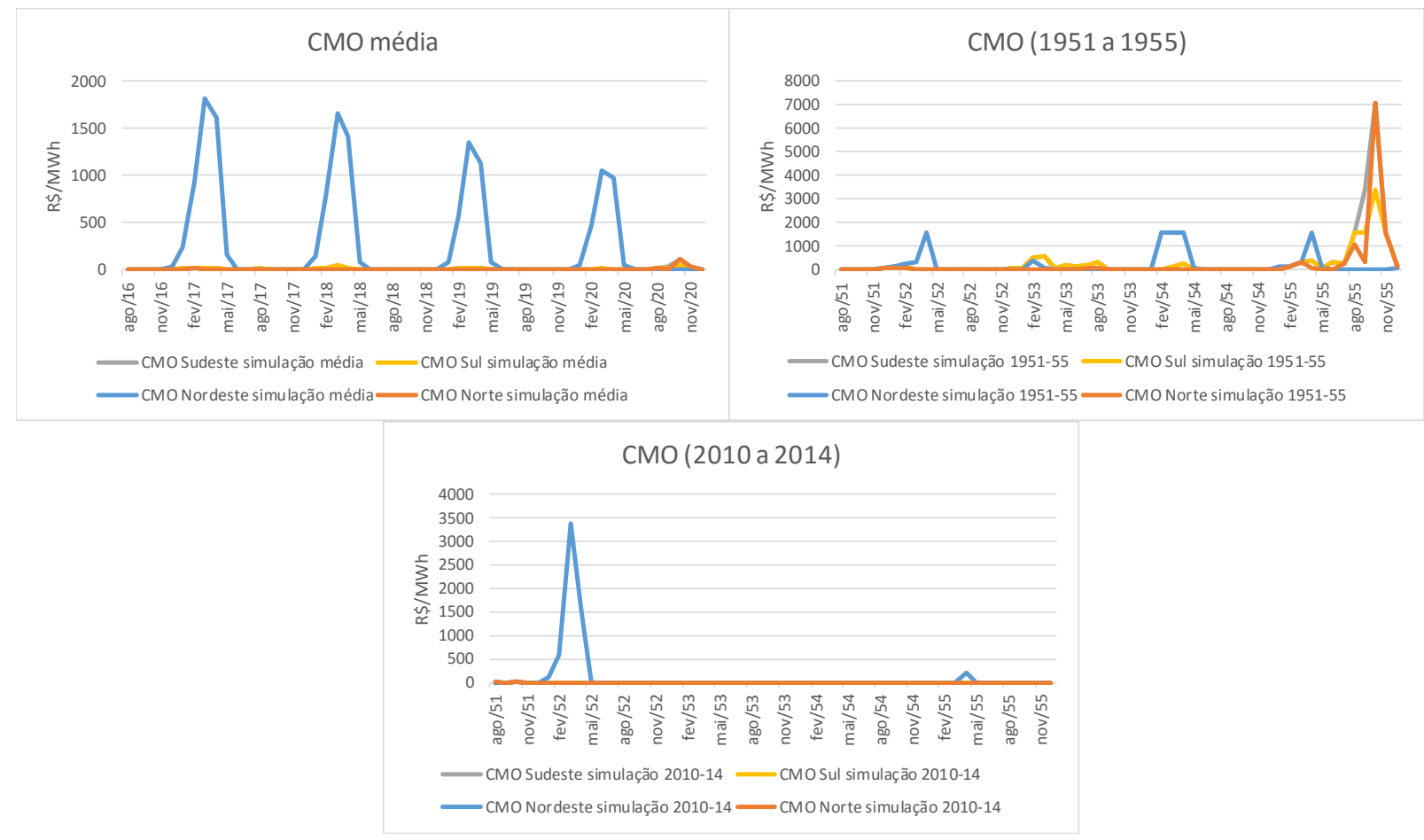

Fonte: Elaboração Própria

A sazonalidade pode ser observada pela Figura 111. Em anos com a hidrologia desfavorável, tem-se uma maior geração eólica referente aos anos secos. Os aumentos dos CMOs da Figura 110 são verificados em momentos de baixa geração eólica. Verifica-se uma geração eólica no Nordeste maior no período de 2010 a 2014. No Sul a sazonalidade não é definida.

Figura 111: Geração Hidráulica vs. Eólica (média e anos secos) caso 4
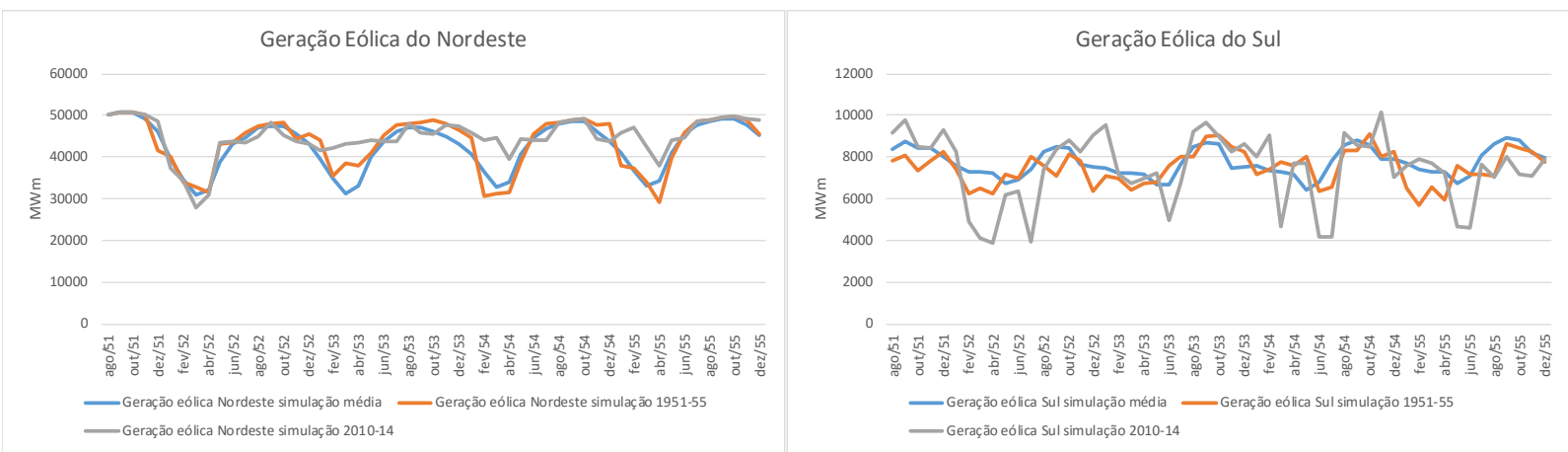

Fonte: Elaboração Própria 


\subsubsection{Conclusões do caso 3}

Considerando-se o aumento da capacidade eólica, há sim um aumento da geração da fonte e maior complementaridade com a hidráulica. No entanto, como houve um aumento muito grande da carga do Nordeste para este cenário hipotético, nos períodos úmidos dos anos e principalmente com relação à média histórica, a geração eólica não é suficiente para o atendimento, apresentando déficits no sistema e aumento dos custos marginais de operação.

\subsubsection{Caso 4}

O quarto caso de estudo mostra a simulação com eólicas do primeiro caso, considerando as séries sintéticas e compara com a simulação oficial de agosto de 2016 também com séries sintéticas.

\subsubsection{Análise de mês específico}

A Tabela 20 mostra o CMO e as gerações hidráulicas, térmicas e eólicas para os submercados, considerando-se a simulação com séries sintéticas com as eólicas em reservatórios equivalentes em um mês específico, no caso agosto do quarto ano. Além disso, a tabela mostra os valores do caso oficial também com séries sintéticas. 
Tabela 20: Análise de CMO e geração em agosto do quarto ano

\begin{tabular}{lrr}
\hline \multicolumn{1}{c}{ Agosto quarto ano } & Oficial média & Simulação média \\
\hline CMO Sudeste (R\$/MWh) & 61,06 & 20,37 \\
CMO Sul (R\$/MWh) & 60,10 & 20,08 \\
CMO Nordeste (R\$/MWh) & 24,43 & 1,81 \\
CMO Norte (R\$/MWh) & 28,95 & 7,53 \\
\hline Geração Hidráulica SE & 26.802 & 27.071 \\
Geração Hidráulica S & 11.149 & 11.016 \\
Geração Hidráulica NE & 4.813 & 4.450 \\
Geração Hidráulica N & 5.566 & 4.597 \\
Geração Hidráulica SIN & 48.330 & 47.134 \\
\hline Geração Térmica SE & 2.940 & 2.785 \\
Geração Térmica S & 819 & 787 \\
Geração Térmica NE & 601 & 572 \\
Geração Térmica N & 1.279 & 1.216 \\
Geração Térmica SIN & 5.638 & 5.361 \\
\hline Geração Eólica S & 868 & 1.055 \\
Geração Eólica NE & 8.262 & 9.548 \\
Geração Eólica SIN & $\mathbf{9 . 1 3 0}$ & $\mathbf{1 0 . 6 0 3}$ \\
\hline
\end{tabular}

Fonte: Elaboração Própria

A geração eólica da simulação em agosto é maior do que o valor determinístico tanto para o Sul, quanto para o Nordeste. Desta forma, há menor necessidade de geração hidráulica e térmica, diminuindo-se os custos marginais de operação. Por outro lado, ao se considerar a geração eólica em fevereiro, conforme Tabela 21, a geração do Nordeste é menor do que o caso oficial, necessitando de maior geração de outras fontes para atender a carga. Como os níveis dos reservatórios da simulação ficam mais elevados do que no caso oficial, uma vez que se tem gerado mais com eólicas, a geração hidráulica da simulação é maior do que o caso oficial, necessitando de menor geração térmica e consequentemente os custos marginais são menores. 
Tabela 21: Análise de CMO e geração em fevereiro do quinto ano

\begin{tabular}{lrr}
\hline \multicolumn{1}{c}{ Fevereiro último ano } & Oficial média & Simulação média \\
\hline CMO Sudeste (R\$/MWh) & 23,38 & 10,20 \\
CMO Sul (R\$/MWh) & 24,57 & 10,20 \\
CMO Nordeste (R\$/MWh) & 8,46 & 2,61 \\
CMO Norte (R\$/MWh) & 8,52 & 2,99 \\
\hline Geração Hidráulica SE & 43.678 & 43.138 \\
Geração Hidráulica S & 6.017 & 6.819 \\
Geração Hidráulica NE & 6.143 & 7.389 \\
Geração Hidráulica N & 8.241 & 7.526 \\
Geração Hidráulica SIN & $\mathbf{6 4 . 0 7 9}$ & $\mathbf{6 4 . 8 7 2}$ \\
\hline Geração Térmica SE & 2.872 & 2.740 \\
Geração Térmica S & 1.070 & 1.056 \\
Geração Térmica NE & 595 & 575 \\
Geração Térmica N & 1.257 & 1.218 \\
Geração Térmica SIN & 5.794 & $\mathbf{5 . 5 8 7}$ \\
\hline Geração Eólica S & 529 & 874 \\
Geração Eólica NE & 5.174 & 3.938 \\
Geração Eólica SIN & 5.704 & 4.812 \\
\hline
\end{tabular}

Fonte: Elaboração Própria

\subsubsection{Custo marginal de operação anual do caso 4}

O custo marginal de operação apresenta redução a partir do segundo ano para a série com simulações eólicas, quando comparada com as séries oficiais sintéticas. 
Figura 112: CMO médio anual dos submercados com séries oficiais vs. Simulação caso 4

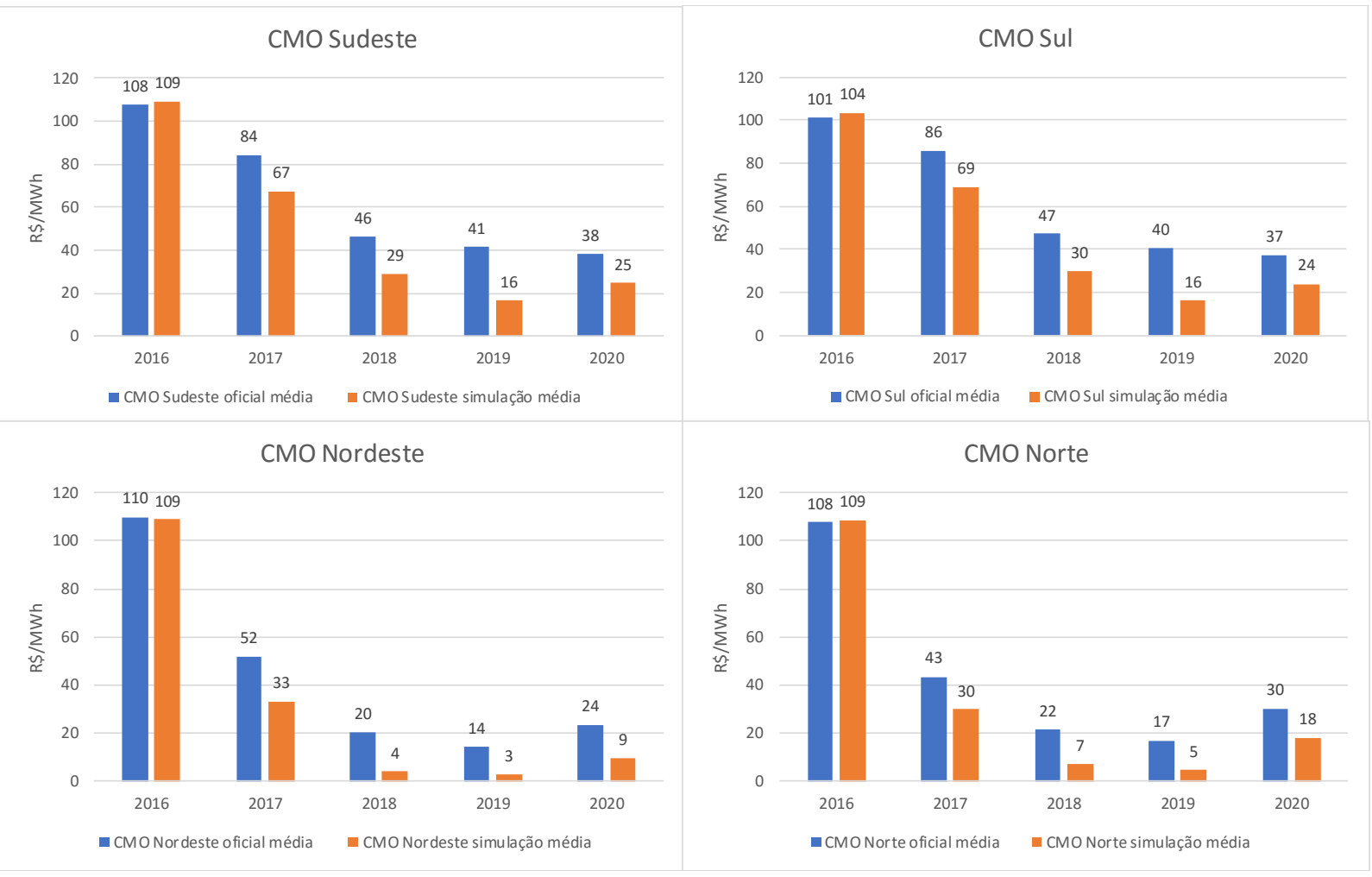

Fonte: Elaboração própria

\subsubsection{Custo marginal de operação mensal do caso 4}

O CMO mensal mostra em geral valores mais baixos da simulação eólica do que com as séries oficiais. A Figura 113 mostra os custos marginais mensais dos submercados, evidenciando a redução dos valores quando comparado as séries oficiais. 
Figura 113: CMO médio mensal dos submercados com séries oficiais vs. Simulação caso 4

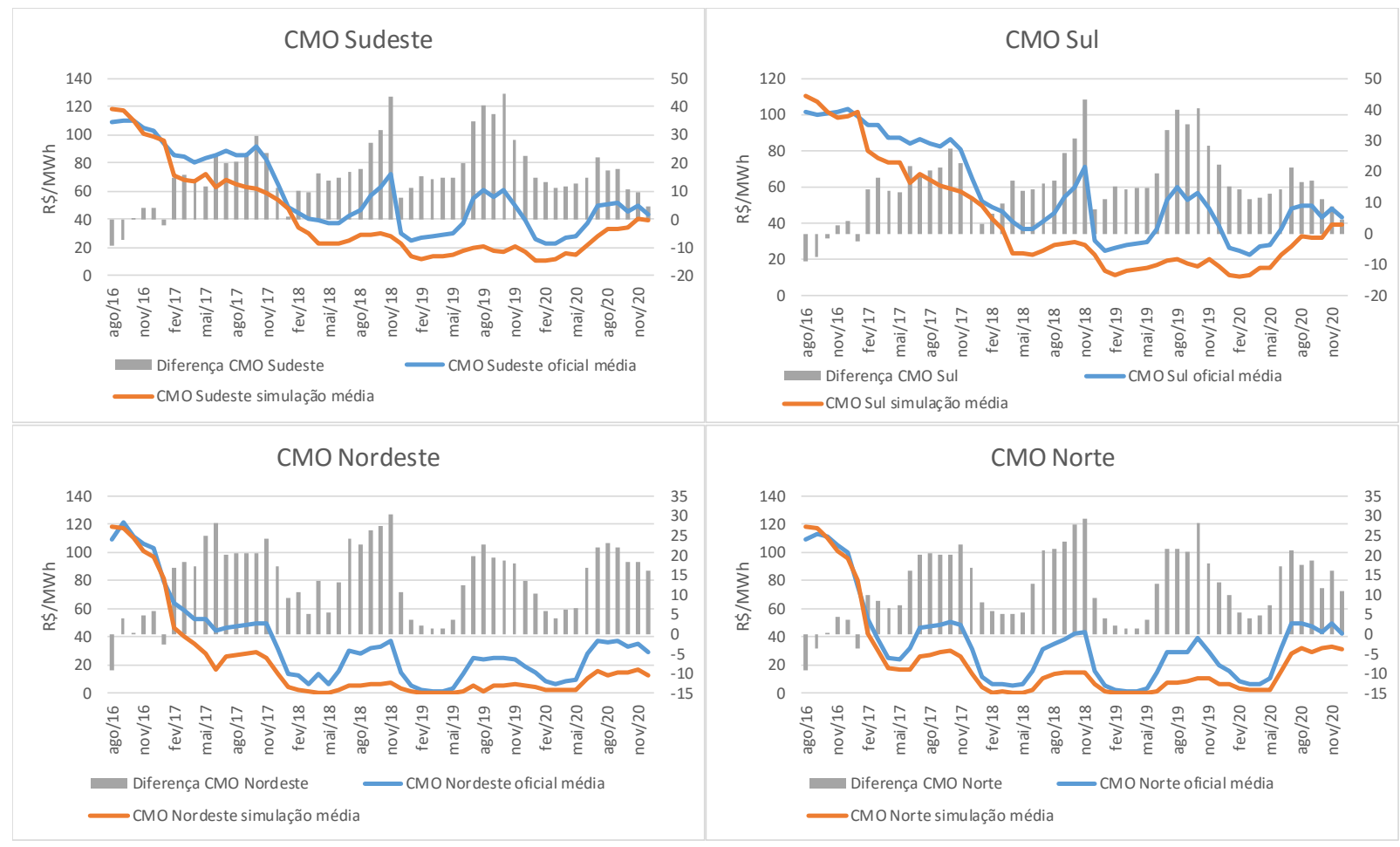

Fonte: Elaboração própria

\subsubsection{Geração hidráulica do caso 4}

A geração hidráulica no Sudeste com a simulação do caso 4 apresentou valores menores do que a série oficial na maior parte do período considerando o cenário médio. No Nordeste, no entanto, a geração hidráulica foi maior nos períodos úmidos dos anos e menor nos períodos secos, dada a complementaridade com a geração eólica. 
Figura 114: Geração hidráulica anos médios oficial vs. Simulação caso 4

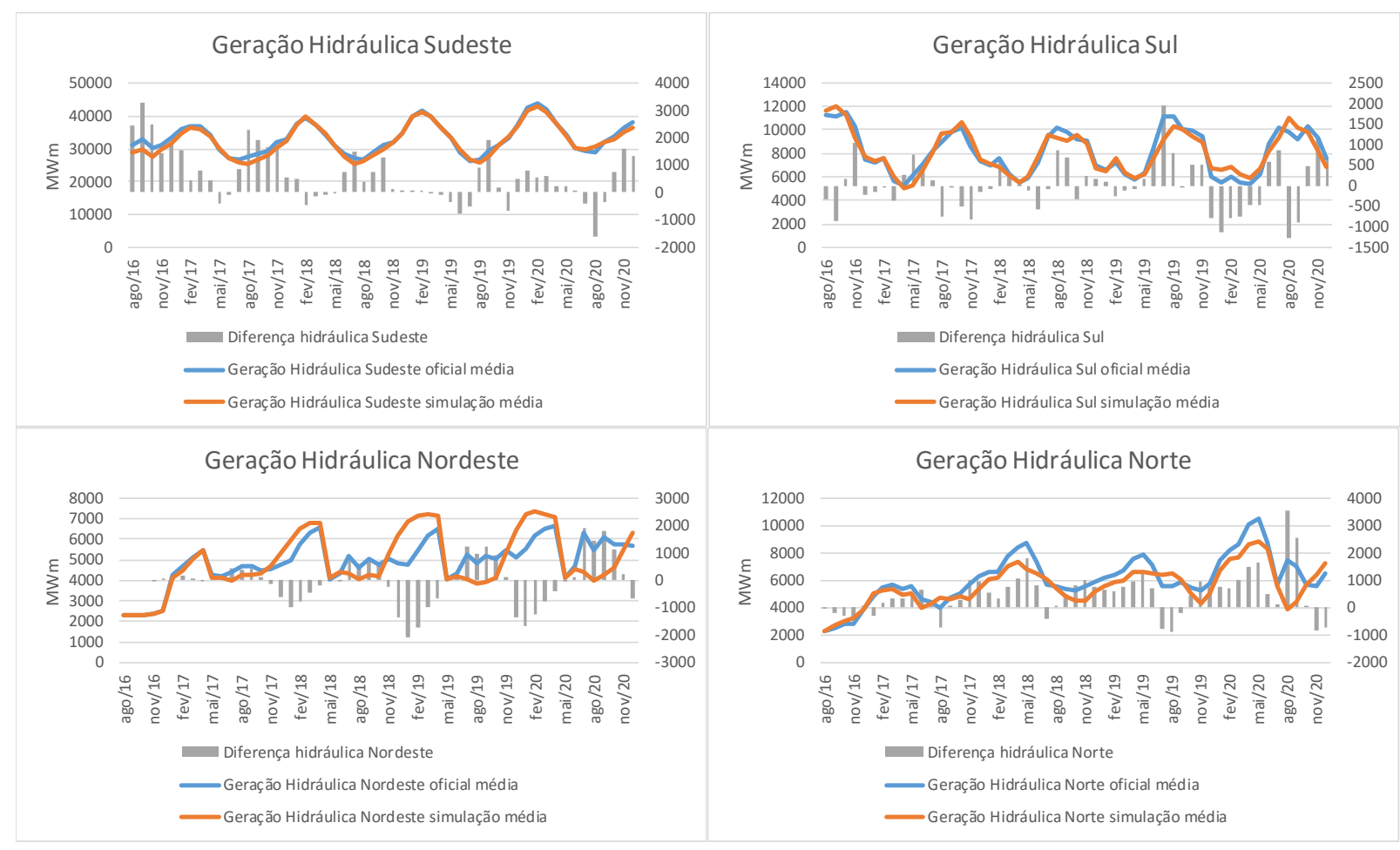

Fonte: Elaboração própria

\subsubsection{Geração térmica do caso 4}

Em relação a geração térmica, pode-se verificar na Figura 115, que a geração foi menor na simulação do que no caso oficial com séries sintéticas na maior parte do período, em todos os submercados. 
Figura 115: Geração térmica anos médios oficial vs. Simulação caso 4

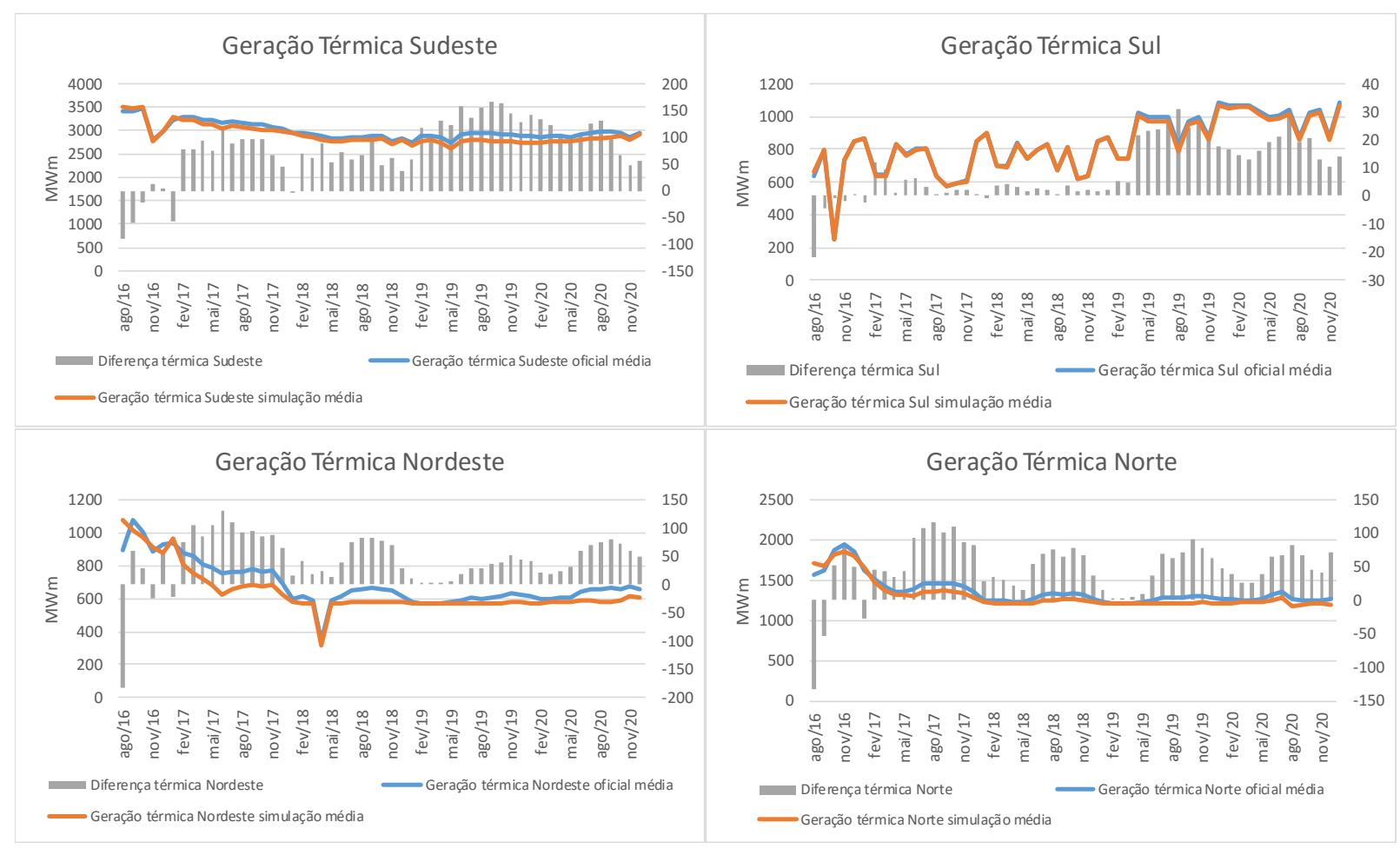

Fonte: Elaboração própria

\subsubsection{Geração eólica do caso 4}

Nota-se no caso 4 que a geração eólica do Nordeste também apresenta valores maiores no período seco dos anos e geração menores no período úmido do que no caso oficial com séries sintéticas, representando a sazonalidade da fonte. No Sul, a geração da simulação apresentou valores sempre maiores do que no caso oficial. 
Figura 116: Geração Eólica séries históricas vs. Simulação caso 4
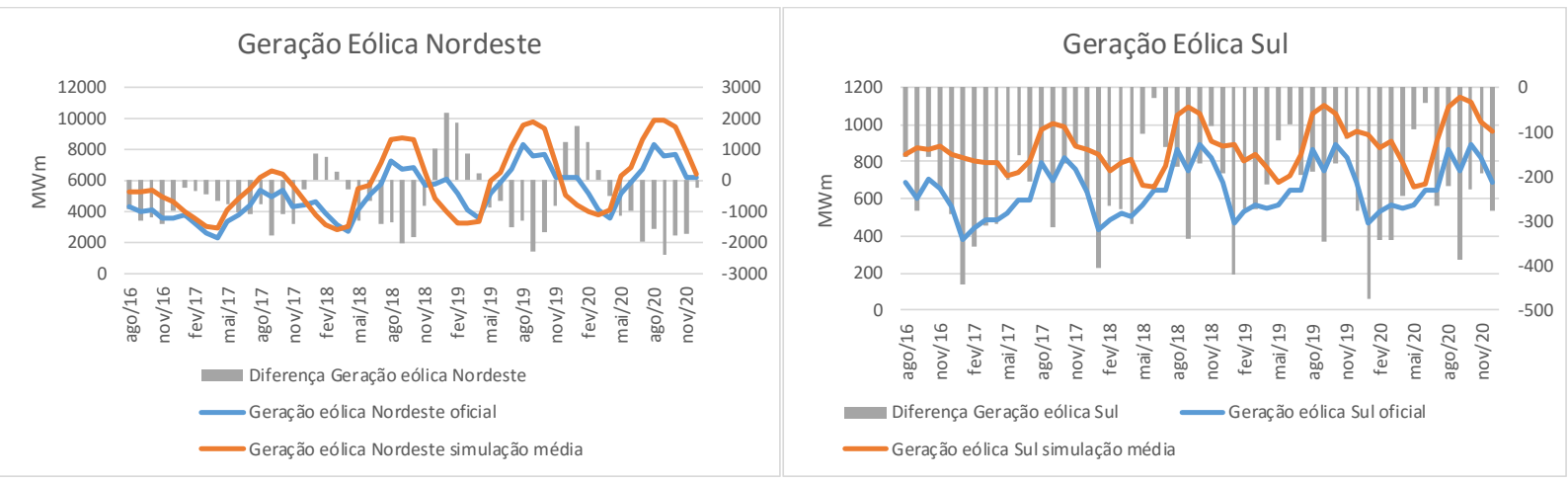

Fonte: Elaboração própria

\subsubsection{Complementaridade do caso 4}

A complementaridade da hidráulica e eólica no Nordeste é evidente no caso considerando as médias e no Sul não se verifica a complementaridade.

Figura 117: Geração Eólica no Nordeste e no Sul (média) caso 4
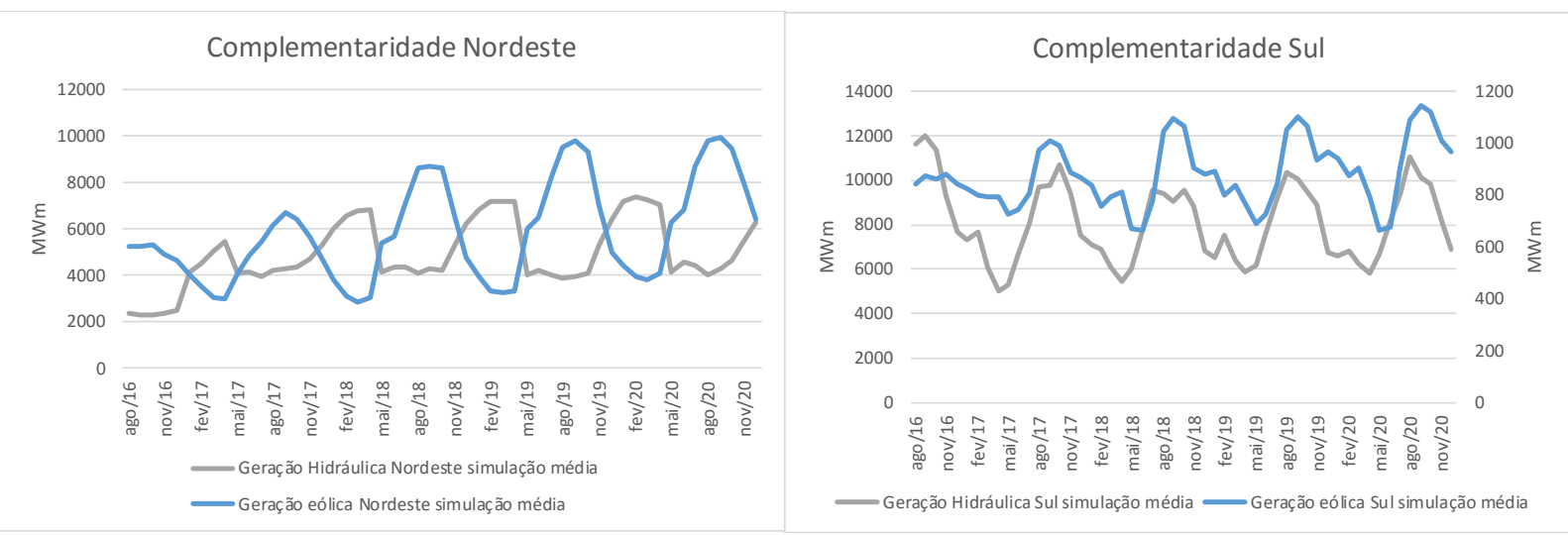

Fonte: Elaboração própria

A simulação do quarto caso é representada em séries sintéticas, por isso não é mostrada a comparação com meses dos anos históricos.

\subsubsection{Conclusões do caso 4}

No caso com séries sintéticas, os custos marginais da simulação também apresentam 
redução em praticamente todo o horizonte e em todos os submercados, mantendo-se as conclusões dos casos anteriores, com aumento da geração eólica na maioria dos cenários. No entanto, pôdese observar que em alguns períodos úmidos dos anos, a geração eólica ficou menor do que no caso oficial, mostrando a complementaridade e sazonalidade da fonte de modo inequívoco, realçado ainda mais pela representação estocástica da geração eólica.

A Tabela 22 mostra o custo total de operação e custo da geração térmica dos casos oficiais e simulados. Os custos reduzem na simulação com eólicas em Reservatórios Equivalentes de Energia quando comparados com os casos oficiais com séries históricas ou sintéticas. Nos casos 2 e 3 há um aumento dos custos, uma vez que o caso 2 é crítico e necessita de maior geração térmica para atendimento da carga. Já no caso 3, há um aumento de carga e capacidade eólica, por isso há um aumento do custo total, mas o custo da geração térmica não aumenta proporcionalmente como nos outros casos, uma vez que se gera mais eólicas neste caso.

Tabela 22: Custo da geração térmica e custo total de operação dos casos

\begin{tabular}{lcccccc}
\hline $\begin{array}{c}\text { Custo de operação das } \\
\text { séries simuladas (R\$ 10^6) }\end{array}$ & Oficial & Ofistóricas & Ofintéticas & \multicolumn{2}{c}{ Caso 1} & \multicolumn{2}{c}{ Caso 2 históricas Caso 3 históricas cap. } & Caso 4 \\
históricas & crítico & Eólica aumentada & sintéticas \\
\hline Custo total de operação & $15.312,82$ & $20.825,14$ & $14.446,28$ & $32.418,83$ & $44.640,51$ & $18.852,39$ \\
Custo de geração térmica & $14.288,31$ & $15.401,92$ & $13.992,51$ & $30.764,52$ & $17.284,40$ & $14.694,48$ \\
\hline
\end{tabular}

Fonte: Elaboração Própria 


\section{SÍNTESE, CONCLUSÕES E RECOMENDAÇÕES}

\subsection{Resumo}

A geração eólica em 2016 teve em média participação de aproximadamente $6 \%$ no atendimento da carga de energia brasileira, enquanto que as fontes hidrelétricas tiveram participação de $76 \%$ e as termelétricas, com 18\%. Essa representação com fontes térmicas engloba combustíveis fósseis e nucleares. No entanto, a geração eólica apresentou participação de $8 \%$ em setembro de 2016, dada a sua sazonalidade com maiores velocidades de vento no Nordeste no segundo semestre dos anos.

A energia eólica tem apresentado crescimento importante no sistema elétrico brasileiro, representando em 2017 cerca de 7\% da matriz de capacidade instalada, com 10,8 GW instalados (ANEEL, 2017). A maior participação da potência eólica se concentra na região Nordeste do país, cerca de $80 \%$, sendo os Estados com maior capacidade: Rio Grande do Norte, Bahia e Ceará. O Sul tem aproximadamente o restante da participação, sendo o Rio Grande do Sul o Estado com maior capacidade da região. A região Sudeste apresenta mínima participação.

Apesar da geração eólica apresentar menor participação na matriz de eletricidade brasileira, é esperado que a participação aumente e a tendência é de representar 11,6\% da capacidade instalada em 2024, dadas as expectativas do Plano Decenal da EPE de 2024.

O Operador Nacional do Sistema despacha as usinas para o atendimento da carga de energia, seguindo como diretriz os valores resultantes dos modelos de otimização Newave e Decomp e considerando ajustes para a operação em tempo real que sempre são necessários. Estes modelos, através de um conjunto de arquivos de entrada denominados de deck, fazem a otimização dos valores, verificando-se a quantidade de geração hidráulica e térmica mensal para atender a carga. A otimização é realizada através da minimização do custo total da operação até 5 anos, que leva em consideração o custo imediato e o custo futuro. Para o ONS, os modelos definem o planejamento da operação, a CCEE utiliza os modelos para a formação do preço de energia. A EPE utiliza o modelo para realizar a expansão do setor, através de leilões de usinas e garantia física.

O Sistema é representado de maneira agregada em forma de reservatórios equivalentes para reduzir o esforço computacional, para cada submercado, agrega-se os reservatórios em um reservatório equivalente de energia, obtendo-se a capacidade equivalente deste reservatório e as 
afluências são agregadas em energias afluentes (CCEE \& ONS, 2016). Até dezembro de 2015 eram considerados 4 submercados, representados por 4 Reservatórios Equivalentes de Energia (REE's): Sudeste/Centro-Oeste, Sul, Nordeste e Norte. Em janeiro de 2016, o número de REE's passou para nove, sendo 2 na região Norte, 5 na região Sudeste/Centro-Oeste, continuando apenas 1 no Sul e 1 no Nordeste.

As afluências são representadas de forma estocástica, uma vez que não se conhece os seus valores para o futuro. A incerteza é representada por árvore de cenários onde cada caminho da árvore é denominado de cenário hidrológico e cada nó é uma possível realização de afluência. As realizações seguem um processo estocástico com propriedades estatísticas do histórico, preservadas na construção da árvore.

(MACEIRA; MERCIO, 1997) no Newave a incerteza hidrológica é considerada através de cenários sintéticos de afluências às sub-regiões para os próximos 5 anos. $\mathrm{O}$ modelo utilizado dentro do Newave é denominado de Gevazp (modelagem autoregressiva linear) com base nos últimos 11 meses. O modelo estocástico utilizado no Gevazp é o PAR (p), modelo autoregressivo periódico de ordem p. As afluências neste modelo dependem das afluências que ocorreram nos mesmos locais em até $\mathrm{p}$ meses anteriores. Para cada mês pode haver um valor diferente para o parâmetro "p". Normalmente, afluências em meses iniciais do período chuvoso dependem de 1 ou 2 meses anteriores. Já em meses do período seco, dependem do que ocorreu em vários meses do período úmido anterior.

Após a decomposição do problema, o modelo resolve para cada período e cenário de afluência um problema de otimização minimizando a soma do custo imediato e o custo futuro. $\mathrm{O}$ custo imediato representa o custo de geração de térmicas e eventuais cortes de carga. $\mathrm{O}$ custo futuro representa o valor esperado da operação no futuro em função das afluências passadas e reservatórios finais. A decisão ótima não é gerar somente com hidrelétricas no primeiro estágio, embora o custo operativo da água seja zero, porque a hidrelétrica pode transportar energia de um estágio para outro tendo, desta forma, um custo de oportunidade. O despacho ótimo ocorre quando o valor da água imediato é igual ao valor da água no futuro.

Ao se realizar a otimização do Newave, é considerada uma geração eólica determinística, considerando-se que a geração média de cada mês ocorrerá ao longo do período de simulação. 
Além da eólica, as fontes de biomassa e as pequenas centrais hidrelétricas também seguem nos modelos da mesma forma determinística, condicionando a estratégia de despacho pela geração média mensal. Desta forma, não há representação da incerteza nos modelos para as usinas não despachadas pelo modelo e, dada a previsão de crescimento da fonte eólica na matriz de eletricidade brasileira, o estudo das características desta fonte e a inserção da eólica estocástica passa a ser importante.

Os processos hidrológicos são considerados estocásticos pois são regidos por leis probabilísticas, contemplando variáveis aleatórias e podendo representar eventuais regularidades. A precipitação, as capacidades de infiltração, os escoamentos superficiais, são considerados processos hidrológicos estocásticos (NAGHETTINI \& PINTO, 2007). O estudo dos processos estocásticos refere-se à aleatoriedade verificada através de modelos matemáticos, buscando estabelecer correlações em sequência, no tempo ou no espaço.

(MACHADO, 2016) mostra a geração de séries de geração eólica e de afluência utilizando o modelo (PAR) para o planejamento da operação de médio prazo. Segundo o autor, o modelo gera séries sintéticas hidroeólicas satisfatórias, sendo melhor para a geração de séries sintéticas de energia eólica do que para geração de séries de afluência incremental. Uma das recomendações de trabalho futuro de Machado (2016, p.137) é "estudar o impacto da geração eólica, de forma estocástica via modelo PAR, no Planejamento de Médio Prazo da Operação Hidrotérmica".

A revisão bibliográfica mostrou trabalhos sobre inserção da eólica na matriz de eletricidade, complementaridade entre hidráulicas e eólicas e geração de séries sintéticas de velocidade de vento e de afluências. Todavia, há necessidade da introdução da geração eólica com séries sintéticas nos modelos de otimização oficiais do setor elétrico.

O objetivo principal deste trabalho foi de analisar e propor uma metodologia que permita incluir a variabilidade da geração eólica nos modelos de otimização oficiais do setor elétrico, verificando-se os impactos desta consideração através dos índices de custos marginais de operação, geração hidráulica, térmica e eólica. O trabalho mostrou um panorama geral da fonte eólica no mundo e no Brasil, análises sobre as velocidades de vento e geração eólica em diversas coordenadas do Brasil, além de análise detalhada do Newave, inserção dos dados no modelo e análise dos resultados. 
As questões ligadas a emissão de gases de efeito estufa e a volatilidade dos preços do barril de petróleo motivam o incremento de energia limpa e renovável. A eólica tem apresentado acelerado crescimento mundial. (GWEC, 2016) mostra que o aumento de geração eólica em 2016 foi de $12,6 \%$, atingindo $487 \mathrm{GW}$ instalados.

A China instalou 23,4 GW em 2016, pouco menos do que os $30 \mathrm{GW}$ de 2015, trazendo o seu acumulado para $169 \mathrm{GW}$ instalados. O Brasil é o quinto maior mercado em 2016, passou para nono lugar no ranking dos dez países com o maior acumulado de capacidade instalada, ultrapassando a Itália.

Houve aumento do preço de energia eólica no leilão de 2013 devido ao maior risco considerado, uma vez que o risco de conexão à rede de transmissão foi transferido do consumidor para o gerador, além de mudanças como necessidade de índice de produtividade de geração em P90, com consequente redução da garantia física, antes era de $50 \%$.

O Brasil possui um potencial eólico segundo o Atlas de 2001 de 143 GW. Entretanto, os dados utilizados para este atlas têm referência de valores de 2001, com medições a 50 metros de altura. Hoje as torres podem chegar a 140 metros de altura e estima-se que o potencial brasileiro superaria $300 \mathrm{GW}$, a 100 metros de altura (WITZLER, 2014). O Atlas da Bahia mostra potencial de aproximadamente $70 \mathrm{GW}$ a 100 metros de altura; o Rio Grande do Norte com 47 GW com a mesma taxa de ocupação; o Ceará apresenta $32 \mathrm{GW}$, mas na altura de 70 metros e o Rio Grande do Sul com potencial de $103 \mathrm{GW}$ a 100 metros. Apenas estes quatro Estados juntos, tem-se um potencial de $252 \mathrm{GW}$, sem considerar outros Estados que podem aumentar ainda mais o potencial eólico brasileiro. 
Tabela 23: Potencial eólico nos Estados

\begin{tabular}{|c|c|c|r|r|r|}
\hline \multicolumn{6}{|c|}{ Potencial Eólico BA, RN, CE e RS } \\
\hline Estado & $\begin{array}{c}\text { Altura } \\
(\mathrm{m})\end{array}$ & $\begin{array}{c}\text { Vento } \\
(\mathrm{m} / \mathrm{s})\end{array}$ & $\begin{array}{c}\text { Área } \\
(\mathrm{km} 2)\end{array}$ & $\begin{array}{c}\text { Potência } \\
\text { Instalável } \\
(\mathrm{GW})\end{array}$ & $\begin{array}{r}\text { Energia } \\
\text { Anual } \\
(\mathrm{TWh})\end{array}$ \\
\hline Bahia & 100 & $>=7 \mathrm{~m} / \mathrm{s}$ & 26.998 & 70 & 274 \\
\hline Rio Grande do Norte & 100 & $>=7 \mathrm{~m} / \mathrm{s}$ & 18.053 & 47 & 131 \\
\hline Ceará & 70 & $>=7 \mathrm{~m} / \mathrm{s}$ & 12.426 & 32 & 67 \\
\hline Rio Grande do Sul & 100 & $>=7 \mathrm{~m} / \mathrm{s}$ & 39.529 & 103 & 382 \\
\hline Total & & & 97.006 & 252 & 854 \\
\hline
\end{tabular}

Fonte: Elaboração Própria com base nos Atlas Eólicos

O Nordeste brasileiro tem apresentado severa seca nos últimos anos e tem apresentado necessidade de importação de energia das outras regiões para o atendimento de sua carga. Em setembro de 2016 a geração eólica foi em média a mais alta do ano, contribuindo com $45 \%$ da geração da região.

De acordo com o Operador do Sistema, o estado que gera mais energia eólica atualmente é o Rio Grande do Norte e também com a maior capacidade instalada. A menor capacidade instalada é proveniente de Santa Catarina, em relação aos estados que apresentam geração eólica. Em setembro de 2016, o fator de capacidade registrado pelo Rio Grande do Norte foi de praticamente $57 \%$ e todos os Estados do Nordeste apresentaram fator de capacidade acima de 50\% (ONS, 2017). A geração eólica do Nordeste foi capaz de atender 39\% da carga da região neste mesmo mês, quando a situação dos níveis dos reservatórios estava se caracterizando por um período de evidente escassez.

As bases de dados de velocidade de vento mostradas no quarto capítulo são do MERRA (dados de reanálise - NASA's Modern-Era Retrospective analysis for Research and Applications) e Vortex, modelo atmosférico de mesoescala on-line que estima velocidades de vento de longo período para locais onde não existe medições.

Os dados de magnitude de velocidade de vento do MERRA são horários e disponíveis desde 1980 até 2015 . Utilizando-se os dados de velocidade a 20 e a 50 metros de altura, calculou-se o índice de rugosidade do terreno. De posse do índice, calculou-se a velocidade do vento a 100 metros 
de altura para algumas coordenadas do Brasil. Com base nestas velocidades, calculou-se através da curva da turbina GE de potência nominal de $2.300 \mathrm{~kW}$, a energia gerada em cada velocidade com a turbina.

Para as velocidades menores do que $3 \mathrm{~m} / \mathrm{s}$ e maiores do que $25 \mathrm{~m} / \mathrm{s}$ foram consideradas gerações de energia nulas, para as velocidades entre $12 \mathrm{~m} / \mathrm{s}$ e $25 \mathrm{~m} / \mathrm{s}$, a geração considerada foi condicionada pela curva da turbina com máximo de $2.300 \mathrm{KWh}$. Em seguida, a partir dos dados horários de geração de energia, foi realizada uma média mensal de geração para a turbina considerada em cada uma das coordenadas.

Os valores de correlação dentro da mesma base de dados são altos, mas a partir do momento que se misturam a base de dados do MERRA com o Vortex, as correlações deixam de ser elevadas dentro dos mesmos Estados, necessitando de uma análise mais aprofundada destes valores para verificar se apresentam realmente baixa correlação.

Com base no boxplot das coordenadas dos valores de geração de energia eólica dos diferentes Estados e a matriz de correlação do Vortex, verifica-se que o Ceará apresenta uniformidade entre as coordenadas e alta correlação entre si, o Rio Grande do Norte também apresenta uniformidade e alta correlação, principalmente entre as coordenadas que estão mais ao interior do Estado. Há grande dispersão entre as coordenadas da Bahia e em algumas delas, baixa correlação entre si. Já no boxplot do Rio Grande do Sul percebe-se alguns grupos de similaridade, sendo algumas similares por estarem próximas geograficamente e outras com medianas parecidas, mas com localizações geográficas distantes.

A base de dados do Vortex representa a velocidade de vento horária desde 1982 até 2014 de 16 coordenadas brasileiras a 100 metros de altura. Dez coordenadas no Nordeste (Rio Grande do Norte: João Câmara e Macau; Bahia: Caetité, Morro do Chapéu e Pedra do Reino; Ceará: Amontada, Aracati e Paracuru; Pernambuco: Afrânio e Araripe); e seis coordenadas no Sul (Rio Grande do Sul: Palmar, Osório, Tramandaí, Estrada de Senandes e Coxilha Negra; Santa Catarina: Quilombo).

As coordenadas do Ceará apresentam a mesma sazonalidade entre os meses do ano, com maiores velocidades de vento entre julho e janeiro, e redução entre fevereiro e junho. O histograma da região é similar entre as coordenadas, com maiores frequências de velocidades entre 8 e $10 \mathrm{~m} / \mathrm{s}$. 
As coordenadas da Bahia, apesar de apresentarem sazonalidade semelhante, apresentam diferentes histogramas, sendo que a coordenada de Caetité apresenta maiores velocidades e as coordenadas de Morro do Chapéu e Pedra do Reino, maior frequência de velocidades entre 8 e $12 \mathrm{~m} / \mathrm{s}$. As coordenadas do Rio Grande do Norte também apresentam sazonalidade semelhante e histograma com diferenças, sendo os sites de João Câmara e Macau com maior concentração de velocidades entre 8 e 12 m/s. As coordenadas do Rio Grande do Sul não apresentaram grande variação de velocidade durante o ano e os histogramas são semelhantes entre os sites.

A metodologia da reconstrução das séries históricas de dados de velocidade de vento e geração de energia eólica teve como base o trabalho de (WITZLER, 2014). A partir dos dados de velocidade de vento do Vortex e NOAA, verificou-se para os anos comuns das duas bases a média diária de velocidade de vento, identificando-se os pontos que a correlação entre as bases foi maior do que 0,8 . Por meio da extrapolação vertical, definida através da curva logaritmica dos dados do Vortex, calculou-se os valores de velocidade do NOAA na altura de 120 metros, altura do rotor considerada nesta tese. Através das velocidades médias e desvios padrão médios dos dados da Vortex, calculou-se a distribuição de Weibull para cada mês do histórico. Com as 12 curvas de Weibull, utilizou-se da velocidade média diária da NOAA para a construção da distribuição de Weibull, construindo-se desta forma os parâmetros da Weibull diária com os valores de velocidade da NOAA. Em seguida calculou-se a energia gerada com a curva de potência da turbina otimizada escolhida para cada site, de forma a obter o maior fator de capacidade. Com base nos valores de geração diária em MWh, fez-se uma soma de todos os dias do mês para transformar em dados mensais, tendo-se então uma base de dados desde 1948 a 2014.

Como o Newave considera os dados históricos de vazões desde 1931 a 2014 (para a simulação de agosto de 2016), verificou-se, a partir do histórico de afluências do Nordeste, os anos calendário, do período histórico em que não se dispunha de séries reconstruídas de velocidade do vento, que fossem hidrologicamente mais parecidos aos anos do período 1948 a 2014. A partir de então, utilizou-se os valores de geração eólica reconstruídos para associar um perfil de vento aos anos do período histórico até 1947, associando-se a cada um desses anos um perfil de vento correspondente ao ano hidrológico, pós 1947, mais semelhante, do ponto de vista de hidrologia, ao ano do período de lacuna, permitindo assim compor a base de dados desde o início do horizonte. 
Os valores reconstruídos de geração de cada site histórico mensal de 1948 a 2014 e, por similaridade, os valores de 1931 a 1947 são introduzidos no modelo Newave, após serem transformados em PU pela divisão do valor da geração pela potência da turbina considerada para o determinado site e a consideração da potência a ser instalada em cada Estado. Inclui-se estes valores sazonalizados como se fossem vazões de rios com usinas a fio d' água de geração eólica no modelo Newave, adicionando-se 4 Reservatórios equivalentes de energia no Nordeste e 2 reservatórios equivalentes de energia no Sul. Ainda, considera-se a expansão das fontes eólicas por Estado no modelo. Oito arquivos do deck do Newave são modificados em cada simulação para inserção dos dados em REEs: SISTEMA, REE, CONFHD, MODIF, POSTOS, VAZPAST, VAZOES e HIDR.

Das usinas não simuladas, representadas pelas eólicas, $\mathrm{PCH}^{\prime} \mathrm{s}$ e usinas a biomassa consideradas no Newave, a geração eólica representa $92 \%$ de participação dessas usinas no Nordeste, considerando-se o deck de agosto de 2016. No mesmo período, as eólicas representam 34\% das usinas do Sul. Estes valores de geração determinística foram excluídos, para fins desse estudo, dos dados de entrada do programa, na medida em que, no momento seguinte, se considerou a re-inserção dessa capacidade de produção através de usinas hidráulicas a fio d'água, uma vez que estas apresentam modelagem considerando as afluências passadas para previsão de séries sintéticas futuras. Para isso foram criados postos para cada site em seus respectivos Reservatórios Equivalentes de Energia, sendo eles: Ceará, Rio Grande do Norte, Bahia, Piauí + Pernambuco, Rio Grande do Sul e Santa Catarina. Para cada usina eólica criada, colocou-se a capacidade instalada de acordo com cada Estado considerado nesta tese, além da expansão das usinas consideradas dos leilões já realizados até agosto de 2016, no deck consideradas como em construção. Detalhes das usinas a fio d'água foram mantidos para as eólicas, exceto a evaporação que não foi considerada, além de outras simplificações como produtibilidade de "um" e altura de "um" metro de queda d' água, para que a energia gerada seja exatamente igual à "vazão eólica" afluente, posto que essa já foi calculada em unidade de energia.

Foram feitas 4 simulações do modelo Newave e comparadas com a série oficial de agosto de 2016, sendo elas:

1) "Simulações eólicas históricas": séries históricas com turbinas otimizadas considerando diversos sites eólicos com sua representação histórica reconstruída de acordo com 
metodologia mostrada no item 5.3 desta tese, 4 REEs no Nordeste e 2 no Sul de geração eólica;

2) "Simulação crítico históricas": a partir do caso 1, com nível de reservatório inicial de agosto de 2014 e aumento de carga em 8\% em todos os submercados;

3) "Capacidade eólica aumentada": com base no caso 1, considerando aumento da capacidade eólica em 10 vezes, próxima da capacidade instalada hidráulica, com a manutenção das térmicas e aumento de carga do Nordeste e do Sul para ficar compatível com o aumento da oferta;

4) "Simulações eólicas sintéticas": idem ao caso 1, mas considerando as séries sintéticas.

Os principais resultados que se desejou observar foram:

- A complementaridade da eólica com a hidráulica, verificando-se em períodos de hidrologia desfavorável, a eólica é suficiente para contribuir mais nestes períodos;

- Se a metodologia estocástica consegue mostrar a variabilidade da eólica e se o impacto nos resultados é importante;

- Se em períodos críticos, com baixas afluências e carga elevada, a geração eólica é mais elevada do que em um cenário médio nas simulações;

- Se com o aumento da capacidade eólica, esta ajuda mais o sistema, uma vez que a eólica representa hoje aproximadamente $9 \%$ da capacidade hidráulica;

- Avaliar o ganho adicional de informação e conhecimento considerando-se as séries sintéticas.

\subsection{Conclusões}

A simulação com eólicas em Reservatórios Equivalentes de Energia mostrou a complementaridade da geração eólica com a hidráulica na região Nordeste. Em períodos de hidrologia desfavorável, a eólica consegue gerar mais e ajudar no atendimento da carga, evitandose elevação dos custos pelo despacho de usinas térmicas e consequentemente considerando melhor a oferta de energia do sistema do que em modelos determinísticos.

Em cenários críticos, como no segundo estudo de caso, a eólica não consegue praticamente aumentar a geração em relação ao primeiro caso, uma vez que sua geração máxima já está sendo 
considerada, posto que é representada por hidráulicas a fio d' água. Mesmo assim, os custos marginais do estudo foram menores do que o caso oficial crítico, dado que a maior geração eólica em relação a este caso é maior, reduzindo-se os custos marginais devido ao menor despacho térmico.

Com o aumento hipotético da capacidade eólica, a geração eólica passou a ser a principal fonte de energia. Em períodos médios e considerando-se meses cuja sazonalidade da geração eólica é baixa, os custos marginais devido aos despachos térmicos necessários podem aumentar significativamente. A simulação mostrou que em períodos de hidrologia desfavorável, houve melhores condições de vento e a geração eólica foi superior. Estes tipos de cenários representados por hidrologias adversas, não são contemplados em modelos determinísticos, o que mostra ainda mais a relevância de se considerar cenários de geração eólica na otimização do sistema.

A simulação com séries sintéticas também mostrou, na maioria dos cenários, redução dos custos marginais com a consideração da representação estocástica da geração eólica, dado o aumento da geração. A simulação mostrou a variabilidade da eólica através das gerações menores do que no caso oficial no período úmido, ou maiores em períodos secos, identificando a complementaridade e sazonalidade da fonte.

Os benefícios da metodologia apresentada, em comparação com a metodologia determinística atualmente empregada para a geração eólica nos modelos de otimização, podem ser classificados em dois grupos principais: (i) aqueles associados à representação de séries sintéticas e o estabelecimento de cenários plausíveis de geração eólica considerando-se a variabilidade da fonte para o planejamento do setor elétrico; e (ii) aqueles relacionados à quantificação dos custos marginais associados e sua volatilidade. Em particular, os benefícios do grupo (i) permitem suprir uma deficiência da metodologia utilizada hoje para a otimização da operação e decisão dos despachos das demais fontes de energia, considerando a complementaridade da fonte eólica com a hidráulica e representando a variabilidade das séries eólicas. Os benefícios do grupo (ii) se relacionam à redução dos custos marginais da operação, reduzindo a necessidade de despacho térmico para atendimento da carga do sistema, atenuando a sua volatilidade, além da redução dos custos totais de operação. 
Para a representação da variabilidade da geração eólica, foram adotadas premissas simplificadoras, devido principalmente à indisponibilidade de dados que sirvam para dar suporte a uma modelagem mais acurada. A base de dados considera valores de reanálise, apenas considerados alguns sites dos Estados do Nordeste e Sul do país. Para uma análise mais aprofundada, recomenda-se a utilização de base de dados com medições das velocidades de vento com anemômetros juntamente com dados de reanálise, além de um maior número de sites, abrangendo grande parte das regiões. Além disso, recomenda-se a consideração de turbinas reais, uma vez que usinas otimizadas ou pessimistas podem influenciar na determinação do histórico das séries. Mesmo assim, através da comparação dos resultados considerando a geração eólica determinística e os casos representando a variabilidade da geração eólica, foi possível identificar impactos importantes desta para o planejamento do setor elétrico brasileiro.

Apesar deste trabalho não ter a finalidade de prever a geração eólica, mas tendo em vista os relevantes impactos mesmo com algumas simplificações, conclui-se que é importante e urgente que seja investigada a metodologia determinística utilizada nos modelos, na medida em que a consideração de séries sintéticas altera significativamente os resultados, recomendando enfaticamente inserir a representação da incerteza inerente da geração eólica nos modelos, assim como se faz no caso das hidráulicas.

\subsection{Principais contribuições}

Este trabalho apresentou como principal contribuição a representação das séries de geração eólicas reconstruídas no modelo Newave através do modelo existente de geração de séries de afluências. Através de um artifício, necessário para se poder utilizar o modelo "oficial" do setor, que é de código fechado e inacessível aos usuários, que consiste em representar as plantas eólicas como se fossem usinas a fio d'água, que não possuem reservatórios e geram toda a água que chega na usina. Assim, as eólicas, que também devem produzir toda energia do vento afluente à usina, sem nenhuma capacidade de estocagem, produzem energia através dos ventos "afluentes" às usinas, permitindo verificar o impacto da consideração das séries na otimização do sistema. A complementaridade da geração hidráulica com a eólica pôde ser observada na região Nordeste, além da maior geração em momentos de hidrologia desfavorável. Em modelos determinísticos, esta variação não é possível de ser observada e considerada, identificando assim uma deficiência na 
metodologia empregada atualmente. A geração eólica maior em momentos críticos de hidrologia, dada pela sua complementaridade com a hidráulica identificada nas simulações deste estudo, não apenas contribui para reduzir os custos marginais, como traz o benefício de atenuar a sua volatilidade, reduzindo-se os despachos térmicos e mantendo a segurança na oferta de energia. $\mathrm{O}$ cenário hipotético de aumento da capacidade eólica foi importante no sentido de mostrar a variabilidade da eólica, uma vez que sendo esta a principal fonte de oferta, em cenários desfavoráveis de vento, pode causar aumento dos despachos térmicos, até mesmo a ocorrência de déficits no sistema e incremento significativo dos custos marginais.

\subsection{Trabalhos futuros}

Através destes pontos, indica-se que a consideração da variabilidade da geração eólica deve ser melhor investigada, uma vez que mostra a complementaridade para o sistema e precisa ser melhor representada nos modelos atuais de otimização do sistema. Se for implementada uma representação conforme sugerida anteriormente, a eólica pode permitir a redução dos custos marginais de operação, deixando-os mais constantes e previsíveis, aumentando o nível dos reservatórios e reduzindo os riscos de atendimento da carga.

Apesar da recomendação da utilização do PAR (p) por (MACHADO, 2016) para geração de cenários eólicos, não foi o enfoque deste trabalho avaliar se este modelo utilizado no Newave é o ideal para a geração de séries sintéticas de geração eólica. Por conseguinte, sugere-se a análise deste e outros modelos de geração de séries para esta finalidade no Newave. Além disso, existe inconsistência do tratamento do PAR (p) no Newave referente à correlação espacial entre ruídos. Assim, sugere-se para trabalhos futuros, um estudo detalhado da matriz de correlação ao se utilizar séries de geração eólica.

Sugerem-se estudos mais aprofundados de vento e suas medições para atualizar o potencial eólico brasileiro, uma vez que o último levantamento é de 2001 e apenas alguns estados apresentam uma previsão em anos mais recentes. Com torres mais altas e novas tecnologias o potencial pode ser muito maior e com o incremento da capacidade instalada eólica prevista no Plano Decenal da EPE, o estudo da variabilidade eólica se torna cada vez mais importante. Além disso, o estudo das medições de velocidades de vento, juntamente com dados de reanálise podem identificar mais 
bacias eólicas e, sendo estas consideradas na otimização do modelo, poderão contribuir ainda mais na complementaridade do sistema. A modelagem da velocidade de vento em distintos intervalos de tempo, com modelos diferentes para o curto, médio e longo prazos também podem ser interessantes para representação da variabilidade em trabalhos futuros.

Uma limitação deste trabalho foi a de utilizar turbinas otimizadas, apresentando o maior fator de capacidade por região considerada, por não ser disponível publicamente esta informação nas pesquisas realizadas. A recomendação é a de utilizar em trabalhos futuros curvas de turbinas reais ao invés de turbinas otimizadas, trazendo a realidade da operação para os estudos.

Outro ponto a analisar é a periodicidade das séries temporais de velocidade de vento de não apenas um ano, mas as periodicidades plurianuais, mostrando as quebras climáticas que os episódios de ocorrência de vento podem apresentar e que hoje não se considera nos modelos de geração de cenários. No contexto de séries temporais, uma característica importante é a estacionariedade. Isto porque, sem a estacionariedade a quantidade de modelos a serem considerados cresce muito, dificultando a tarefa de modelagem estatística. É, portanto, uma tarefa importante, a pesquisa acerca de transformações que induzam à estacionariedade das séries de dados a utilizar.

Quando há redução nas velocidades dos ventos e consequente diminuição da geração eólica principalmente no Nordeste do Brasil, há uma necessidade de geração térmica fora da ordem de mérito para atendimento da carga do sistema. Isso ocorre devido aos reservatórios das usinas hidrelétricas da região estarem passando por um período de escassez e não conseguem prover o atendimento da carga. Esse despacho térmico adicional necessário na operação real do sistema é ressarcido via Encargos de Serviço do Sistema ao invés de ser incluído no custo marginal da operação, uma vez que é uma operação ex-post. Há necessidade de se estudar se esta é a melhor forma de ressarcir a variabilidade das velocidades do vento.

Um ponto interessante a ser estudado é a questão financeira, verificando-se como seria um MRE (Mecanismo de Realocação de Energia) considerando as simulações deste trabalho. 


\section{REFERÊNCIAS BIBLIOGRÁFICAS ${ }^{19}$}

ABEEólica. Boletim Anual de Geração Eólica 2016. Disponível em:

$<$ http://www.abeeolica.org.br/wpcontent/uploads/2017/05/424_Boletim_Anual_de_Geracao_Eolica_2016_Alta.pdf $>$.Acesso em: 26 mai. 2017.

ALEXIADIS, M.C.; DOKOPOULOS P.S., SAHSAMANOGLOU, H.S.; MANOUSARIDIS, I. M. Short-term forecasting of Wind speed and related electrical power. Solar Energy. Volume 63, julho de 1998. Páginas 61-68.

AMARAnTE, O. A. C.; ZACK, M. B. J.; SÁ, A. L. Atlas do Potencial Eólico Brasileiro. Brasília, 2001.

ANEEL. BIG - Banco de Informações de Geração. Banco de Dados, Agência Nacional de Energia Elétrica. Disponível em:

http://www2.aneel.gov.br/aplicacoes/capacidadebrasil/capacidadebrasil.cfm>. Acesso em: 19 mai. 2016, 01 out. 2016 e 26 mai. 2017.

ANEEL. Resolução Normativa no 440, de 05 de julho de 2011. Diário Oficial de 13 jul. 2011, seção 1, p. 61, v. 148, n. 133.

. Resolução Normativa no 476, de 13 de março de 2012. Diário Oficial de 26 mar. 2012, seção 1 , p. 67, v. 149, n. 59.

Atlas do Potencial Eólico do Ceará. Disponível em: <

http://www.seinfra.ce.gov.br/index.php/downloads/category/6-energia?download=16\%3Aatlasdo-potencial-eolico-do-ceara $>$. Acesso em: 03 jun. 2016.

Atlas do Potencial Eólico do Estado da Bahia. Projeto de Pesquisa e Desenvolvimento CoelbaAneel. Disponível em:

$<$ http://www.cresesb.cepel.br/publicacoes/download/atlas_eolico/atlas_eolico_BA.pdf $>$ Acesso em: 03 jun. 2016.

Atlas Eólico do Rio Grande do Norte. Projeto de Pesquisa e Desenvolvimento Cosern-Aneel. Disponível em:

$<$ http://www.cresesb.cepel.br/publicacoes/download/atlas_eolico/atlas_eolico_RN.pdf $>$ Acesso em: 03 jun. 2016.

Atlas Eólico do Rio Grande do Sul. Disponível em:

$<$ https://dl.dropboxusercontent.com/u/25365701/Atlas_Eolico_Rio\%20Grande_do_Sul_2014.pdf >. Acesso em: 03 jun. 2016.

\footnotetext{
${ }^{19}$ De acordo com a Associação Brasileira de Normas Técnicas (ABNT NBR 6023).
} 
BASIS module WINDPRO., windPro. www.emd.dk: EMD International A/S. Disponível em: $<$ www.emd.dk>. Acesso em: 03 jun. 2016.

BEZERRA, B.; BARROSO, L. A.; CUNHA, G.; CARVALHO, M.; ÁVILA, P.; PEREIRA, M. $\mathrm{V}$. Análise do percentual máximo para a inserção de energia eólica na matriz elétrica brasileira sob a ótica energética. XXII SNPTEE, 2013.

CARVALHO, M. R. M.; BEZERRA, B.; COSTA JR, L. C. D.; ÁVILA, P. L.; FERREIRA, L. A.; BARROSO, L. A.; PEREIRA, M. L. Análise Probabilística do Suprimento de Ponta no Setor Elétrico Brasileiro: Impacto da Inserção Eólica. XXII Simpósio de Especialistas em Planejamento da Operação e Expansão Elétrica, 2012.

CASTINO, F.; FESTA, R.; RATTO, C.F. Stochastic modelling of Wind velocities time series. Journal of Wind Engineering and Indutrial Aerodynamics. Volumes 74-76, abril de 1998. Páginas 141-151.

CAVADOS, G. A. Análise do impacto da introdução das fontes intermitentes no setor elétrico brasileiro: estudo de caso da região Nordeste. Dissertação de Mestrado - Rio de Janeiro, RJ: Universidade Federal do Rio de Janeiro, 2015.

CCEE, Câmera de Comercialização de Energia Elétrica. Deck de preços do Newave de agosto de 2016. Disponível em: <

https://www.ccee.org.br/portal/faces/acesso_rapido_header_publico_nao_logado/biblioteca_virtu al?palavrachave $=$ Conjunto $\% 20 \mathrm{de} \% 20$ arquivos $\% 20$ para $\% 20 \mathrm{c} \% \mathrm{C} 3 \%$ A1lculo\&_afrLoop $=118075$ 0398458471\#\%40\%3F_afrLoop\%3D1180750398458471\%26palavrachave\%3DConjunto\%2Bde $\% 2$ Barquivos $\% 2 \mathrm{Bpara} \% 2 \mathrm{Bc} \% 25 \mathrm{C} 3 \% 25 \mathrm{~A} 11 \mathrm{lculo} \% 26$ adf.ctrl-state $\% 3 \mathrm{Dmdp} 1$ ilsqw_75>. Acesso em: 05 ago. 2016.

Metodologia de preços. Disponível em:

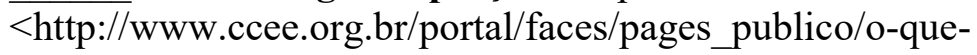
fazemos/como_ccee_atua/precos/metodologia_de_precos?_afrLoop $=1728647622722473 \# \% 40 \%$ 3F_afrLoop\%3D1728647622722473\%26_adf.ctrl-state\%3Dm7kg8g65e_90>. Acesso em: 24 jul. 2014.

Histórico de PLD. Disponível em:

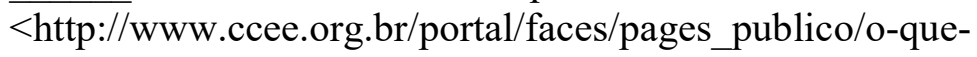

fazemos/como_ccee_atua/precos/precos_medios?_afrLoop $=1728506136633920 \# \% 40 \% 3 \mathrm{~F}$ afrLo op\%3D1728506136633920\%26_adf.ctrl-state\%3Dm7kg8g65e_61> . Acesso em: 04 jun. $2 \overline{0} 16$. out. 2015.

Preços de Energia, 2015. Disponível em: $<$ http://www.ccee.org.br/>. Acesso em: 25

CCEE; ONS. O SIN e os modelos para o planejamento da operação energética Treinamento NEWAVE - DECOMP. São Paulo, 2015.

. Relatório de Validação da versão 21.1.1 do NEWAVE. Acordo Operacional ONS/CCEE. Rio de Janeiro, nov. 2015. 
CEPEL. Centro de Pesquisas de Energia Elétrica. VENTOS - Previsão e Geração de Cenários de Ventos. Disponível em: http://www.cepel.br/produtos/ventos-previsao-e-geracao-de-cenariosde-ventos.htm. Acesso em 06 nov. 2016.

. Disponível em: <http://www.cepel.br/>. Acesso em: 03 dez. 2013.

CESAR, T. C.; DAVID, P. A. M-S.; PEREIRA, A. O.; SOUZA, R. A.; CARVALHO, R. N. F. Regularização do Suprimento de Energia - O papel da Complementaridade. Grupo de Estudo de Planejamento de Sistemas Elétricos. XXI SNPTEE. Versão 1. Florianópolis, 2011.

DENAULT, M.; DUPUIS, D.; COUTURE-CARDINAL, S. Complementarity of hydro and wind power: Improving the risk profile of energy inflows. Energy Policy. 37 (2009) 5376-5384.

EL-HERI, Y. S.; BORBA, B. S.; BEZERRA, B.; CARVALHO, M. R. M.; DALL'ORTO C. E. R. C. Análise do Impacto Energético da Variabilidade da Produção de Energia Eólica no Sistema Elétrico Brasileiro. Brazil Windpower. Rio de Janeiro, 2016.

EPE. Empresa de Pesquisa Energética. Plano Decenal 2024. Disponível em: $<$ http://www.epe.gov.br/>. Acesso em: 25 out. 2015.

FADIGAS, E. Fundamentos e Viabilidade Técnico-Econômica. Aula 2 - Recursos Eólicos e suas características. Março de 2013. Notas de Aula.

GOOGLE EARTH. [Localização das coordenadas da base de dados MERRA e VORTEX]. 2016.

GWEC. Global Wind Energy Council. Global Wind Report 2014 - Annual market update. Disponível em: http://www.gwec.net/wpcontent/uploads/2015/03/GWEC_Global_Wind_2014_Report_LR.pdf/. Acesso em: 29 out. 2015.

. Global Wind Report 2016 - Annual market update. Disponível em:

http://files.gwec.net/files/GWR2016.pdf. Acesso em: 26 mai. 2017.

HAMILTON, J. Time Series Analysis. Princeton University Press, 1994.

HIPEL, K. W.; MCLEOD, A. I. Time Series Modelling of Water Resources and Environmental Systems. Elsevier, 1994.

JONG, P.; SÁNCHEZ, A. S.; ESQUERRE, K.; KALID, R. A.; TORRES, E. A. Solar and wind energy production in relation to the electricity load curve and hydroelectricity in the northeast region of Brazil. Renewable and Sustainable Energy Reviews. 23 (2013) 526-535.

JUNG, J. BROADWATER, R. Current status and future advances for Wind speed and power forecasting. Renewable and Sustainable Energy Reviews. 31 (2014) 762-777.

KAWANA, S. A. Avaliação energética do aumento da participação eólica no Sistema Interligado Nacional, com ênfase na concentração de plantas geradoras na região Nordeste 
e rebatimento nas condições de Atendimento da demanda de pico. Dissertação de Mestrado, Universidade de São Paulo, 2014.

KLIGERMAN, A. S. Operação Ótima de Subsistemas Hidrotérmicos Interligados Utilizando Programação Dinâmica Estocástica Dual. Dissertação de Mestrado, Unicamp. Campinas, 1992.

LUCAS, E. W. M.; SOUSA, F. A. S.; SILVA, F. D. S; LUCIO, P. S. Modelagem hidrológica determinística e estocástica aplicada à região hidrográfica do Xingú - Pará. Revista brasileira de meteorologia, v.24, n.3, 308-322, 2009.

MACEIRA, M.E.P., MERCIO, C.M.V.B. Stochastic Sreamflow Model for Hydroelectric Systems. Fifth International Conference PMAPS - Probabilistic Methods Applied to Power Systems, Vancouver, Canada, 1997.

MACHADO, R. C. Geração de cenários hidroeólicos para o planejamento da operação energética de médio prazo via modelo autoregressivo periódico. Dissertação de Mestrado Universidade Federal de Santa Catarina. Florianópolis, Santa Catarina, 2016.

MODERN-ERA Retrospective Analysis for Research and Applications. National Aeronautics and Space Administration, Washington, DC. [Online]. Disponível em: < https://gmao.gsfc.nasa.gov/reanalysis/MERRA/> Acesso em: 03 set. 2016.

MIGUEL, J. V. P. A influência da duração da campanha de medição anemométrica na avaliação de recursos eólicos com base na aplicação de metodologia MCP. Dissertação de Mestrado - Universidade de São Paulo, 2016.

MIGUEL, F. K. Aplicação da teoria de portfólio de Markowitz para a geração de energia elétrica proveniente de empreendimentos eólicos no Brasil. Tese de Doutorado. Universidade de São Paulo, 2016.

MUJUMDAR, P. P. Stochastic Hydrology. [Vídeo]. Indian Institute of Science. Department of Civil Eng. 2012. Disponível em: <http://nptel.ac.in/courses/105108079/\#>. Acesso em: 27 ago. 2014.

NAGHETTINI, M.; PINTO, E. J. A. Hidrologia estatística. Belo Horizonte: CPRM, 2007. 553 p. 2007.

OLIVEIRA, F. L. C. Modelo de séries temporais para construção de árvores de cenários aplicadas à otimização estocástica. Tese de Doutorado - Programa de Pós-Graduação em Engenharia Elétrica da PUC-Rio. Rio de Janeiro, RJ, 2013.

OLIVEIRA, F. L. C.; SOUZA, R. C. A new approach to identify the structural order of par (p) models. Pesquisa Operacional, Rio de Janeiro, v. 31, n. 3, páginas 487-498, 2011.

ONS. Operador Nacional do Sistema. Histórico da Operação 2015. Disponível em: $<$ http://www.ons.org.br/>. Acesso em: 25 out. 2015. 
Cronograma Reunião DMSE. Disponível em: <

https://cdre.ons.org.br/PMO/Forms/AllItems.aspx?RootFolder=\%2FPMO\%2FDOCUMENTOS $\% 20 \mathrm{M} \% \mathrm{C} 3 \% 89 \mathrm{DIO} \% 20 \mathrm{PRAZO} \% 2 \mathrm{~F} 2016 \% 2 \mathrm{FPMO}$ AGO16\&FolderCTID=0x012000A26202 D57C8CF844A3C19D39E306FAA6\&View $=\% 7 B 70 \bar{C} 33190-E 72 B-48 D 7-A F D 8-$ 867A1AF1D929\%7D>. Acesso em: 05 ago. 2016.

Usinas não simuladas. Disponível em: $<$

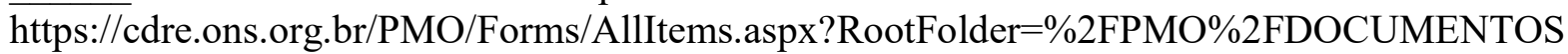
$\% 20 \mathrm{M} \% \mathrm{C} 3 \% 89 \mathrm{DIO} \% 20 \mathrm{PRAZO} \% 2 \mathrm{~F} 2016 \% 2 \mathrm{FPMO}$ AGO16\&FolderCTID=0x012000A26202 D57C8CF844A3C19D39E306FAA6\&View=\%7B70C $33190-E 72 B-48 D 7-A F D 8-$ 867A1AF1D929\%7D>. Acesso em: 05 ago. 2016.

Histórico de geração de energia, energia armazenada e energia natural afluente. Disponível em: <http://www.ons.org.br/historico/geracao_energia.aspx >. Acesso em: 04 jun. 2016.

Histórico de geração de energia. Disponível em:

$<$ http://www.ons.org.br/historico/geracao_energia.aspx>. Acesso em: 26 mai. 2017.

Histórico da operação. Geração de Energia Eólica. Disponível em:

$<$ http://www.ons.org.br/historico/geracao_energia_out.aspx?area=>. Acesso em: 26 mai. 2017

. Informativo Preliminar Diário da Operação. Geração eólica diária do Nordeste e Sul. Disponível em: < http://www.ons.org.br/publicacao/ipdo/Ano_2016/>. Acesso diário em 2016.

PALFI, G. C.; ZAMBON, R. C. Hydro and Wind Power Complementarity and Scenarization in Brazil. World Environmental and Water Resources Congress 2013. Cincinnati, Ohio. pp. 2414-2424.

PEREIRA, M. V. F.; PINTO, L. M. V. G. Stochastic Optimization of a multireservoir hydroelectric system: A Decomposition Approach. Water Resource Research. Volume 21, número 6, páginas 779-792. 1985.

. Multi-stage Stochastic optimization Applied to energy planning. Mathematical Programming, v. 52, páginas 359-375. 1991.

PEREIRA, M. V. F.; OLIVEIRA, G. C.; COSTA, C. C. G.; KELMAN, J. Stochastic Streamflow Models for Hydroelectric Systems. Water Resources Research. Volume 20, número 3, páginas 379-390. Março de 1984.

Potencial Eólico do Estado do Rio Grande do Norte. Projeto de Pesquisa e Desenvolvimento Cosern-Aneel. Disponível em: <

http://www.cresesb.cepel.br/publicacoes/download/atlas_eolico/atlas_eolico_RN.pdf $>$ Acesso em: 03 jun. 2016. 
RICOSTI, J. F. C; SAUER, I. L. An assessment of wind power prospects in the Brazilian hydrothermal system. Renewable and Sustainable Energy Reviews. Volume 19, páginas 742$753,2013$.

RODRIGUES, G. C. Utilização de redes neurais para previsão de ventos no horizonte de 24 horas. Dissertação de Mestrado - Universidade Federal do Rio de Janeiro. Rio de Janeiro, RJ, 2007.

SIQUEIRA, T. G.; SOARES FILHO, S. Comparação entre Programação Dinâmica Estocástica Primal e Dual no Planejamento da Operação Energética. Fifth Latin-American Congress: Electricity Generation and Transmission, 2003, São Pedro, 2003.

SOUZA, R. C.; CAMARGO, M. E. Análise e Previsão de Séries Temporais: Os Modelos ARIMA. $2^{\mathrm{a}}$ edição. 2004.

SUOMALAINEN, K; PRITCHARD, G.; SHARP, B.; YUAN, Z., ZAKERI, G. Correlation analysis on wind and hydro resources with electricity demand and prices in New Zealand. Applied Energy. 137 (2015) 445-462.

WITZLER, L. T. Metodologia para reconstrução de séries históricas de vento e geração eólica visando a análise da complementariedade energética no Sistema Interligado Nacional. Dissertação de Mestrado - Escola Politécnica da Universidade de São Paulo, São Paulo, SP, 2014.

WOO, C.; HO, T.; ZARNIKAU, J.; OLSON, A.; JONES, R.; CHAIT, M.; HOROWITZ, I.; WANG, J. Electricity-market price and nuclear power plant shutdown: Evidence from California. Energy Policy. 73 (2014) 234-244.

ZAMBON, R.C., BARROS, M. T. L., BARBOSA, P. S. F, FRANCATO, A. L., LOPES J. E. G., YEH, W. W-G. Optimization of Large-Scale Hydrothermal System Operation. J. Water Resources Planning and Management (2012) 138:135-143.

ZANG, Y.; WANG, J.; WANG, X. Review on probabilistic forecasting of wind power generation. Renewable and Sustainable Energy Reviews. 32 (2014) 255-270. 
APÊNDICE A - Boxplot dos sites

Boxplot Amontada Mensal

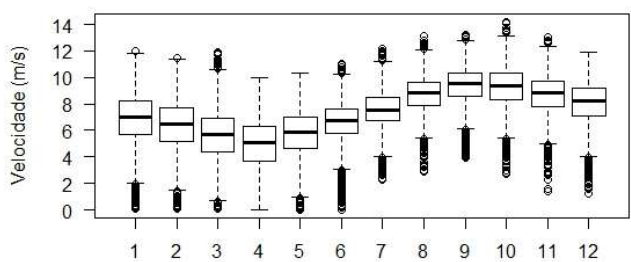

Boxplot Macau Mensal

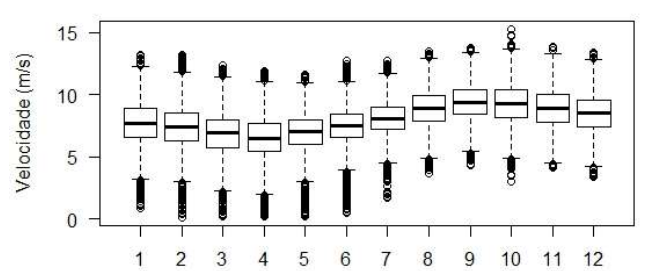

Boxplot Caetité Mensal

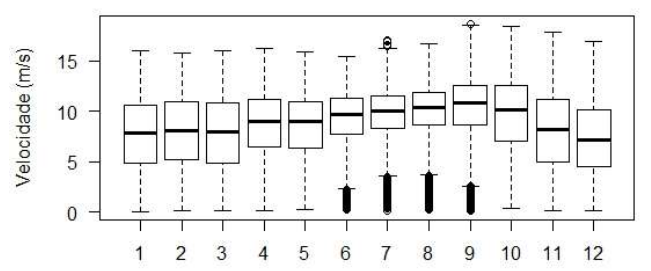

Boxplot Palmar Mensal

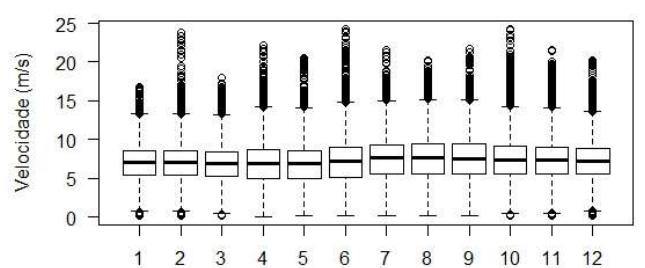

Boxplot Senandes Mensal

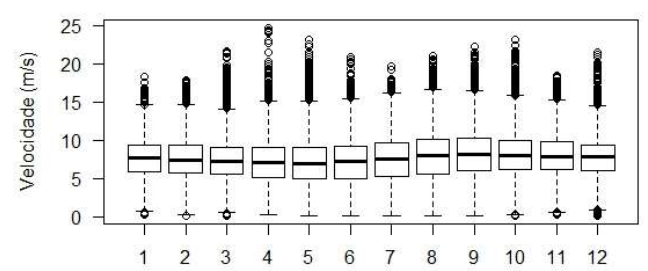

Boxplot Aracati Mensal

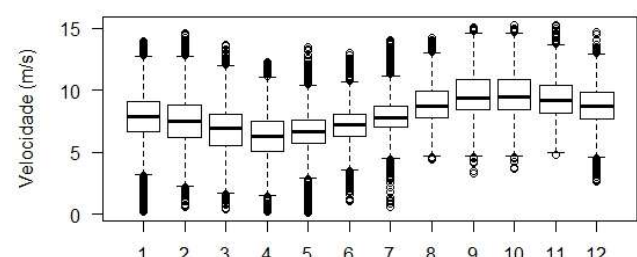

Boxplot Pedra do Reino Mensal

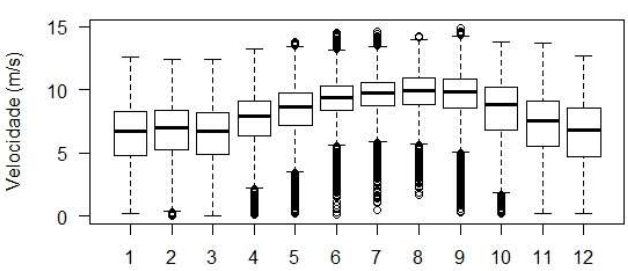

Boxplot Afrânio Mensal

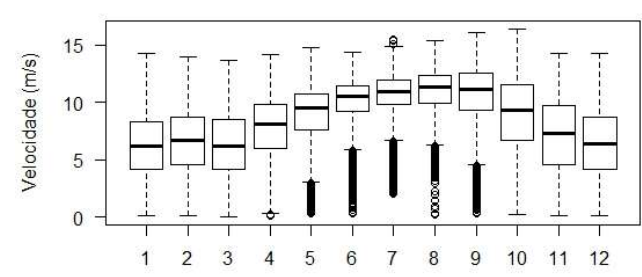

Boxplot Osório Mensal

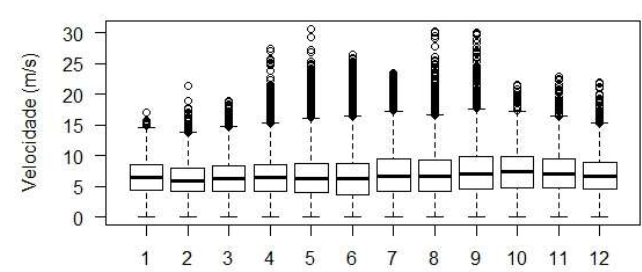

Boxplot Coxilha Negra Mensal

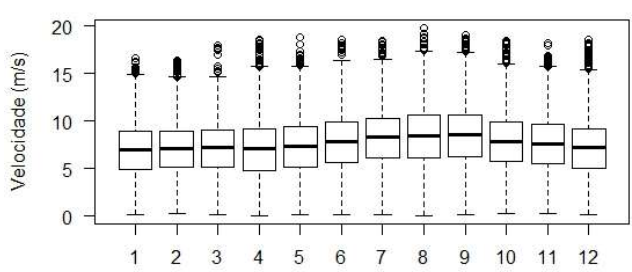

Boxplot João Câmara Mensal

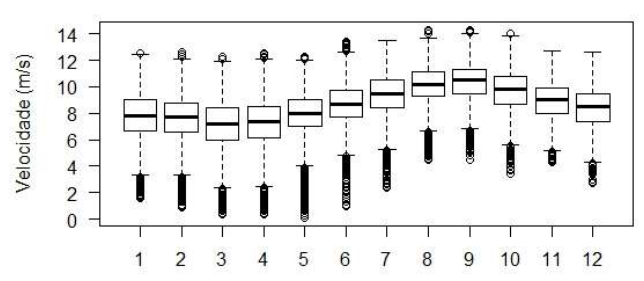

Boxplot Morro do Chapéu Mensal

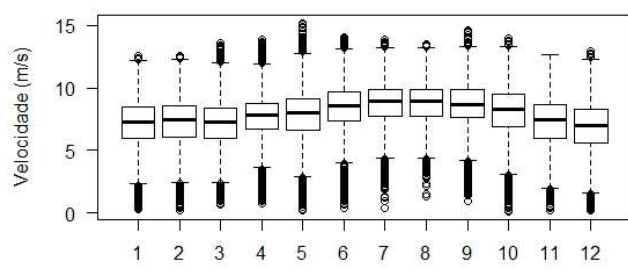

Boxplot Araripe Mensal

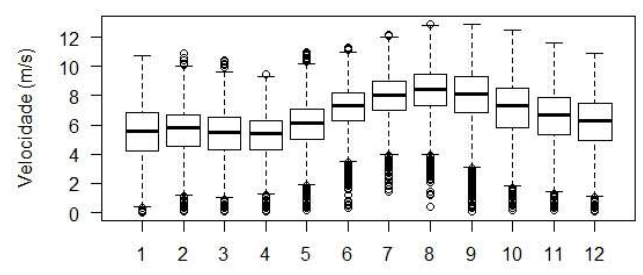

Boxplot Tramandaí Mensa

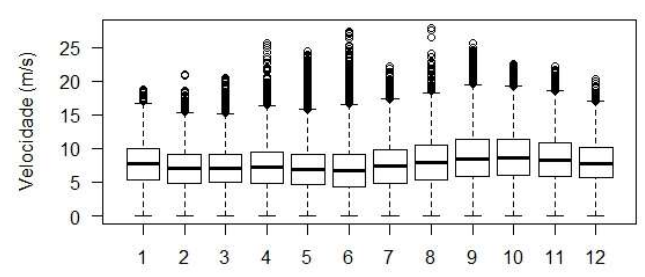

Boxplot Quilombo Mensal

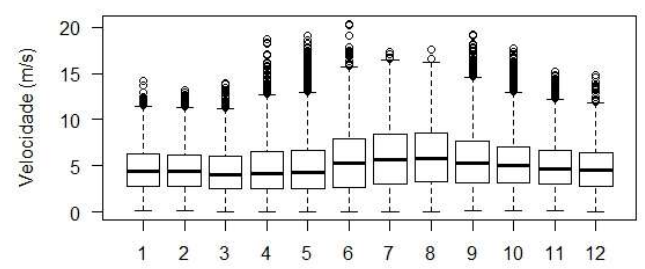




\section{APÊNDICE B - Histograma dos sites}

Histograma de Amontada

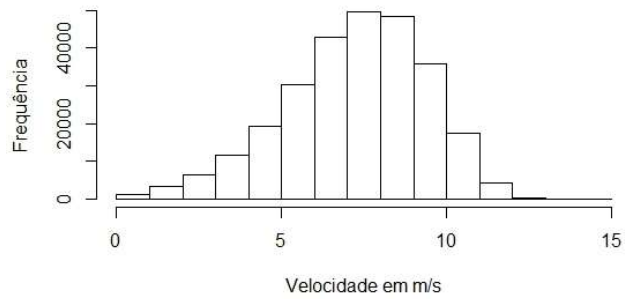

Histograma de Macau

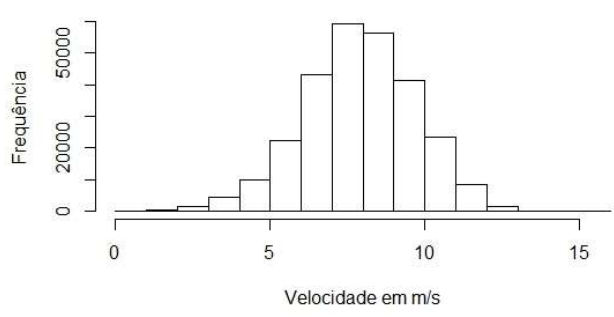

Histograma de Caetité

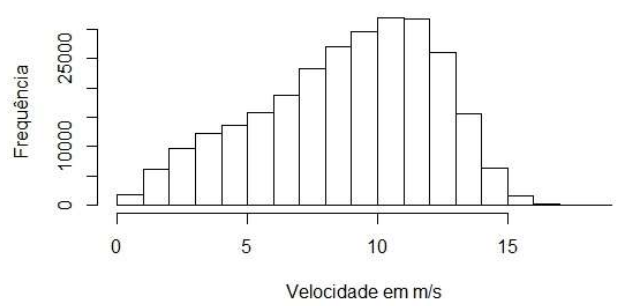

Histograma de Palmar

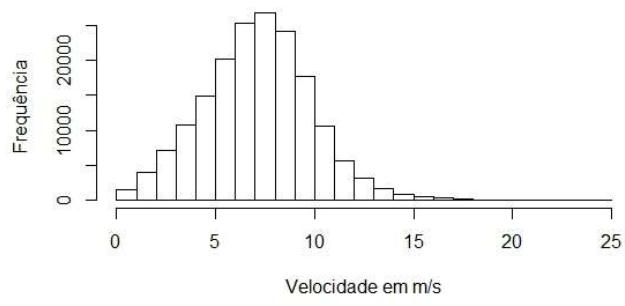

Histograma de Senandes

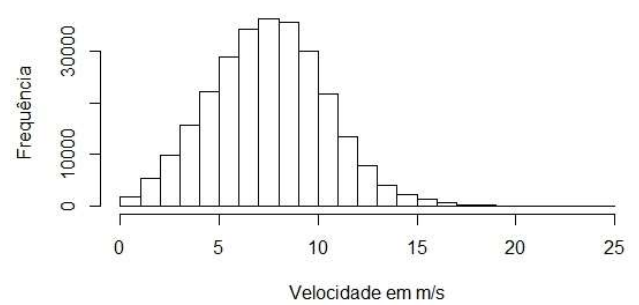

Histograma de Aracati

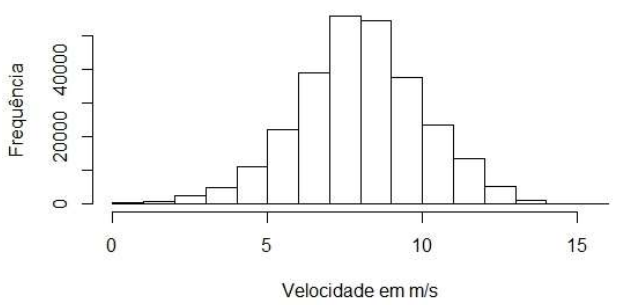

Histograma de Pedra do Reino

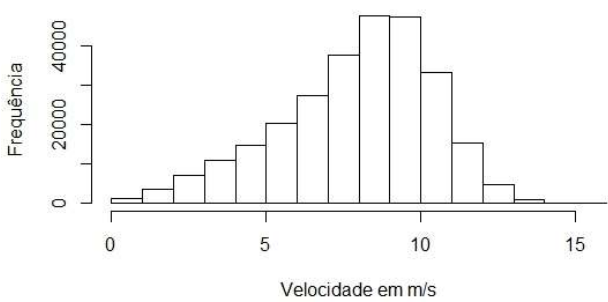

Histograma de Afrânio

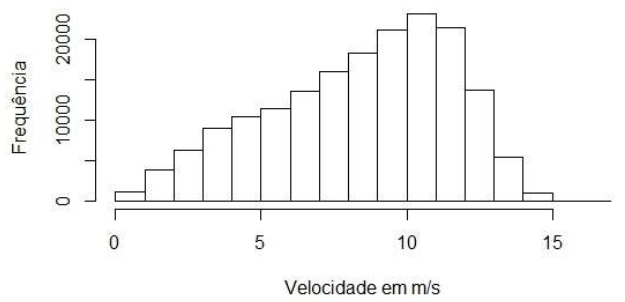

Histograma de Osório

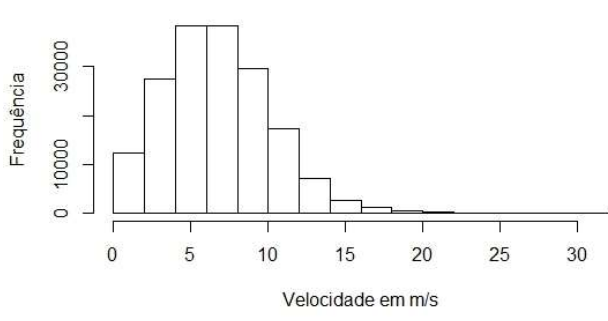

Histograma de Coxilha Negra

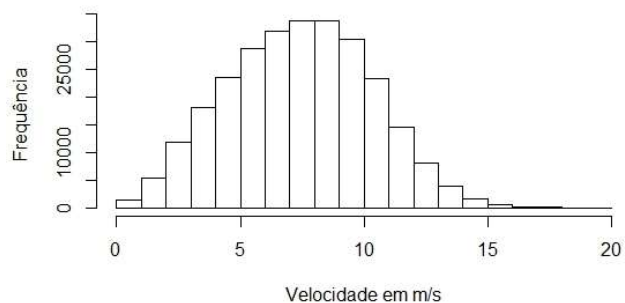

Histograma de João Câmara

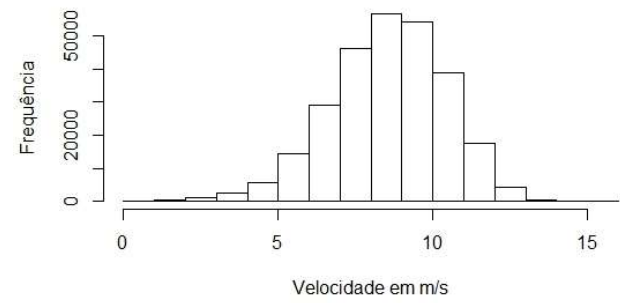

Histograma de Morro do Chapéu

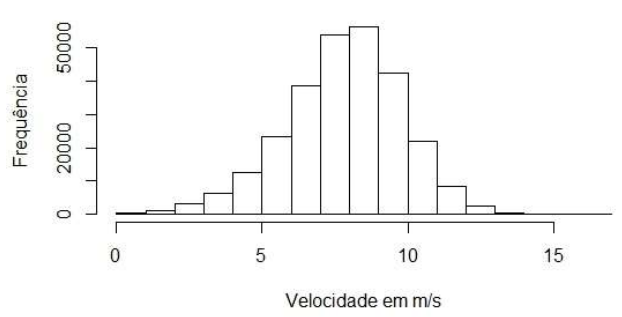

Histograma de Araripe

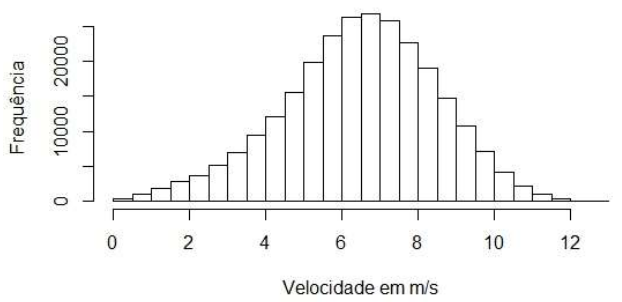

Histograma de Tramandaí

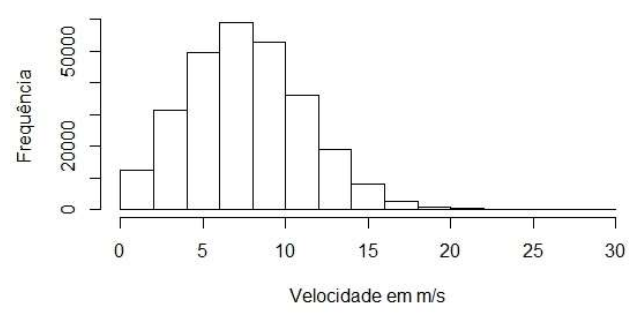

Histograma de Quilombo

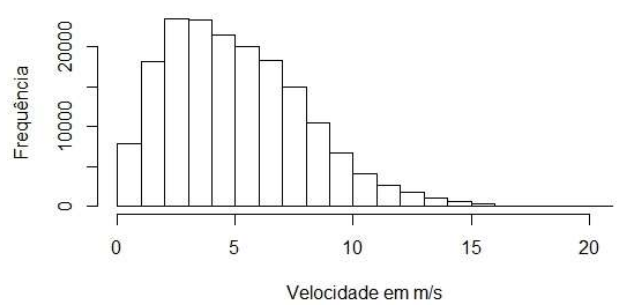




\section{APÊNDICE C - Espectro dos sites}
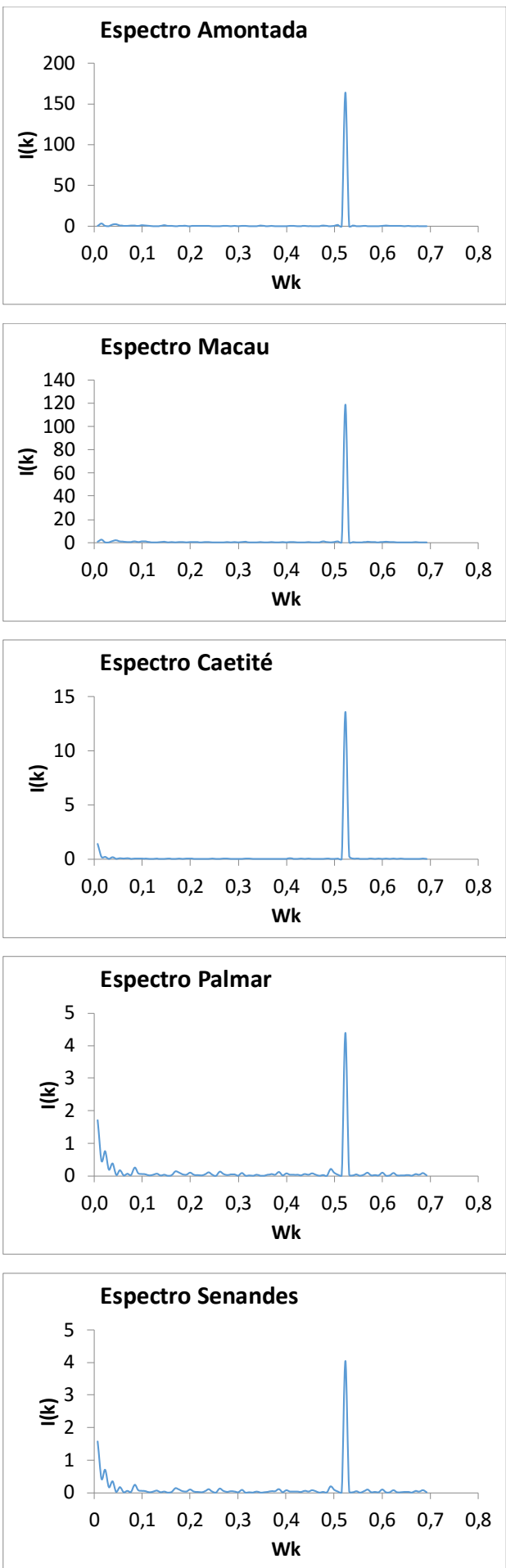
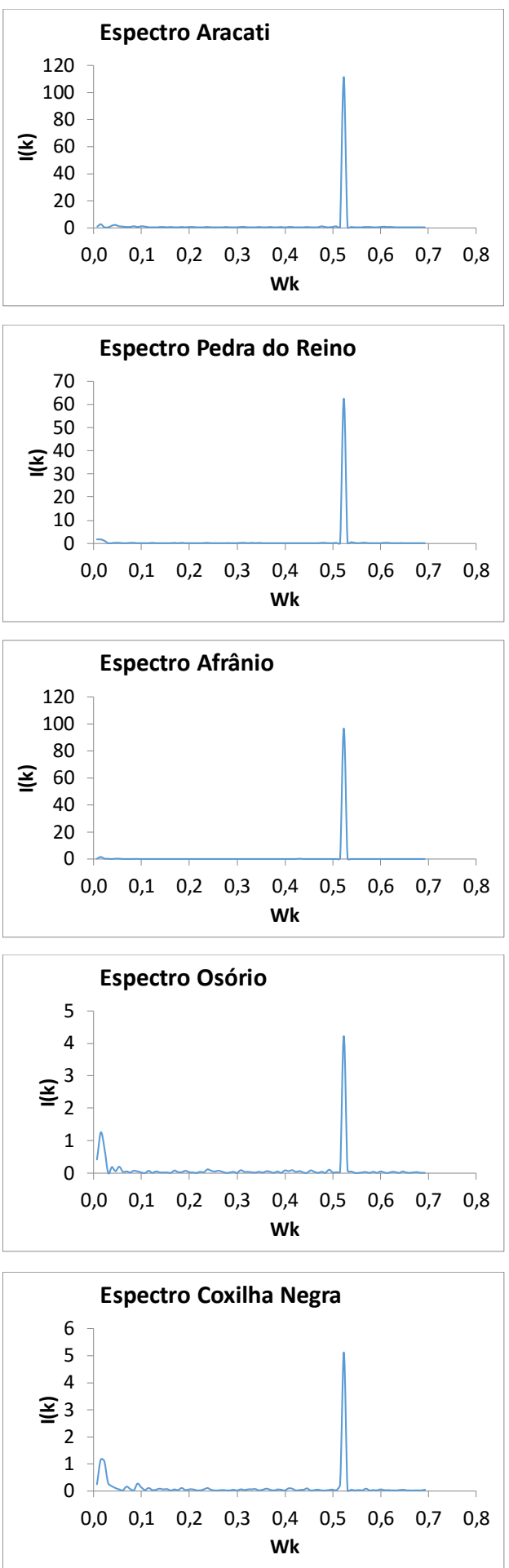
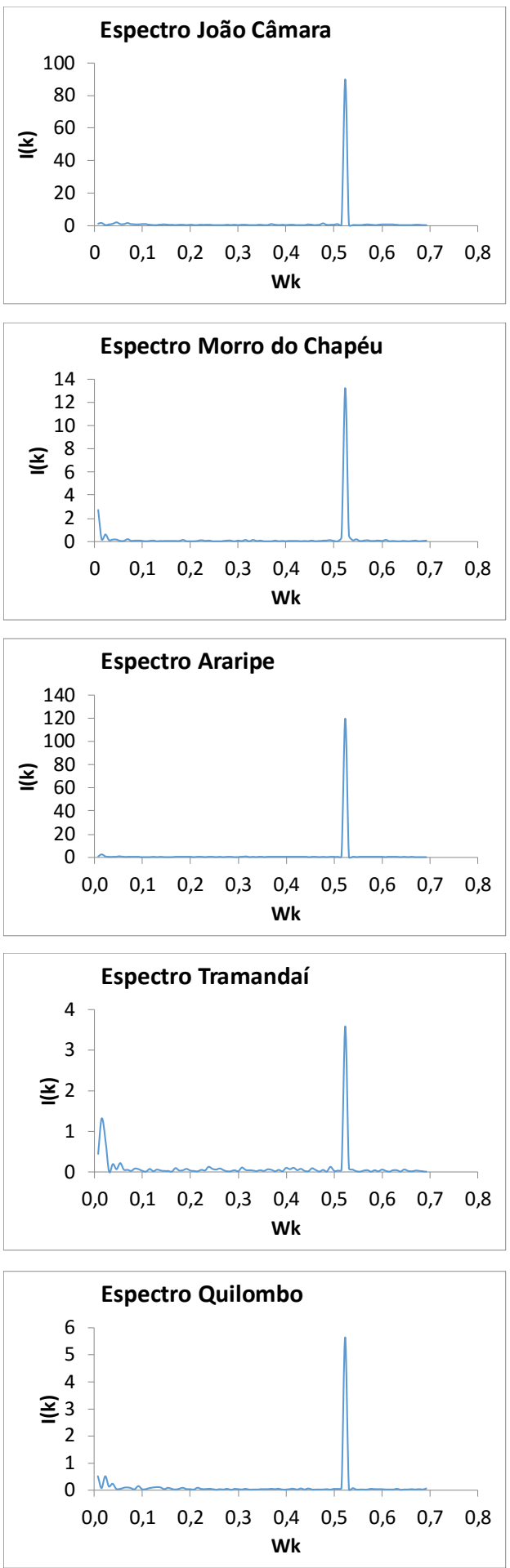